DOE/ID/I2949-w'II

DE92 019333

\title{
EVALUATION OF CERIUM OXIDE COATED \\ CU CERMETS AS INERT ANODES FOR \\ ALUMINUM ELECTROWINNINC
}

Final Report

For Period August 1990 to March 1992

August 1992

Work Performed Under Contract No. DE-FC07-901012949

\author{
Prepared for the \\ U.S. Department of Energy \\ Under DOE Idaho Fte? Office \\ Sponsored by the office of 'che Assistant Secretary \\ for Conservation and Renewable Energy \\ office of Industrial Technologies \\ Washington, D.C.

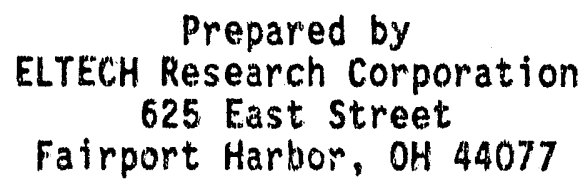




\section{ABSTRACT}

$\mathrm{Cu} / \mathrm{NiFe}_{2} \mathrm{O}_{4}$ cermets were evaluated, with and without an in-situ deposited CEROX coating, in $100 \mathrm{~h}$ laboratory A.l electrowining tests. Bath ratio and current density were varied between tests and corrosion was determined by contamination of the aluminum and cryolite by cermet components (CU, Fe, and $\mathrm{Ni}$ ). Higher bath ratios of 1.5 to 1.6 led to less corrosion and thicker CEROX coatings. Lower current densities led to slightly less corrosion but much less oxidation of the $\mathrm{Cu}$ cermet substrate. At identical test conditions, the corrosion of the CEROX coated cermets was $1 / 7$ that of an uncoated cermet. Corrosion was increased in CERox coated cermets tested under unsaturated alumina conditions. The electrical conductivity of the CEROX coating was measured to be $\sim 0.2 \mathrm{ohm}^{-1} \mathrm{~cm}^{-1}$, resulting in a slight voltage penalty, depending on the thickness of the coating. 
CONTENTS

\section{ABSTRACT}

SUMMARY

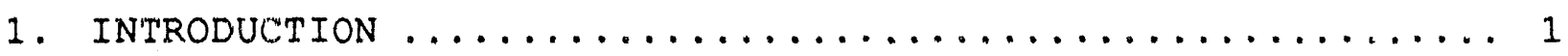

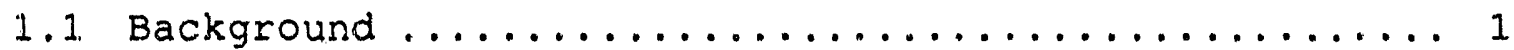

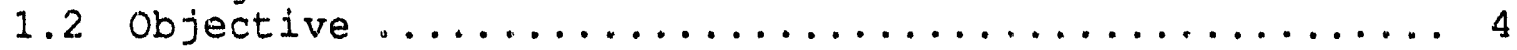

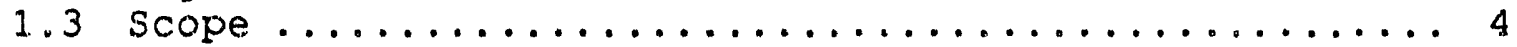

1.4 Technical Accomplishments .................

2. PREVIOUS WORK ON INER'I ANODES ................. 5

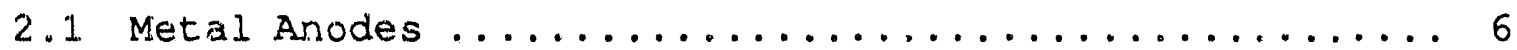

2.2 Boride, Carbide, and Nitride Anodes ............. 6

2.3 Metal Oxide Anodes ......................... 6

2.4 Cermet Arodes ......................... 7

3. PREVIOUS WORK ON CEROX COATINGS ............... 8

3.1 CEROX Discovery and Thermodynamics .............. 8

3.1.1 Electrochemical Deposition of CEROX ....... 8

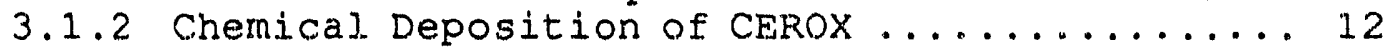

3.1 .3 Cerium Partitioning ................. 12

3.2 DOE Supported Research at ELTECH ............. 14

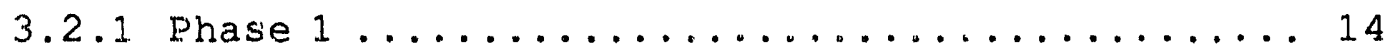

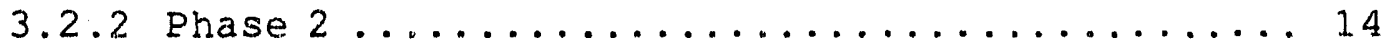

4. MATERIALS AND METHODS .......................... 15

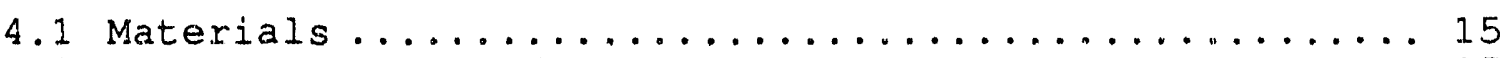

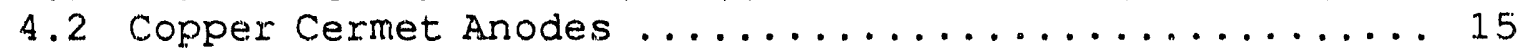

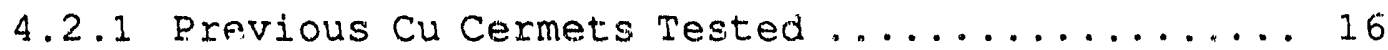

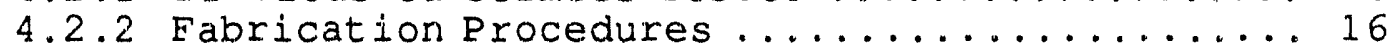

4.2.3 Characterization and Comparison ........... 21

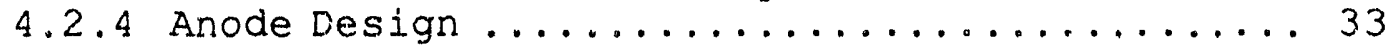

4.3 Long Term Test Cell Design and Procedure ......... 33

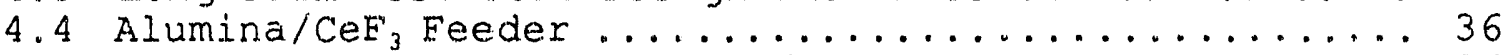

4.5 Non-Saturated Test Cell. Design and Procedure ...... 36

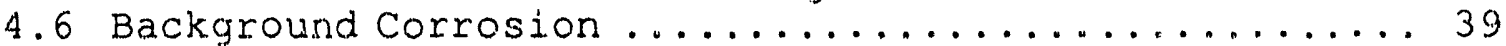

4.7 CEROX Resistance Test Cell Design and Procedure ..... 39

4.8 Analytical Procedures .................... 42

4.8 .1 Bath Ratio Analysis ................ 42

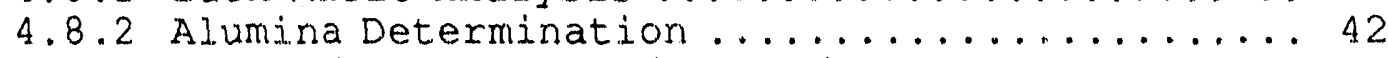

4.8.3 Analysis for Contaminants in Bath and Al Metal 43

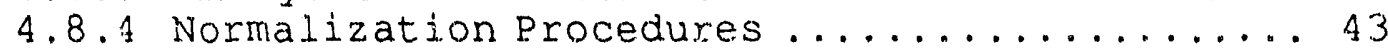

4.8 .5 Microscopy ....................... 44 
5. SATURATEd ALUMINA test' $(100 h) \ldots \ldots \ldots \ldots \ldots \ldots \ldots$

5.1 Experimental Design .................... 45

5.2 Current Density Estimates ................. 45

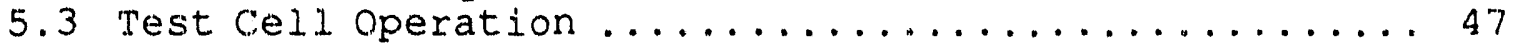

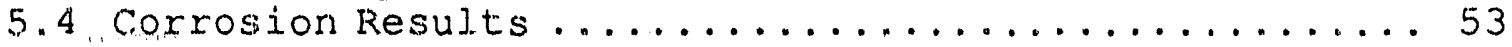

5.5 CEROX Coating and ce Partitioning ............. 63

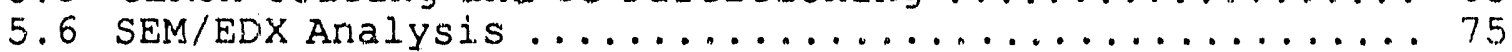

5.7 Discussion and Conclusions on saturated Testing .... 95

6. NONSATURATEd ALUMINA tests $(100 \mathrm{~h}) \ldots \ldots \ldots \ldots . \ldots . \ldots . \ldots 9$

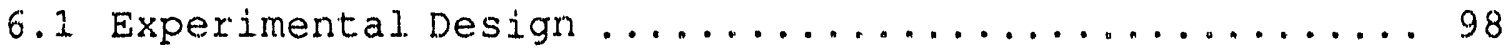

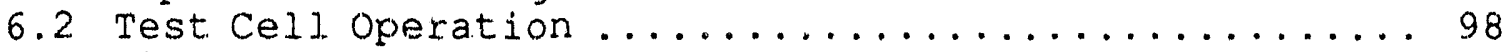

6.3 Microscopy Results ...................... 100

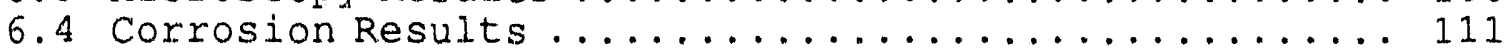

6.5 Discussion and Conclusions on Non-Saturated Testing 111

7. CEROX RESISTANCE MEASUREMENTS .................... 123

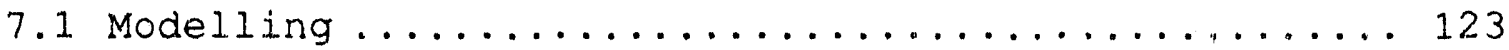

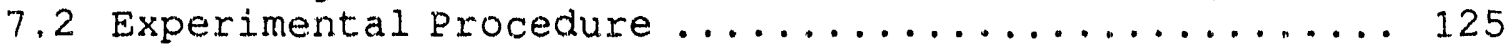

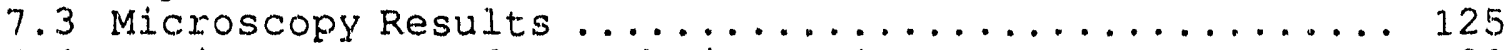

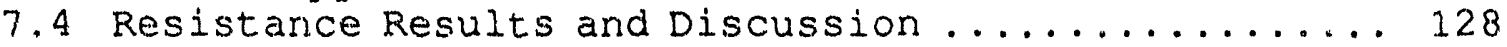

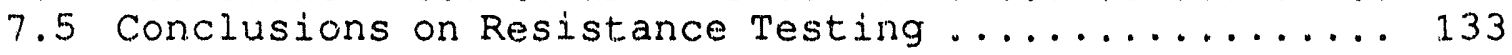

8. CONCLUSIONS ON PHASE 3 TESTING $\ldots \ldots \ldots \ldots \ldots \ldots$

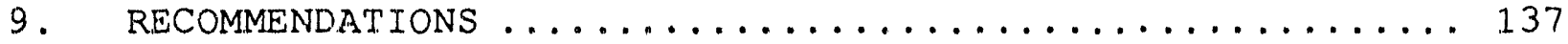

10. REEERENCES ............................. 139

Appendix A - Normalization Example ................ 142 


\section{FIGURES}

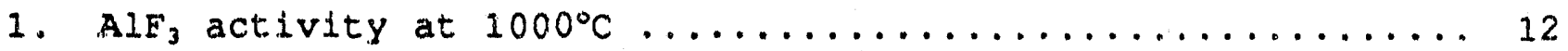

2. Predominance diagram for the oxidation of $\mathrm{CeF}_{3} \ldots \ldots \ldots$

3. Predominance diagram for the oxidation of $\mathrm{CeF}_{3}, \mathrm{AlF}_{3}$ activity

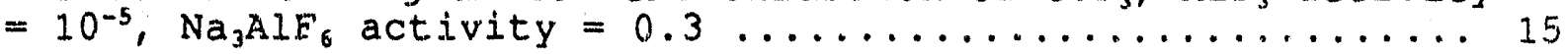

4. Predominance diagram for the oxidation of $\mathrm{CeF}_{3}, \mathrm{AlF}_{3}$ activity

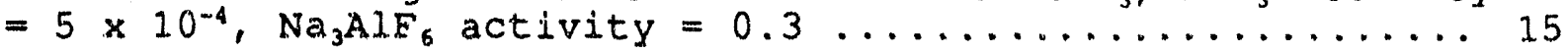

5. SEM photograph of Ceramic Magnetics $\mathrm{NiFe} \mathrm{O}_{4} / \mathrm{NiO}$ spray

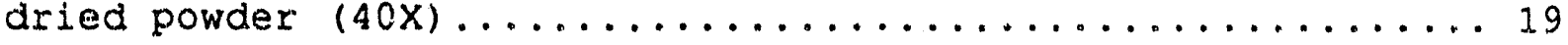

6. SEM photograph of Ceramic Magnetics $\mathrm{NiFe}_{2} \mathrm{O}_{4} / \mathrm{NiO}$ spray

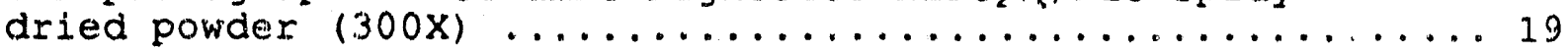

7. SEM photograph of Stackpole $\mathrm{NiFe}_{2} \mathrm{O}_{4} / \mathrm{NiO}$ spray dried

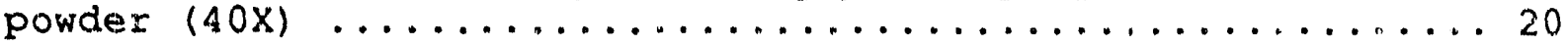

8. SEM photograph of stackpole $\mathrm{NiFe}_{2} \mathrm{O}_{4} / \mathrm{NiO}$ spray dried

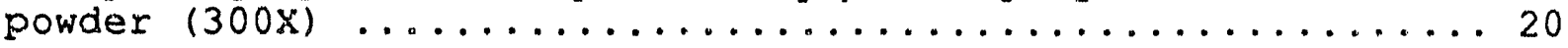

9. SEM photograph of Cerac $\mathrm{C}-1229 \mathrm{Cu}$ powder .............. 21.

10. Electrical conductivity versus temperature for the

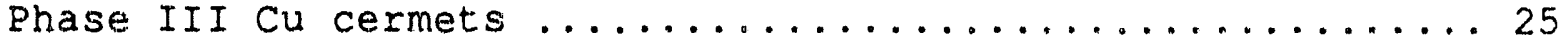

11. Electrical conductivjties of Alcoa, PNL, and ELTECH

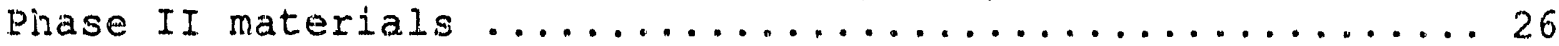

12. Comparison of the conductivity of AlCoa, PNL, and ELTECH

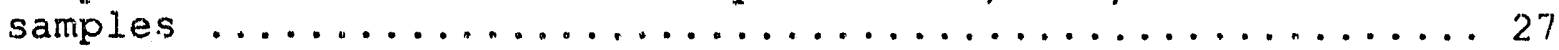

13. Optical micrographs of the phase III Cu cermets from the two sintering schedules and compared to the PNL cermet $\ldots . .28$

14. SEM photographs of EITECH and PNI $C u$ cermets ..........30

15. Phase I anodes from PNL .................... 32

16. Phase II anodes fabricated by ELTECH $\ldots \ldots \ldots \ldots \ldots \ldots \ldots$

17. Phase II anodes fabricated by ELTECH ............ 34

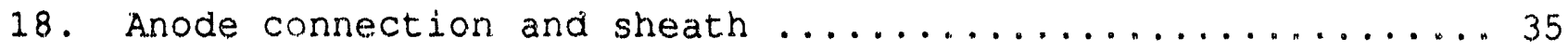

19. Saturated alumina cell design .........................

20. Cell design for experiments with baths containing alumina

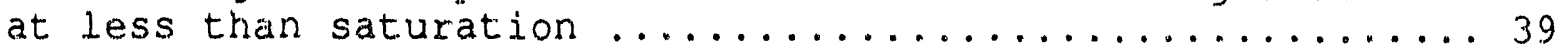

21. CEROX resistance test cell design ............... 42 


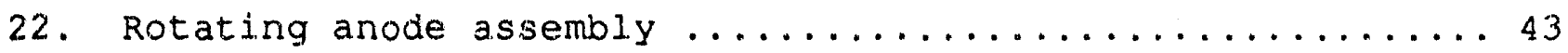

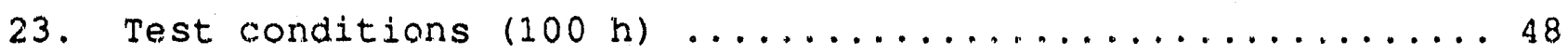

24. Comparison of immersed surface areas on phase II and Phase III anodes ............................ 50

25. Typical bath ratio variations throughout a 100 h test .... 52

26. Examples of typical cell voltage changes during the

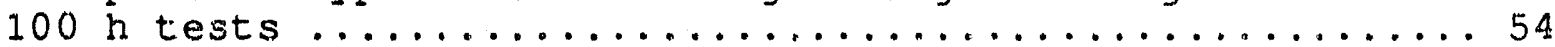

27. Oxidation versus current density for $100 \mathrm{~h}$ alumina

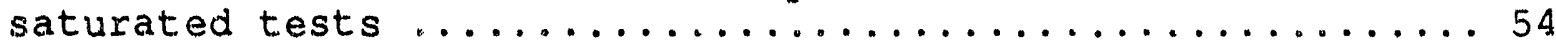

28. Estimated current efficiency as a function of current:

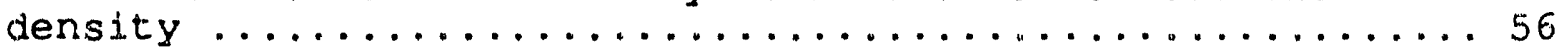

29. Alumina crystals and crust around the tip of the anode from test $13614-47,0.7 \mathrm{~A} / \mathrm{cm}^{2} \ldots \ldots \ldots \ldots \ldots \ldots \ldots \ldots \ldots \ldots$

30. Normalized corrosion versus bath ratio at $1.3 \mathrm{~A} / \mathrm{cm}^{2} \ldots \ldots .60$

31. Normalized corrosion versus bath ratio at $1.6 \mathrm{~A} / \mathrm{cm}^{2} \ldots \ldots, 60$

32. Normalized corrosion versus bath ratio at $1.9 \mathrm{~A} / \mathrm{cm}^{2} \ldots \ldots .61$

33. Normalized corrosion versus current density at a BR of 1.462

34. Normalized corrosion versus current density at a BR of 1.562

35. Normalized corrosion versus current density at a BR of 1.663

36. Normalized corrosion versus current density at a BR of 1.763

37. Anode from test $13614-51,0.5 \mathrm{~A} / \mathrm{cm}^{2}, \mathrm{BR}=1.5 \ldots \ldots \ldots \ldots 66$

38. Anode from test $13614-53,0.5 \mathrm{~A} / \mathrm{cm}^{2}, \mathrm{BR}=1.5 \ldots \ldots \ldots \ldots 66$

39. Anode from test $13614-49,0.7 \mathrm{~A} / \mathrm{cm}^{2}, \mathrm{BR}=1.5 \ldots \ldots \ldots \ldots 67$

40. Anode from test $13614-47,1.0 \mathrm{~A} / \mathrm{cm}^{2}, \mathrm{BR}=1.6 \ldots \ldots \ldots \ldots 67$

41. Anode from test $13614-29,1.3 \mathrm{~A} / \mathrm{cm}^{2}, \mathrm{BR}=1.4 \ldots \ldots \ldots \ldots 68$

42. Anode from test $13614-35,1.3 \mathrm{~A} / \mathrm{cm}^{2}, \mathrm{BR}=1.5 \ldots \ldots \ldots \ldots 68$

43. Anode from test $13614-21,1.3 \mathrm{a} / \mathrm{cm}^{2}, \mathrm{BR}=1.6 \ldots \ldots \ldots \ldots 69$

44. Anode from test $13614-31.1 .3 \mathrm{~A} / \mathrm{cm}^{2}, \mathrm{BR}=1.7 \ldots \ldots \ldots \ldots 69$

45. Anode from test $13614-25,1.6 \mathrm{~A} / \mathrm{cm}^{2}, \mathrm{BR}=1.4 \ldots \ldots \ldots \ldots 70$

46. Anode from test $13614-19,1.6 \mathrm{~A} / \mathrm{cm}^{2}, \mathrm{BR}=1.4 \ldots \ldots \ldots \ldots 70$ 
47. Anode from test $13614-39,1.6 \mathrm{~A} / \mathrm{cm}^{2}, \mathrm{BR}=1.5 \ldots \ldots . \ldots 71$

48. Anode from test $13614-37,1.6 \mathrm{~A} / \mathrm{cm}^{2}, \mathrm{BR}=1.6 \ldots \ldots \ldots \ldots$

49. Anode from test $13614-27,1.6 \mathrm{~A} / \mathrm{cm}^{2}, \mathrm{BR}=1.7 \ldots \ldots \ldots 72$

50. Anode from test $13614-41,1.9 \mathrm{~A} / \mathrm{cm}^{2}, \mathrm{BR}=1.4 \ldots \ldots \ldots . \ldots 73$

51. Anode from test $13614-15,1.9 \mathrm{~A} / \mathrm{cm}^{2}, \mathrm{BR}=1.6 \ldots \ldots \ldots . \ldots 73$

52. Anode from test $13614-45,1.3 \mathrm{~A} / \mathrm{cm}^{2}, \mathrm{BR}=1.6$, no cerium .... 74

53. Cerium partition coefficient as a function of $B R \ldots . . . .75$

54. Weight percent $C e$ in the Al and bath as a function of BR .. 76

55. Weight percent $C e$ in the bath as a function of $B R \ldots . \ldots 76$

56. CEROX on the anode from test $13614-53 \ldots \ldots \ldots \ldots \ldots \ldots$

57. Higher magnification of the CEROX coating on the anode

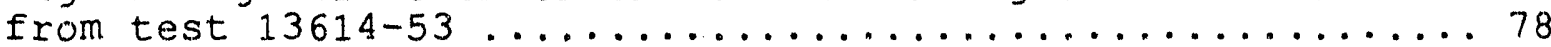

58. CEROX on the anode from test $13614-4$ 9............79

59. Higher magnification of the CEROX coating on the anode

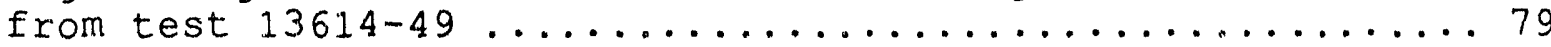

60. CEROX on the anode from test $13614-21 \ldots \ldots \ldots \ldots$

61. Higher magnification of the CEROX coating on the arode

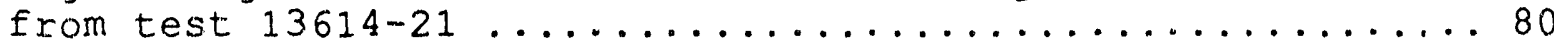

62. CEROX on the anode from test $13614-35 \ldots \ldots \ldots \ldots \ldots \ldots$

63. Higher magnification of the CEROX coating on the anode

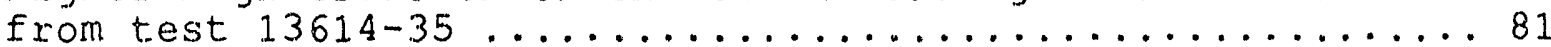

64. CEROX on the anode from test $13614-41 \ldots \ldots \ldots \ldots$. . . .

65. Higher magnification of the CEROX coating on the anode

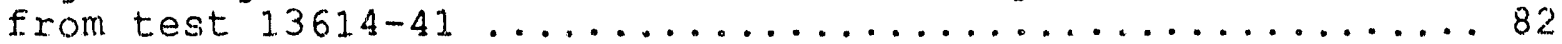

66. $\mathrm{CeF}_{3}$ and $\mathrm{Cu}$ oxide layer between the substrate and the CEROX coating (Anode 13614-53) ................... 66

67. Interface between the substrate and the CEROX coating

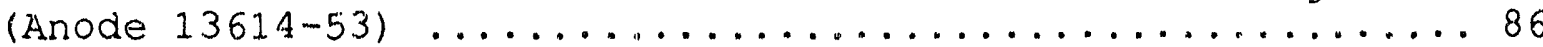

68. Cu depleted layer next to the CEROX coating

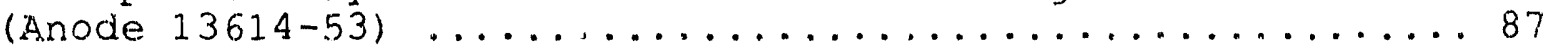

69. High magnification of the $\mathrm{Cu}$ depleted zone in Figure $53 \ldots 87$ 
70. The $\mathrm{Cu}$ oxide region in anode $13614-53 \ldots \ldots \ldots$

71. Near the edge of the $C u$ oxide region (Anode 13614-53) ... 88

72. In the center of the unoxidized area of anode 13614-53 ...89

73. At the edge of anode $13614-49 \ldots \ldots \ldots \ldots \ldots \ldots$

74. The boundary between the porous $\mathrm{Cu}$ depleted layer and the denser $\mathrm{Cu}$ metal $(13614-49) \ldots \ldots \ldots \ldots \ldots \ldots \ldots$

75. The interface between the CEROX coating and the substrate

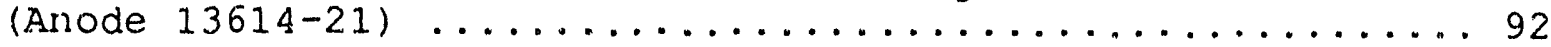

76. The CEROX coating, $\mathrm{Cu}$ depleted zone, and $\mathrm{Cu}$ oxide region

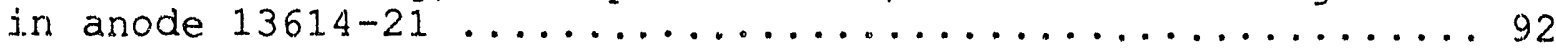

77. Porous and dense bands alternate within the oxidized

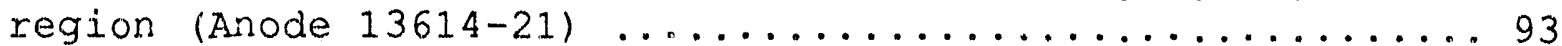

78. Higher magnification of Eigure $77 \ldots \ldots \ldots \ldots \ldots$

79. The $\mathrm{Cu}$ oxide rich zone from Eigure $78 \ldots \ldots \ldots \ldots \ldots$

80. The porous zone from Eigure $78 \ldots \ldots \ldots \ldots \ldots \ldots$

81. The boundary between the cu oxide region and the cu metal

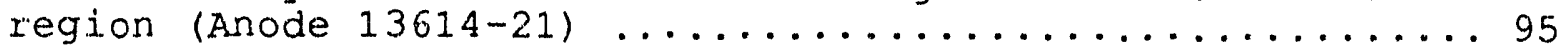

82. Cu metal region in the center of the anode $13614-21 \ldots 95$

83. The Cu depleted region at the edge of anode 13614-35 ....96

84. The $\mathrm{cu}$ oxide region in anode $13614-35 \ldots \ldots \ldots$

85. The edge of anode $13614-41 \ldots \ldots \ldots \ldots \ldots \ldots$

86. Higher magnification of layer $\mathrm{S}$ from Figure $85 \ldots \ldots . \ldots 9$

87. Layered structure in the oxidized region of anode 13614-41 99

88. Bath ratio fluctuations during experiment HS-2 ....... 103

89. Bath ratio fluctuations during experiment HS-3 ....... 103

90. Bath ratio fluctuations during experiment $\mathrm{HS}-4 \ldots \ldots \ldots 3$

91. Bath ratio fluctuations during experiment HS-5 ........ 103

92. Bath ratio fluctuations during experiment HS-6 ....... 104

93. Alumina concentration fluctuations during HS $-2 \ldots \ldots 6$

94. Alumina concentration fluctuations during HS-3 ....... 106 
95. Alumina concentration fluctuations during $\mathrm{HS}-4 \ldots \ldots \ldots$

96. Alumina concentration fluctuations during HS-5 ...... 106

97. Alumina concentration fluctuations during HS-6 ....... 107

98. Current efficiencies of the nonsaturated tests ....... 108

99. The CEROX coating on anode Hs $-2 \ldots \ldots \ldots \ldots \ldots$

100. The CEROX coating on anode $\mathrm{HS}-3 \ldots \ldots \ldots \ldots \ldots$

101. The CEROX coating on anode HS $-4 \ldots \ldots \ldots \ldots \ldots \ldots \ldots$

102. The CEROX coating on anode $\mathrm{HS}-5 \ldots \ldots \ldots \ldots \ldots \ldots \ldots$

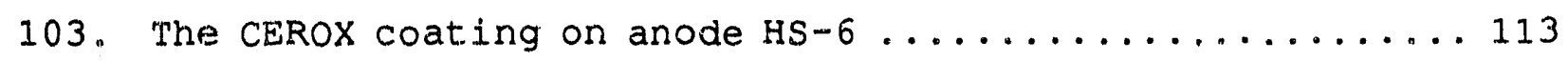

104. The wto $\mathrm{Ce}$ in bath and metal for the nonsaturated alumina

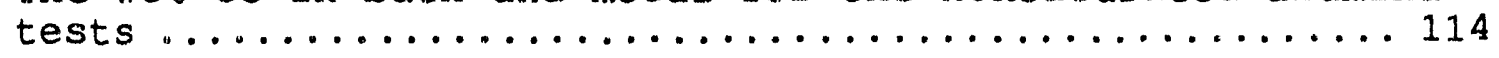

105. Ce partition coefficient in the nonsaturated alumina

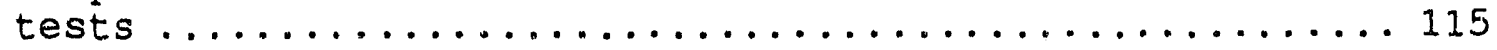

106. The edge of HS-2 next to the CEROX coating ......... 117

107. The oxidized region in $\mathrm{HS}-2 \ldots \ldots \ldots \ldots \ldots \ldots \ldots \ldots$

108. Edge of HS-3 next to the CEROX coating ............ 118

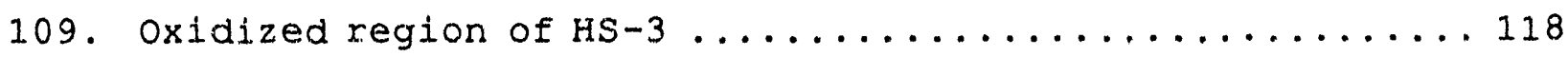

110. Edge of HS -4 next to the CEROX coating .............. 119

111. The oxidized region in $\mathrm{HS}-4 \ldots \ldots \ldots \ldots \ldots \ldots \ldots$

112. Edge of HS -5 next to the CEROX coating ..............120

113. The oxidized region in $\mathrm{HS}-5 \ldots \ldots \ldots \ldots \ldots \ldots$

114. Edge of HS -6 next to the CEROX coating ............. 121

115. The oxidized region in $\mathrm{HS}-6 \ldots \ldots \ldots \ldots \ldots \ldots \ldots \ldots$

116. Normalized corrosion versus alumina concentration for

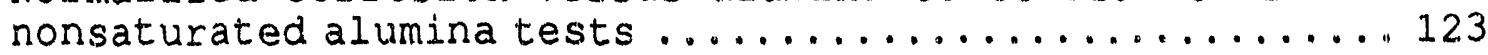

117. Anode corrosion versus $B R\left(C D 0.7 \mathrm{~A} / \mathrm{cm}^{2}\right.$, alumina=6 wt 8 ) 124 118. Anode corrosion versus $C D$ (BR 1.5, alumina=6 wt 8 ) .... 125 119. Physical schematic of the CEROX coating system ....... 128 120. (a) Electronic circuit model of the system .......... 129 


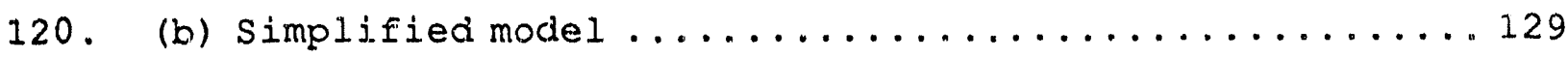

121. CEROX coatings on anodes from resistance tests ....... 131

122. Resistance as a function of $C D$ and rotation rate,

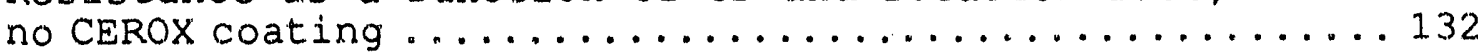

123. Resistance as a function of $C D$ and rotation rate, coating thickness $=0.7 \mathrm{~mm} \ldots \ldots \ldots \ldots \ldots \ldots \ldots \ldots \ldots \ldots$

124. Resistance as a function of $\mathrm{CD}$ and rotation rate,

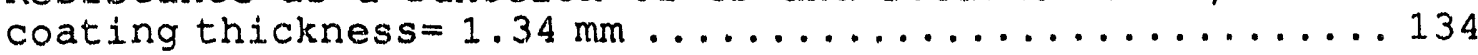

125. Resistance as a function of $C D$ and rotation rate,

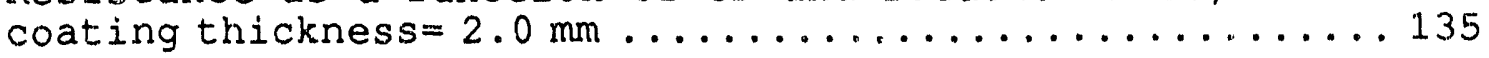

126. Cylindrical system ............................ 37

1.27. Conductivities calculated from the experimental data ... 138 


\section{TABLES}

1. Energy requirements for the Hall-heroult process .........3

2. Chemical analysis of $\mathrm{Ni}$ Ferrite/Cu cermets ...........23

3. Comparison of phases in ELTECH and PNL samples .........31

4. Current density estimates .................... 51

5. Normalized corrosion for saturated tests $(100 \mathrm{~h}) \ldots \ldots . \ldots 58$

6. $\mathrm{Ee}, \mathrm{Ni}$, and $\mathrm{Cu}$ ratios of normalized corrosion values ..... 64

7. Average phase composition in tested anodes ...........84

8. Cu oxidation and $\mathrm{Cu}$ depletion thickness ............ 85

9. Nonsaturated alumina test conditions ............... 102

10. Impurities in bath and metal in the nonsaturated tests ... 122 


\section{SUMMARY}

The Department of Energy (DTE) supported Phase III project was a continuation of a Phase I and Phase II project that were performed by ELTECH Research Corporation to demonstrate the viability uf CEROX coated (cerium oxide) $\mathrm{Cu}$ cermets as inert anodes in aluminum electrowinning. Phase I (October 1986 to June 1987) demonstrated that a CEROX coating could be deposited in situ on a Cu cermet in short term tests $(8 \mathrm{~h})$ and that corrosion of the $\mathrm{Cu}$ cermet substrate was reduced by the application of the coating. Phase II (December 1987 to April 1989) extended testing to $100 \mathrm{~h}$ for a range of bath ratios (BR) and current densities (CD). The least corrosion was at the highest $B R(1.6)$ and $C D\left(1.4 \mathrm{~A} / \mathrm{cm}^{2}\right)$ examined. Phase III (August 1990 to March 1992) was undertaken to investigate $C D$ and $B R$ lower and higher than the best conditions from Phase II so the optimum CEROX operating conditions could be defined.

Phase III consisted of seventeen $100 \mathrm{~h}$ tests at BR from 1.4 to 1.7 and $C D$ from $0.5 \mathrm{~A} / \mathrm{cm}^{2}$ to $1.9 \mathrm{~A} / \mathrm{cm}^{2}$. Fifteen tests were conducted with a CEROX coating on $\mathrm{Ni}$ ferrite/Cl: cermet substrates fabricated by ELTECH. One test was conducted with a CEROX coating on a similar substrate fabricated by Battelle pacific Northwest Laboratories (PNL) and one test was conducted with an ELTECH substrate without a CEROX coating. All tests were conducted in a test cell lined with alumina, therefore all tests were conducted in an electrolyte saturated with alumina.

Since industrial application of these anodes would probably be in an electrolyte not saturated with alumina, a special test cell was designed to operate under unsaturated alumina conditions. Five $100 \mathrm{~h}$ experiments were carried out in this cell at the best BR and $C D$ conditions from the saturated testing, and at 4,6 , and $7.2 \%$ alumina (corresponding to $\sim 50,75$, and $90 \%$ of saturation, respectively).

Phase I had demonstrated that the CEROX coating was somewhat resistive and imposed a slight voltage penalty on the anode. Electrical resistance measurements were performed to define the resistance of the coating and an economic analysis was performed to determine the economic impact of this additional resistance.

The least corrosion and thickest, densest CEROX coatings were at a $\mathrm{BR}$ of 1.5 to 1.6. There was a slight decrease in corrosion with decreasing $C D$. At identical conditions ( $\mathrm{BR}$ of $1.6, \mathrm{CD}$ of

$\left.1.3 \mathrm{~A} / \mathrm{cm}^{2}\right)$, the CEROX coating decreased corrosion compared to an uncoated $\mathrm{Cu}$ cermet by a factor of 7. Lower alumina concentrations led to increased corrosion in CEROX coated cermets, however, a CEROX coating was deposited on the anodes under these conditions and did appear to reduce corrosion compared to an uncoated $\mathrm{Cu}$ cermet in an alumina saturated bath.

The $\mathrm{Cu}$ cermets anodes underwent extensive oxidation and increased porosity at the high $C D$, as well as redistribution of the phases witnin the cermet. At lower $C D$ the oxidation thickness was limited 
and the changes within the microstructure were confined to the thin oxidized region. Euring the operation of the anodes at high SD, the cell voltage liose at the oxjdation prograssed.

The conductivity af the CEnox coating was $\sim 0.2 \Omega^{-1} \mathrm{~cm}^{-1}$. Based on a price of 2.5 cents/kwh, $90 \%$ current efficlency, a $1 \mathrm{~mm}$ thick CEROX coating, and operation at $0.7 \mathrm{~A} / \mathrm{cm}^{2}$, this conductivity translates into an increased cost of $\sim \$ 25 /$ ton of aluminum.

Because of the extensive oxidation of the cu cermets, research on Improving the cermet ox on new substrates was recommended. Short term screening tests were suggested to examine new materials for resistance to corrosion and oxidation. Ionger term testing $(100 \mathrm{~h})$ on the most successtul matexials, with and without a CaROX coating, would follow.

The CEROX coating appeared most effective at high BR in alumina saturated baths. Corrosion was increased at lower $B R$ and lower alumina contents. Because lower BR and alumina contents are more likely in industrial cells, studies of the cerox coating under. these concitions were recommended in order to determine if deposition of the coating and the protection of the substrate could be improved at these conditions. 


\section{EVALUATION OF CERIUM OXIDE COATED \\ CU CERMETS AS INERT ANODES FOR \\ ALUMINUM ELECTROWINNING}

\section{INTRODUCTION}

The EITECH Phase III Anode project consisted of long-term tests $(100 \mathrm{~h})$ of nickel ferrite/nickel oxide/copper cermet anodes with in situ anodicaliy deposited cerium oxide (CEROX) coatings. The research focused on three areas. Tests were operated at: high bath ratios (BR) of 1.4 to 1.7 and a range of current densities (CD) in baths saturated with alumina in order to define the lowest corrosion conditions with a CEROX coating. At the best unditions for saturated baths, tests were operated in nonsaturated baths to determine the effect of low alumina on the protection offered by the CEROX coating. In addition, the voltage penalty and associated increased energy costs were investigated for operating with a CEROX coating on a copper cermet as compared to operating without a CEROX coating.

After the introduction, the report will review previous work on inert anodes and the CEROX coating. Materials and test procedures will be described, and then the three sections of the research will. be described in detail: the saturated alumina tests, the nonsaturated alumina tests, and the CEROX resistarice measurements. conclusions and recommendations will then be discussed.

\subsection{Background}

In the conventional Hall-Heroult process, anode carbon is consumed according to the reaction

$\mathrm{Al}_{2} \mathrm{O}_{3}+3 \mathrm{C}+3 / 2 \mathrm{C}=2 \mathrm{Al}+3 / 2 \mathrm{CO}_{2}$

with the side reaction of

$\mathrm{AL}_{2} \mathrm{O}_{3}+3 \mathrm{C}=2 \mathrm{AL}+3 \mathrm{CO}$.

Although (according to Equation 1) $0.33 \mathrm{~kg}$ of carbon is theoretically required for each kilogram of aluminum, the actual. consumption is nearly $0.5 \mathrm{~kg}$. The exit gas from a Hall-Heroult cell contains 10 to $50 \%$ Co.' Loss of carbon is also caused by selective oxidation, crackirg, and arcing. Because of metal purtiy considerations, a relatively pure coke with ${ }^{\circ}$ ow ash content must he used as anode carbon. Further, nonuniform werar of the carbon anode imposes an erergy penalty because a uniforn inter-electrode gap cannot be maintained. 
Because of the cost of building and maintaining a carbon anode plant and the energy penalty associated with the use of carbon anodes, the use of inert anodes has long been proposed. ${ }^{2,3}$ Inert anodes offer the promise of operating cost-savings by elimination of consumable carbon anodes and lower cell voltages, achieved by reduction of the anode-cathode distance and reduction of anode polarization. The energy requirement for the conventional HallHeroult cell is summarized in Table $1 .^{4}$

With an inert anode, the net cell reaction is

$\mathrm{Al}_{2} \mathrm{O}_{3}=2 \mathrm{Al}+3 / 2 \mathrm{O}_{2}$.

The reversible potential for this reaction at $1000^{\circ} \mathrm{C}$ is $2.2 \mathrm{~V}$ compared to $1.15 \mathrm{~V}$ for the conventional process. Despite this, a net energy savings is expected with the use of inert anodes. ${ }^{5}$ One major savings would be in petroleum coke and its energy content. It has been estimated that U.S. consumption of petroleum coke for anode carbon is $2.27 \mathrm{M}$ ton $/ \mathrm{y}^{6}$

In addition, the increased voltage can be more than offset by lower overvoltage and ohmic losses. The polarization requirement for an inert anode has been reported to be $0.2 \mathrm{~V}$ less than that of a carbon electrode." The electrical conductivity of the cermet anodes may become 3 times that of carbon ${ }^{7}$ and would greatly reduce the ohmic losses in the anode.

Another major savings would be associated with a more compact cell design and better operation. The use of an inert anode in combination with a wettable cathode also offers the potential. of: reducing the interelectrode distance; thus, greatly lowering the ohmic drop in the electrolyte. The Aluminum Company of America (Alcoa) has estimated that if the anode-cathode gap could be lowered from the present 4.4 to $1.9 \mathrm{~cm}$, a 238 decrease in the energy requirement would be achieved. ${ }^{6}$ The energy cequirement of a Hail-Heroult cell using inert anodes is also summarized in Table 1. It is assumed that the anode-cathode gap is half that used in the conventional process and the anode polarization is 0.2 $V$ less than that in the carbon electrodes, while anode conductivity is unchanged. Additional energy savings may also result from reduced pollution control costs and decreased voltage drop in external cell components.

The material requirements of an inert anode in an aluminum rediction cell include: ${ }^{2,3}$

Low solubility in the molten cryolite bath

- Oxidation resistance

- Thermal shock resistance

- Electrical conductance greater than or comparable to carbon

- Low oxygen overpotential

- Adequate mechanical strength. 
Table 1. Energy requirements for the Hall-Heroult process

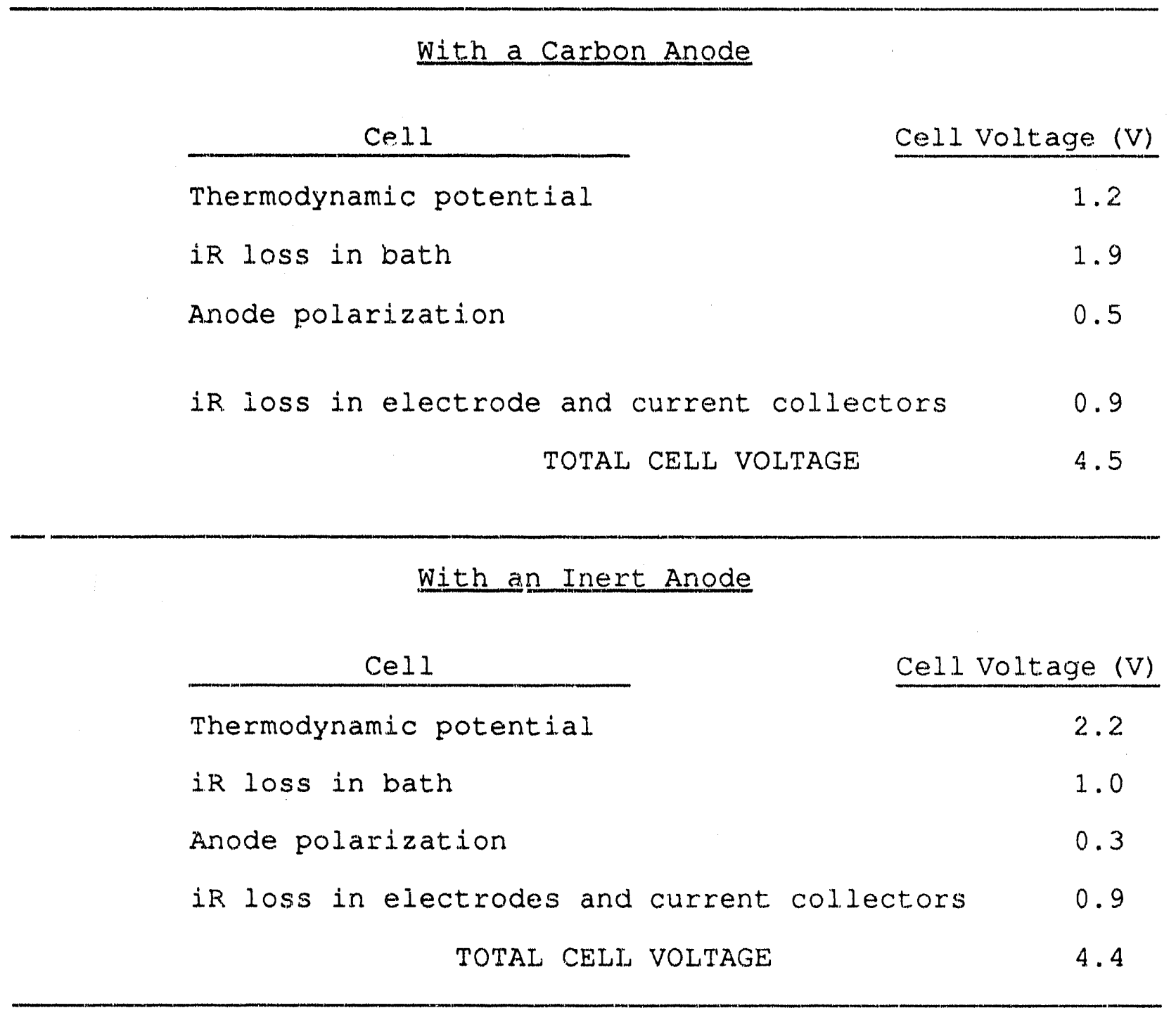


In addition to these requirements, the material must have adequate resistance to the dissolved aluminum found in the electrolyte, ${ }^{B}$ be low in cost, and easily fabricated into large shapes.

Early work on inert anodes concentrated on metals and ceramic oxides. Netals thet generally have high electrlcal conductivity (with the exception of some of the precious metals) were subjected to massive oxidation. Some of the oxide ceramics have been found to have very low solubility in cryolite melts, but characteristically have low conductivities. It is generally acknowledged that no metal oxide has been found to meet the requirements of an inert anode.

In recent years, various cermet anodes (developed by Alcoa) ${ }^{6}$ have received considerable attention. By including a metallic phase in the ceramic matrix, high electrical conductivity cermets have been obtained while maintaining the corrosion-resistance properties of the ceramic. The most promising results were obtained with a material containing a nickel ferrite matrix and 17 wto $\mathrm{Cu}$. Targeted dissolution rates were obtained in laboratory tests with this cermet. However, these dissolution rates have not been proven in pilot-scale tests. Battelle Pacific Northwest Laboratories ( $P N$ ) continued he work on $\mathrm{Cu}$ cermets. Again, low dissolution rates were achievad in the laboratory but were not proven in a pilot-scale test.

Since 1982, ELTECH Research Corporation has proven the anodic deposition of a cerium oxyfluoride (CEROX) from conventional HallHeroult cryolite melts." This led to the proposed use of CEROX as a self-forming anode coating, deposited insitu. The significance of this concept is that it provides a mechanism for the protection of an anode substrate against corrosive attack.

The Phase III DOE supported resezrch is a continuation of phase I and thase II research. In Phase I, the insitu CEROX coating was evaluated for protection of $\mathrm{SnO}_{2}$ and $\mathrm{Cu}$ cermet anodes from the cryolite bath in short-term testing (nominal $10 \mathrm{~h})^{10}$. No detectable attack on the cermet substrate was evident under the best phase I conditions. Phase II investigations involved measuring the protection afforded by the CEROX coating to Cu cermet anodes in $100 \mathrm{~h}$ tests at varying $B R$ and $C D .{ }^{11} \mathrm{~A} C D$ of $1.4 \mathrm{~A} / \mathrm{cm}^{2}$ and $a$ BR of 1.6 yielded the best CEROX coating and the least corrosion.

\subsection{Objective}

Phase III was performed to rigorously define the best conditions for CEROX growth and minimum corrosion of the anode substrate. The tasks were directed toward insitu deposition of the CEROX coatings on nickel ferrite/copper cermets. 


\subsection{Scope}

The primary scope of this research was to investigate alumina saturated, high BR (up to 1.7 ) and high $C D$ (up to $1.9 \mathrm{~A} / \mathrm{cm}^{2}$ ) conditions in $100 \mathrm{~h}$ tests to find the minimum corrosion of the CEROX-coated Cu cermet substrate. The scope was expanded during the test program to include lower $C D$ tests as well (down to 0.5 $\left.\mathrm{A} / \mathrm{cm}^{2}\right)$. The best $\mathrm{BR}$ and $\mathrm{CD}$ conditions from the saturated testing were used in nonsaturated alumina tests to determine the effect of lower alumina concentrations on the corrosion. Short-term $6 \mathrm{~h}$ tests were performed to ascertain the voltage penalty associated with the CEROX coating.

Corrosion resistance was defined by chemical analysis of the cryolite bath and metal for the cermet components. Microstructural analysis by optical microscopy, scanning electron microscopy (SEM), and energy dispersive $x$-ray analysis (EDX) was performed on selected samples to examine the CEROX coating and the substrate to evaluate corrosion resistance and microstructural changes during testing. An economic analysis was performed to determine the cost impact of the voltage penalty from the presence of the CEROX coating on the $\mathrm{Cu}$ cermet.

\subsection{Technical Accomplishments}

The investigations conducted during this test program have shown that the densest and most protective CEROX coatings deposited on Cu cerinets form at a BR of 1.5 to 1.6. Lowest total corrosion $(0.471$. wt 8$)$ was achieved at a $B R$ of 1.5 and $C D$ of $0.5 \mathrm{~A} / \mathrm{cm}^{2}$. There appears to be little correlation between $\mathrm{CD}$ and corrosion, however, there may be a slight trend toward lower corrusion at lower $C D$. Diffici?ties with operating our $100 \mathrm{~h}$ test cell at $10 \mathrm{~W}$ CD hampered the evaluation of the effect of $C D$ on corrosion. In baths with decreased alumina concentration, CEROX coatings were successfully deposited but total corrosion was increased up to 2.42 wt 8 in baths operated at. $75 \%$ alumina saturation.

The Cu cermet substrates were found to oxidize at all CD but oxidation was more pronounced in the tests operated at $1.3 \mathrm{~A} / \mathrm{cm}^{2}$ and higher. In most of those tests, this resulted in increased celi voltage as the test progressed.

At a $B R$ of 1.6 and $C D$ of $1.3 \mathrm{~A} / \mathrm{cm}^{2}$ a $C u$ cermet operated without a CEROX coating resulted in 7 times the total corrosion of a CEROXcoated anode operated at the same zonditions 15.113 wt 8 versus 0.7318 wt 8 ). In addition, the uncoated anode was tapered while the c.erox-coated anode had little dimensional change.

The CEROX coating resistance was measured by rotating cylinder experiments for coatings $0.7,1.34$, and $2.0 \mathrm{~mm}$ thick. An electrical conductivity of $0.20 \pm 0.05 \Omega \Omega^{-1} \mathrm{~cm}^{-1}$ was calculated. The additional energy cost associated with this added resistance was 
calculated assuming operation at $0.7 \mathrm{~A} / \mathrm{cm}^{2}$, a $1 \mathrm{~mm}$ thick CEROX coating, a current efficiency of $90 \%$, and an energy cost of 2.5 cents/kwh. The additional cost for operating with a CEROX coating was calculated to be $\$ 26.21 /$ ton of Al. 


\section{PREVIOUS WORK ON INERT ANODES}

The use of inert anodes in aluminum reduction cells has been proposed since the time of Hall's initial invention. Indeed, Hall himself devoted a great deal of effort in the pursuit of an oxygen evolving anode. Unfortunately, the problems initially encountered, i.e., metal contamination, anode life, conductivity, and cost still persist today. Past efforts to develop an inert anode have been reviewed by Billehaug and Oye. ${ }^{2}$ More recent efforts have largely concentrated on cermet materials in work carried out first at Alcoa and later at PNL. A summary of previous work is presented in Subsections 2.1 to 2.4 .

\subsection{Metal Anodes}

Although platinum group metals may be suitable as metai anodes, the prohibitive cost would preclude their use. Less noble metals are generally not suitable as inert anodes. Belyaev and studentsovi2,13 found that $\mathrm{Cu}, \mathrm{Ni}, \mathrm{Cr}$, and $\mathrm{Ag}$ were not resistant to uxygen. The oxide layers that formed spalled off, exposing fresh metal surfaces to be attacked. Kronenberg ${ }^{14}$ also found $\mathrm{Cu}$ and $\mathrm{Ni}$ to be severely attacked under anodic polarization. Copper anodes (criginally suggested by Hall) have been tested on an industrial scale with no success. ${ }^{15}$

\subsection{Boride, Carbide, and Nitride Anodes}

Refractory metal borides, carbides, and nitrides have been proposed as anodes. However, studies with these materials have shown that in all cases, they have severly corroded during electrolysis. ${ }^{16}$

\subsection{Metal Oxide Anodes}

Oxide ceramics have been studied as inert anodes for aluminum electrowinning by the Hall-Heroult process because of their stability in the presence of oxygen. However, all examined candidate materials exhibit a finite solubility in the cryolite melt, which leads to unacceptably high metal contamination levels in the electrowon aluminum. Moreover, the least soluble oxides are thermodynamically uncable with respect to the aluminum that is dissolved in the electrolyte. These problems are the major obstacles in the development of the dimensionally stable anode technology.

Early investigations by Belyaev and Studentsov ${ }^{12}$ identified $\mathrm{Fe}_{3} \mathrm{O}_{4}$, $\mathrm{SnO}_{2}, \mathrm{NiO}$, and zno as the oxides having the lowest solubility in molten cryolite and the highest stability in laboratory polaxization tests. The rate of corrosion of a $\mathrm{Fe}_{3} \mathrm{O}_{4}$ anode was found to be independent of $\mathrm{CD}$. The electrowon aluminum was also found to contain up to $1.5 \% \mathrm{Fe}$. 
In a subsequent study, Belyaev ${ }^{17}$ found that ferrites such as $\mathrm{NiOFe}_{2} \mathrm{O}_{3}$ and $\mathrm{ZnFe}_{2} \mathrm{O}_{4}$ had higher electrical conductivity and better corrosion resistance than the pure oxides. Since then, $z$ large number of patents have been issued describing the use of metal oxide and mixed metal oxides as inert anodes. However (in nearly all cases) the most serious problem continues to be the dissolution of the oxide into the cryolite ${ }^{3}$ and in turn, the contamination of the electrowon aluminum.

of the oxides considered, $\mathrm{SnO}_{2}$ has received the most attention because of low solubility ${ }^{2}$ and high electrical conductivity achieved by doping. Unfortunately, unacceptably high levels of sn in the electrowon aluminum have been repeatedly observed. ${ }^{18}$ It has been proposed that the corrosion of the $\mathrm{SnO}_{2}$ is through chemical. attack by dissolved aluminum, which is present at a level of several tenths of a percent.19,20 Various engineering approaches have been attempted to reduce $\mathrm{SnO}_{2}$ corrosion, 18,21,22 including oxygen protection. However, none of these approaches have been commercially adopted.

\subsection{Cermet Anodes}

In 1982, Alcoa ${ }^{23}$ disclosed the development of a cermet anode composed of $70 \% \mathrm{NiFe}_{2} \mathrm{O}_{4} / \mathrm{NiO}$ and $30 \% \mathrm{Ni}$. Both the ceramic phase and metal phase were continuous in this material. The $\mathrm{NiFe}_{2} \mathrm{O}_{4} / \mathrm{NiO}$ had low chemical solubility in cryolite. The Ni phase improved both the electrical conductivity of the material and the mechanical properties such as thermal shock resistance.

Rapid development of this material led to the eventual testing in a 2500 A pilot ceil." Although failure of the test after $21 \mathrm{~d}$ of operation was attributed to degradation of the cermet/steel. conductor connection, an autopsy of the tested anode revealed that microstructural changes in the cermet precluded extended operation of the cell. Later studies indicated that corrosion of the Ni phase by oxidation or by the electrolyte occurs during operation, causing cracking and bath penetration.

The leaching of the metal phase from the cermet led Tarcy to screen various pure metals and commercially available alloys to find a material with a higher polarization requirement for anodic dissolution than $\mathrm{Ni}$. Although none of the metals or alloys tested (other than platinum) were sufficiently resistant to serve alone as an inert anode, $\mathrm{Cu}$ and $\mathrm{Cu} / \mathrm{Ni}$ alloys were proposed to be promising candidates for a metal phase in the cermet. It was found that the passivating layer on $\mathrm{Cu}$ and $\mathrm{Cu} / \mathrm{Ni}$ alloys tends to spall off the surface of a metal surface, but not when incorporated into the ceramic matrix.

Subsequently, Ray ${ }^{25}$ developed a new cermet material in which the $\mathrm{Ni} / \mathrm{Fe}$ alloy is replaced by $\mathrm{Cu} / \mathrm{Ni} / \mathrm{Fe}$. It was reported that this material does not degrade with time and forms an inactive Jayer 
that prevents loss of the metallic phase.

A series of cermet materials containing 83 to 95 wt 8 metal oxide and 5. to 17 wto $\mathrm{Cu}$ metal was examined in $30 \mathrm{~h}$ laboratory bench tests. ${ }^{26}$ The aluminum produced contained impurities of 0.03 to $0.07 \% \mathrm{Ni}, 0.26$ to $0.34 \% \mathrm{Fe}$, and 0.05 to $0.12 \% \mathrm{Cu}$. These levels fall just within the Alcoa target of total impurities of $<0.58$.

Alcoa discontinued research on the $\mathrm{Cu}$ cermets in 1985 and the research was continued at PNL. PNL investigated changes in the composition of the $\mathrm{Cu}$ allov phase and changes in processing of the cermet in order to improve electrical conductivity and decrease anode wear. Iittle corrosion of the anodes was found in laboratory scale tests.

A $15 \mathrm{~cm}$ diameter prototype cermet anode produced by Cercom, Inc. was tested by PNL at the Reynolds Manufacturing Technology Laboratory (MTL). ${ }^{27,28}$ The anode was operated at $0.69 \mathrm{~A} / \mathrm{cm}^{2}$ with a BR of 1.25 to 1.4 during most of the test. The bath was close to alumina saturation throughout the run, which lasted $113.5 \mathrm{~h}$. The concentration of $\mathrm{Fe}, \mathrm{Ni}$, and $\mathrm{Cu}$ in the aluminum produced at the cathode increased throughout the test, peaking at 2.57 wto $\mathrm{Fe}, 2.93$ wt. $\mathrm{Ni}, 1.56$ wt $\mathrm{Cu}$ and 8.06 wto total impurities. In addition, the ferrite anode lost about $6 \mathrm{~mm}$ from the diameter of the anode. Two $\mathrm{Cu}$ cermet reference anodes of the same composition as the test anode were lost in the bath during the test, undoubtedly contributing to the total impurities. However, the test was stili disappointing because of the high level of impurities in the aluminum and the dimensional loss to the anode. 


\section{PREVIOUS WORK ON CEROX COATINGS}

ELTECH Systems Corporation has been actively involved in research on inert anodes for aluminum electrowinning since the mid-1970s. The program initially involved screening of various oxide ceramics (including $\mathrm{SnO}_{2}$ ) and cermets; several promising candidates were identified, 29,30 although unacceptable high corrosion rates would prevent commercial use. In 1982, the CEROX coating technology was discovered.

\subsection{Cerox Discovery and Thermodynamics}

The CEROX coating technology was discovered in 1982 when it was found that a $\mathrm{CeO}_{2}$ coating could be anodically deposited from a molten cryolite electrolyte. When 1 wt: $\mathrm{CeO}_{2}$ was added to a conventional Hall-Heroult cell bath, it was noted that a $1 \mathrm{~mm}$ thick gray-blue coating was formed on the surface of a palladium anode. Subsequent $x$-ray diffraction of the coating confirmed the major phases to be $\mathrm{CeO}_{2}$, with cryolite detected as a minor phase. Later, it was found that a small amount of $E$ (about 0.1 mol) is present within the $\mathrm{CeO}_{2}$. The deposition of the CEROX coating was found to be quite reproducible and applicable to both netallic and ceramic substrates. The first patent describing the CEROX coating technology was issued in 1987.31

The thermodynamics of the Ce-Al-Na-O-F system has been examined. The anodic deposition of CEROX can be effectively described as either an electrochemical or chemical process. Both cases are presented here.

\subsubsection{Electrochemical Deposition of CERUX}

The electrochemical deposition of $\mathrm{CeO}_{2}$ can be expressed as two half reactions and is written

Anode: $2 \mathrm{CeF}_{3}+4 / 3 \mathrm{Al}_{2} \mathrm{O}_{3}=2 \mathrm{AlF}_{3}+2 \mathrm{CeO}_{2}+2 / 3 \mathrm{Al}^{+3}+2 \mathrm{e}^{-}$

Cathode: $2 / 3 \mathrm{Al}^{+3}+2 \mathrm{e}^{-}=2 / 3 \mathrm{Al}$.

The net reaction would be

$2 \mathrm{CeF}_{3}+4 / 3 \mathrm{Al}_{2} \mathrm{O}_{3}=2 \mathrm{CeO}_{2}+2 \mathrm{AlF}_{3}+2 / 3 \mathrm{Al}$.

The delta $G^{\circ}$ for this reaction at $1300 \mathrm{~K}$ is $141390 \mathrm{cal}$, which corresponds to an applied emf of $3.06 \mathrm{~V}$. The anodic deposition of $\mathrm{CeO}_{2}$ is in competition with the oxygen evolution reaction, written as

$\mathrm{Al}_{2} \mathrm{O}_{3}=2 \mathrm{AI}+3 / 2 \mathrm{O}_{2}$ 。

Equation (5) has a free energy change of 301680 cal, corresponding to an applied emf of $2.18 \mathrm{~V}$. 
Based on standard free energy change only, it would appear that $\mathrm{CeO}_{2}$ deposition would never occur. However, it must be noted that delta $G^{\circ}$ for Equation (4) is influenced by the $\mathrm{AlF}_{3}$ activity, which in pure cryolite has been estimated to be between $10^{-5}$ and $10^{-3} .^{1}$ Yoshida and Dewing estimated the AlF activity in a cryolite bath with varying cryolite ratios (Eigure 1) ${ }^{20}$. In order to visualize the dependence of $\mathrm{CeO}_{2}$ deposition on $\mathrm{AlF}_{3}$ activity and applied potential, a predominance diagram (Figure 2) was constructed from $E * A * C * T$ qalculations (MCGill University). All species other than $\mathrm{AlF}_{3}$ were assumed to be in their standard state. In addition to Equation (4), the equilibria written as

$2 \mathrm{CeF}_{3}+\mathrm{Al}_{2} \mathrm{O}_{3}=\mathrm{Ce}_{2} \mathrm{O}_{3}+2 \mathrm{AlF}_{3}$

$1300 \mathrm{~K}$ delta $\mathrm{G}^{\circ}=86559 \mathrm{cal}$

$\mathrm{Ce}_{2} \mathrm{O}_{3}+1 / 3 \mathrm{Al}_{2} \mathrm{O}_{3}=2 \mathrm{CeO}_{2}+2 / 3 \mathrm{Al}$

$1300 \mathrm{~K}$ delta $\mathrm{G}^{\circ}=54830 \mathrm{cal}$

$\mathrm{Ce}+\mathrm{Al.F} \mathrm{F}_{3}=\mathrm{CeF}_{3}+\mathrm{Al}$

$1300 \mathrm{~K}$ delta $\mathrm{G}^{\circ}=-65734 \mathrm{cal}$

$2 \mathrm{Ce}+\mathrm{Al}_{2} \mathrm{O}_{3}=\mathrm{Ce}_{2} \mathrm{O}_{3}+\mathrm{Al}$

$1300 \mathrm{~K}$ delta $\mathrm{G}^{\circ}=-44918 \mathrm{cal}$

were considered. As can be seen in Figure 2 (at $A_{1} F_{3}$ activities $<10^{-3}$ ) the deposition of $\mathrm{CeO}_{2}$ becomes thermodynamically possible at normal $\mathrm{O}_{2}$ evolving potentials in pure cryolite. The $\mathrm{CeO}_{2}$ deposition is not possible at $\mathrm{CO}_{2}$ evolving potentials at practical $\mathrm{AlF}_{3}$ activities. It is also predicted that at very acidic conditions (high $\mathrm{AlF}_{3}$ activity $10^{-2}$ or greater), $\mathrm{CeO}_{2}$ deposition is not favored at $\mathrm{O}_{2}$ evolving potentials.

In summary, $\mathrm{CeO}_{2}$ deposition is possible, largely because of the low $\mathrm{AlF}_{3}$ activity in cryolite melts. In normal acidic melts, deposition can occur at high $\mathrm{O}_{2}$ overpotentials.

\subsubsection{Chemical Deposition of CEROX}

Cerium oxide deposition could also occur by chemical oxidation of $\mathrm{CeF}_{3}$ by the reaction

$2 \mathrm{CeF}_{3}+\mathrm{Al}_{2} \mathrm{O}_{3}+1 / 2 \mathrm{O}_{2}=2 \mathrm{CeO}_{2}+2 \mathrm{AlF}_{3}$

$1300 \mathrm{~K}$ delta $\mathrm{G}^{\circ}=40892 \mathrm{cal}$. 


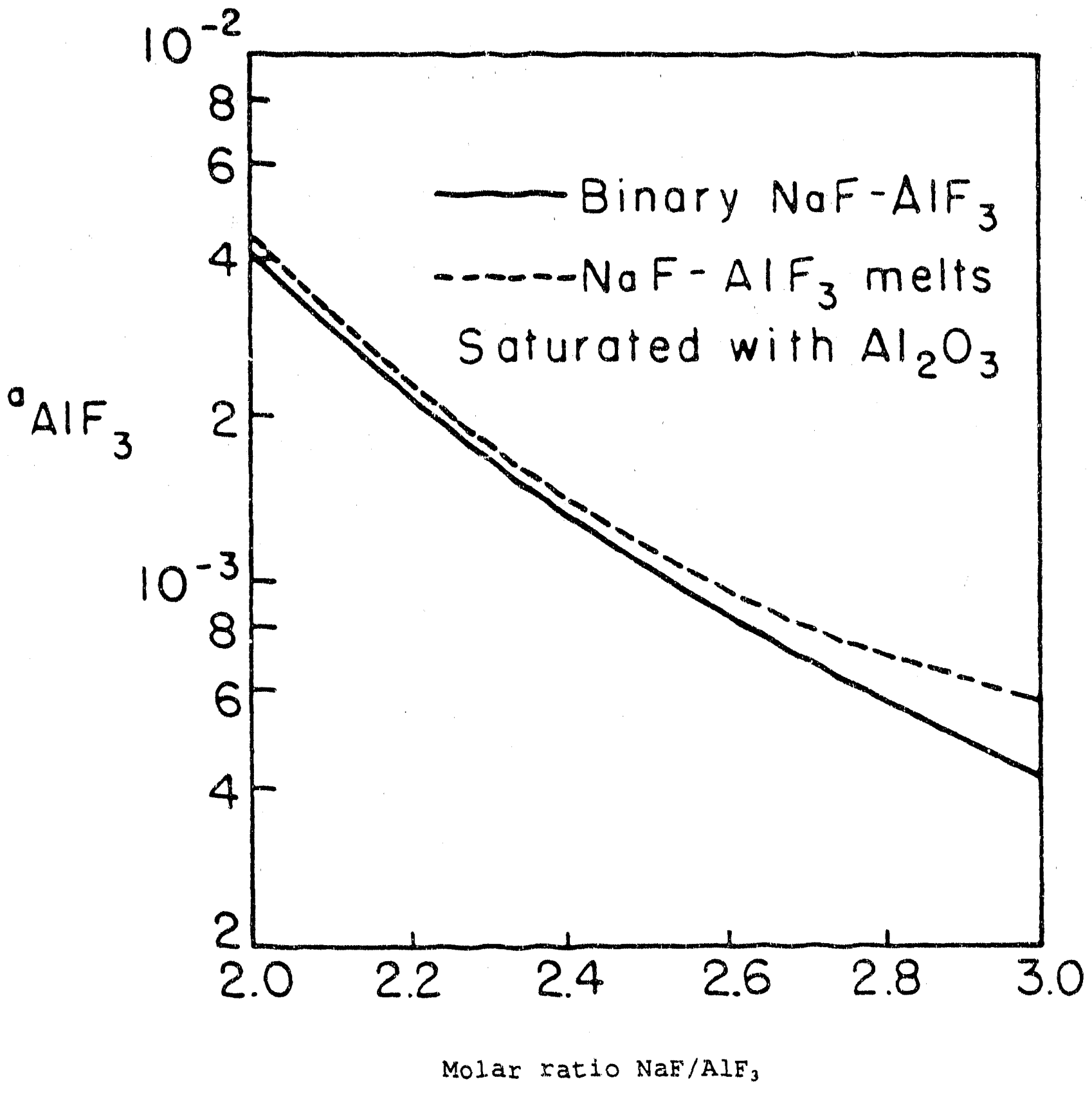

Figure 1. $\mathrm{AlF}_{3}$ activity at $1000^{\circ} \mathrm{C}$, from Yoshida and Dewing. ${ }^{18}$ 


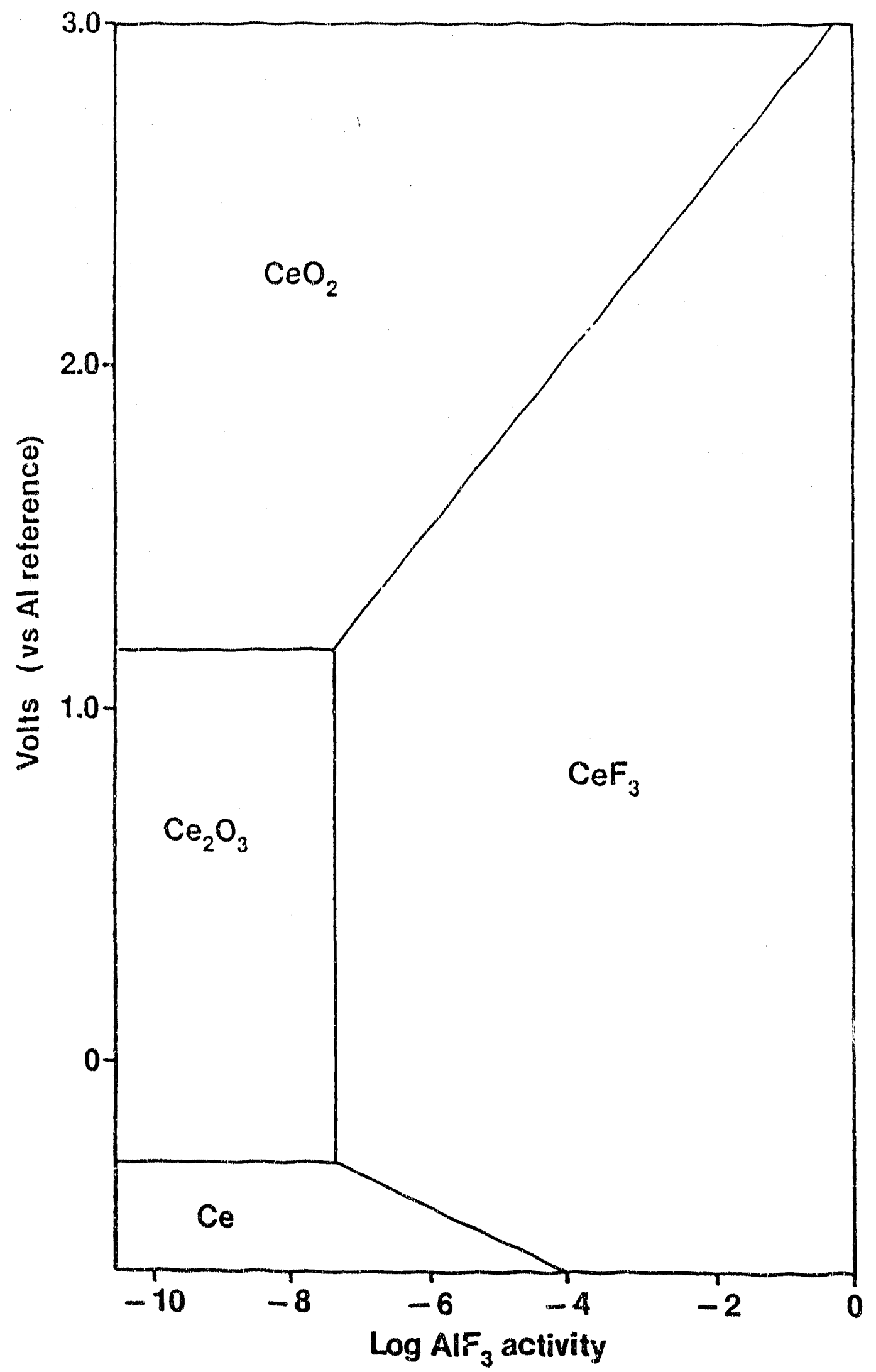

Figure 2. Predominance diagram for the oxidation of $\mathrm{CeF}_{3}$. 
From the large positive value of delta $G^{\circ}$ it is clear that the reaction is not spontaneous with all species in their standard states. However, the equilibrium is shifted to the right in a cryolite melt, where a low activity of $\mathrm{AlF}_{3}$ is present.

Eigure 3 shows a predominance diagram of the Ce-Al-Na-O-F system at. $1300 \mathrm{~K}$, plotting the $\log \mathrm{Al}_{2} \mathrm{O}_{3}$ activity versus the $\log \mathrm{O}_{2}$ pressure. An activity ot $10^{-5}$ was assumed for $A_{1} F_{3}$. The activity of $\mathrm{Na}_{3} \mathrm{Al}_{6}$ was set at 0.3 . As would be expected, $\mathrm{CeO}_{2}$ formation is favored at high $\mathrm{Al}_{2} \mathrm{O}_{3}$ activity and $\mathrm{O}_{2}$ pressure. At 1 atm $\mathrm{O}_{2}$, the critical $\mathrm{Al}_{2} \mathrm{O}_{3}$ activity is $3 \times 10^{-4}$.

For comparison, an ldentlcal diagram was constructed assuming an $\mathrm{AlF}_{3}$ activity of $5 \times 10^{-4}$ (Figure 4). In this case, more oxidizing conditions are required to form $\mathrm{CeO}_{2}$. At 1 atm $\mathrm{O}_{2}$, the critical $\mathrm{Al}_{2} \mathrm{O}_{3}$ activity is $\sim 0.3$.

Just as with the electrochemical oxidation, the chemical oxidation of $\mathrm{CeF}_{3}$ to $\mathrm{CeO}_{2}$ is possible only because of the low activity of $\mathrm{AlF}_{3}$ in cryolite. In acidic melts, $\mathrm{CeO}_{2}$ deposition is less likely. High $\mathrm{Al}_{2} \mathrm{O}_{3}$ activity and $\mathrm{O}_{2}$ pressure promote oxidation.

\section{1 .3 Cerium Partitioning}

In a Hall-Heroult cell using CEROX coated anodes, an equilibrium is expectied to be established between the $C e$ in the aluminum and CeF ${ }_{3}$ in the melt and is given by

$$
\begin{aligned}
\mathrm{CeF}_{3}+\mathrm{Al} & =\mathrm{Ce}+\mathrm{AlF} \mathrm{F}_{3} \\
& 1300 \mathrm{~K} \text { delta } \mathrm{G}^{\circ}=66047 \mathrm{cal} .
\end{aligned}
$$

According to Equation (11), with the reactants and products in their standard state, $A l$ will not reduce $\mathrm{CeF}_{3}$. However, the

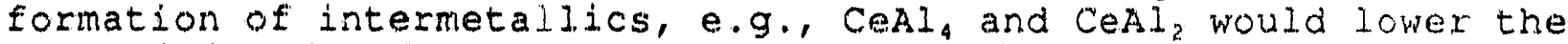
Ce activity in $A$. and promote the reduction of CeF ${ }_{3}$. Lower $\mathrm{AlF}_{3}$ activities also promote the formation of Ce in the A.l.

The distribution of Ce in the Al and the melt should be determined by the equilibrium established by the above reaction. Therefore, we have

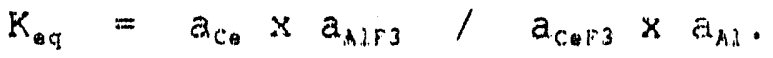

Assuming the activity of $A_{1 .} F_{3}$ and $A l$ should be constant we can therefore define a partition coefficient as the ratio of ce in the Al and the $c e$ in the melt as

$P C=\frac{C e(A L)}{C e(M e I t)}$. 


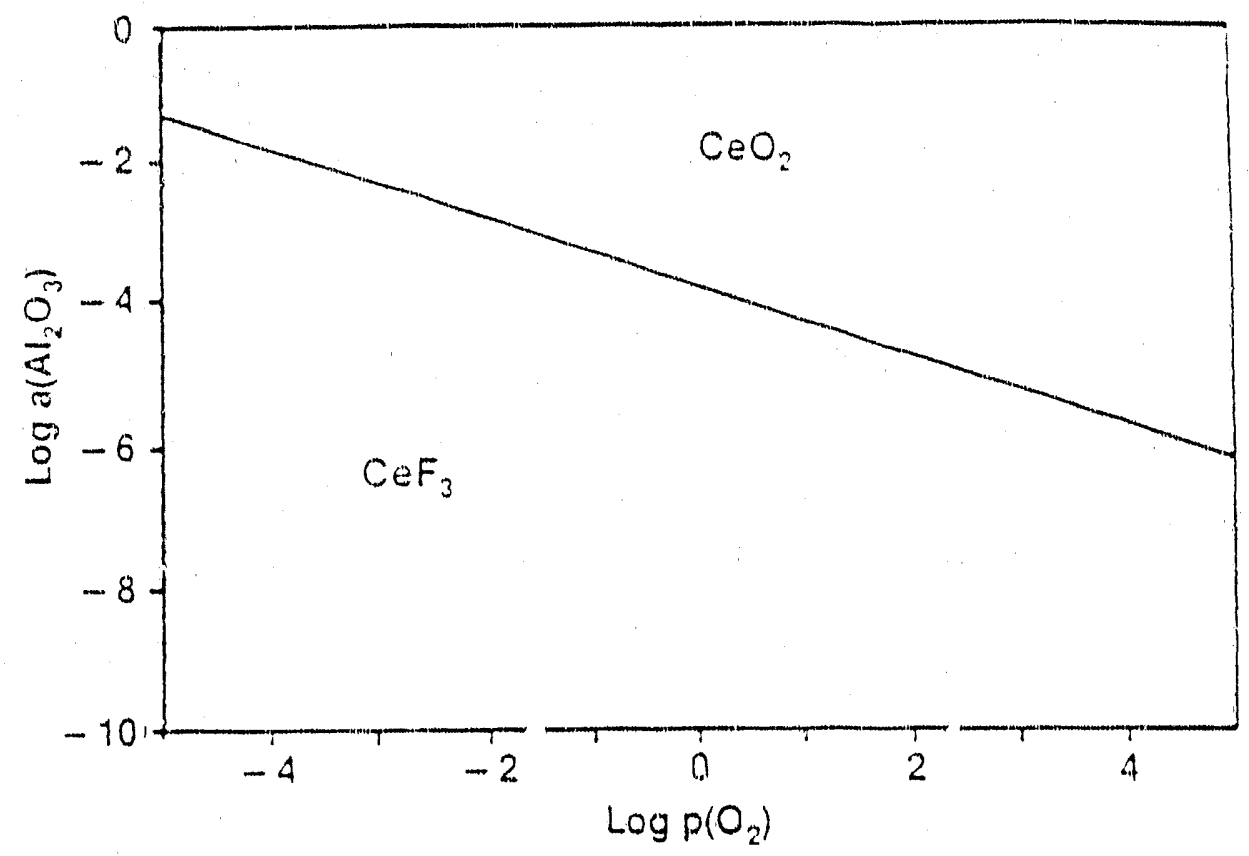

Figure 3. Exedominance diagram for the oxidation of $\mathrm{CeF}_{3}$. $\mathrm{AlF}_{3}$ activity $=10^{-5}, \mathrm{Na}_{3} \mathrm{AlF}_{6}$ activity $=0.3$

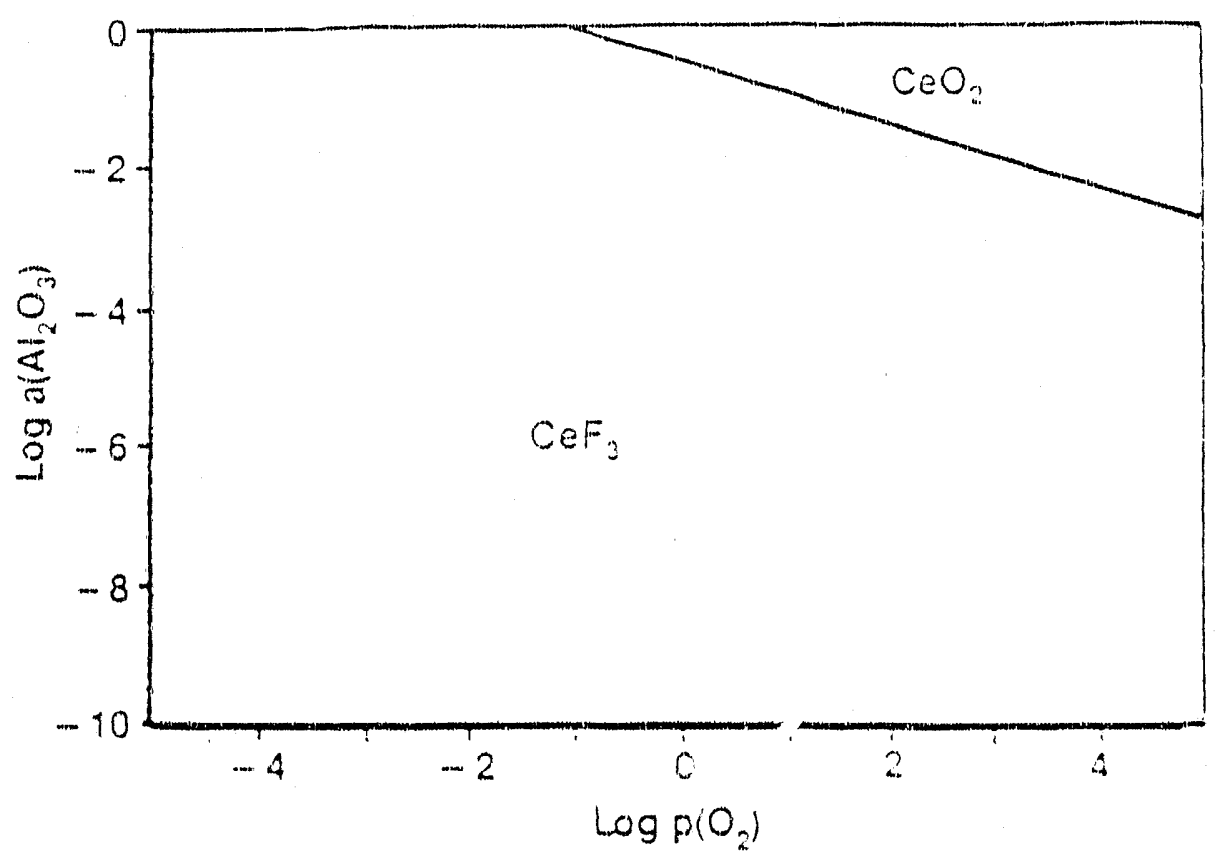

Eigure 4. Predominance diagram for the oridation of CeF, $A F_{3}$ activity $=5 \times 10^{\circ}, \mathrm{Na}_{3} \mathrm{AlE}_{6}$ activity $=0.3$ 
This should be nearly constant for conditions with low Ce concentration but will vary with $\mathrm{AlF}_{3}$ activity.

\subsection{DOE Supported Research at ELTECH}

This profect was Phase III of an ongoing study to determine the amount of protection the CEROX coating offers to an anode substrate and to define the influence of optrating conditions on the CEROX coating protection. Phase I was cumpleted in June 1.987 while Phase II was completed in April $1989.10,11$

\section{2 .1 Phase I}

Phase I experiments were conducted to study the insitu deposition of the CEROX coating on $\mathrm{SnO}_{2}$ and $\mathrm{Ni}$ ferrite/Cu cermet (from PNI) anodes. Ten hour tests were conducted on each substrate at a BR of 1.35 and $C D$ of $0.8,1.4$, and $2.0 \mathrm{~A} / \mathrm{cm}^{2}$ with $\mathrm{CeO}_{2}$ corcentrations of $0.5 \%, 1.0 \%$, and $1.5 \%$. In addition, the $\mathrm{Ni}$ ferrite was operated under the same $B R$ and $C D$ conditions in Ce-free baths. Ten hour testg were also conducted on the CEROX-coated cermet with additives in the bath.

CEROX coatings were easily deposited on both substrates and were found to decrease the attack on both $\mathrm{SnO}_{2}$ and the Cu cermets. The thickness of the CEROX coating was primarily dependent on the amount of cerium in the bath while current density had a lesser effect. Coatings were generally thicker and more uniform at lower $C D$. The corrosion of Ce-free anodes was found to increase with $C D$. The thickest coatings, at low $C$ and high cerium concentrations were the most protective. A voltage increase was found to be associated with the CEROX coating.

\subsection{2 phase II}

Phase II was undertaken to extend the testing time on ELTECHfabricated Ni ferrite/Cu cermets to $100 \mathrm{~h}$ under varying BR (1.2, 1.35, and 1.6$)$ and $C D\left(0.6,1.0,1.4 \mathrm{~A} / \mathrm{cm}^{2}\right)$ conditions. Additions of $18 \mathrm{CeF}_{3}$ were made in the $100 \mathrm{~h}$ tests to achieve a CERox coating thickness of $1 \mathrm{~mm}$. A Ce-free anode was operated for comparison at the $1.35 \mathrm{BR}$ and $1.0 \mathrm{~A} / \mathrm{cm}^{2}$ current density. Short-term testing on industrial bath compositions (BR 1.07 to 1.4) with commercially available additives was also conducted.

The preserice of the CEROX coating significantly reduced the impuritles in the metal and bath by $>978$ at a BR of 1.35 and $C D$ of $1.0 \mathrm{~A} / \mathrm{cm}^{2}$. The lowest contamination of the aluminum occurred at a $B R$ of 1.6 and a $C D$ of $1.4 \mathrm{~A} / \mathrm{cm}^{2}$ where total Fe was 0.04 wt $\frac{8}{8}$ and total impurities were $0.15 \mathrm{wt}$. Severe anode corrosion was observed in test performed at the $0.6 \mathrm{~A} / \mathrm{cm}^{2} \mathrm{CD}$ and when cerium was not added to the bath until after electrolysis had commenced. An conomic analysis estimated the ce recovery cost from the aluminum to be $\$ 7.82 /$ ton of Al produced. 


\section{MATERIALS AND METHODS}

\subsection{Materials}

Synthetic cryolite from American Fluoride (AF) Co. (Lot 1178 Fine Powder No. 1-680) was used in most of the experiments. Midway through the testing it was found that cryolite is no longer available from American Fluoride Co. Therefore, Type $k$ cryolite from Washington Mills (WM) Electro Minerals Corporation was employed. In both cryolites, $\mathrm{Ni}, \mathrm{Cu}$, and $\mathrm{Ce}$ were below detection limits of the ICP. AF cryolite contained $1039 \mathrm{ppm} \mathrm{Si}$ and 50 to $80 \mathrm{ppm}$ of $\mathrm{Fe}$ while WM cryolite contained $1064 \mathrm{ppm}$ Si and 378 to $406 \mathrm{ppm} F e$. All non-saturated alumina tests were conducted with the WM cryclite and the last saturated tests, 13614-49, $-51,-53$, and -55 , were with the WM cryolite.

Other materials included Fisher Scientific certified grade A-59]. anhydrous aluminum oxide of $99 \%$ purity, Cerac A-11.15 aluminum Fluoride of $99.9 \%$ purity, Fisher scientific sodium fluoride certified grade S-299 ( 100 ppm Fe), Fisher scientific calcium fluoride certified grade $\mathrm{C}-89$, and cerium fluoride \#21118 from Johnson Matthey Electronics (JME) 99.98 purity (Rare Earth Oxide). The aluminum added to the cell at the beginning of the test was \$1.0571, 99.9998 pure from JME. Any sodium carbonate additions were Fisher scientific purified grade 5261 , calcined and dried.

\subsection{Copper Cermet Anodes}

The copper cermet anodes used in Phase III testing were fabricated by ELTECH with the intention of producing a cermet as similar to the Alcoa $\mathrm{Cu}$ cexmets as possible. Improvements were made in fabrication over those cermets used in Phase II and made by ELTECH.

\subsubsection{Previous Copper Cermets rested}

In Phase I, PNI supplied the $\sim 0.75$ in. dianeter $\mathrm{Cu}$ cermet anodes that were produced from Stackpole Corp. Ni ferrite/Nio spray dried powders and made according to the PNI methods at that time (1986). The anodes were fabricated with Alcoa procedures and were expected to be like the Alcoa Cu cermets. Density achieved was $\sim 6.0 \mathrm{~g} / \mathrm{cm}^{3}$ ( $\sim 998$ of theoretical density).

In Rhase II, ELTECH fabricated the copper cermet anodes employed in testing. Ni ferrite powder was produced by calcining NiO

(51.7 wto ) and $\mathrm{Fe}_{2} \mathrm{O}_{3}(48.3$ wto $)$ together at $900^{\circ} \mathrm{C}$ in air. After calcining, the material was passed through a 50 mesh screen, v-blended with 17 wto Cu powder (CERAC $2 \mu \mathrm{m}$ ), and isopressed in rubber molds. The green bars were then sintered in argon at $1350^{\circ} \mathrm{C}$ for $0.5 \mathrm{~h}$. The sintered anodes were $\sim 0.67$ in. diameter with a maximum density of $5.76 \mathrm{~g} / \mathrm{cm}^{3}(\sim 94.98$ of TD). 
In Phase III, all anodes were fabricated by ELTECH. However, changes were made in the fabrication procedure to eliminate the problems with the Phase II anodes and to produce a material more like that of Alcoa. To improve the sintered density (from $5.76 \mathrm{~g} / \mathrm{cm}^{3}$ to the TD of $\sim 6.07 \mathrm{~g} / \mathrm{cm}^{3}$ ) and reduce porosity spray dried ferrite powders were employed. To reduce oxygen hang up noted on the flat-bottomed anodes of Phase II, anodes were machined to have a hemispherical end.

In the Phase II ELTECH produced anodes, excessive bleeding of $C u$ during sintering caused loss of some of the 17 wt $\% \mathrm{Cu}$ and suggested that the $\mathrm{Cu}$ phase was interconnected in the cermet. PNL suggested that an intermediate sintering hold at $1070^{\circ} \mathrm{C}$ helps to prevent $\mathrm{Cu}$ bleedout. ${ }^{32}$ It was recommended in the phase II report that future anodes be fabricated with a non-interconnected Cu phase, presumably like that of Alcoa, 11 to reduce oxidation and corrosion of the Cu phase.

\subsubsection{Eabrication Procedures}

$\mathrm{Ni}$ ferrite/Nio plasma sprayed powder was purchased from ceramic Magnetics, Inc. This material was fabricated by them under the direction of RNL following the Alcoa procedures for fabrication of 5324 ferrite powder. ${ }^{6}$ The $\mathrm{Ni}$ ferrite/NiO powder is shown in Figures 5 and 6 and compared to the stackpole powder (Figures 7 and 8). The Ceramic Magnetics powder consists of spherical spray dried granules with a bimodal size distribution. The large particles are $225 \mu \mathrm{m}$ in diameter while the numerous small particles are 5 to $50 \mu \mathrm{m}$ and often appear to adhere to the larger particles.

The Ni ferrite/NiO was V-blended with 17 wto Cerac C-1229 Cu powder for $30 \mathrm{~min}$. The powder is reportedly $2 \mu \mathrm{m}$ in size. Figure 9 shows the $\mathrm{Cu}$ to be spherical and range from $<1$ to $\sim 4 \mu \mathrm{m}$ in diameter. After the $V$-blending, the powdex was divided into $60 \mathrm{~g}$ batches, packed into $1 \mathrm{in}$. rubber isopress bags, and isopressed at $25 \mathrm{kpsi}$ with a $15 \mathrm{~s}$ hold. One end of each green anode was machined on a lathe to have a hemispherical end.

The green forms were sintered in a tube furnace in an argon atmosphere with 100 to 1000 ppm $O_{2}$ (as specified by Alcoa ${ }^{6}$ ). A Zircoa oxygen sensor was employed to monitor the $\mathrm{O}_{2}$ level. throughout the sintering run. 


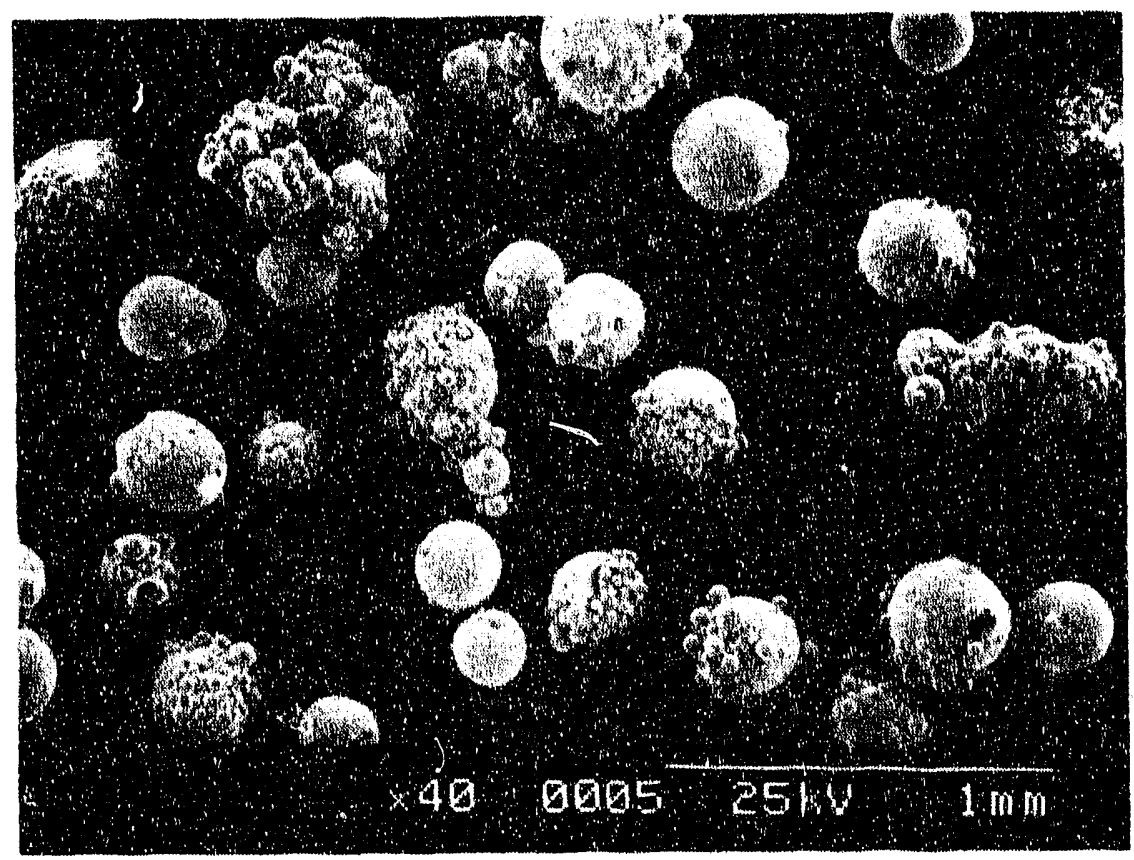

Eigure 5. SEM photograph of Ceramic Magnetics $\mathrm{NiFe}_{2} \mathrm{O}_{4} / \mathrm{NiO}$ spray dried powder (40X).

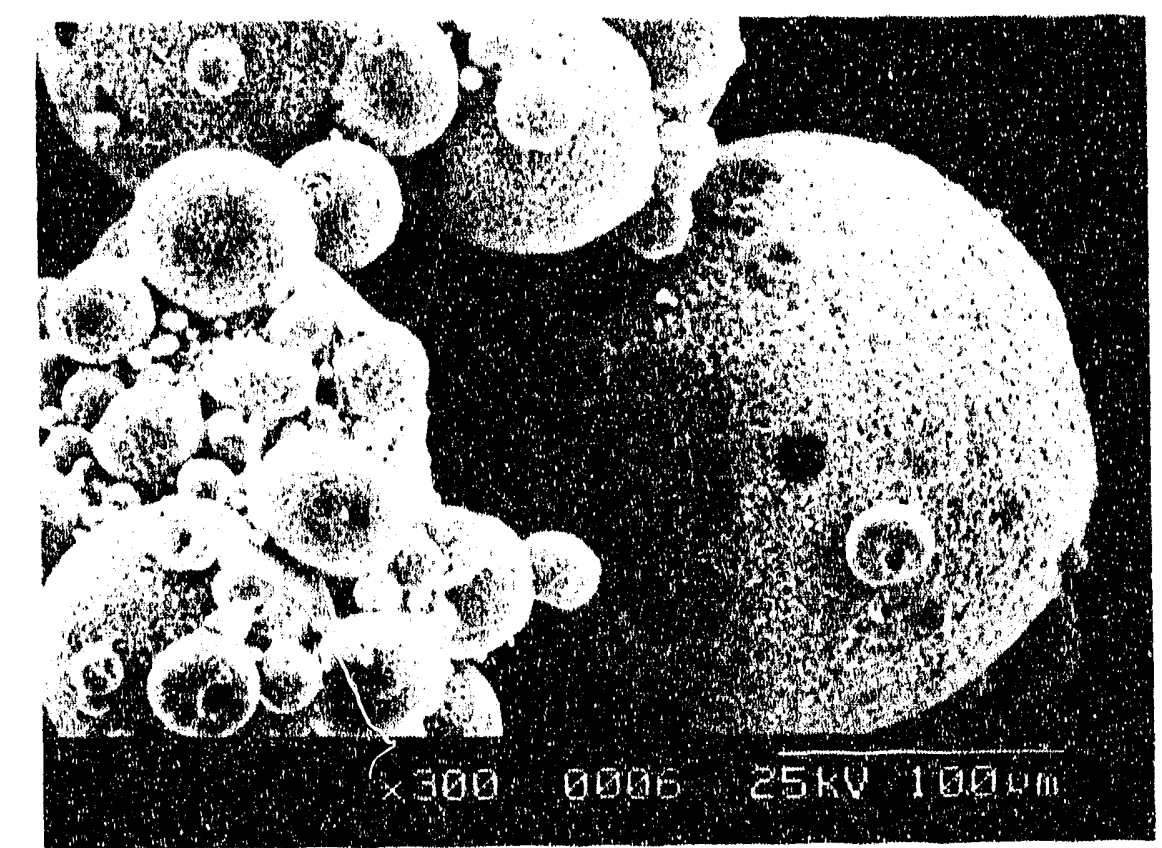

Eigure 6. SEM photograph of Ceramic Magnetics $\mathrm{NiFe}_{2} \mathrm{O}_{4} / \mathrm{NiO}$ spray dried powder $(300 \mathrm{X})$. 


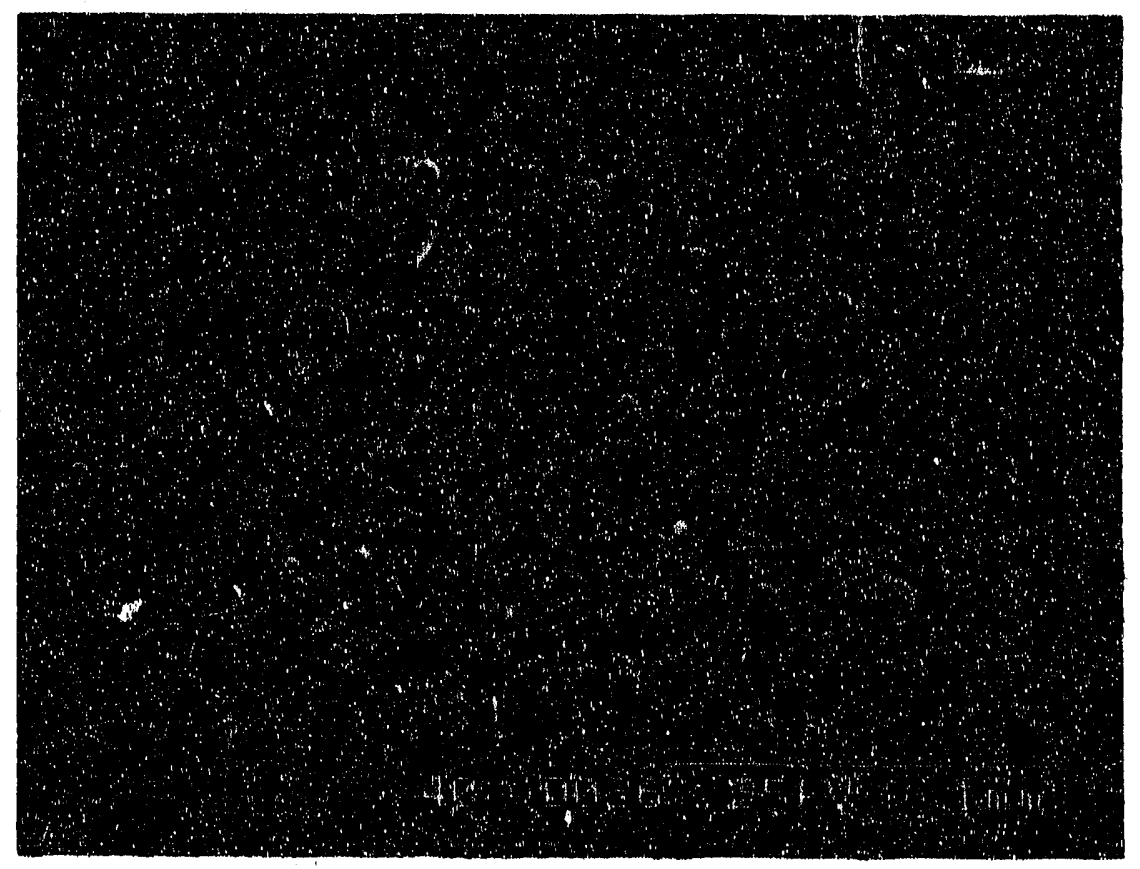

Figure 7. SEM photograph of stackpole $\mathrm{NiEe}_{2} \mathrm{O}_{4} / \mathrm{NiO}$ spray dried powder $(40 \mathrm{X})$.

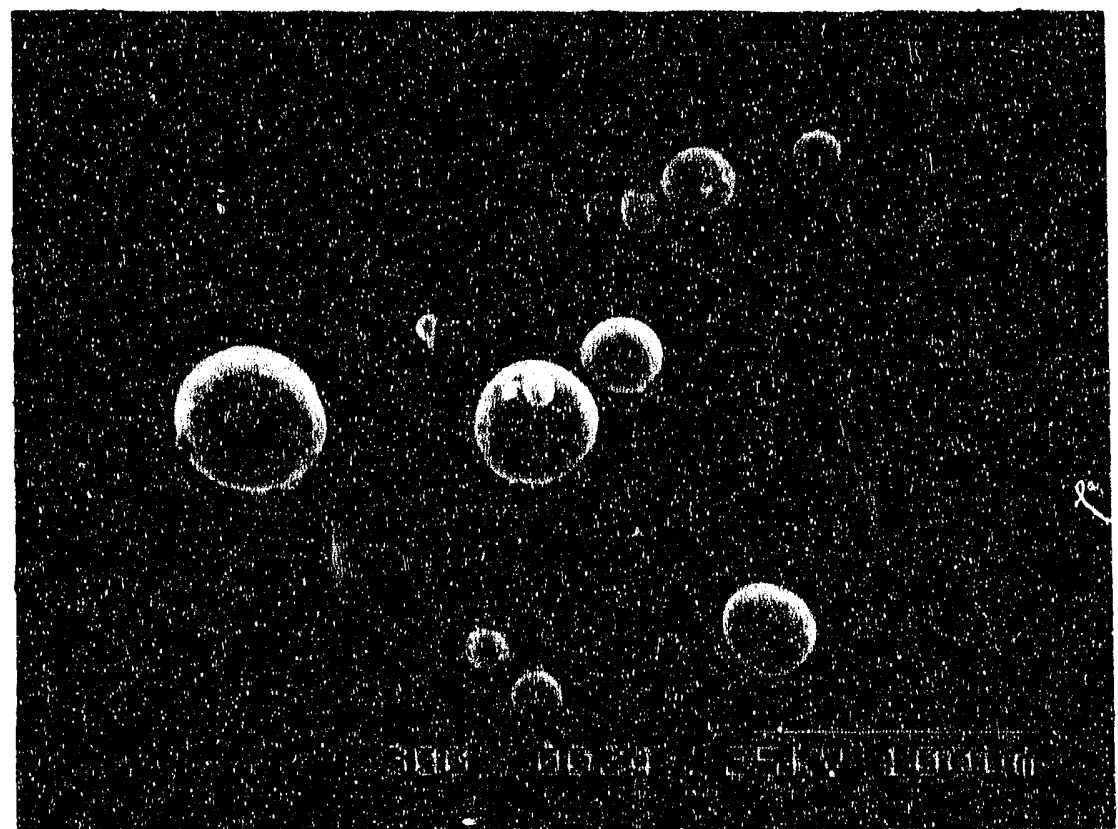

Eigure 8. SEM photograph of stackpole $\mathrm{NiFe}_{2} \mathrm{O}_{4} / \mathrm{NiO}$ spray dried powder $(300 \mathrm{X})$. 


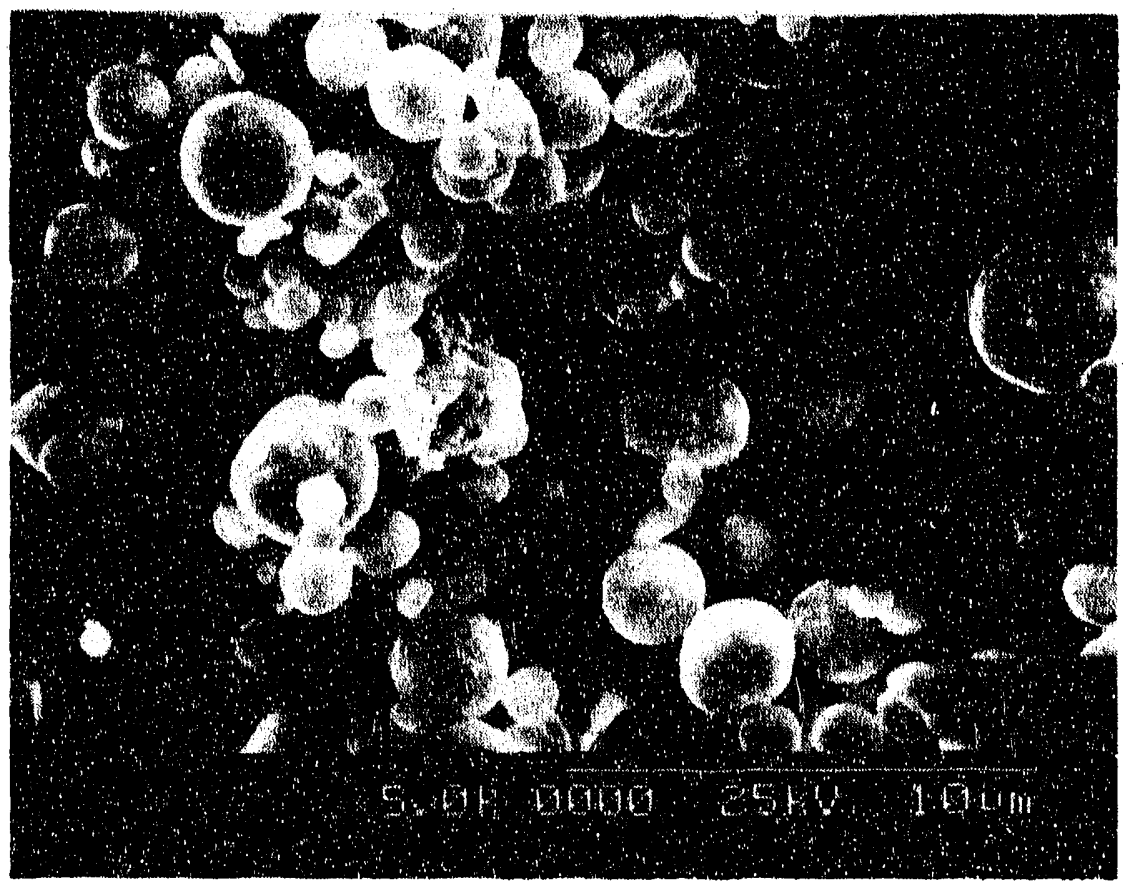

Figure 9. SEM photograph of Cerac C-1229 Cu powder (5000X). 
Two sintering schedules were investigated.

1. ELTECH'S Phase II

$3^{\circ} \mathrm{C} / \mathrm{min}$ to $1350^{\circ} \mathrm{C}$, hold at $1350^{\circ} \mathrm{C}$ for $0.5 \mathrm{~h}$, cool down at furnace cooling rate

2. Similar to the schedule of PNL

$2^{\circ} \mathrm{C} / \mathrm{min}$ to $1070^{\circ} \mathrm{C}$, hold at $1070^{\circ} \mathrm{C}$ for $2 \mathrm{~h}$, $1^{\circ} \mathrm{C} / \mathrm{min}$ to $1300^{\circ} \mathrm{C}$, hold at $1300^{\circ} \mathrm{C}$ for $8 \mathrm{~h}$, cool down at furnace cooling rate.

Samples from both schedules were examined (see Subsection 4.2.3) and the PNL-type sintering schedule was chosen for fabrication of all test anodes. Midway through the test program, it was revealed that the current sintering schedule of PNL is to a temperature of $1250^{\circ} \mathrm{C}$. Several anodes were also sintered at that temperature for comparison, but because the testing had already begun the sintering schedule was not changed for the tested anodes.

After sintering, any $\mathrm{Cu}$ that has squeezed out and beaded on the surface is removed and any surface coating is ground off with SiC paper. Densities achieved with schedule \#1 averaged $\sim 5.95 \mathrm{~g} / \mathrm{cm}^{3}$ while those with schedule $\# 2$ were from 5.99 to $6.00 \mathrm{~g} / \mathrm{cm}^{3}$.

Twelve anodes $0.385 \mathrm{in.}$ in diameter, $1.18 \mathrm{in.}$ long were received from PNL for comparison to the ELTECH material in long-term tests. The average density was $6.05 \mathrm{~g} / \mathrm{cm}^{3}$ ( $99.7 \mathrm{~g}$ of TD).

\subsubsection{Characterization and Comparison}

Samples from each sintering schedule were dissolved by fusion in a molten $\mathrm{Na}_{2} \mathrm{O}_{2}$ flux and the elements analyzed with an inductively coupled plasma spectrometer (ICP). The results are shown in Table 2. The ELTECH anodes sintered at 1300 and $1350^{\circ} \mathrm{C}$ lose some of the $\mathrm{Cu}$ as small balls squeezed out onto the surface. This reduced the $\mathrm{Cu}$ in the cermet from 17 wt to 11.3 and 1.2 .8 wto $\mathrm{Cu}$ in the Phase II and Phase III anodes, respectively, sintered to $1350^{\circ} \mathrm{C}$. The Phase III anodes sintered to $1300^{\circ} \mathrm{C}$ lost less $\mathrm{Cu}$, with $\sim 13.7$ wt: remaining in the anodes. The anode sintered at $1250^{\circ} \mathrm{C}$ for comparison in Phase III did not have any $\mathrm{Cu}$ on the surface after sintering and contained 18.6 wt 8 Cu after sintering. Because the PNL anodes from Phase I and III contain $\sim 18$ wto $\mathrm{Cu}$, they were probably also sintered at $1250^{\circ} \mathrm{C}$ or less.

one method to evaluate the interconnectedness of the $\mathrm{Cu}$ phase in the cermet was by measuring the electrical conductivity. Electrical conductivity of a cermet sintered with schedule \#1, one sintered with schedule \#2, and a PNL Phase III cermet was measured at Thermophysical properties Research Laboratory (TPRL) at Purdue University. A commercial push rod dilatometer was modified to 
Table 2. Chemical analysis of $\mathrm{Ni}$ Ferrite/Cu cermets.

\begin{tabular}{|c|c|c|c|c|}
\hline Material & $8 \mathrm{Cu}$ & $8 \mathrm{Fe}$ & $8 \mathrm{Ni}$ & $8 \mathrm{Fe} / \mathrm{Ni}$ \\
\hline $\begin{array}{l}\text { Phase I - PNL anodes } \\
\text { (Average of } 3 \text { ) }\end{array}$ & 18.1 & 28.5 & 32.5 & 0.88 \\
\hline $\begin{array}{l}\text { Phase II - ELTECH anodes } \\
\text { (Average of } 2 \text { ) }\end{array}$ & 12.8 & 30.0 & 34.6 & 0.87 \\
\hline $\begin{array}{l}\text { Phase III - Sintering } \\
\text { Schedule } \# 1\end{array}$ & 11.3 & 29.5 & 34.3 & 0.86 \\
\hline $\begin{array}{l}\text { Phase III - Sintering } \\
\text { Schedule \#2 } \\
\text { (Average of } 2 \text { ) }\end{array}$ & 13.7 & 30.0 & 35.1 & 0.85 \\
\hline Phase III - PNL anodes & 17.9 & 27.8 & 32.9 & 0.84 \\
\hline $1250^{\circ} \mathrm{C}$ sintering & 18.6 & 26.5 & 3.3 & 0.82 \\
\hline
\end{tabular}


handle the 4-probe electrical resistivity testing by removing the push rods and substituting electrodes and a voltage probe holder.

Measurements were taken from room temperature to $1000^{\circ} \mathrm{C}$, during heating and cooling, first in He and then twice in air. During the measurements in air, the surface of the cermets oxidized making electrical contact difficult in some cases. However, good agreement was found between electrical resistivity in He and air.

The conductivities versus temperature are shown in Figures 10 (a), (b), and (c). The conductivity of the cermet sintered wit i the rapid sintering schedule to higher temperature (\#1) is much more metallic in character with only a slight increase in conductivity with temperature. Room temperature conductivity averaged

$\sim 117 \Omega^{-1} \mathrm{~cm}^{-1}$ while the conductivity at $1000^{\circ} \mathrm{C}$ averaged $157 \Omega^{-1} \mathrm{~cm}^{-1}$. The electrical conductivity of the cermet sintered to $1300^{\circ} \mathrm{C}$ with the slower sintering schedule (\#2) and the intermediate hold at $1070^{\circ} \mathrm{C}$ is much different. The room temperature conductivity averaged $\sim 8.4 \Omega^{-1} \mathrm{~cm}^{-1}$ while the conductivity at $979^{\circ} \mathrm{C}$ was $\sim 63 \Omega^{-1} \mathrm{~cm}^{-1}$. The conductivity change with increasing temperature appears more semiconductive in nature. The PNL sample falls between the two EITECH cermet:s with a room temperature conductivity of $\sim 58 \Omega^{-1} \mathrm{~cm}^{-1}$ and a condustivity at $988^{\circ} \mathrm{C}$ of $128.9 \Omega^{-1} \mathrm{~cm}^{-1}$.

The conductivities of an ELTECH Phase II anode, a PNI, Phase I anode (PNL48-1B) and the Alcoa $\mathrm{Ni}$ ferrite material and $\mathrm{Cu}$ cermet are shown for comparison in Eigure 11.6 The PNL material oxidized during the first heat-up, yielding a much different conductivity versus temperature behavior on it's second heat-up.

In Figure 12, the phase III materials are compared to the Phase 2 ELTECH cermets, the Phase I PNI material (1st heat-up) and the Alcoa material. The dense and conductive phase III EITECH cermet sintered with schedule \#1 was the most conductive and metallic-like material while the ELTECH Phase III cermet sintered with schedule * 2 was most like the Alcoa material. Therefore, because the object was to duplicate the Alcoa material as much as possible, the sintering schedule \#2 was employed for all anodes used in Phase III testing. However, it should be noted that the electrical resistivity measurements do not provide a quantitative measurement of $\mathrm{Cu}$ interconnectivity; it only shows how similar one material is to another.

The Phase III cermets were also examined by optical microscopy and SEM/EDX analysis. Optical microscopy micrographs are shown in Figure 13 (a), (b), and (c) for anodes sintered with the fast schedule, slow schedule, and the PNL Phase III anode. Cu grains (white) are irregular in shape, as are the NiO phases (dark gray), while the $\mathrm{NiFe}_{2} \mathrm{O}_{4}$ grains (medium gray) are blocky to roundish in shape. $\mathrm{NiFe}_{2} \mathrm{O}_{4}$ grains usually surround the Cu particles. occasionally the outline of an original spray dried particle is seen. There are no significant differences in the size, shape, or 

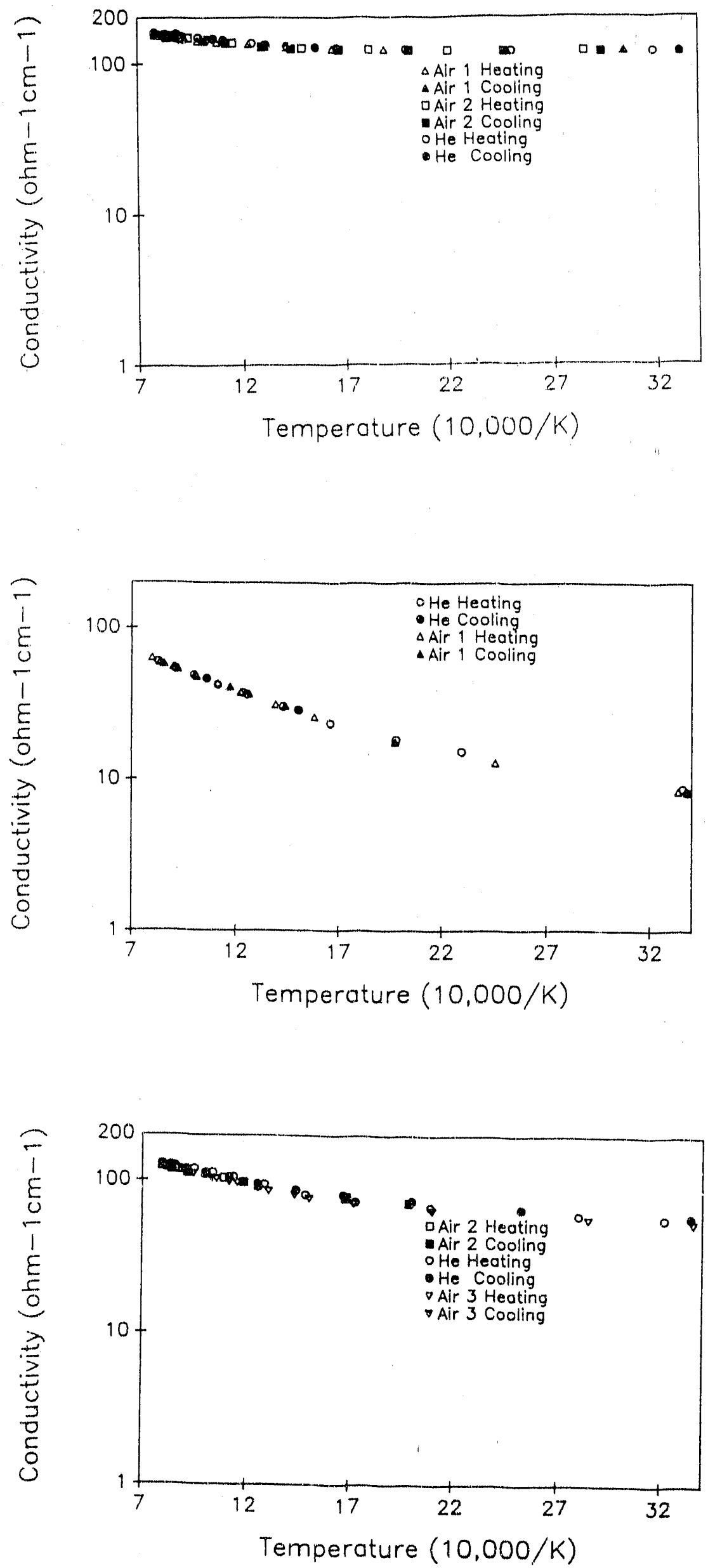

Eigure 10. Electrical conductivity versus temperature for the Phase III $\mathrm{Cu}$ cermets.

(a) ELTECH cermet, fast sintering schedule. (b) ELTECH cermet, slow sintering schedule. (c) PNL cermet. 


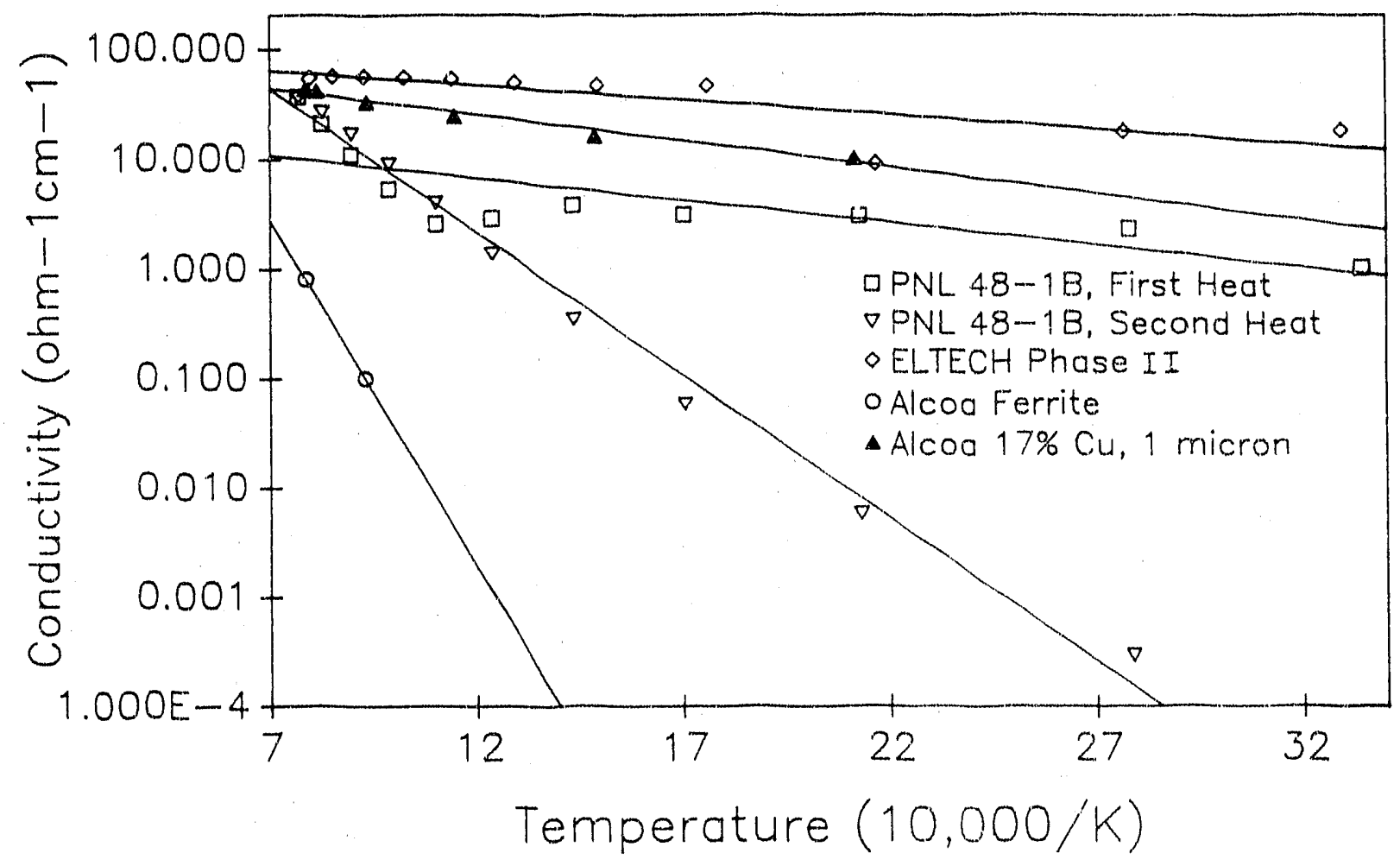

Figure 11. Electrical conductivities of Alcoa, PNL, and ELTECH Phase II materials. 


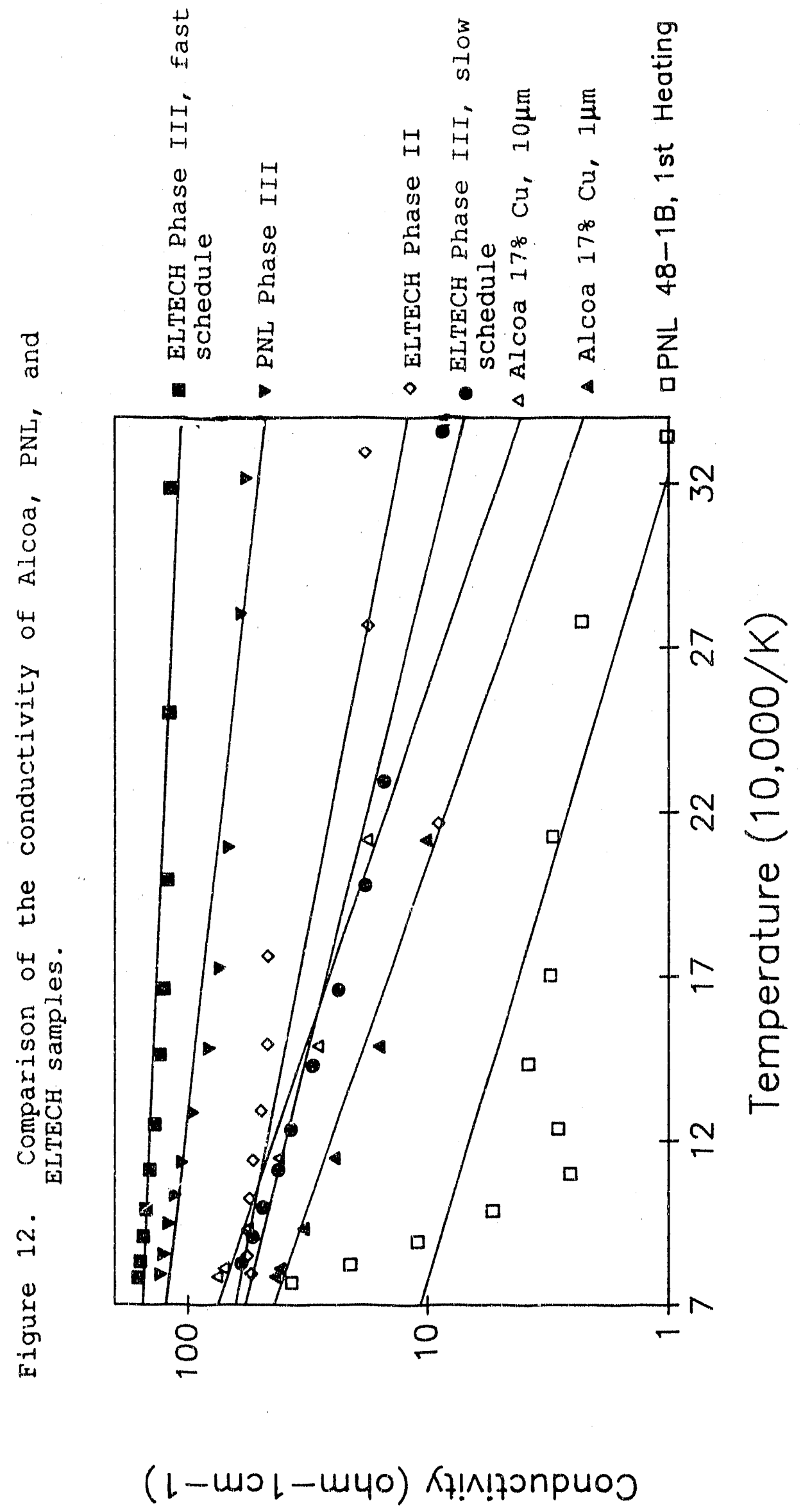


activities aiso promot

The distribution of $\mathrm{Ce}$ in the by the equilibrium establish we have

$K_{e q}=a_{c \theta} \times a_{A L F 3} / a_{C Q F 3} \times a$ Assuming the astivity of $A$ l. therefore define a partition $A l$ and the $C e$ in the melt as

$\mathrm{PC}=\frac{\mathrm{Ce}(\mathrm{AI})}{\mathrm{Ce}(\mathrm{MeIt})}$. 
composition of the phases between the ELTECH samples sintered with schedule \#1 or \#2. In the PNL sample, the phases are also similar in size and shape but the median size of the cu particles appears slightly greater and $C u$ abundance is slightly highex.

SEM photographs of each material are shown in Eigure 14 (a), (b), and (c). EDX analysis was performed on the three phases in each sample and Noran Standardiess Quantitative (SQ) analysis was performed to estimate the stoichiometry of each phase. EDX analysis and the size of the phases is surnmarized in Table 3 . EDX analysis shows that the composition of the $\mathrm{NiO}$ and $\mathrm{NiFe}_{2} \mathrm{O}_{4}$ of the ELTECH and PNL samples are similar while the composition of the Cu alloy phase is more $\mathrm{Ni-rich}$ in the ELTECH samples. The PNL alloy contains -22.9 wto $\mathrm{Ni}$ and 2.3 wt $\mathrm{Fe}$ while the ELTECH Cu phase contains $\sim 11.9$ wt $\mathrm{Ni}$ and 3.6 wto $\mathrm{Fe}$. Alcoa samples fabricated with 17 wt cu (screened) reportedly contain a Cu alloy phase with 14.5-16.3 wto $\mathrm{Ni}$ and 1.3 to 2.5 wt $\mathrm{Fe}$. In all $1000 \mathrm{x}$ photos, A is $\mathrm{Cu}, \mathrm{B}$ is $\mathrm{NiFe}_{2} \mathrm{O}_{4}$, and $\mathrm{C}$ is $\mathrm{NiO}$.

SEM micrographs of the Cu cermets employed in each phase of the project are shown in Figures 15, 16, and 17 for comparison.

\subsubsection{Anode Desian}

Phase II anodes were flat bottomed with an alumina sheathed Inconel 600 current connector (Figure 18). The Inconel rod was threaded and screwed into a threaded platinum-plated copper connector crosspiece. In Phase III, the end of the anode was hemispherical. The same current connector configuration was employed, but an outer alumina sheath was added to prevent any flaking from the upper sides of the anode that were exposed to cryolite vapor. This limited the corrosion of the anode to the portion exposed to the cryolite bath. The alumina sheath was held on by slightly notching the anode and by using alumina cement (Eisher C218 Alundum) around the top of the anode.

\subsection{Long-rerm Test cell Design and Procedure}

The long-term test cell design is the same as that used during Phase II testing (Eigure 19). A $30.5 \mathrm{~cm}$ high $\times 8 \mathrm{~cm}$ in diameter graphite crucible (Stackpole Grade 2191 , reportedly 0.03 wt: Fe) with a conical botcom was lined with an alumina liner (Vesuvius MCDanal. Alumina 998) to insulate the sides of the crucible. This provided a derined cathode area on the bottom of the cell. An alumina sheathed Inconel $600 \mathrm{rod}$ was threaded into the top of the graphite crucible to make the cathode connection.

Approximately $45 \mathrm{~g}$ of Al was added to the bottom of the cell before adding the bath mixture. The bath $(\sim 650 \mathrm{~g})$ was then blended to the desired composition and placed in the crucible on top of the $A l$. Bath mixtures contain 5 wt $\mathrm{CaF}_{2}, 1$ wto $\mathrm{CeF}_{3}$, and 8 wto $\mathrm{Al}_{2} \mathrm{O}_{3}$. Enough $\mathrm{NaF}$ or $\mathrm{AlF}_{3}$ was added to obtaln the desired $\mathrm{BR}$. The celi 


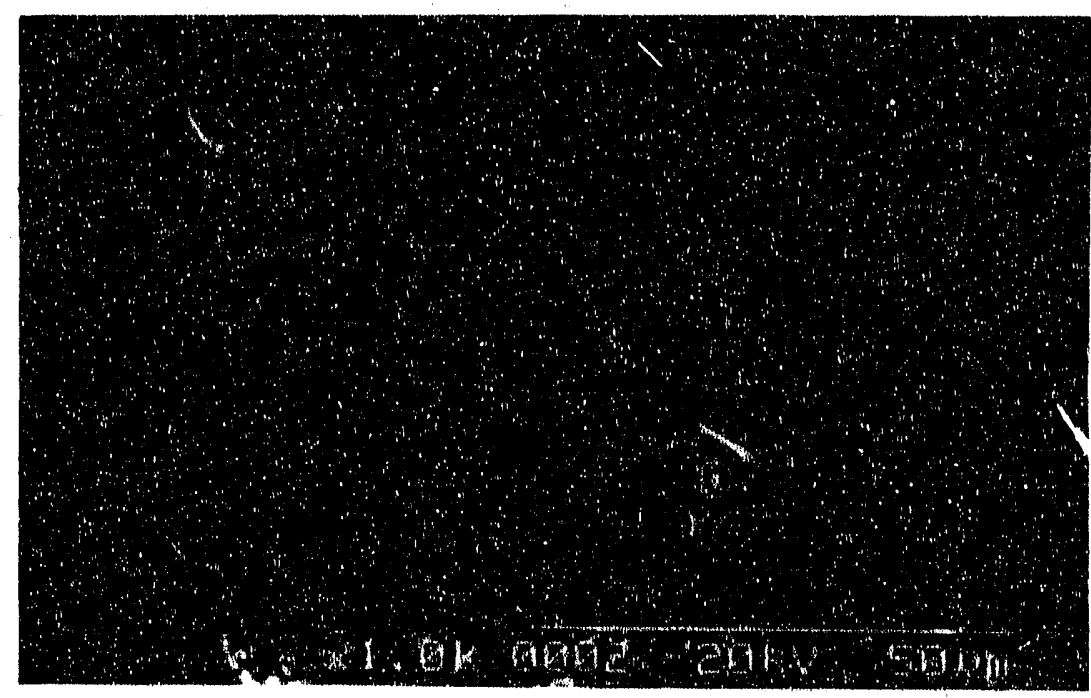

(a) East sintering schedule. $D=C u, E=N i O$, $\mathrm{E}=\mathrm{NiE} \mathrm{e}_{2} \mathrm{O}_{4}$

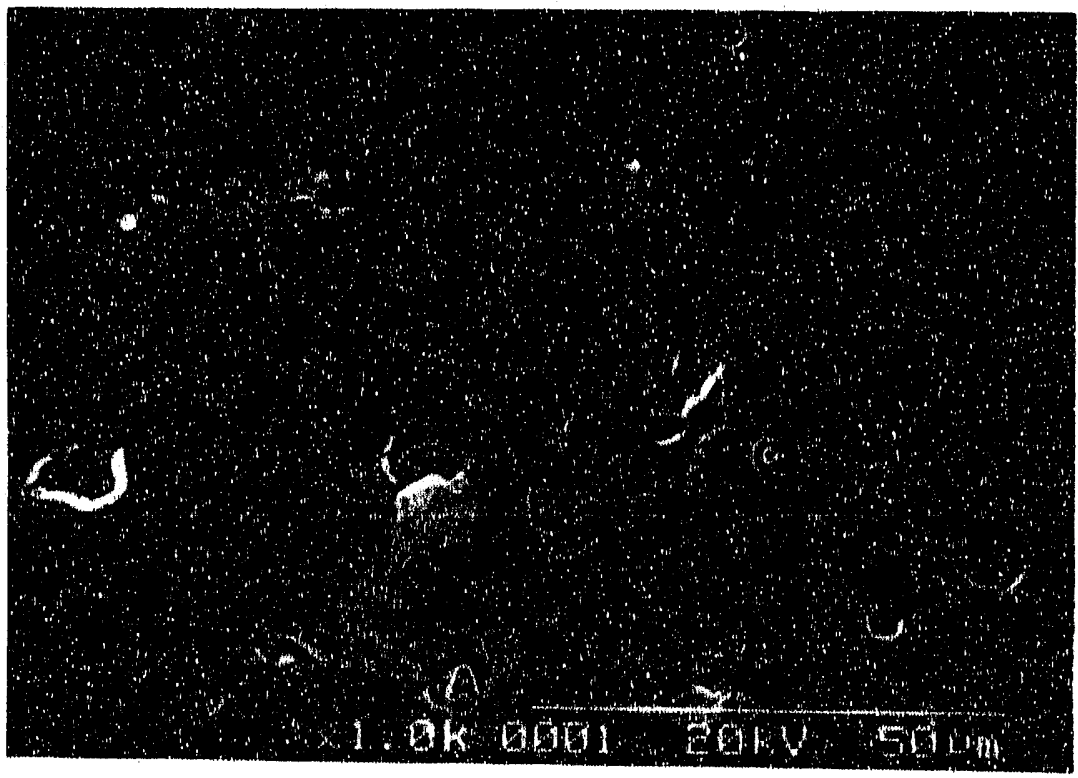

(b) Slow sintering schedule. $\mathrm{A}=\mathrm{Cu}, \quad \mathrm{B}=\mathrm{NiFe} \mathrm{O}_{4}$ $\mathrm{C}=\mathrm{NiO}$

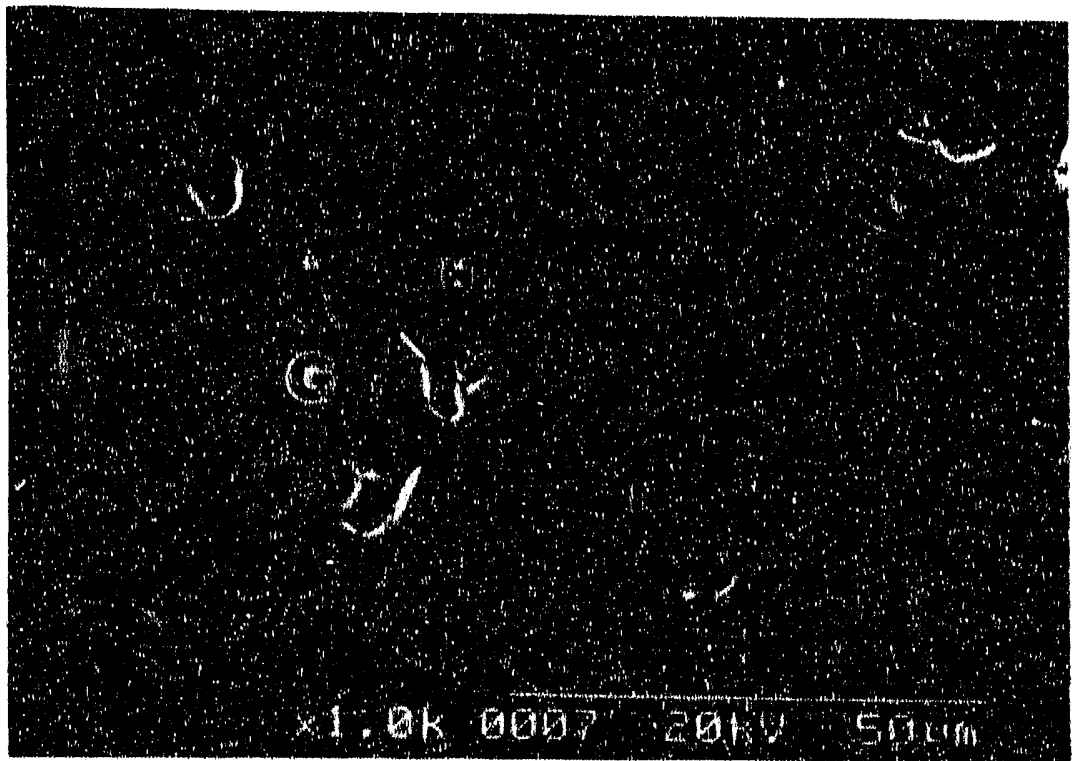

(c) PNI anode. $\mathrm{G}=\mathrm{Cu}, \quad \mathrm{H}=\mathrm{NiO}$ $\mathrm{I}=\mathrm{NiFe} \mathrm{O}_{2} \mathrm{O}$

Eigure 14. SEM photographs of ELTECH and PNI, CU cermets $(1000 \mathrm{X})$. 
Table 3. Comparison of phases in ELTECH and PNL samples.

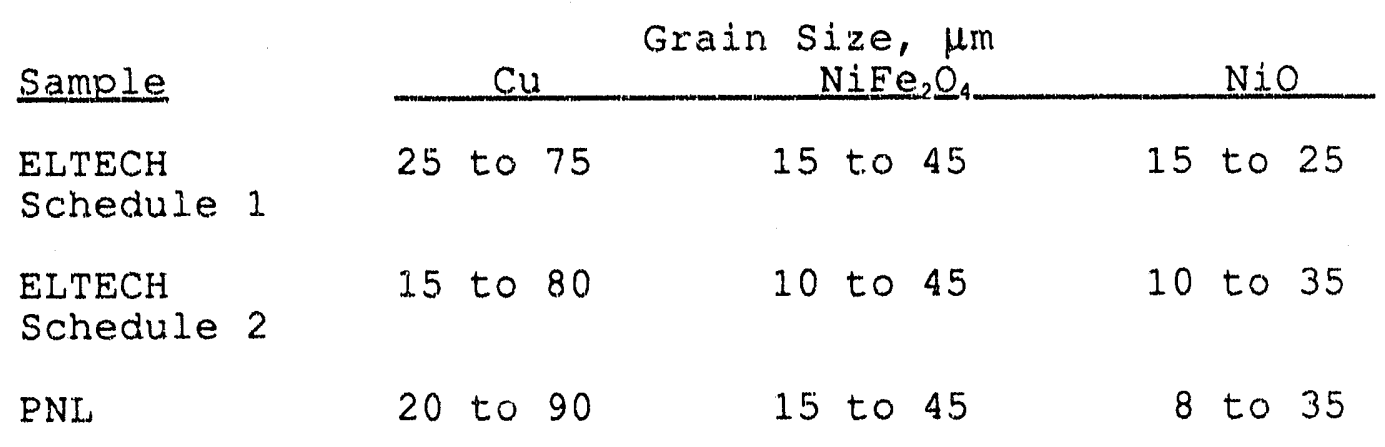

Sample

ELTECH

Schedule 1

ELTECH

Schedule 2

PNL

\begin{tabular}{|c|c|c|}
\hline $\mathrm{NiO}$ & $\begin{array}{l}\text { lase Composition, } \\
\text { NiEe }{ }_{2} \underline{O}_{4}\end{array}$ & wt 8 \\
\hline $\begin{array}{rr}0.88 & \text { Cuo } \\
85.31 & \text { NiO } \\
13.82 & \text { Feo }\end{array}$ & $\begin{array}{rl}1.38 & \mathrm{CuO} \\
25.34 & \mathrm{NiO} \\
73.27 & \mathrm{Fe}_{2} \mathrm{O}_{3}\end{array}$ & $\begin{array}{r}83.85 \mathrm{Cu} \\
12.71 \mathrm{Ni} \\
3.44 \mathrm{Ee}\end{array}$ \\
\hline $\begin{array}{rr}0.96 & \mathrm{CuO} \\
84.1 .4 & \mathrm{NIO} \\
14.90 & \mathrm{FeO}\end{array}$ & $\begin{array}{ll}0.84 \mathrm{CuO} \\
26.36 \mathrm{NiO} \\
72.80 \mathrm{Fe}_{2} \mathrm{O}_{3}\end{array}$ & $\begin{array}{r}85.23 \mathrm{Cu} \\
11.09 \mathrm{Ni} \\
3.68 \mathrm{Ee}\end{array}$ \\
\hline $\begin{array}{rl}0.00 & \mathrm{CuO} \\
85.24 & \mathrm{NiO} \\
14.76 & \text { FeO }\end{array}$ & $\begin{array}{rl}0.17 & \mathrm{CuO} \\
22.04 & \mathrm{NiO} \\
77.80 & \mathrm{Ee}_{2} \mathrm{O}_{3}\end{array}$ & $\begin{array}{r}74.81 \mathrm{Cu} \\
22.90 \mathrm{Ni} \\
2.29 \mathrm{Fe}\end{array}$ \\
\hline
\end{tabular}




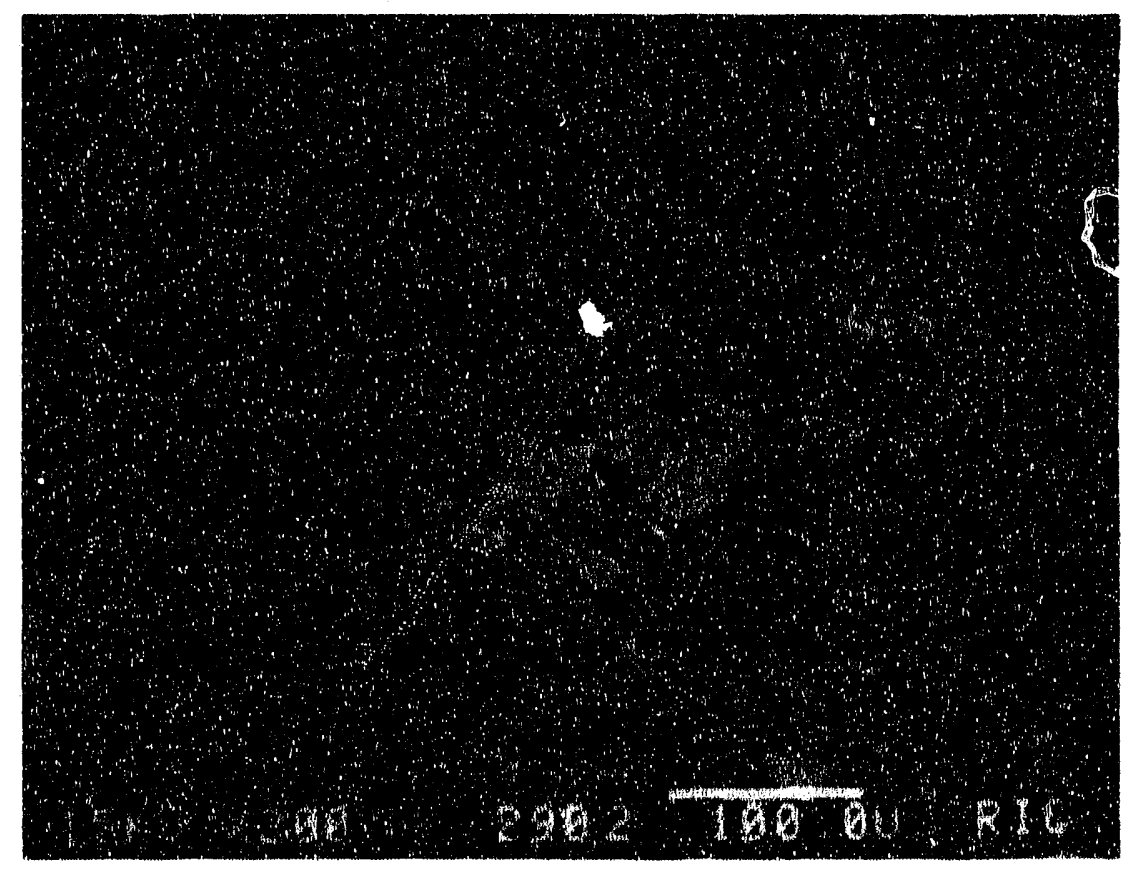

(a) $200 x$

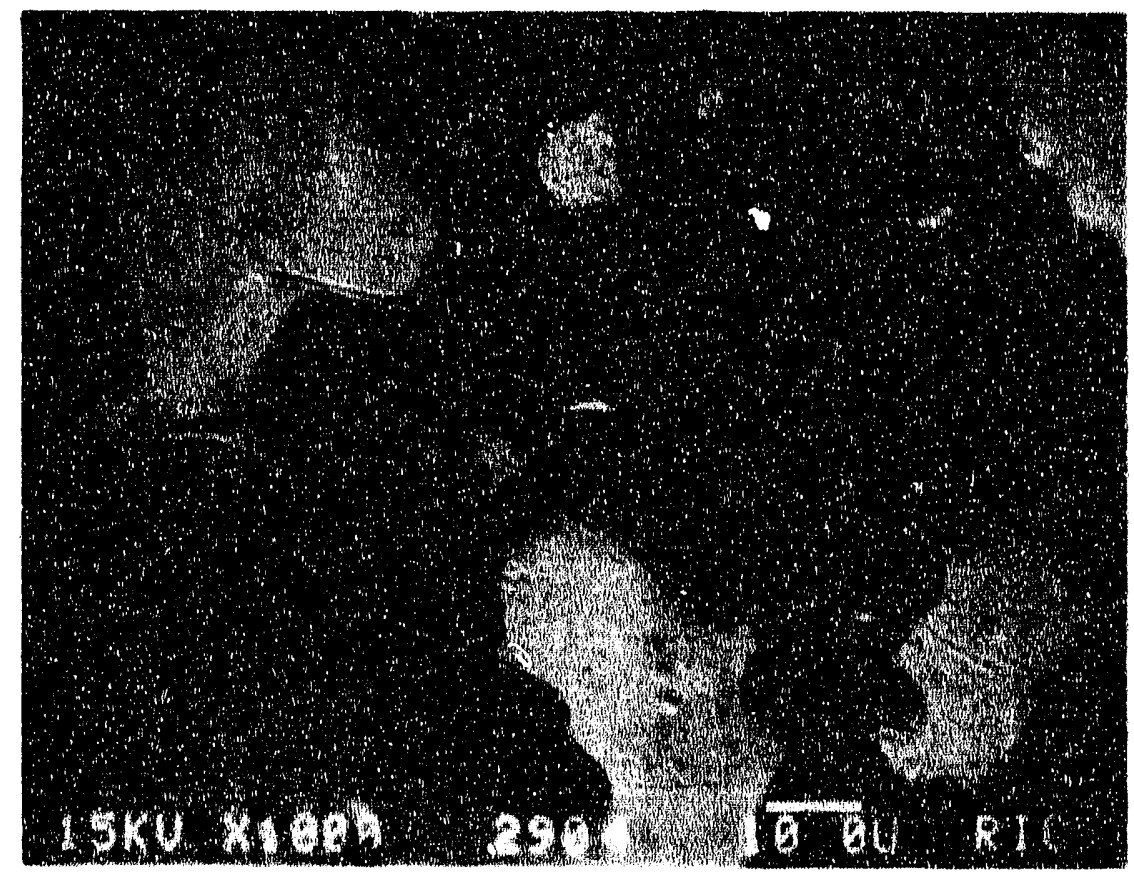

(b) $1000 \mathrm{x}$

Figure 15. Phase I anodes from FNL. 


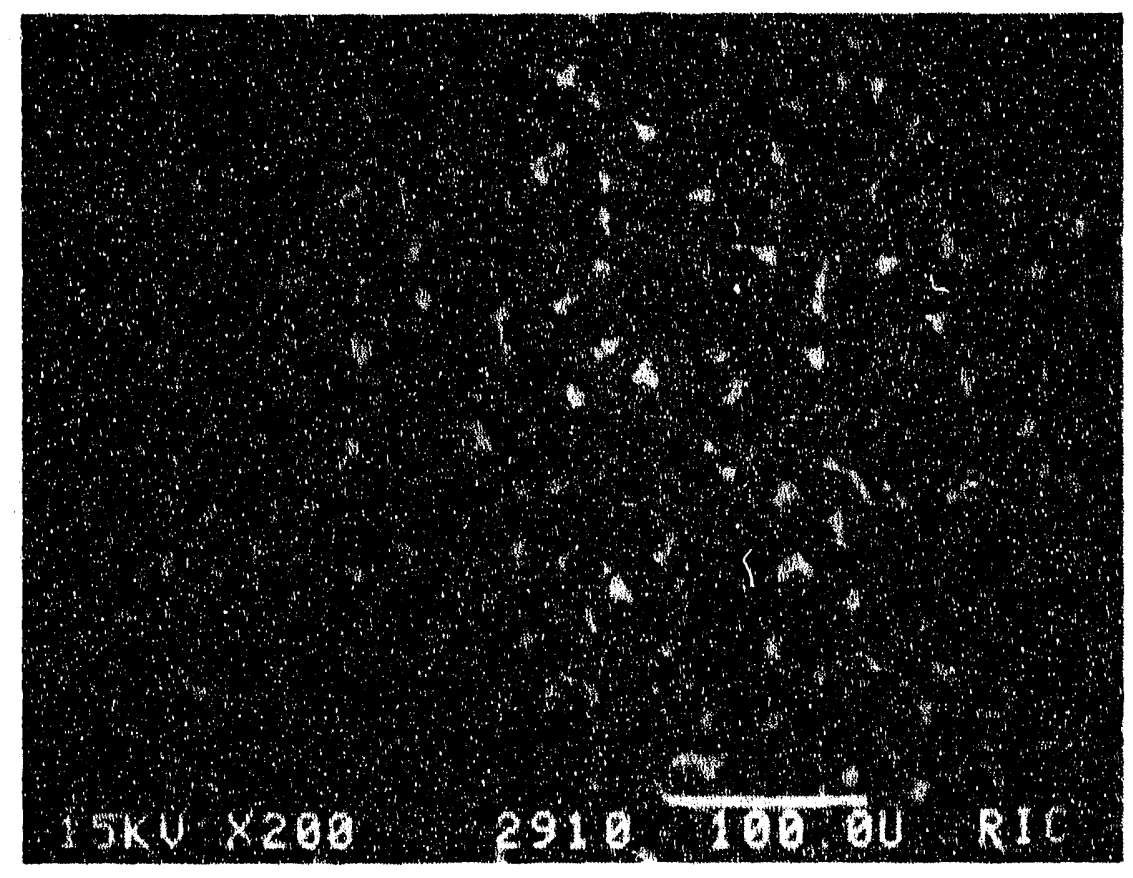

(a) $200 x$

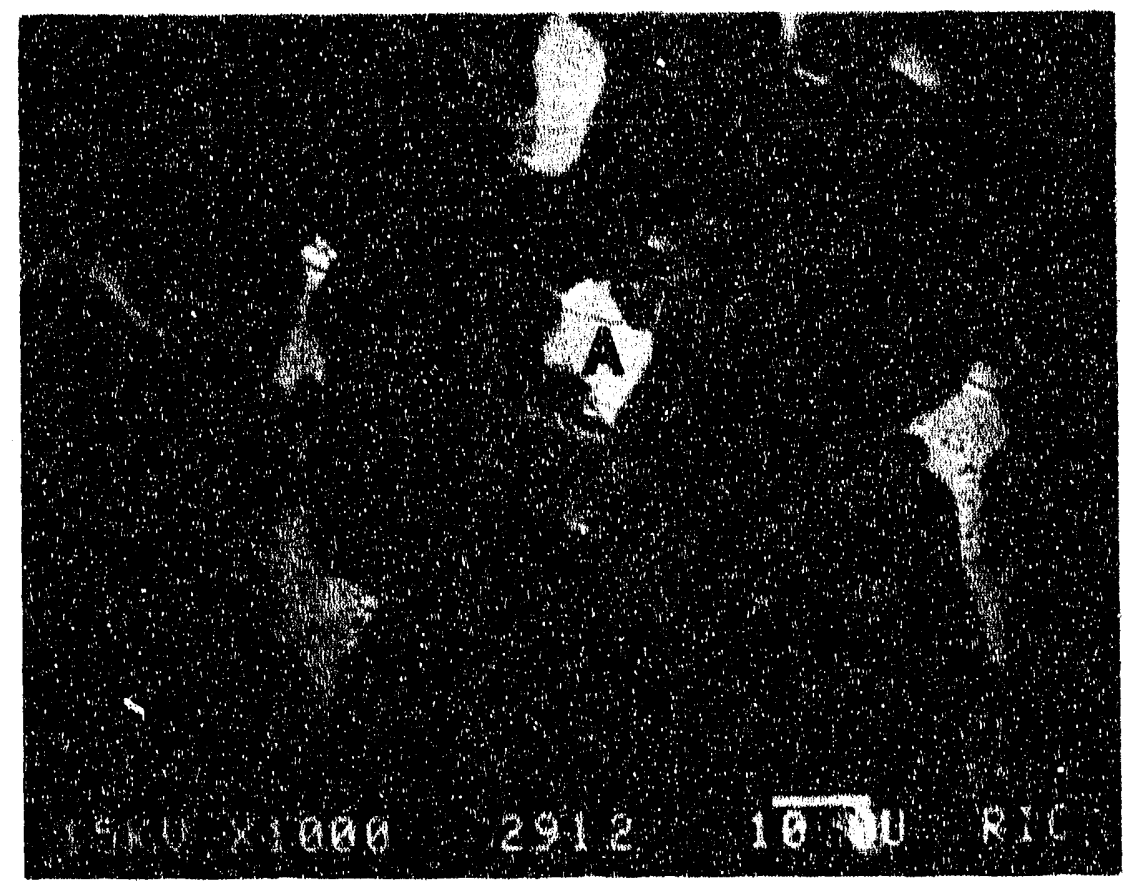

(b) $1000 \mathrm{X}$

Figure 16. Phase II anodes fabricated by ELTECH. 


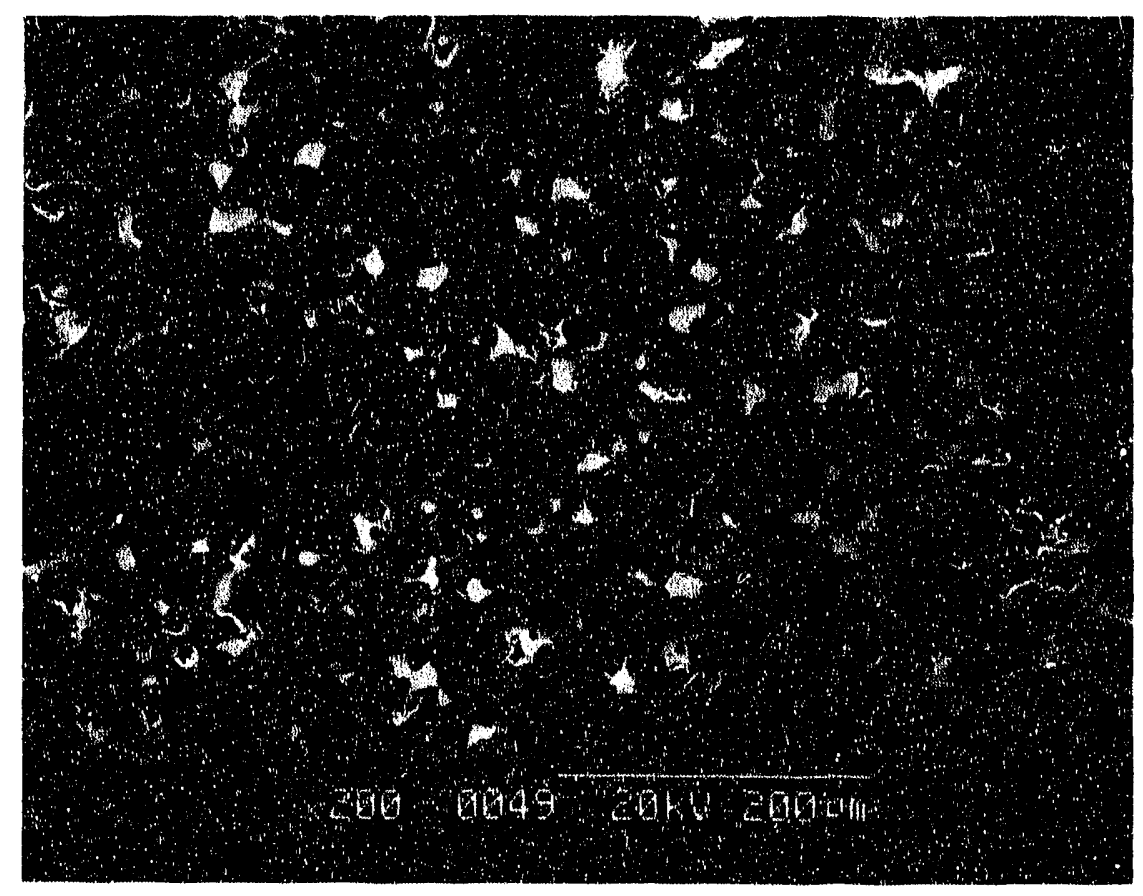

(a) $200 x$

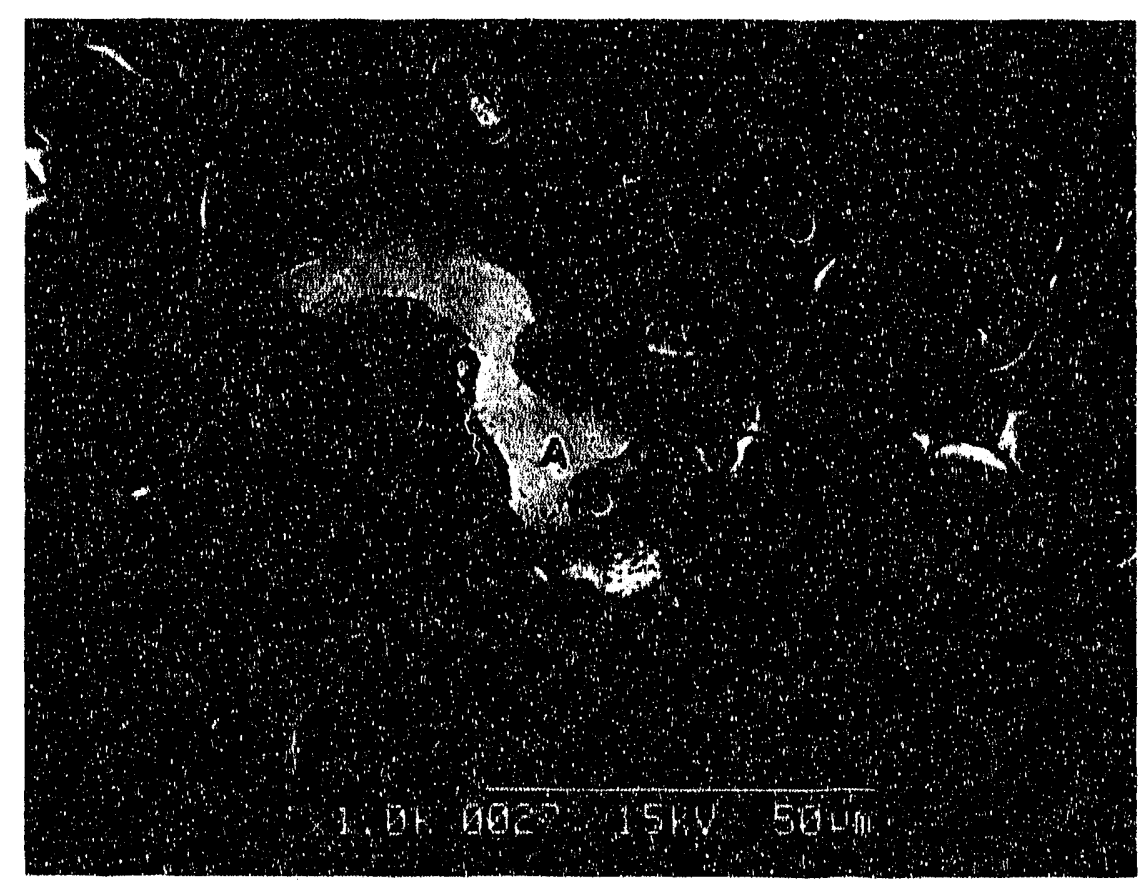

(b) $1000 \mathrm{X}$

Eigure 17. Phase III anodes fabricated by ELTECH. 
Phase II

Phase III

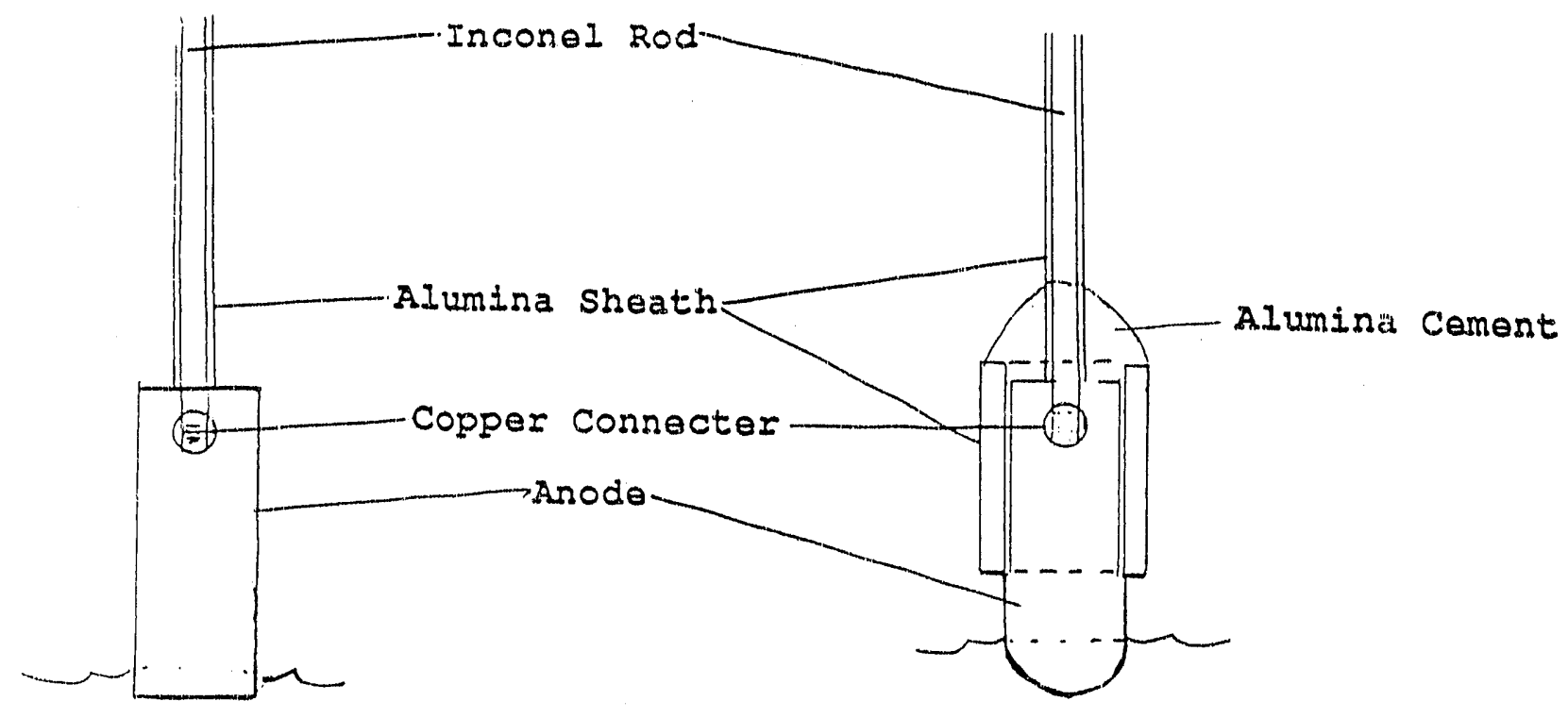

Figure 18. Anode connection and sheath. 


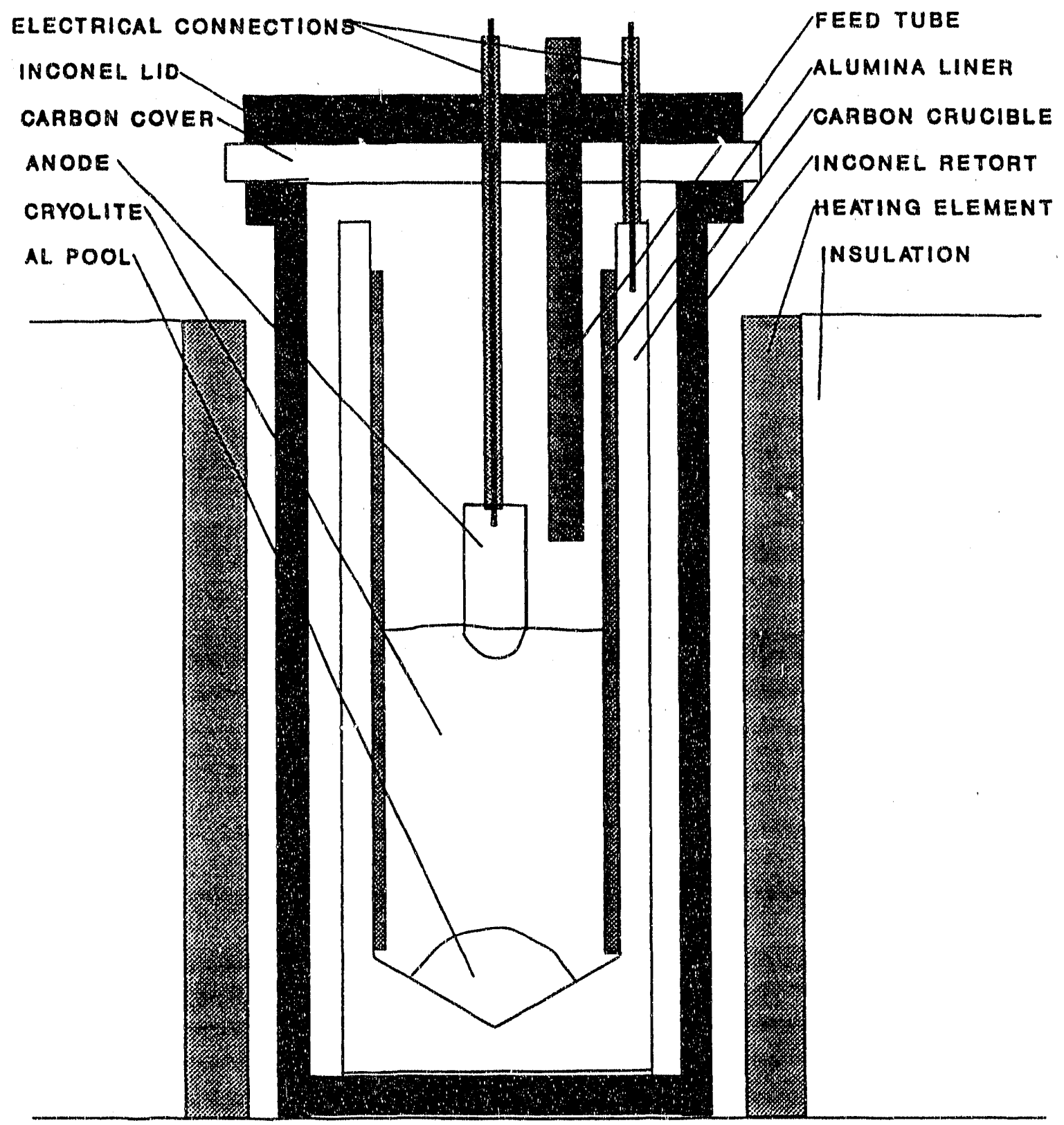

Figure 19. Saturated alumina cell design. 
assembly was then placed in an Inconel 601 retort in a Iindberg 56622 crucible furnace and the lid (with the anode attached) was placed on the retort. An alumina castable refractory shielded the sides of the retort from the bath vapors and a graphite plate coverd the top of the retort to prevent reaction of the Inconel lid with the vapors.

At $\sim 4$ a.m. the furnace was automatically turned on for $1000^{\circ} \mathrm{C}$ and it usually up to temperature by $8 \mathrm{a} . \mathrm{m}$. The temperature of the bath was measured and the furnace controller was adjusted to maintain a bath temperature of 970 to $990^{\circ} \mathrm{C}$. Temperature was monitored daily. In some cases where crusting was a problem, temperatures as high as $999^{\circ} \mathrm{C}$ were occasionally reached.

The desired current was established, the power to the cell was turned on, and the anode was slowly lowered into the cell. Electrical connection was established when the anode made electrical contact with the bath. Immersion depth was then adjusted. Voltage was recorded on a chart recorder. Bath depth was determined by immersing a Mo rod into the bath once a day. Bath mixture was added to maintain a bath $\sim 6$ to $7 \mathrm{~cm}$ deep.

The BR was measured at $\sim 6,24,48,72$, and $96 \mathrm{~h}$ into the test. Additions of $\mathrm{Na}_{2} \mathrm{CO}_{3}, \mathrm{NaF}$, or $\mathrm{AlF}_{3}$ are added to bring the $\mathrm{BR}$ to the desired level. $\mathrm{Al}_{2} \mathrm{O}_{3}$ and $\mathrm{CeF}_{3}$ additions were made hourly assuming a 758 current efficiency. In low CD tests where current efficiency (CE) was found to be lower, additions were made assuming $308 \mathrm{CE}$.

When the test was completed, the anode was removed from the bath, the current to the cell was turned off, and the furnace was turned off.

\subsection{Alumina/Cerium Fluoride Eeeder}

A semi-automated feeder was used to feed the test cells during night. The feeder had a mounted carousel with 20 plastic vials, each with a $10 \mathrm{~g}$ capacity. The carousel was rotated by an air powered cylinder that was controlled by an electrically powered solenoid switch. A metal rod dumped the plastic vials and another rod returned the vials to an upright position as the carousel rotateed (once an hour). The vials were dumped into a funnel. that was attached to an alumina tube that ended $\sim 2$ in. above the bath.

\subsection{Nonsaturated Test Cell Design and Procedure}

A novel cell design was developed as part of phase III to test materials in nonsaturated conditions. Previous attempts to operate unsaturated tests in a laboratory cell were unsuccessful because of rapid dissolution of the alumina liner ${ }^{10}$ or from lack of an adequate alternative liner material. ${ }^{11}$ 
Several modifications were made to the existing long-term cell design to produce an acceptable cell for nonsaturated alumina testing. In the saturated alumina test cell design (Eigure 19), an alumina liner was employed to prohibit current flow from the anode to the sidewalls of the carbon crucible. Because the bath was saturated, dissolution of the liner was slow enough to perform long term testing $(100 \mathrm{~h})$. In tests that are not saturated with alumina, the alumina liner quickly dissolved and raised the alumina concentration in the bath. In addition, as the Iiner dissolved it lost integrity and current flowed to the crucible side wall. A satisfactory material could not be found to replace alumina as a liner. ${ }^{11}$

If there was not a defined cathode area and the crucible became conductive, impurities (i.e., $\mathrm{Ni}, \mathrm{Cu}, \mathrm{Fe}$ ) plated out on the extensive exposed carbon surface leading to efficient stripping of the impurities from the electrolyte, and thus faster dissolution of the anode. In addition, a greater amount of dissolved Al may have been present in the cryolite melt, leading to more rapid deterioration of the anode. Another problem was the excessive $\mathrm{Al}_{4} \mathrm{C}_{3}$ that formed on the sidewalls, reducing $C E$ and producing shorting." A final problem with a unlined cathodic graphite crucible was that $\mathrm{Na}$ intercalates into the graphite, causing a decreasing $\mathrm{BR}$ and difficulty in controlling the BR.

The nonsaturated test cell design (like the saturated design) employed a graphite crucible (Southern Graphite 2191). However, the AI cathode was electrically isolated from the carbon crucible so that no side wall conduction occured even though the crucible was exposed (Figure 20). An Inconel 600 current connector rod sheathed in alumina, was L-shaped and penetrated through a hole in the bottorn side of the crucible. The Inconel was threaded into a carbon rod current collector. To protect the cathode connection from molten cryolite corrosion, the connection was encased in pure solid cryolite. The cryolite was kept frozen by keeping the lower part of the cell cool. The vertical temperature gradient was maintained by applying heat only to the regions of the cell where molten bath was desired, and by allowing the bottom of the cell assembly to be exposed to the ambient room temperature $\left(\sim 25^{\circ} \mathrm{C}\right)$. In addition, the bottom frozen cryolite had a higher melting point $\left(\sim 30^{\circ} \mathrm{C}\right)$ than the molten bath mixture containing additives ( $\mathrm{CaF}_{2}$, $\left.\mathrm{Al}_{2} \mathrm{O}_{3}\right) .{ }^{1}$ The crucible was contained in an alumina retort with a carbon lined Inconel 601 lid. Argon was supplied to the extericr and the interior of the cell to reduce oxidation of the crucible:

\footnotetext{
"Personal communication with Dr. E. Dewing, formerly of Alcan International Limited.
} 


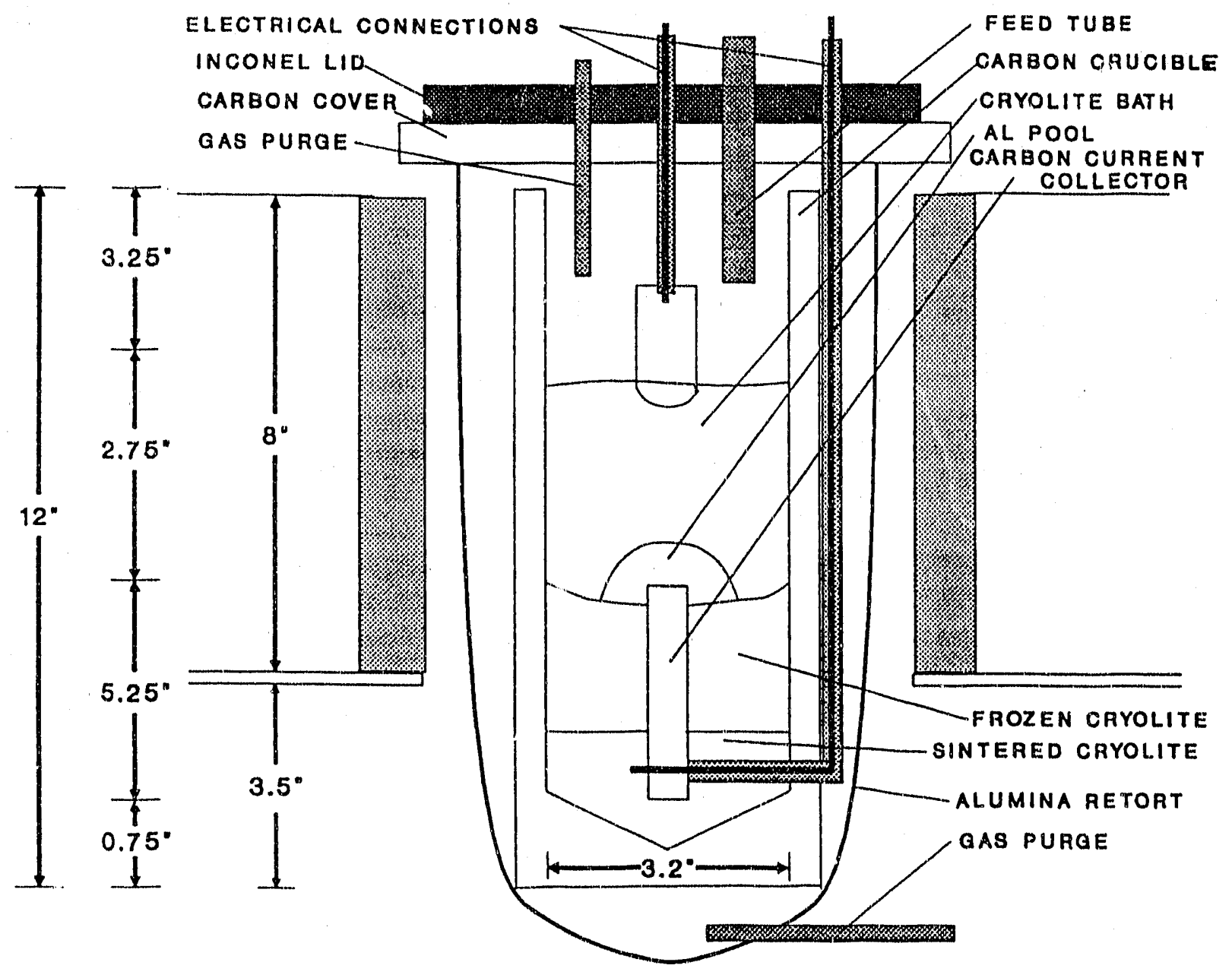

Eigure 20. Cell design for experiments with baths containing alumina at less than saturation. 
In each test, $10 \mathrm{~g}$ of $\mathrm{Al}$ were loaded into the cell along with $650 \mathrm{~g}$ of the bath mixture, which contained $5 \% \mathrm{CaF}_{2}$ and $28 \mathrm{CeF}_{3}$. $\mathrm{NaF}, \mathrm{AlF}_{3}$, and $\mathrm{Al}_{2} \mathrm{O}_{3}$ were in the bath mixtures at the desired levels for each particular test. The cell was lowered into an alumina retort and placed into a modified Lindberg model 56622 furnace. The modifications. were necessary to provide the zoned heating requirements described above for the cell design. The anode assembly and graphite plate/Inconel retort lid were placed over the cel1. The anode, alumina feed tube, electrical connections (sheathed with alumina tubes), and gas purges entered the cell through holes in the cover. Argon was fed around the cell at $200 \mathrm{~cm}^{3} / \mathrm{s}$ and the cell. was heated to $980^{\circ} \mathrm{C}$.

Once the cell was up to temperature, bath samples were taken and alumina concentiration and $\mathrm{BR}$ were measured. The alumina content was then adjusted to ensure the proper starting concentration for a given test. The anode was then lowered $8 \mathrm{~mm}$ into the bath and electrolysis was begun.

Samples were perlodically taken (at least onceiday) and analyzed for free alumina and $B R$. Adjustments were made to maintain targeted values by adding $\mathrm{Al}_{2} \mathrm{O}_{3}, \mathrm{Na}_{2} \mathrm{CO}_{3}$, or $\mathrm{ALF}_{3}$ to maintain the bath at the desired composition. The cell was fed a mixture of $\mathrm{Al}_{2} \mathrm{O}_{3}$ and $\mathrm{CeF}_{3}$ hourly based on 758 current efficiency. Electrical isolation between the aluminum pool and the graphite crucible was periodically checked and was always maintained.

After $100 \mathrm{~h}$ of operation the anode was raised above the bath, and the cell was allowed to cool to room temperature.

\subsection{Background Corrosion}

The background contamination of $\mathrm{Fe}, \mathrm{Ni}$, and $\mathrm{Cu}$ to the system were subtracted from the measured contamination after testing to determine the contribution from the anode. The background levels were investigated and corrected for in Phase II and the same corrections were employed in Phase III corrosion calculations.

Fe, $\mathrm{Ni}$, and $\mathrm{Cu}$ background contamination were from the cell hardware as well as the raw materials used in the cell. In Phase II, the long-term cell configuration (with the anode above the bath) was brought to operating temperature and then shut down, and bath and metal was analyzed for $\mathrm{Fe}, \mathrm{Ni}$, and $\mathrm{Cu}$. The background corrosion was calculated as grams of $\mathrm{Fe}, \mathrm{Ni}$, and $\mathrm{Cu}$ and subtracted from all corrosion test results. The background corrosion was $0.05 \mathrm{~g}$ Fe, $0.08 \mathrm{~g} \mathrm{Ni}$, and $0.004 \mathrm{~g} \mathrm{Cu}$.

In the tests with the WM cryolite (since the Fe content of the cryolite averaged $400 \mathrm{ppm}$ while that in the AF cryolite was $\sim 50 \mathrm{prm})$ a different correction had to be made to account for the Fe from the cryolite. In those tests, Fe contamination from the cryolite was calculated based on the weight of cryolite employed in 
the test and then was subtracted from the total Fe corrosion. Fe corrections were from 0.26 to $0.38 \mathrm{~g}$ for the half saturated testing and were $0.226 \mathrm{~g}$ for the saturated testing.

\subsection{CEROX Resistance Test Cell Design and Procedure}

A rotating cylinder design was chosen for the reisitance measurements to provide controlled convection to the system (Figure 21). The experimental cell consisted of an alumina crucible

$(7.5 \mathrm{~cm}$ diameter $\times 10 \mathrm{~cm}$ high) with a graphite liner $(0.64 \mathrm{~cm}$ thick), which served as the cathode. Electrical contact to the graphite was made by way of a threaded Inconel rod $(0.125$ in. in diameter). The cell was loaded with $140 \mathrm{~g}$ of electrolyte yielding a solution height of $1.5 \mathrm{~cm}$. The bath was 5 wt $8 \mathrm{CaF}_{2}$, 9 wto $\mathrm{Al}_{2} \mathrm{O}_{3}$, and 1.8 to 4.5 wto $\mathrm{CeF}_{3}$ (depending on the coating thickness desired), and the balance cryolite (BR of 1.5). The cell was heated in a Thermolyne corporation model 1701 furnace. A boron nitride (BN) cover was placed over the furnace opening.

The anode was a cermet cylinder $(0.71 \mathrm{~cm}$ in diameter) core-drilled from a larger cermet fabricated as described in subsection 4.2.4. The cermet cylinder was press-fitted into a graphite plug that was threaded at the other end to screw into a steel rod. The steel piece was tapped at the opposing end and screwed into a spindle that fit into the collet of a Pine Instruments Co. electrode rotator. The anode assembly (Figure 22) was heated above the bath until the operating temperature of $980^{\circ} \mathrm{C}$ was achieved. The anode was lowered into the electrolyte and electrolysis was started.

The anode was coated for $5 \mathrm{~h}$ at $240 \mathrm{ma} / \mathrm{cm}^{2}$ using a stonehart Associates Inc. BC 1200 potentiostat. After the coating period, the current was set to zero and the system was allowed to equilibrate for 10 to $15 \mathrm{~min}$. Then the anode was rotated, current. pulses were applied, and voltage measurements were taken.

\subsection{Analytical Procedures}

In both the long-term saturated and nonsaturated testing, the bath mixture was monitored daily for $\mathrm{BR}$. In addition, the $\mathrm{Al}_{2} \mathrm{O}_{3}$ content was monitored in nonsaturated tests. After completion of tests, the cells were dismantled and the bath was separated from the aluminum. The bath was crushed, fused, and analyzed by ICP and the aluminum was sampled, dissolved, and analyzed by ICP. The anode was cross-sectioned for analysis.

\subsubsection{Bath Ratio Analysis}

In the long-term tests, bath composition monitoring was necessary because of sodium adsorption by the carbon crucible and losses of volatile components. If the $B R$ was expected to be below 1.5 , a titration method involving the digestion of the bath sample with KOH, acidification with $\mathrm{HCl}$, and titration with $\mathrm{KOH}$ was employed. ${ }^{34}$ 


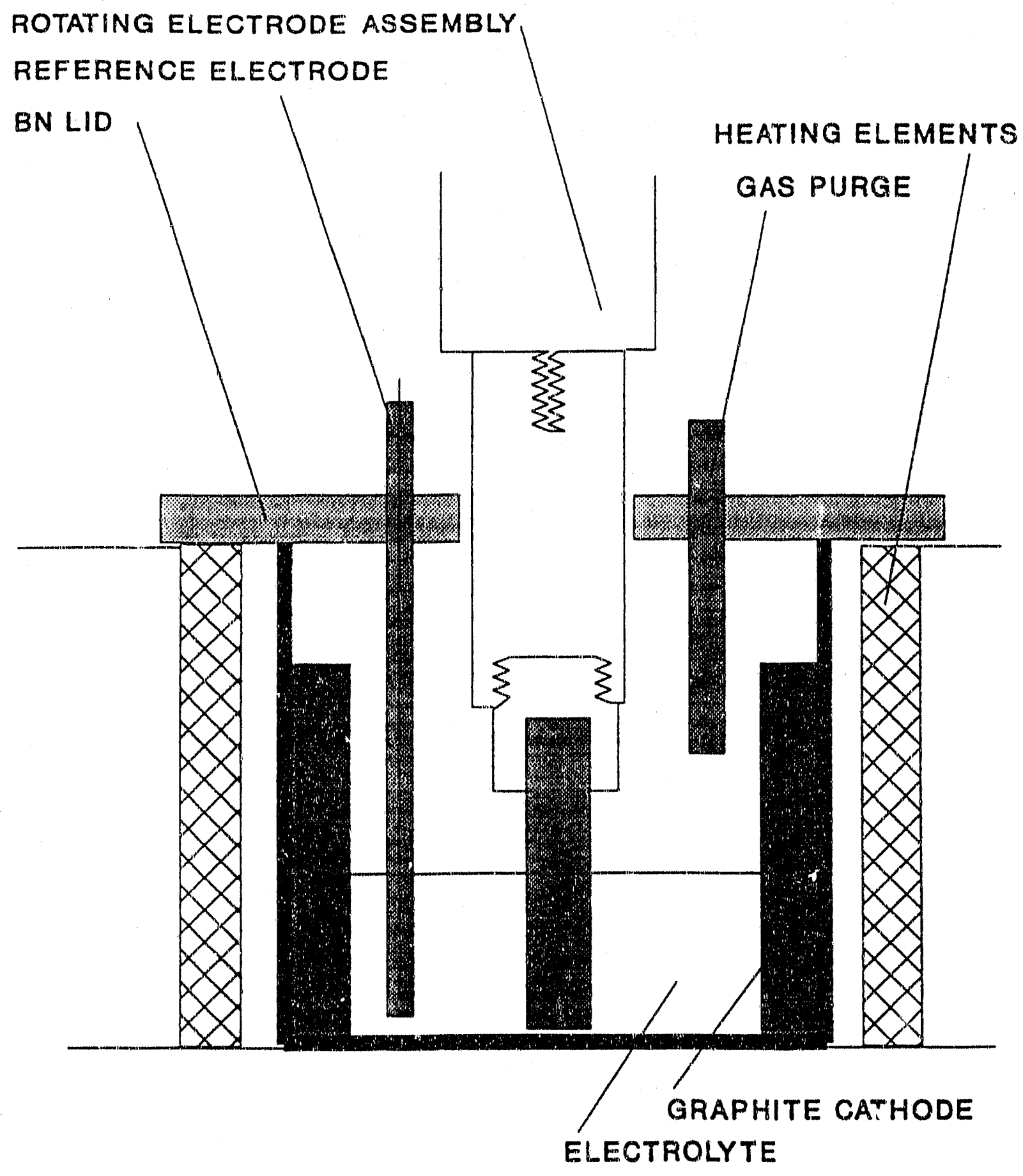

Figure 21. CEROX resistance test cell cesign. 


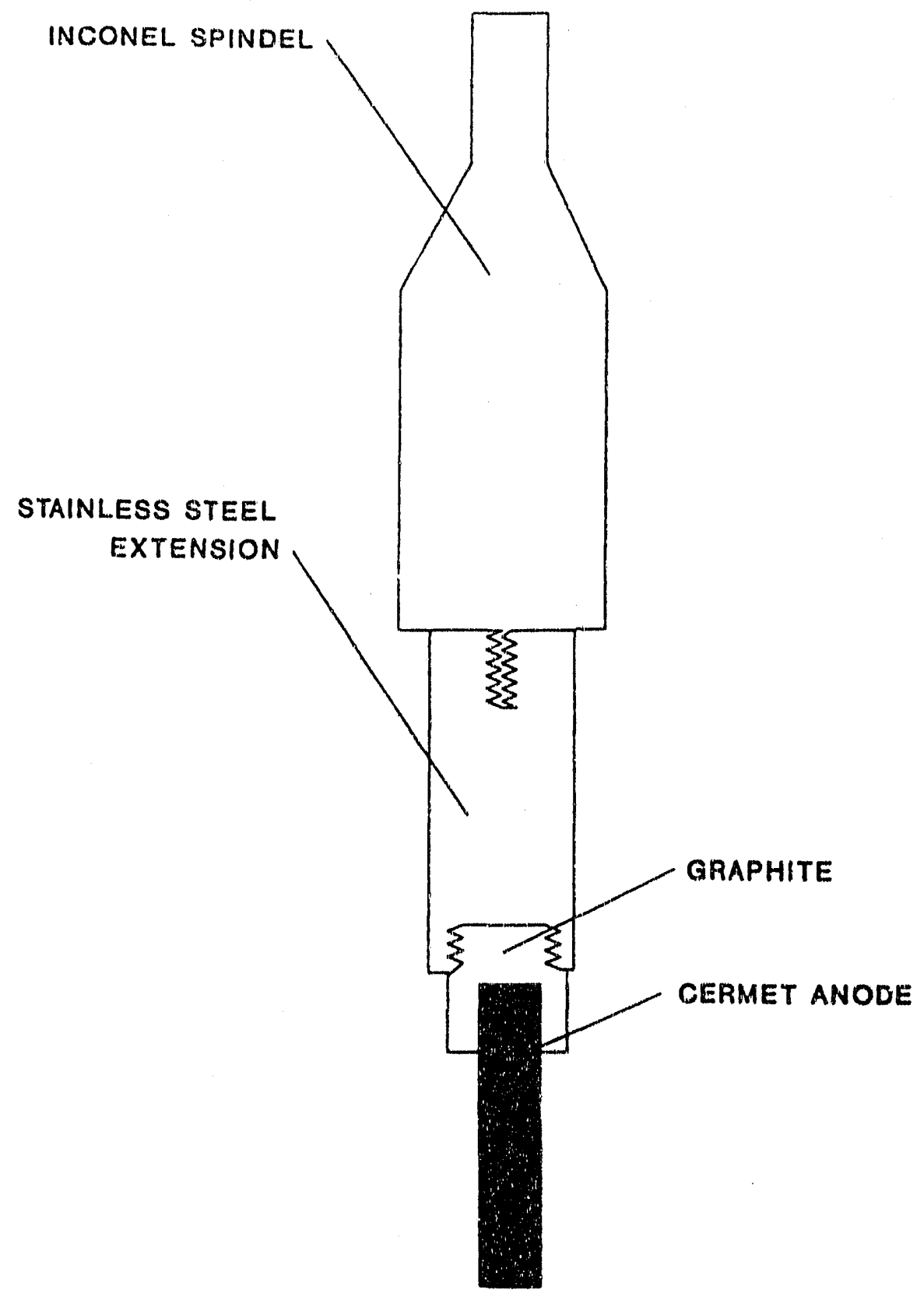

Figure 22 . Rotating anode assembly. 
The procedure is described in detail in the Phase II report, "I once the wti of excess $\mathrm{AlF}_{3}$ was calculated, the $\mathrm{AlF}_{3}$ in the cryolite is calculated by

$A L F_{3} C r Y=\frac{87-8 A_{1} E_{3}}{2.5}$

The BR was then calculated by using the formula

$\mathrm{BR}=$

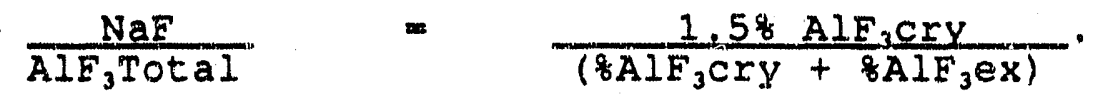

These equations are based on $58 \mathrm{CaF}_{2}$ and $88 \mathrm{Al}_{2} \mathrm{O}_{3}$ and would slightly vary if different amounts of additives were used.

In tests with a BR of 1.5 or above, or where the BR analysis for the KOH titration method was out of range, a second BR analysis method was employed. The method employed was the thorium nitrate method, as developed by MTL." The method takes about 3 to $4 \mathrm{~h}$ and is suitable for a range of $\mathrm{BR}$.

\subsubsection{Alumina Determination}

In the determination of free alumina a $1 \mathrm{~g}$ sample was crushed to -100 mesh with a mortar and pestle and then digested in $50 \mathrm{~mL}$ of a 30 wt aluminum chlorlde hexahydrate solution. The solution was boiled in a $100 \mathrm{~mL}$ beaker for $30 \mathrm{~min}$ on a hot plate covered with a watch glass and stirred with a magnetic stirrer. After digestion, the hot solution was allowed to cool for $30 \mathrm{~min}$ before filtration and careful washing. The precipitate was washed with deionized

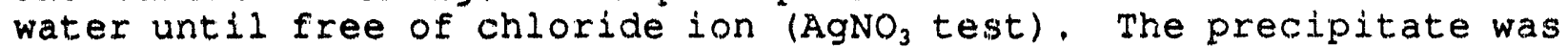
then dried in an oven at $110^{\circ} \mathrm{C}$ and gravimetrically determined by normal procedures.

\subsubsection{Analysis for Contaminants in the Cryolite Bath and Al Metal}

The bath was crushed with a mortar and pestle and then mixed and milled with alumina balls to -100 mesh. Duplicate samples were sent for ICP analysis. Sample preparation for the ICP analysis involved fusing $0.2 \mathrm{~g}$ of the cryolite sample with $1.5 \mathrm{~g}$ of $\mathrm{Na}_{2} \mathrm{O}_{2}$, cooling, and dissolving in water with $1: 1 \mathrm{HNO}_{3}$. The solution was then analyzed for $\mathrm{Ee}, \mathrm{Ni}, \mathrm{Cu}$, and $\mathrm{Ce}$ on the ICP with appropriate standard solutions containing $\mathrm{Na}_{2} \mathrm{O}_{2}$ and $\mathrm{HNO}_{3}$.

'Personal communication with C. Compton, Manufacturing Technology Laboratory, Reynolds Metals Company, Muscle Shoals, Alabarna. 
The aluminum metal particles were remelted in an alumina crucible at $1000^{\circ} \mathrm{C}$ in argon. After cooling to room temperature, the aluminum ball was sectioned using a struer Discotom cut-off saw with a SiC blade and two center section samples were prepared. Contaminants were removed from the cut surfaces of the samples by polishing with a $180 \mathrm{grit}$ SiC cloth. Two samples of each Al ball was sent for ICP analysis.

An aluminum sample of $\sim 2 \mathrm{~g}$ was dissolved in $1: 1 \mathrm{HCl}$ on a hot plate that was covered with a watch giass. The solution was filtered to remove any undissolved components. The undissolved components were analyzed by TEFA. The solution was diluted with DI water and analyzed by ICP for $\mathrm{Fe}, \mathrm{Ni}, \mathrm{Cu}$, and $\mathrm{Ce}$ with an appropriate standard in $1: 1 \mathrm{HCl}$.

\subsubsection{Normalization Procedures}

Ali ICP corrosion values of the cryolite and metal were normalized to project the industrial metal purity that would result from use of these anodes (assuming $95 \% \mathrm{CE}$ ). In the normalization process all of the $\mathrm{Fe}, \mathrm{Ni}$, and $\mathrm{Cu}$ in both bath and metal were added together and recalculated as contaminants in the aluminum. This simulates the industrial cell environment where transfer of the contaminants from the bath to the Al is rapid. This procedure should predict the maximum corrosion values.

Normalization involved the following steps:

1. The Fe, Ni, and Cu ICP analyses for the bath and metal were multiplied by the recovered welght of bath and metal (in grams) to determine the $\mathrm{Fe}, \mathrm{Cu}$, and $\mathrm{Ni}$ contamination in grams, giving

wt of $\mathrm{Al}$ metal $\mathrm{X}-\frac{8 \mathrm{Fe}, \mathrm{Ni} \text { or } \mathrm{Cu} \text { in Al }}{100}=\mathrm{g}$ of $\mathrm{Fe}$, $\mathrm{Ni}$, or
recovered

wt of bath recovered

$$
\begin{aligned}
& \mathrm{X} \text { - } \mathrm{Fe}_{\mathrm{Ni}} \mathrm{Ni} \text { or } \mathrm{Cu} \text { in } \mathrm{Al}=\mathrm{g} \text { of } \mathrm{Fe}, \mathrm{Ni} \text {, or } \\
& 100 \text { or } \mathrm{Cu} \text { in the bath. }
\end{aligned}
$$

2. The contamination for each element in the bath and Al metial were added together, which gives

$\mathrm{g}$ of $\mathrm{Fe}, \mathrm{Ni}$, or $\mathrm{Cu}+\mathrm{g}$ of $\mathrm{Fe}, \mathrm{Ni}$, or $\mathrm{Cu}=$ Total $\mathrm{g}$ of in Al metal in the cryolite $\mathrm{Fe}, \mathrm{Ni}$, or $\mathrm{Cu}$

3. The background corrosion was subtracted

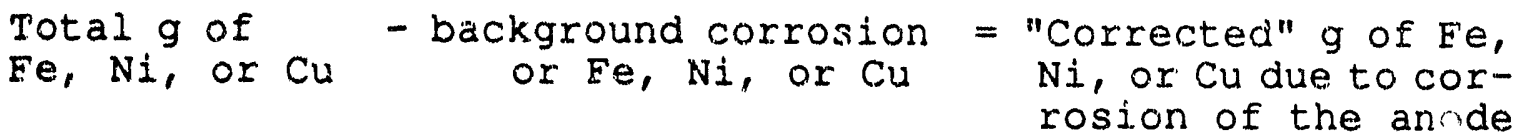


4. The corrosion was normalized for the theoretical amount of aluminum produced at the given $C D$, for the given amount of time, and assuming $95 \% \mathrm{CE}$ by the relation
g of $\mathrm{Fe}, \mathrm{Ni}$ or $\mathrm{Cu} \times 100=$ of impurities of $\mathrm{Fe}, \mathrm{Ni}$, or $\mathrm{Cu}$ $g$ of Al (theoretical) projected in an industrial Al pool.

A sample calculation is given in Appendix A for a Ce-free test operated at $1 \mathrm{~A} / \mathrm{cm}^{2}$ and $\mathrm{a} B \mathrm{BR}$ of 1.35 . All values and graphs in this report use normalized values.

\subsubsection{Microscopy}

Anodes were cross-sectioned with a Buehler Isomet cut-off saw using a diamond wafer blade. The anodes were cut perpendicular to the anode surface, mounted in epoxy, and polished with diamond grit to a $1 / 4 \mu \mathrm{m}$ diamond finish. All tested anodes were examined with a Nikon optiphot optical microscope. Five anodes were also examined by SEM/EDX. A Hitachi S-2300 SEM was employed to examine the cermets and CEROX coatings. Secondary and backscatter imaging were both employed. Phases were analyzed with a Noran (Tracor Northern) Series II $x$-ray Analyzer. A standardless quantitative analysis program (SQ, Noran) was utilized to calculate the stoichiometry of the phases, assuming an anion amount. The presence of light elements (i.e., $O, F, C$ ) could be detected with a beryllium thin window detector. 


\section{SATURATED ALUMINA TESTS $(100 \mathrm{H})$}

Seventeen $100 \mathrm{~h}$ saturated alumina tests were completed to evaluate the CEROX coating protection at high BR ( $\geq 1.4)$ on $\mathrm{Ni}$ ferrite/Cu cermets. Twelve test conditions, two repeats, and one ce-free test were originally proposed. Changes were made to the test program while it was in progress so that 13 test conditions were investigated plus two repeats, one Ce-free test, and one test of the PNL cermet material (with CEROX).

\subsection{Experimental Design}

A comparison between Phase II and Phase III test conditions is shown in Figure 23. Numbers next to the points indicate the experiment number conducted at those conditions. In Phase II, BR of $1.2,1.35$, and 1.6 were investigated at $C D$ of $0.6,1.0$, and 1.4 $\mathrm{A} / \mathrm{cm}^{2}$. Phase III concitions were chosen to bracket the best condition found in phase II testing (BR 1.6, CD of $1.4 \mathrm{~A} / \mathrm{cm}^{2}$ ). The original proposed 12 test conditions were at $B R$ of $1.4,1.5,1.6$, and 1.7 at $C D$ of $1.3,1.6$, and $1.9 \mathrm{~A} / \mathrm{cm}^{2}$. After performing 10 tests plus one repeat, it was decided to investigate lower $C D$ conditions instead of completing the original experimental design. Thus, two tests were operated at $a \mathrm{BR}$ of 1.5 and $C D$ of $0.5 \mathrm{~A} / \mathrm{cm}^{2}$, one test was operated at a $B R$ of 1.5 and $C D$ of $0.7 \mathrm{~A} / \mathrm{cm}^{2}$, and one test was operated at a $B R$ of 1.6 and $C D$ of $1.0 \mathrm{~A} / \mathrm{cm}^{2}$. The $C e$ free experiment was conducted at a BR of 1.6 and $C D$ of $1.3 \mathrm{~A} / \mathrm{cm}^{2}$. $A \mathrm{Cu}$ cermet sample from PNL was also tested for comparison (with a CEROX coating) at a $B R$ of 1.5 and $C D$ of $0.7 \mathrm{~A} / \mathrm{cm}^{2}$ (experiment \#55). All tests except for the Ce-free test were conducted with 1 wto $\mathrm{CeF}_{3}$ added to obtain a CEROX coating $\sim 1 \mathrm{~mm}$ thick.

\subsection{Current Density Estimates}

In Phase II, flat bottomed anodes were used and it was assumed that all current was from the bottom of the anode. However, the anode was imnersed from $1 / 8$ to $1 / 4$ in. to maintain an electrical contact, and a CEROX coating formed on the edges indicating that some current was from the sides. Numerous assumptions as to the current distribution in those experiments can be made; three assumptions were considered here.

Phase II

1. The current is entirely from the bottom of the anode

2. The majority of the current (80\%) is from the bottom of the anode

3. Current density is even across the bottom and the sides of the anode.

In Rhase II, assumption 1 was used. However, based on the presence of CEROX coating on the sides of the anodes, 2 or 3 is probably more realistic. Because our cathode area is confined to the bottom 


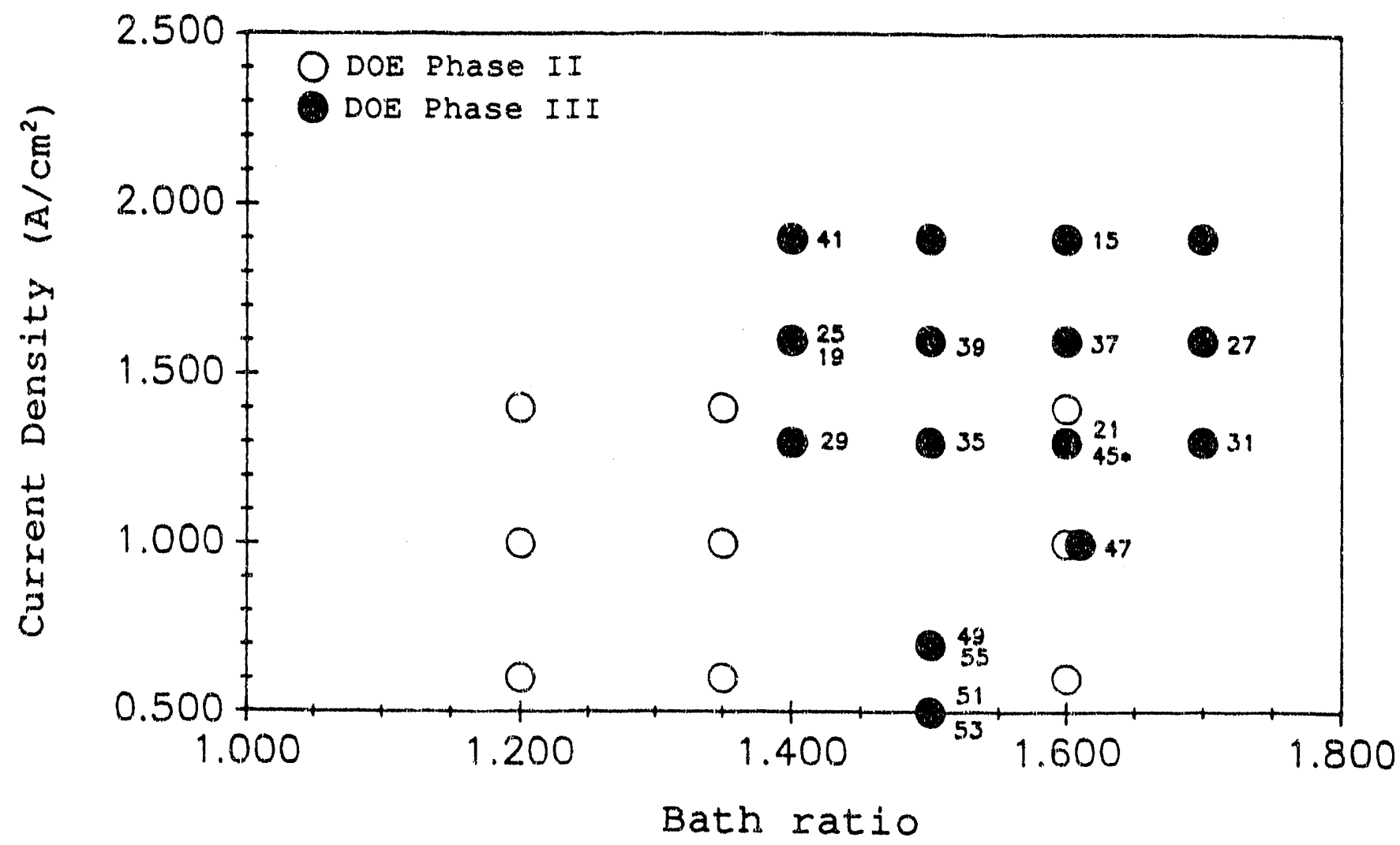

Figure 23. Test conditions $(100 \mathrm{~h})$ 
of the cell and the distance to the bottom is $\sim 6 \mathrm{~cm}$, assumption 3 is probably not accurate either. Therefore, the real current distribution was probably closer to assumption 2 in Phase II.

For Phase III, with anodes having a hemispherical bottom it was assumed that current density is uniform on the hemispherical tip.

As shown in Figure 24, the surface area on the side of Phase II anodes is significant compared to the bottom surface area. By choosing assumption 2 for Phase II, our CD estimates of those tests are reduced. Phase III test conditions were chosen to bracket Phase II conditions. Therefore, those test conditions must be correlated to the modified Phase II CD estimates. Table 4 compares the CD estimates for the Phase II and Phase III based on the above assumptions and using the surface areas shown in Figure 24. The immersed surface area in Phase II was slightly greater (4.81 versus $3.73 \mathrm{~cm}^{2}$ ) but the surface area at the peak CD was greater in

Phase III $\left(3.73\right.$ versus $\left.2.27 \mathrm{~cm}^{2}\right)$. This resulted in a higher current in Phase III anodes and greater production of oxygen.

\subsection{Test Cell Operation}

Because of the exposed carbon on the bottom of the carbon crucible $\mathrm{Na}$ was intercalated into the carbon resulting in reduced $B R$ during the duration of the test. BR analyses were taken at $\sim 6,24,48$, 72 , and $96 \mathrm{~h}$ of operation. Because BR dropped, it was necessary to add $\mathrm{Na}$ to the cell to bring the ratio back to the desired level. In Phase II acidic baths, $\mathrm{Na}_{2} \mathrm{CO}_{3}$ was added to bring the NaF level up by the reaction

$3 \mathrm{Na}_{2} \mathrm{CO}_{3}+2 \mathrm{AlF}_{3}=6 \mathrm{NaF}+\mathrm{Al}_{2} \mathrm{O}_{3}+3 \mathrm{CO}_{2}$ (gas).

In Phase III, $\mathrm{Na}_{2} \mathrm{CO}_{3}$ additions were employed in acidic baths and $\mathrm{NaF}$ was added directly to basic baths. Typically, BR would fall 0.1 to 0.2 in the first $6 \mathrm{~h}$ and about that same amount between 6 and $24 \mathrm{~h}$ of testing. As experience was gained with the amount of additions necessary to bring the BR to the desired level, additions were made throughout the day to try to maintain a more constant BR. BR still dropped during the night because of the inability to make bath additions during that time ( $\mathrm{NaF}$ and $\mathrm{Na}_{2} \mathrm{CO}_{3}$ plug the funnel and feed tube).

Figure 25 shows some typical examples of BR variation during $100 \mathrm{~h}$ tests. Generally, at a desired BR of 1.4, BR averaged from 1.3 to 1.45 but dropped as low as 1.1 at the $24 \mathrm{~h}$ bath analysis. At a BR of 1.5, it varied between 1.3 and 1.55 , at a BR of 1.6 , it varied between 1.4 and 1.65 , and at a BR of 1.7 , it generally ranged from 1.43 to 1.7 , but did drop to 1.38 at one point. Thus, BR was not constantly maintained throughout the tests because of the use of the carbon crucibles. BR in the tests overlap and average lower than the specified BR for each test. $\mathrm{NaF}$ or $\mathrm{Na}_{2} \mathrm{CO}_{3}$ 
Phase II

Phase III

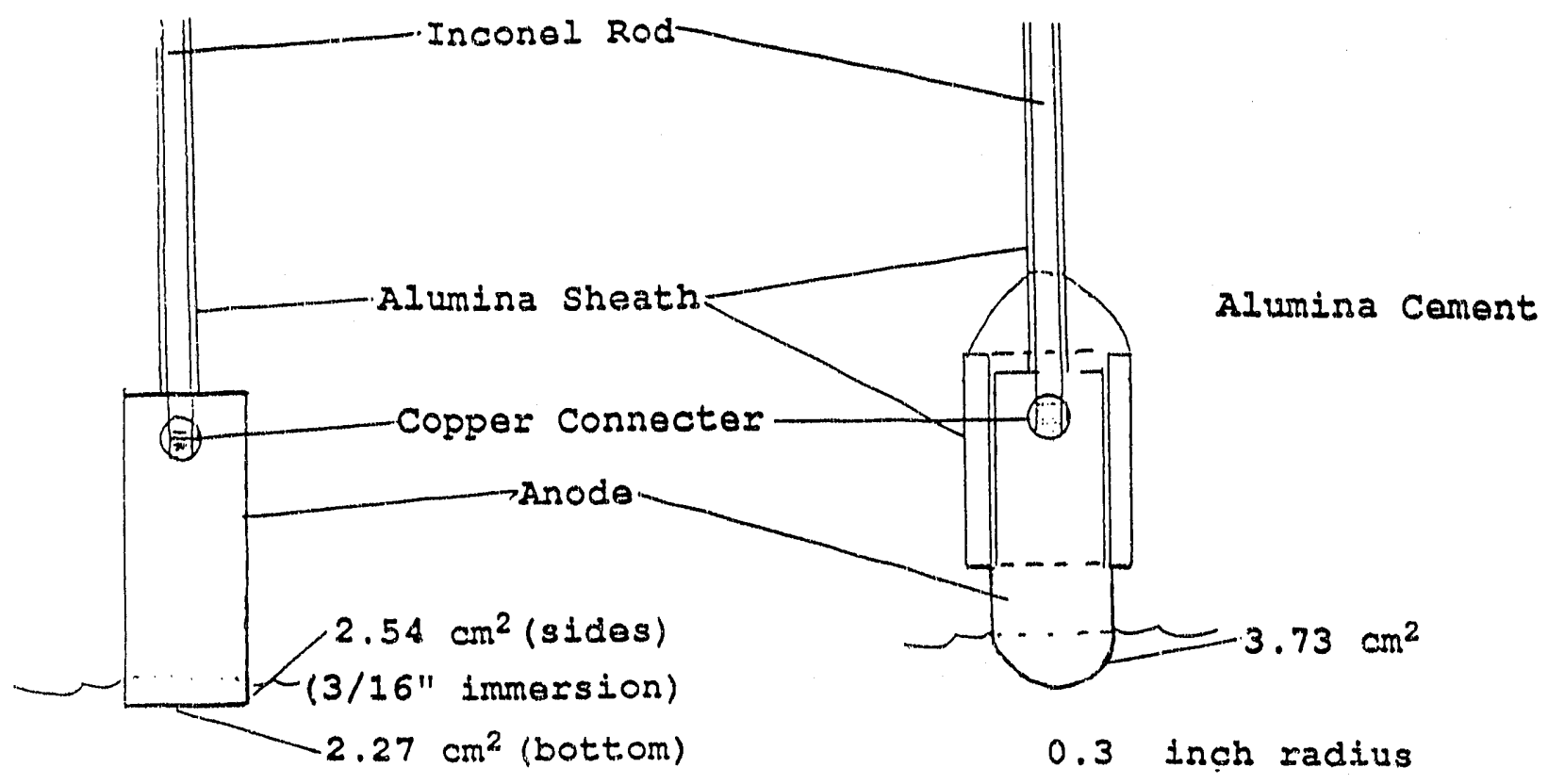

Figure 24. Comparison of immersed surface areas on Phase II and Phase III anodes. 
Table 4. Current density estimates

Phase II

1. All current from bottom Phase II chosen conditions

2. Majority (80\%) of current from bottom. More accurate Phase II CD estimates

3. Even current distribution

Phase III

1. Even current distribution proposed conditions

2. Even current distribution actual run conditions after correlation to Phase II
Estimated Current Density in $\mathrm{A} / \mathrm{cm}^{2}$

$\begin{array}{lll}0.60 & 1.00 & 1.40 \\ 0.48 & 0.80 & 1.12 \\ 0.28 & 0.47 & 0.66\end{array}$

1.30

1.60

1.90

1.04

1.28

1.52 

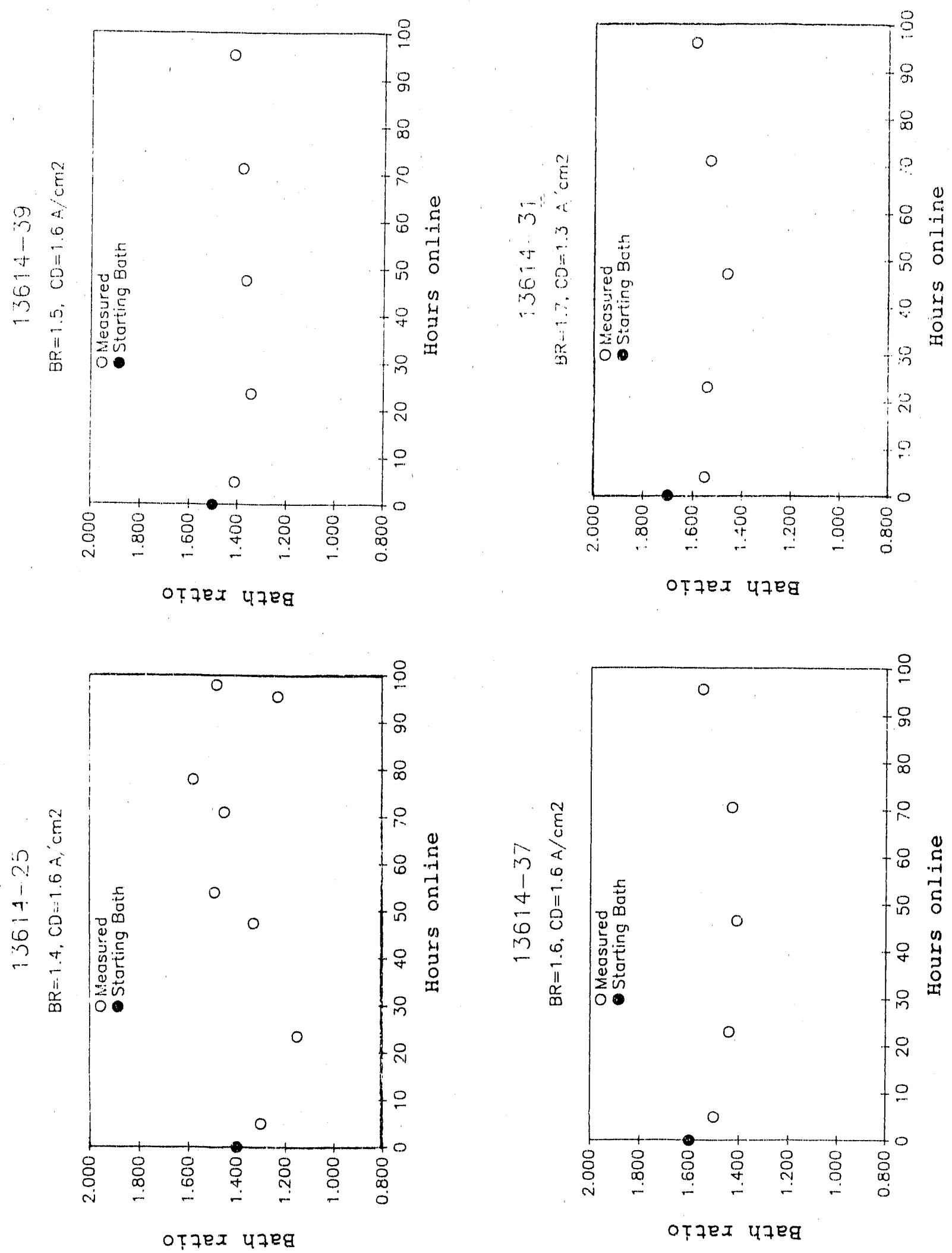

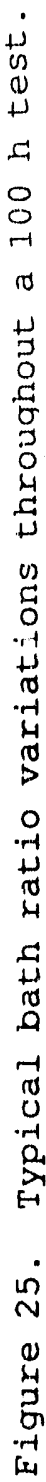


was added every day, and the effect of these constant additions close to the anodes is not known. NaF contains 100 ppm Fe, but the most NaF added in a test was calculated to only add $0.03 \%$ Fe to the normalized $\mathrm{Fe}$ values.

At the beginning of the test, cell voltage was generally from $2.6 \mathrm{~V}$ at a $C D$ of $0.5 \mathrm{~A} / \mathrm{cm}^{2}$ to $4.2 \mathrm{~V}$ at a $C D$ of $1.9 \mathrm{~A} / \mathrm{cm}^{2}$. The voltage peaked at $\sim 1.5 \mathrm{~h}$ then dropped slightly, usually to a baseline level after $4 \mathrm{~h}$. This baseline level ranged from $3.0 \mathrm{~V}$ at $0.5 \mathrm{~A} / \mathrm{cm}^{2}$ to $5 \mathrm{~V}$ at the higher $\mathrm{CD}$, with increases from the start of the test ranging from 0.1 to $1.1 \mathrm{~V}$. Presumably, this increase in voltage to the baseline level is because of the development of the CEROX coating and to the development of a bubble layer on the anode. The Ce-free anode had a voltage increase of $0.2 \mathrm{~V}$ during this time period.

In most cases, the voltage then was fairly constant with only a small decrease or increase through the midpoint of the test ( $50 \mathrm{~h})$. In two tests at $C D$ of 1.3 and $1.6 \mathrm{~A} / \mathrm{cm}^{2}$ voltage increases were $1 \mathrm{~V}$ from the baseline level. Between the midpoint and the end of the test, some tests experienced a large increase in cell voltage. In the worst case, an increase in cell voltage of $3 \mathrm{~V}$ was noted while typical increases were in the range of 0.25 to $1.3 \mathrm{~V}$. Typical examples of cell voltage increases are shown in Figure 26.

After testing was completed, the anodes were cross-sectioned and examined. Particularly in the high $C D$ anodes, $C u$ metal was no longer apparent in the outer portion of the anode (more detail is descrired in subsection 6.3) and the $\mathrm{Cu}$ connector rod was also somewhit oxidized. This indicates that the increase in voltage noted during the tests is directly related to $C D$ and thus oxidation of the cermet and the anode connection. In anodes operated at the higher $C D$ where oxidation was extensive, there was evidence that the alumina sheath (present on the exterior of the anode for protection from cryolite) had limited the height of the oxidized region.

Observation of the voltage increase during testing and the loss of metaliic $\mathrm{Cu}$ in the outer region of the anode at high $C D$ led to changes in the experimental test program design. Instead of completing the tests at a $C D$ of $1.9 \mathrm{~A} / \mathrm{cm}^{2}$, it was decided to perform a few tests at lower $C D\left(1.0,0.7\right.$, and $\left.0.5 \mathrm{~A} / \mathrm{cm}^{2}\right)$ to compare oxidation, voltage increase, and corrosion.

The thickness of the Cu metal depleted zones ranged from $0.1 \mathrm{~cm}$ at $0.5 \mathrm{~A} / \mathrm{cm}^{2}$ to $2.6 \mathrm{~cm}$ at the higher $\mathrm{CD}$. The oxidation thicknesses for each test was divided by the $100 \mathrm{~h}$ of the test to give an oxidation rate per hour for comparison (Eigure 27). This implies that oxidation is linear, but in reality, there is no way to determine the oxidation rate profile without running a number of tests for different lengths of time. The radius of the anodes is $\sim 0.76 \mathrm{~cm}$ so that when the radius of the anode has been oxidized 


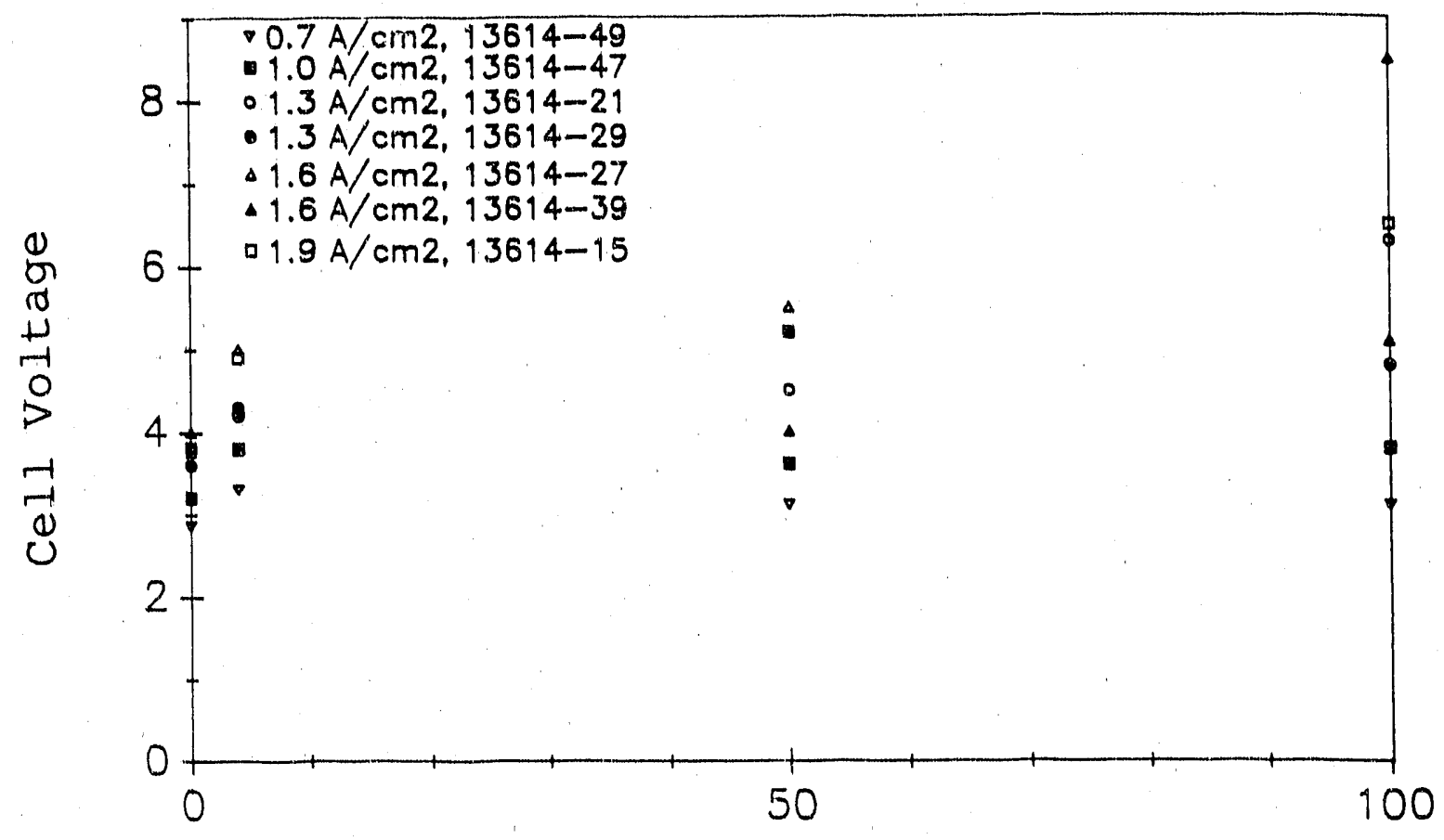

Hours

Eigure 26. Examples of typical cell voltage changes during the $100 \mathrm{~h}$ tests.

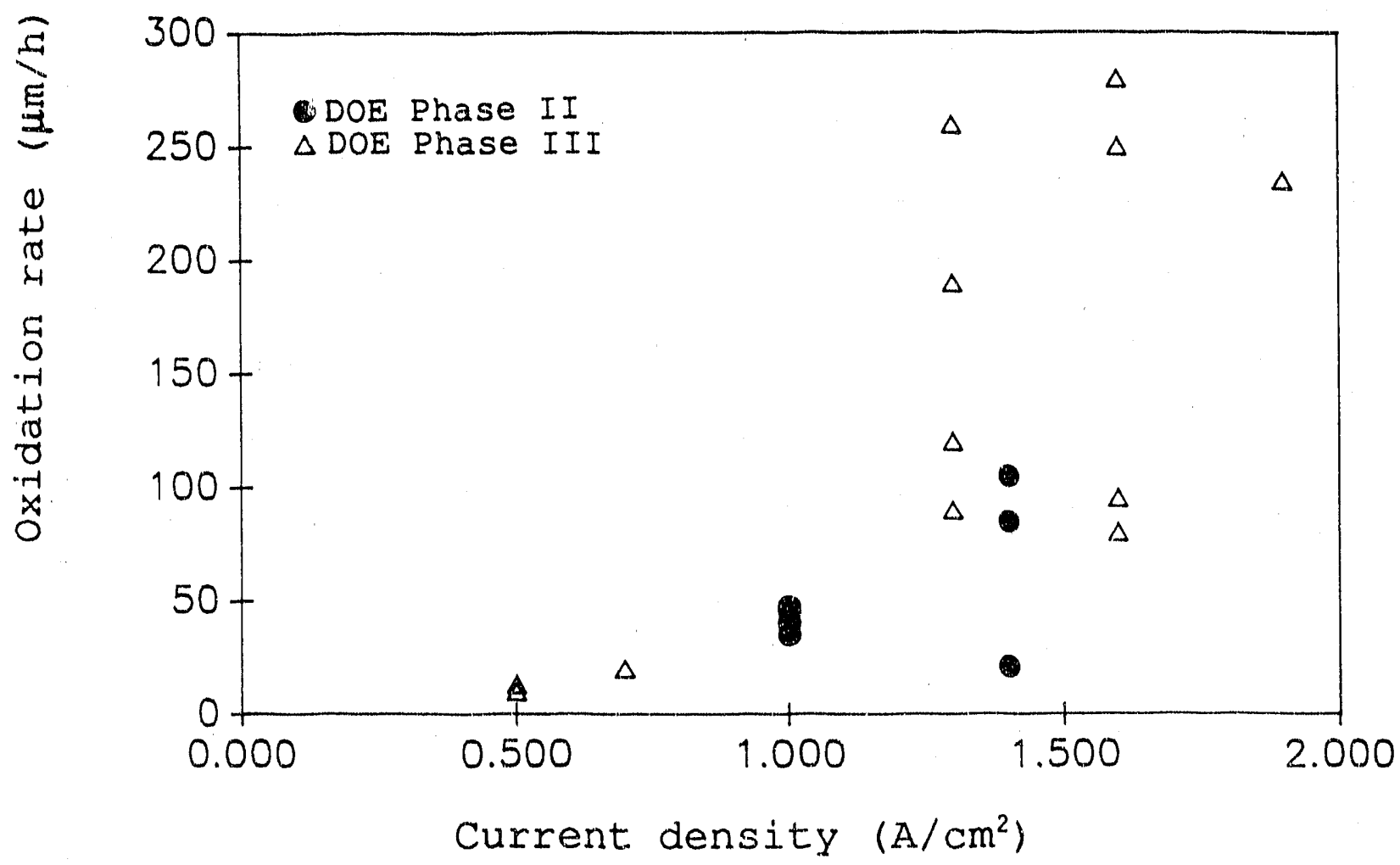

Figure 27. Oxidation versus current density for $100 \mathrm{~h}$ alumina saturated tests. 
from each outer edge, the depth of oxidation (height) really did reveal anything about the rate of oxidation. The $0.76 \mathrm{~cm}$ oxidation corresponds to a rate of $\sim 76 \mu \mathrm{m} / \mathrm{h}$ in the $100 \mathrm{~h}$ tests. Therefore, the apparent increase in oxidation rate at the higher $C D$ is probably caused by this artifact.

$\mathrm{CE}$ were estimated based on the recovered weight of aluminum versus the theoretical amount of aluminum that should be produced at a given current. $\mathrm{Al}_{2} \mathrm{O}_{3}$ and $\mathrm{CeF}_{3}$ were added assuming $75 \% \mathrm{CE}$ for the high $\mathrm{CD}$ tests and $308 \mathrm{CE}$ for the 0.5 and $0.7 \mathrm{~A} / \mathrm{cm}^{2}$ tests. In the higher $C D$ tests, $C E$ was usually 20 to 55\%. In the tests at the 0.5 and $0.7 \mathrm{~A} / \mathrm{cm}^{2} \mathrm{CD}$, after testing there was actually less aluminum than the starting amount of $45 \mathrm{~g}$ (Figure 28). In addition, at the low $C D$ there was a serious problem with crusting around the anode. Crystals were found to radiate around the sides of the anodes near the meltiine and had a tendency to grow downwards around the hemispherical bottom as the test progressed (Eigure 29). X-ray diffraction (XRD) revealed that the crystals were $\mathrm{Al}_{2} \mathrm{O}_{3}$ with some cryolite. The alumina crystals could electrically isolate part of the hemispherical bottom of the anode, changing the surface area that was conducting current and disrupting the CEROX coating. This problem was most apparent in test 13614-51. The alumina sheath may have accentuated the problem by acting as a nucleation site for the alumina crystals.

There are a number of explanations for low CE described in the literature. ${ }^{1}$ These include reoxidation of the dissolved metallic species in the bath (Al or other) by anode gas or air, evaporation of metallic species, reduction of other species (i.e., $\mathrm{Ni}, \mathrm{Fe}$, or $\mathrm{Cu}$, current losses, and $\mathrm{Na}$ reduction in baths high in NaF. In addition, some Al may react with the graphite crucible to form $\mathrm{Al}_{4} \mathrm{C}_{3}$, which can then dissolve in the bath, forming $\mathrm{Al}-\mathrm{O}-\mathrm{F}$ species. The CE estimates shown in Figure 28 appear to follow a linear trend. Because the $C E$ versus $C D$ is fairly linear and some $C E$ are negative, the reaction causing loss of $\mathrm{CE}$ may be independent of the current applied (i.e., a loss caused by a chemical reaction not an electrochemical one). Changes in cell design and operation may be possible to reduce the oxidation of any dissolved Al by air at the meltine and to reduce the formation of $\mathrm{Al}_{4} \mathrm{C}_{3}$ by reducing the exposed carbon on the bottom of the cell.

\subsection{Corrosion Results}

As described in Subsection 4.8.3 and 4.8.4, all bath and Al samples were analyzed by ICP and the data were normalized. Normalized corrosion results are shown in Table 5. The five lowest total corrosion tests are delineated with an asterisk; the anodes from those five test.s were analyzed by SEM/EDX. 


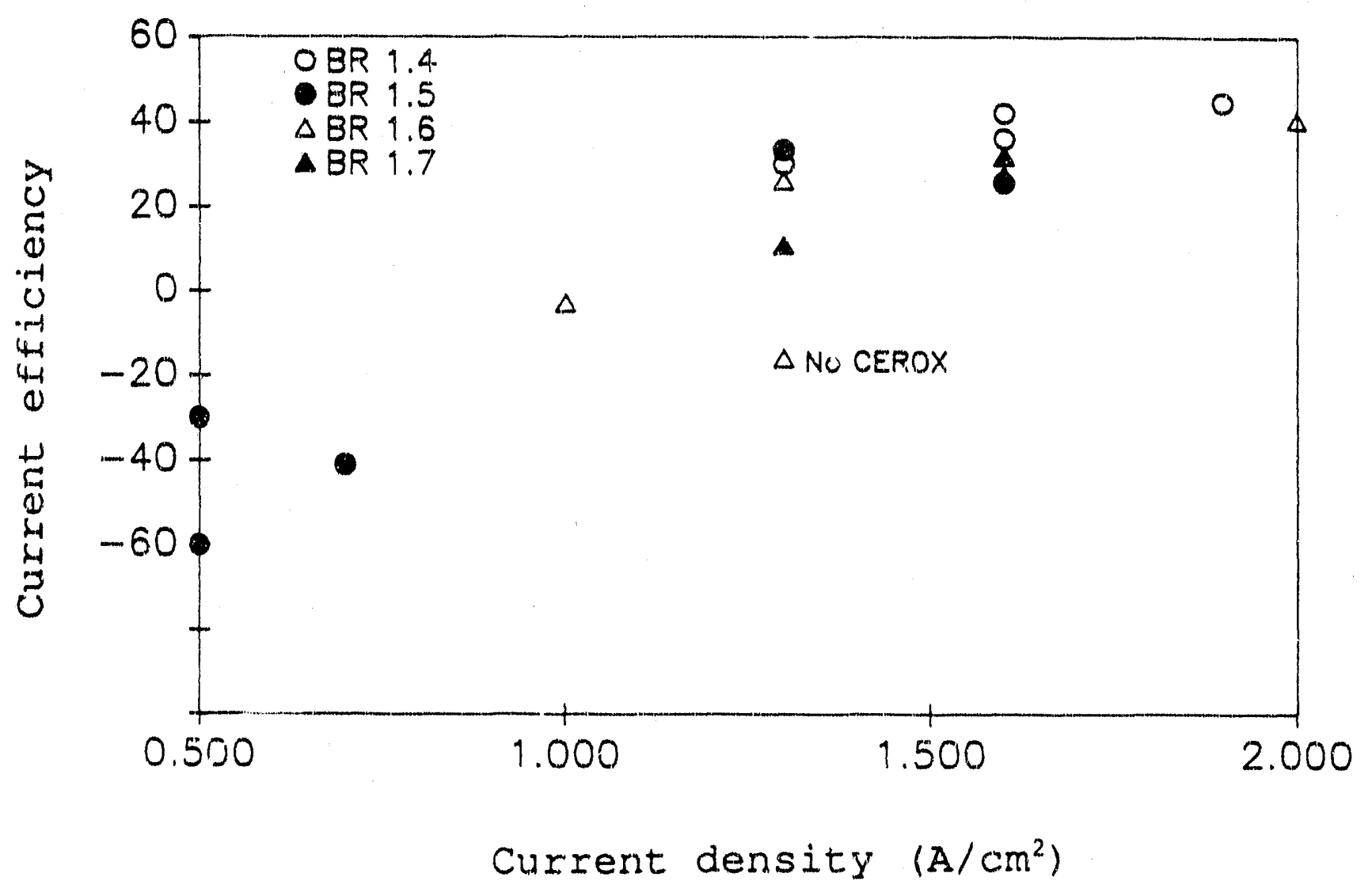

Eigure 28. Estimated current efficiency as a function of current density. 


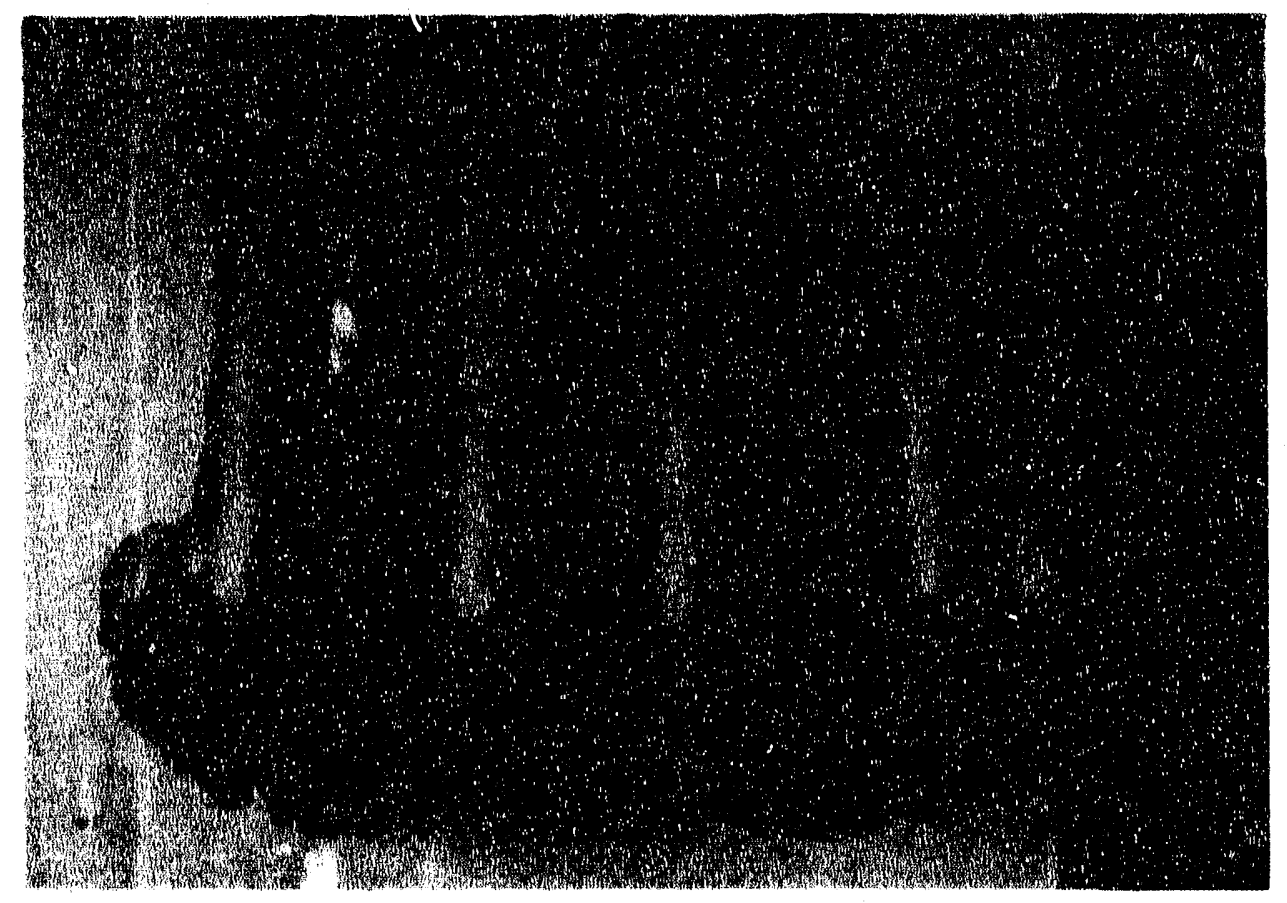

Figure 29. Alumina crystals and crust around the tip of the anode from test $13614-47,0.7 \mathrm{~A} / \mathrm{cm}^{2}$. 
Table 5. Normalized corrosion for saturated tests $(100 \mathrm{~h})$.

\begin{tabular}{|c|c|c|c|c|c|c|}
\hline \multirow[b]{2}{*}{ Test } & \multirow[b]{2}{*}{$\underline{\mathrm{BR}}$} & \multirow[b]{2}{*}{$\mathrm{CD}, \mathrm{A} / \mathrm{cm}^{2}$} & \multicolumn{4}{|c|}{ Normalized Impurities } \\
\hline & & & Wt: $\mathrm{Ee}$ & Wt: $\mathrm{Ni}$ & Wt ${ }^{\circ} \quad \mathrm{Cu}$ & Totals \\
\hline $\begin{array}{l}13614-15 \\
13614-19 \\
13614-21 * \\
13614-25 \\
13614-27 \\
13614-29 \\
13614-31 \\
13614-35 * \\
13614-37 \\
13614-39 \\
13614-41 * \\
13614-45 \\
\text { (Ce-free) }\end{array}$ & $\begin{array}{l}1.6 \\
1.4 \\
1.6 \\
1.4 \\
1.7 \\
1.4 \\
1.7 \\
1.5 \\
1.6 \\
1.5 \\
1.4 \\
1.6\end{array}$ & $\begin{array}{l}1.9 \\
1.6 \\
1.3 \\
1.6 \\
1.6 \\
1.3 \\
1.3 \\
1.3 \\
1.6 \\
1.6 \\
1.9 \\
1.3\end{array}$ & $\begin{array}{l}0.421 \\
0.385 \\
0.250 \\
0.387 \\
0.310 \\
0.403 \\
0.350 \\
0.207 \\
0.422 \\
0.394 \\
0.202 \\
1.866\end{array}$ & $\begin{array}{l}0.210 \\
0.299 \\
0.200 \\
0.341 \\
0.299 \\
0.268 \\
0.303 \\
0.1 .00 \\
0.451 \\
0.280 \\
0.142 \\
1.944\end{array}$ & $\begin{array}{l}0.412 \\
0.480 \\
0.282 \\
0.526 \\
0.490 \\
0.588 \\
0.419 \\
0.430 \\
0.587 \\
0.383 \\
0.445 \\
1.303\end{array}$ & $\begin{array}{l}1.043 \\
1.164 \\
0.732 \\
1.254 \\
1.100 \\
1.259 \\
1.072 \\
0.737 \\
1.460 \\
1.057 \\
0.789 \\
5.113\end{array}$ \\
\hline $\begin{array}{l}13614-47 \\
13614-49 \star \\
13614-51 \\
13614-53 \star \\
13614-55 \\
\text { (PNL cermi }\end{array}$ & $\begin{array}{l}1.6 \\
1.5 \\
1.5 \\
1.5 \\
1.5\end{array}$ & $\begin{array}{l}1.0 \\
0.7 \\
0.5 \\
0.5 \\
0.7\end{array}$ & $\begin{array}{l}0.312 \\
0.138 \\
0.496 \\
0.123 \\
0.659\end{array}$ & $\begin{array}{l}0.178 \\
0.162 \\
0.115 \\
0.032 \\
0.046\end{array}$ & $\begin{array}{l}0.362 \\
0.370 \\
0.228 \\
0.317 \\
0.366\end{array}$ & $\begin{array}{l}0.852 \\
0.670 \\
0.839 \\
0.471 \\
1.072\end{array}$ \\
\hline
\end{tabular}


Normalized corrosion results are shown graphically as a function of $B R$ for various $C D$ in Eigures 30 through 32 . At $1.3 \mathrm{~A} / \mathrm{cm}^{2}$ there appears to be a minimum in corrosion at a BR of 1.6. The Ce-free anode operated at these same conditions had a total corrosion of 5.1138 , which is 7 times higher than the anode with a CEROX coating (total corrosion of $0.732 \%$ ). At the $1.6 \mathrm{~A} / \mathrm{cm}^{2}$ a minimum in corrosion at a particular BR is not evident, while at $1.9 \mathrm{~A} / \mathrm{cm}^{2}$ there are to few data points to determine whether a minimum exists between a BR of 1.4 and 1.6 .

$C D$ versus corrosion results are shown in Eigures 33 through 36 . At. BR of $1.5,1.6$, and 1.7 there appears to be a slight downward trend with decreasing $C D$. The corrosion at a BR of 1.4 does not follow this trend but the experiment at a $C D$ of $1.9 \mathrm{~A} / \mathrm{cm}^{2}$ may be anomalous.

Ee levels in the bath ranged from 0.0174 to 0.0743 , averaging 0.0429 . Levels of $\mathrm{Ni}$ averaged 0.0482 (ranging from 0.0112 to 0.1027 ) and $\mathrm{Cu}$ levels averaged 0.0606 (ranging from 0.0154 to $0.1034)$. In contrast, the level of $\mathrm{Fe}, \mathrm{Ni}$, and $\mathrm{Cu}$ in the bath from the Ce-free test were $0.1697,0.2176$, and 0.1408 , respectively.

Normalized corrosion values in the metal were 0.123 to $0.4968 \mathrm{Fe}$ $(0.320 \%$ average), 0.0315 to $0.451 \% \mathrm{Ni}(0.2258$ average), and 0.228 to $0.588 \% \mathrm{Cu}(0.4218$ average). In most tests, $\mathrm{Ni}$ was the lowest corrosion species, $\mathrm{Ee}$ was intermediate, and $\mathrm{Cu}$ was highest.

Total normalized corrosion for CEROX-coated anodes ranged from 0.471 to 1.46\%. Target corrosion is around $0.15 \% \mathrm{Fe}, 0.02 \% \mathrm{Ni}$, and $0.02 \% \mathrm{Cu}$. In the best tests the $\mathrm{Fe}$ and $\mathrm{Ni}$ corrosion values were close to these targets, but $c u$ was unacceptably higher.

Fe, Ni, and Cu corrosion results were compared to the ratios of the elements found in the as-made cermet. The results are shown in Table 6. Cu corrosion appears to be high compared to both Fe, and $\mathrm{Ni}$ while $\mathrm{Ee}$ corrosion appears high when compared to the amount of $\mathrm{Ni}$ present in the aluminum. In the one Ce-free experiment, the Fe to ivi ratio is closest to those found in the cermet. This might suggest that the CEROX coating is most effective at reducing $\mathrm{Ni}$ corrosion. However, more experiments need to be conducted to verify this.

A small diameter $(\sim 1 \mathrm{~cm})$ anode was supplied by PNL for comparison testing. The anode was tested at a BR of 1.5 and $C D$ of $0.7 \mathrm{~A} / \mathrm{cm}^{2}$ with 1 wto $\mathrm{CeF}_{3}$ in the bath. As with the ELTECH anodes at low CD, Low $C E$ resulted and crusting occurred around the anode. Corrosion was $0.6598 \mathrm{Fe}, 0.0468 \mathrm{Ni}, 0.366 \% \mathrm{Cu}$, and $1.071 \%$ total. The $\mathrm{Ni}$ and $\mathrm{Cu}$ corruition values are in the same range as ELTECH samples at similar conditions, but $F e$ was slightly higher. on crosssectioning, the anode was found to be oxidized $2 \mathrm{~cm}$ into the anode. Thus, the PNL material behaved very similarly to the ELTECH materials in these tests, and the small difference in cu content 


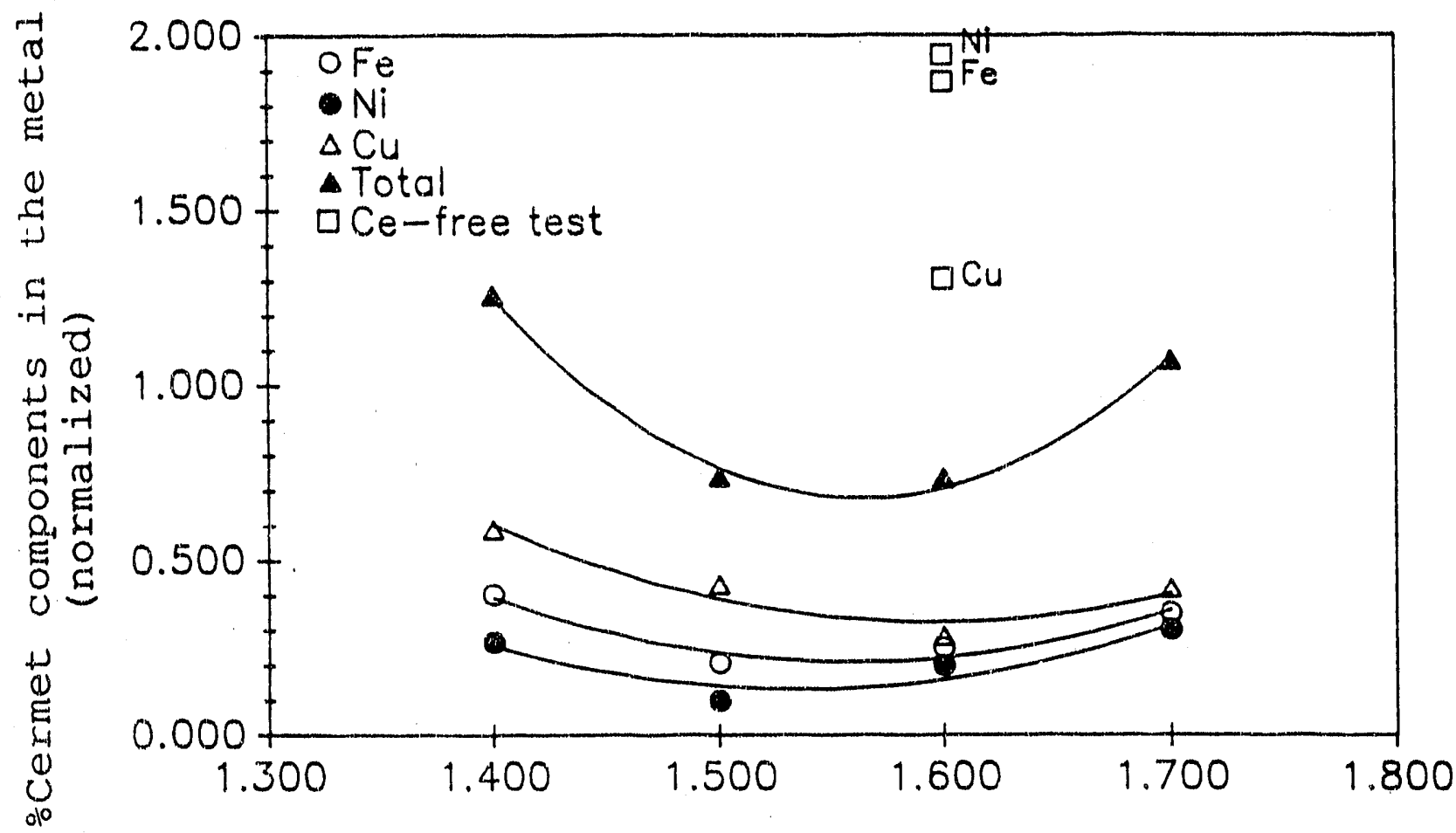

Bath ratio

Figure 30. Normalized corrosion versus bath ratio at $1.3 \mathrm{~A} / \mathrm{cm}^{2}$.

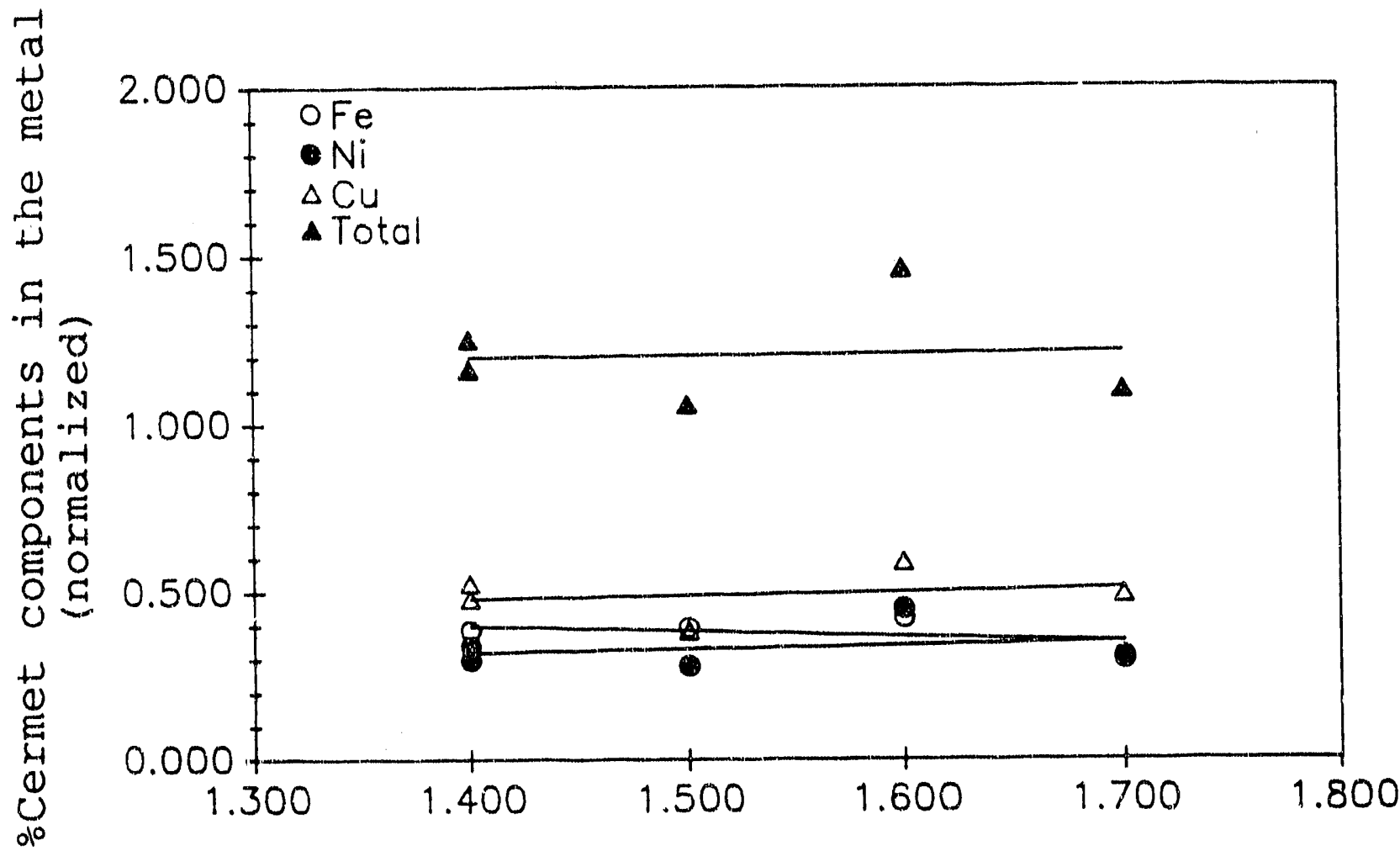

Bath ratio

Eigure 31. Normalized corrosion versus bath ratio at $1.6 \mathrm{~A} / \mathrm{cm}^{2}$. 


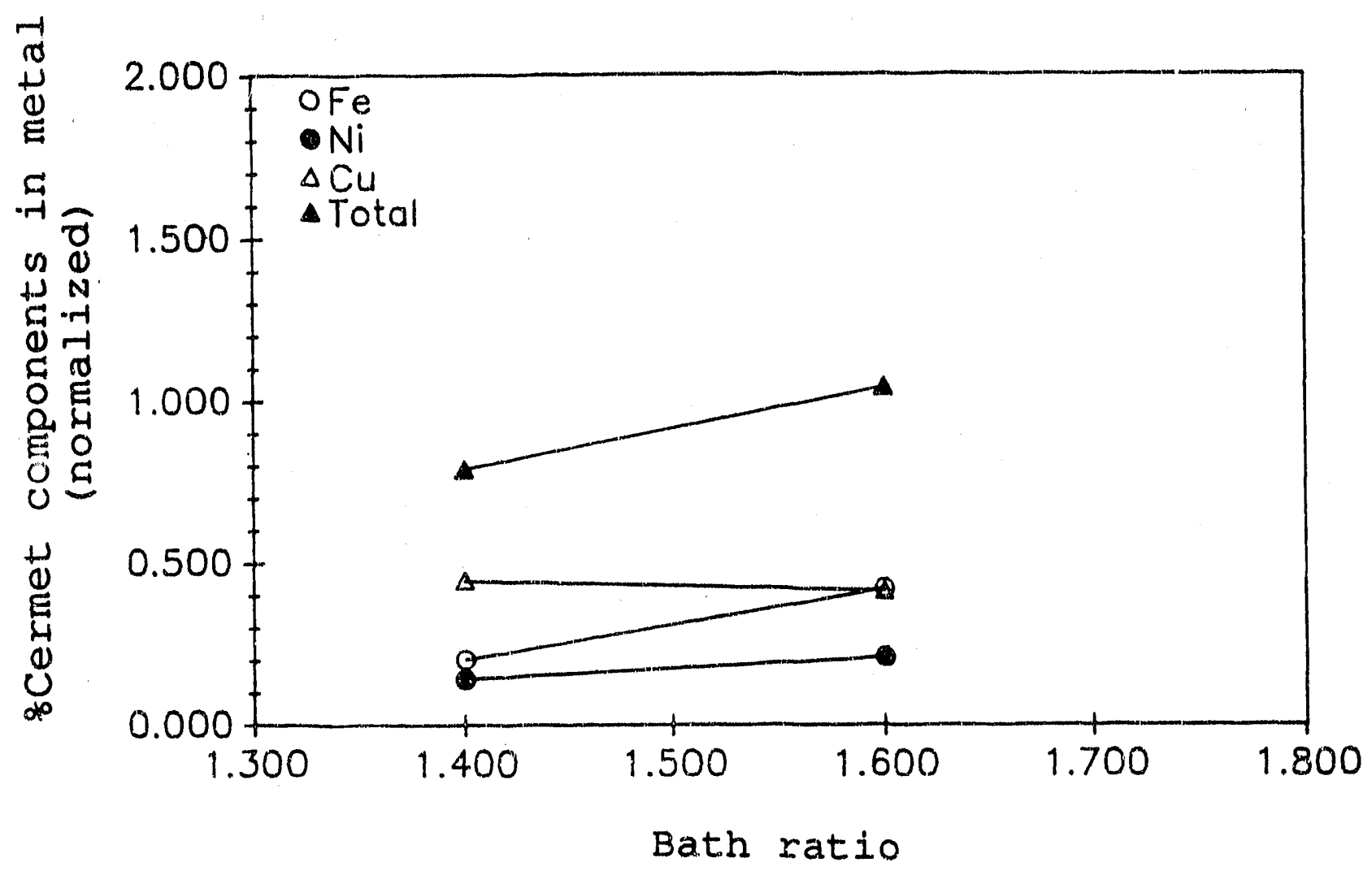

Figure 32. Normalized corrosion versus bath ratio at $1.9 \mathrm{~A} / \mathrm{cm}^{2}$. 


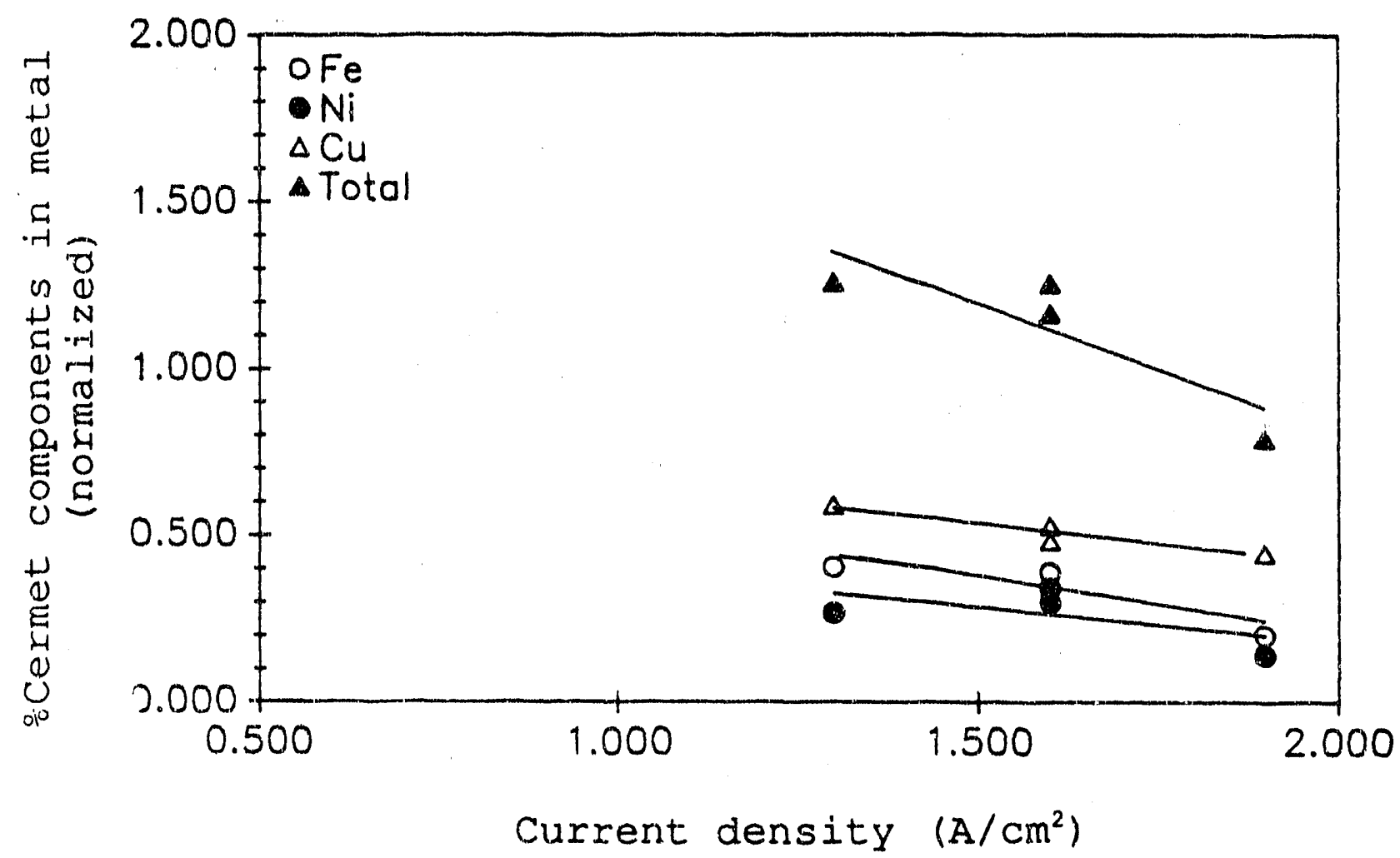

Figure 33. Normalized corrosion versus current density at a BR of 1.4 .

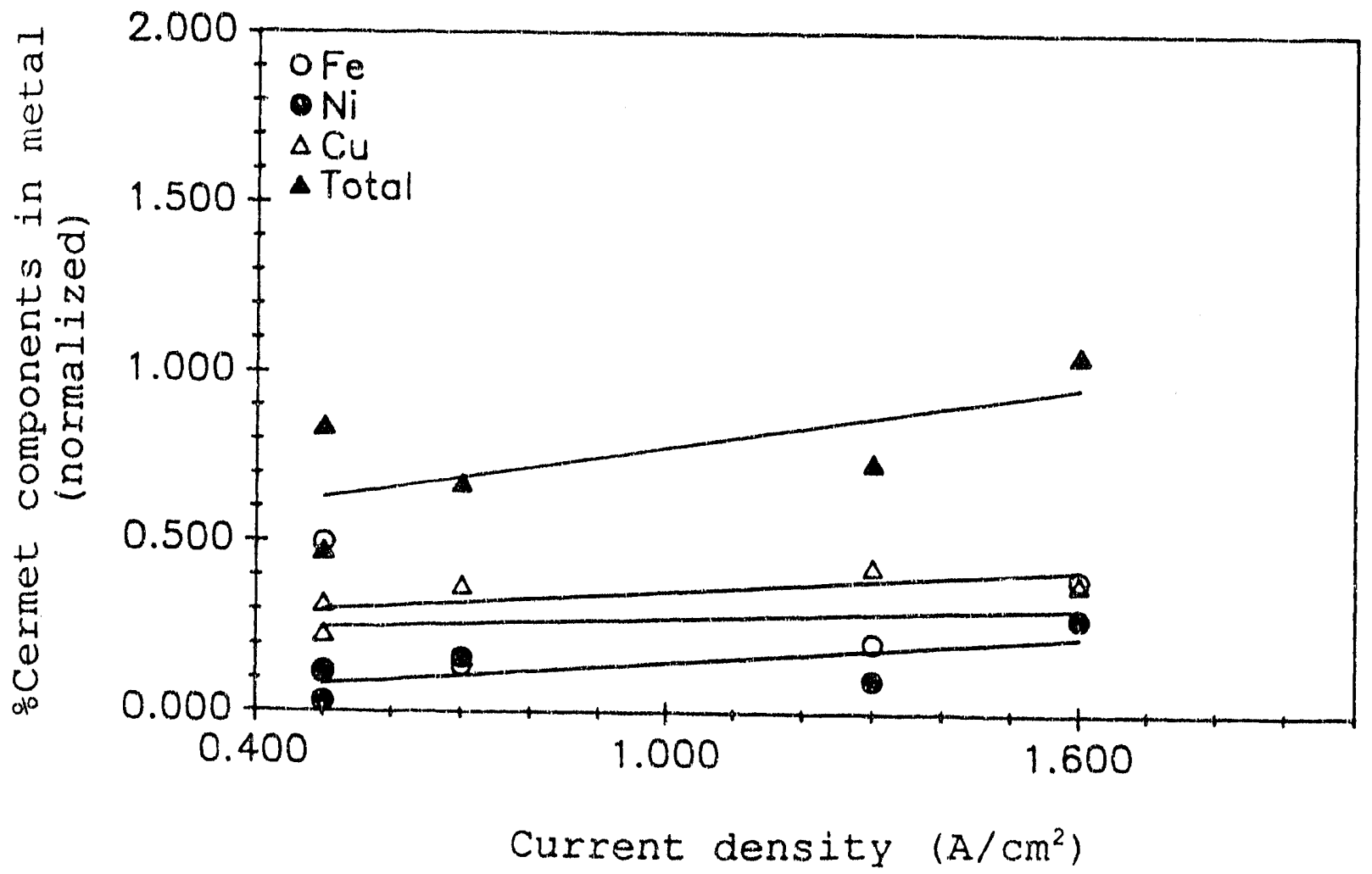

Figure 34. Normalized corrosion versus curcent density at a BR of 1.5 . 


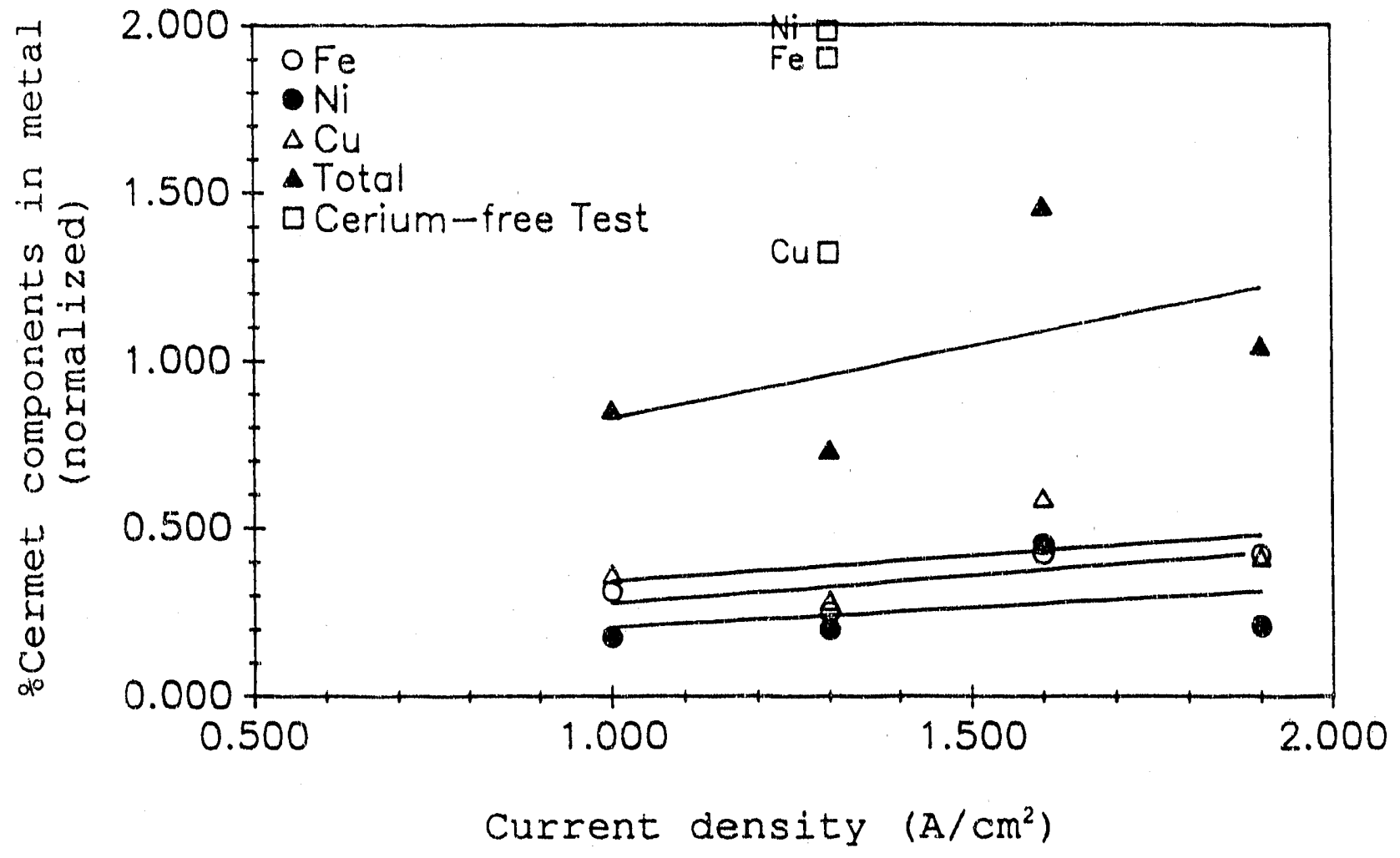

Eigure 35. Normalized corrosion versus current density at a BR of 1.6 .

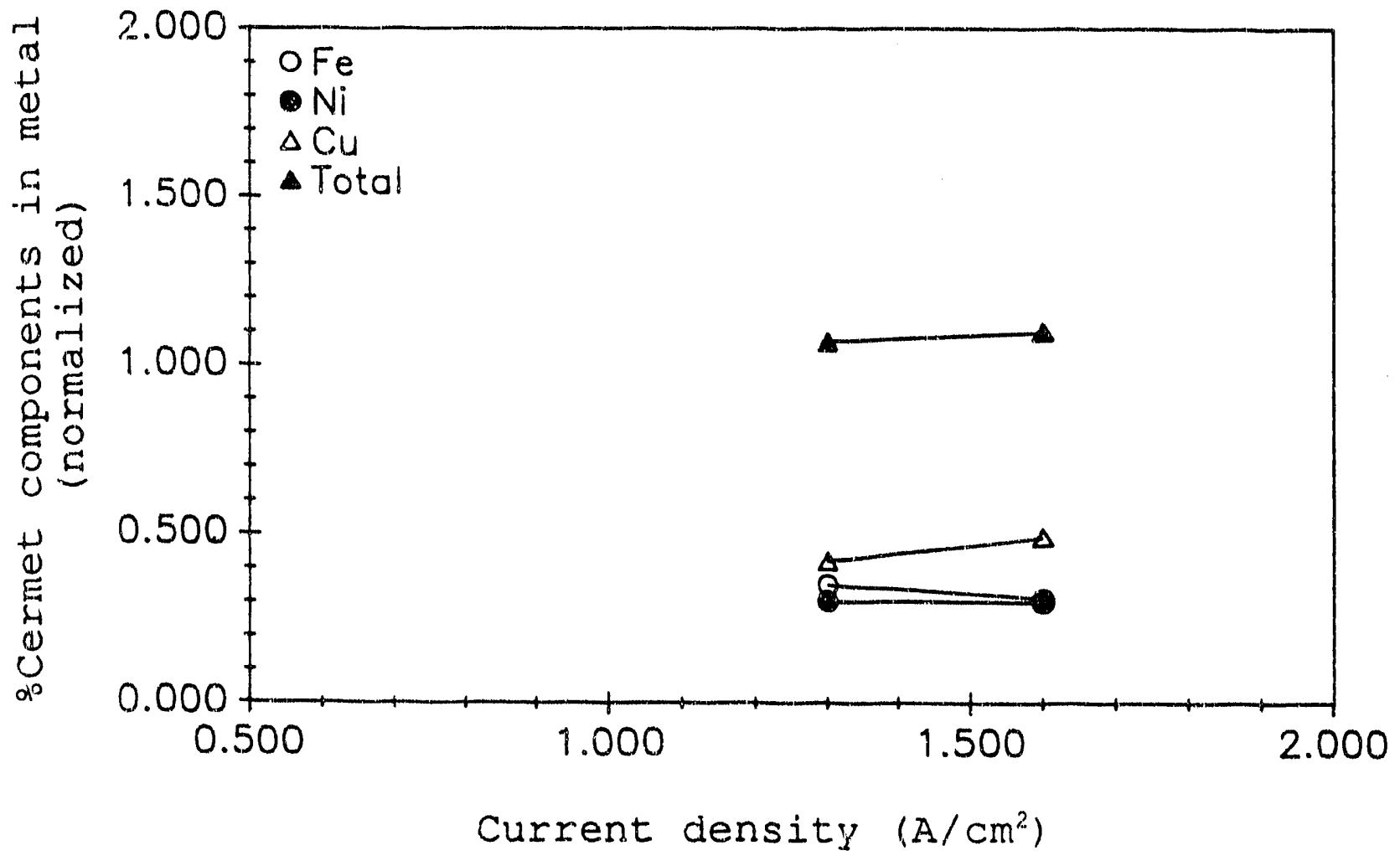

Figure 36. Normalized corrosion versus current density at a BR of 1.7 . 
Table 6. Fe, $\mathrm{Ni}$, and Cu ratios of normalized corrosion values.

\begin{tabular}{|c|c|c|c|}
\hline Experiment & $\mathrm{Fe} / \mathrm{Ni}$ & EeLCu & Ni/Cu \\
\hline Untested Cermet & 0.85 & 2.19 & 2.56 \\
\hline $\begin{array}{l}13614-45 \\
\text { Ce-free }\end{array}$ & 0.95 & 1.43 & 1.49 \\
\hline \multicolumn{4}{|c|}{$\mathrm{BR}=1.4$} \\
\hline $\begin{array}{l}13614-29 \\
13614-25 \\
13614-19 \\
13614-41\end{array}$ & $\begin{array}{l}1.50 \\
1.13 \\
1.29 \\
1.42\end{array}$ & $\begin{array}{l}0.68 \\
0.74 \\
0.80 \\
0.45\end{array}$ & $\begin{array}{l}0.46 \\
0.65 \\
0.62 \\
0.32\end{array}$ \\
\hline \multicolumn{4}{|c|}{$\mathrm{BR}=1.5$} \\
\hline $\begin{array}{l}13614-51 \\
13614-53 \\
14614-49 \\
13614-55 \text { (PNL) } \\
13614-35 \\
13614-39\end{array}$ & $\begin{array}{l}4.30 \\
3.89 \\
0.84 \\
24.18 \\
2.07 \\
1.40\end{array}$ & $\begin{array}{l}3.78 \\
0.39 \\
0.37 \\
1.79 \\
0.48 \\
1.02\end{array}$ & $\begin{array}{l}2.18 \\
0.10 \\
0.44 \\
0.13 \\
0.23 \\
0.73\end{array}$ \\
\hline \multicolumn{4}{|c|}{$\mathrm{BR}=1.6$} \\
\hline $\begin{array}{l}13614-47 \\
13614-21 \\
13614-37 \\
13614-15\end{array}$ & $\begin{array}{l}1.74 \\
1.25 \\
0.94 \\
2.01\end{array}$ & $\begin{array}{l}0.86 \\
0.89 \\
0.72 \\
1.02\end{array}$ & $\begin{array}{l}0.49 \\
0.71 \\
0.77 \\
0.51\end{array}$ \\
\hline \multicolumn{4}{|c|}{$\mathrm{BR}=1.7$} \\
\hline $\begin{array}{l}13614-31 \\
13614-27\end{array}$ & $\begin{array}{l}1.15 \\
1.03\end{array}$ & $\begin{array}{l}0.84 \\
0.64\end{array}$ & $\begin{array}{l}0.72 \\
0.61\end{array}$ \\
\hline
\end{tabular}


and microstructure between the two untested materials does not seem to effect the corrosion and oxidation of the material.

\subsection{CEROX Coating and Ce Partitioning}

Each anode was cross-sectioned and the CEROX coating was examined. Low magnification photographs $(8 \mathrm{x})$ of the CEROX coating on each anode are shown in Figures 37 through 51. The coatings were generally 0.4 to $1.6 \mathrm{~mm}$ thick with elongated grains that radiate from the surface of the anode. In some cases, such as the anodes from tests 13614-29 and 13614-27, the coating on the tip of the anode was very thin. Many coatings were discontinuous, as shown in anodes from tests 13614-35, 13614-19, and 13614-25. When the coating was discontinuous, it was sometimes obvious that between CEROX clumps (where the anode was bare) that there was increased corrosion of the substrate. Some coatings such as those from tests 13614-21 and 13614-47, appeared very dense and continuous. In fact, the most dense appearing coating was found on the anode from test 13614-21. In some areas where CEROX is present, the interface with the substrate is irregular. This indicates that the CEROX has regrown on a corroded substrate.

The Ce-free anode is shown for comparison in Figure 52. Before testing, the anode was originally the same diameter as that from test 13614-21, but was tapered and oxidized after testing.

Ce partitioning $\left(\mathrm{Ce}_{\text {metal }} / \mathrm{Ce}_{\text {bath }}\right)$ between the bath and aluminum was calculated from ICP arialysis of the $c e$ in the bath and aluminum. An experiment in which bath and aluminum were melted for $3 \mathrm{~h}$ and then cooled and analyzed (no electrolysis, 1 wt: $\mathrm{CeF}_{3}$ in bath) showed a Ce partition coefficient of $2.7 \mathrm{wt} \% / 0.489 \mathrm{wt} \%=5.52$ at a BR of 1.5. Average Ce partitioning for Phase I (BR of 1.35) was $\sim 5.92$ and in Phase II short-term tests (BR of 1.05 to 1.4), was 6.88. In Phase III, $C e$ in the bath, metal, and Ce partitioning were examined versus $B R$ and $C D$. The Ce partitioning (Figure 53) shows a gradual trend toward higher partition coefficient at higher $\mathrm{BR}$.

The amount of $\mathrm{Ce}$ in the metal (Figure 54) ranges from $\sim 1.5$ to $\sim 2.4$ wto. There appears to be a small increase in Ce in the metal with BR. The $\mathrm{Ce}$ in the bath (Figure 55) ranges from 0.15 to 0.23 wt: There may be a trend toward a slight decrease in ce in the bath at higher BR.

Equation (17) describes the transfer of ce between the bath and the Al giving

$\mathrm{CeF}_{3}+\mathrm{Al}=\mathrm{AlF}_{3}+\mathrm{Ce}$.

As BR increases and the amount of $\mathrm{AlF}_{3}$ decreases, the amount of metaliic Ce would be expected to increase, as observed in Phase III experiments. 


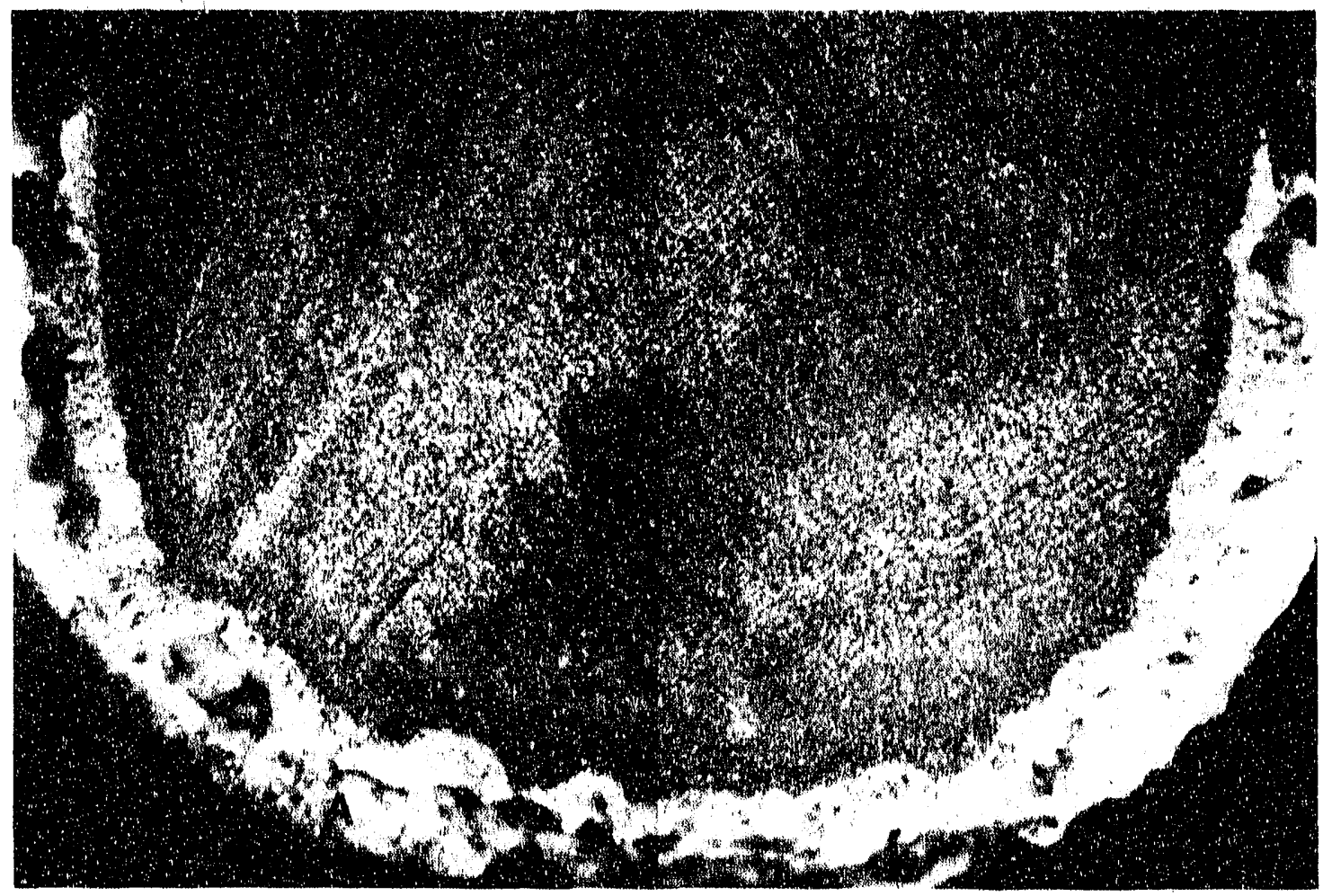

Figure 37. Anode from test $13614-51,0.5 \mathrm{~A} / \mathrm{cm}^{2}, \mathrm{BR}=1.5$ (8X). Note the crusting around the tip of the anode (A).

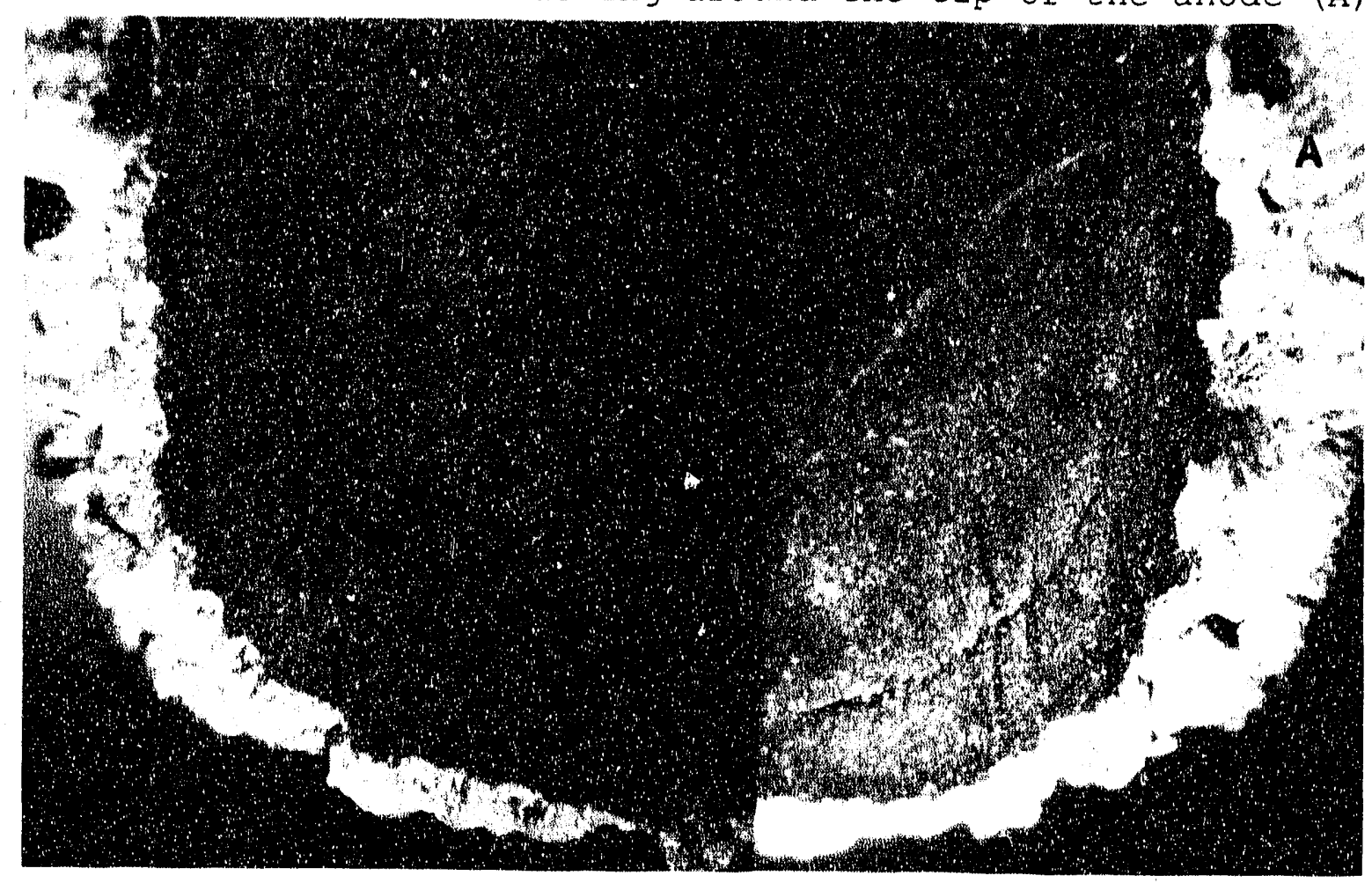

Figure 38. Anode from test $13614-53,0.5 \mathrm{~A} / \mathrm{cm}^{2}, \mathrm{BR}=1.5$ (8X). Some crusting is present near the meltiine. 


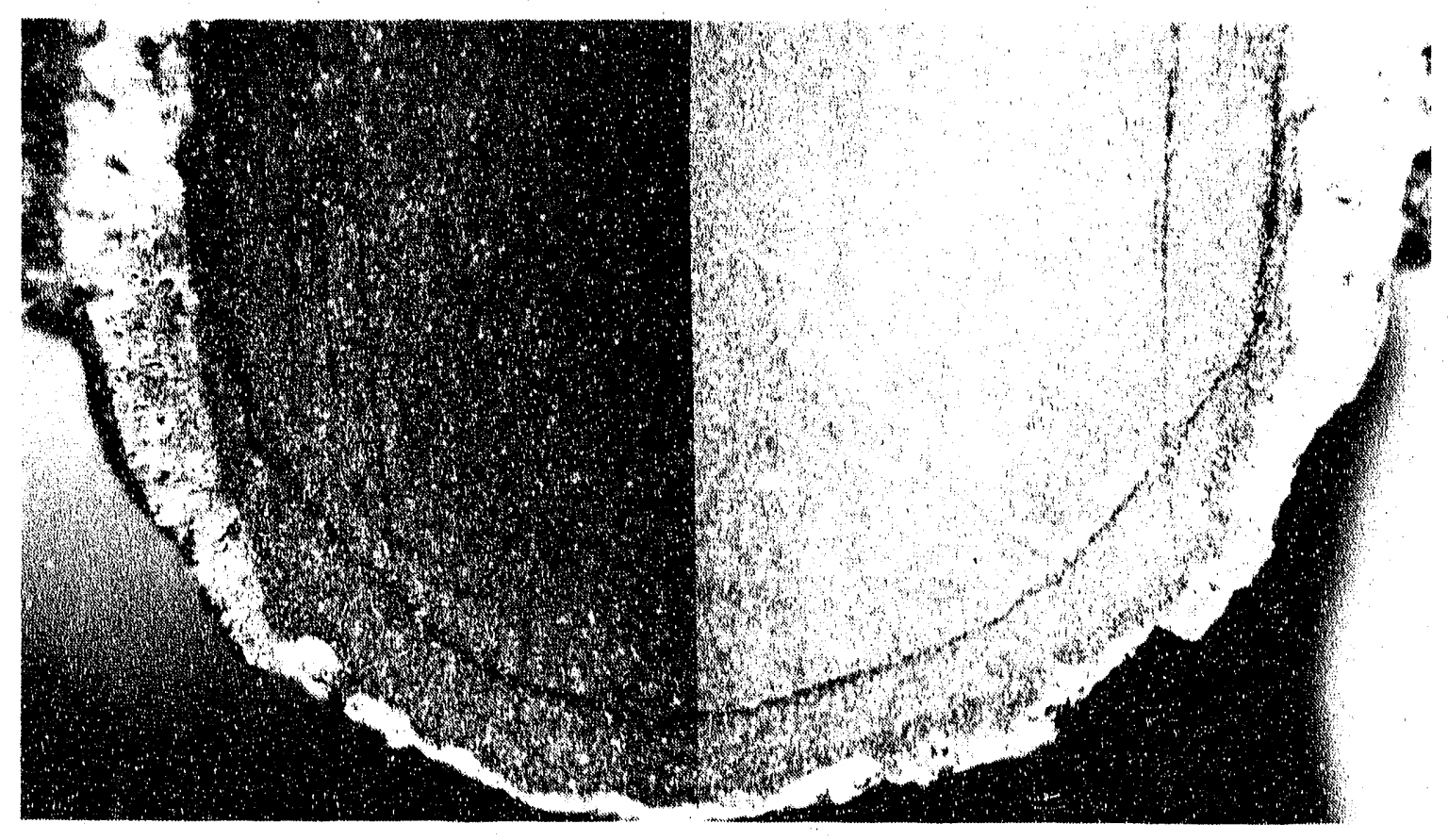

Figure 39. Anode from test $13614-49,0.7 \mathrm{~A} / \mathrm{cm}^{2}, \mathrm{BR}=1.5$ ( $\left.8 \mathrm{X}\right)$.

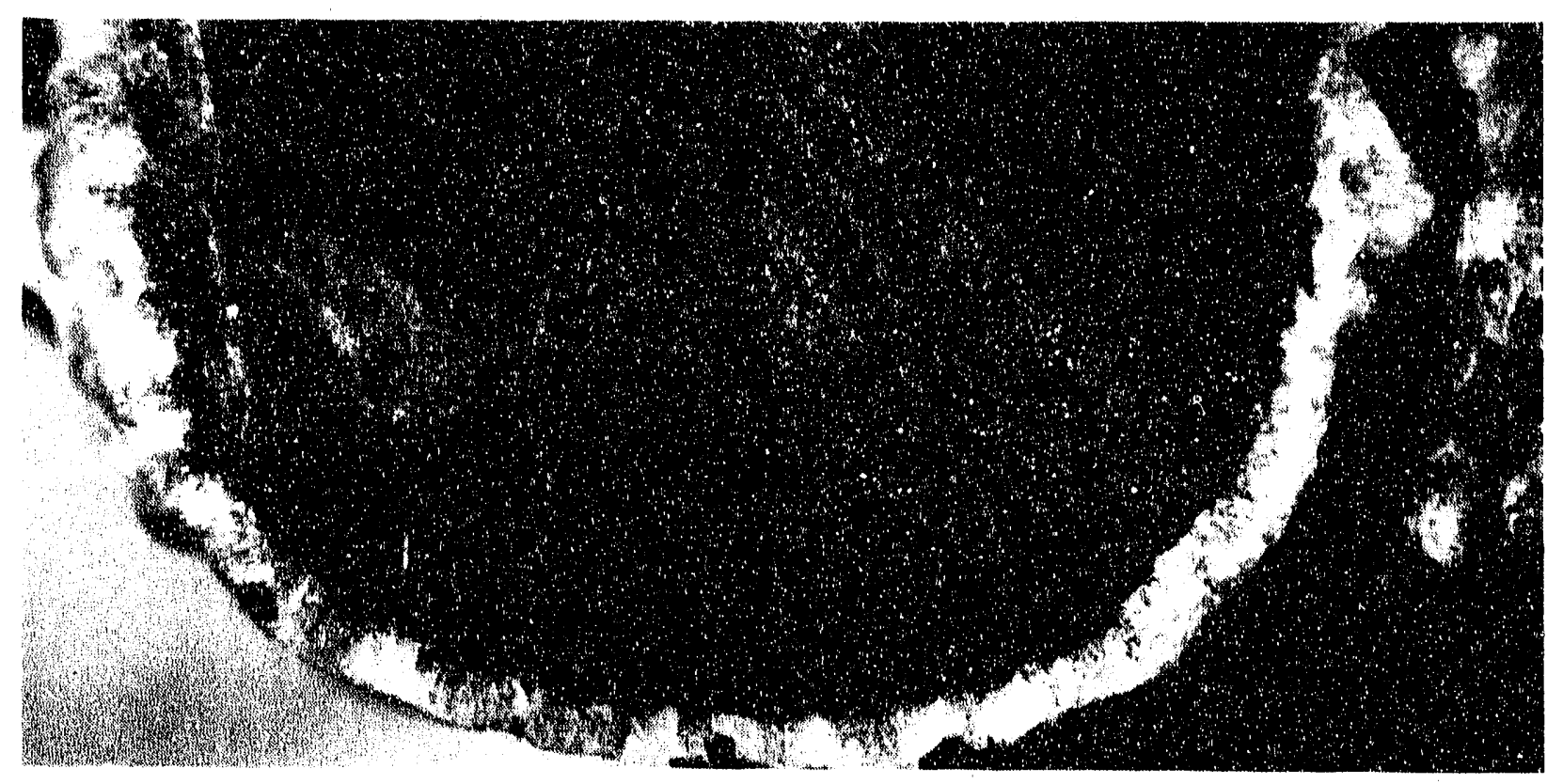

Figure 40. Anode from test $13614-47,1.0 \mathrm{~A} / \mathrm{cm}^{2}, \mathrm{BR}=1.6$ (8X). 


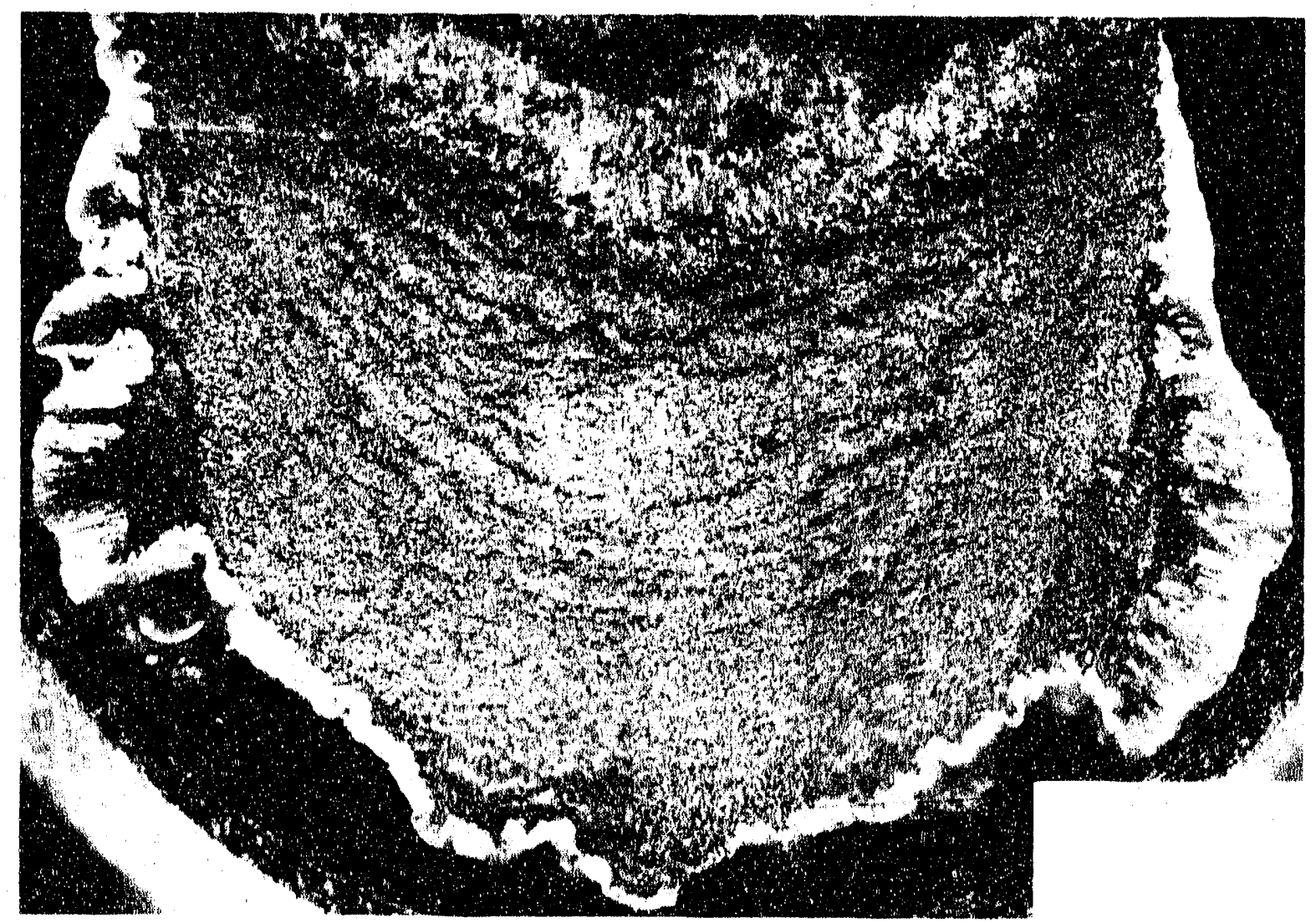

Figure 41. Anode from test $13614-29,1.3 \mathrm{~A} / \mathrm{cm}^{2}, \mathrm{BR}=1.4$ (8X).

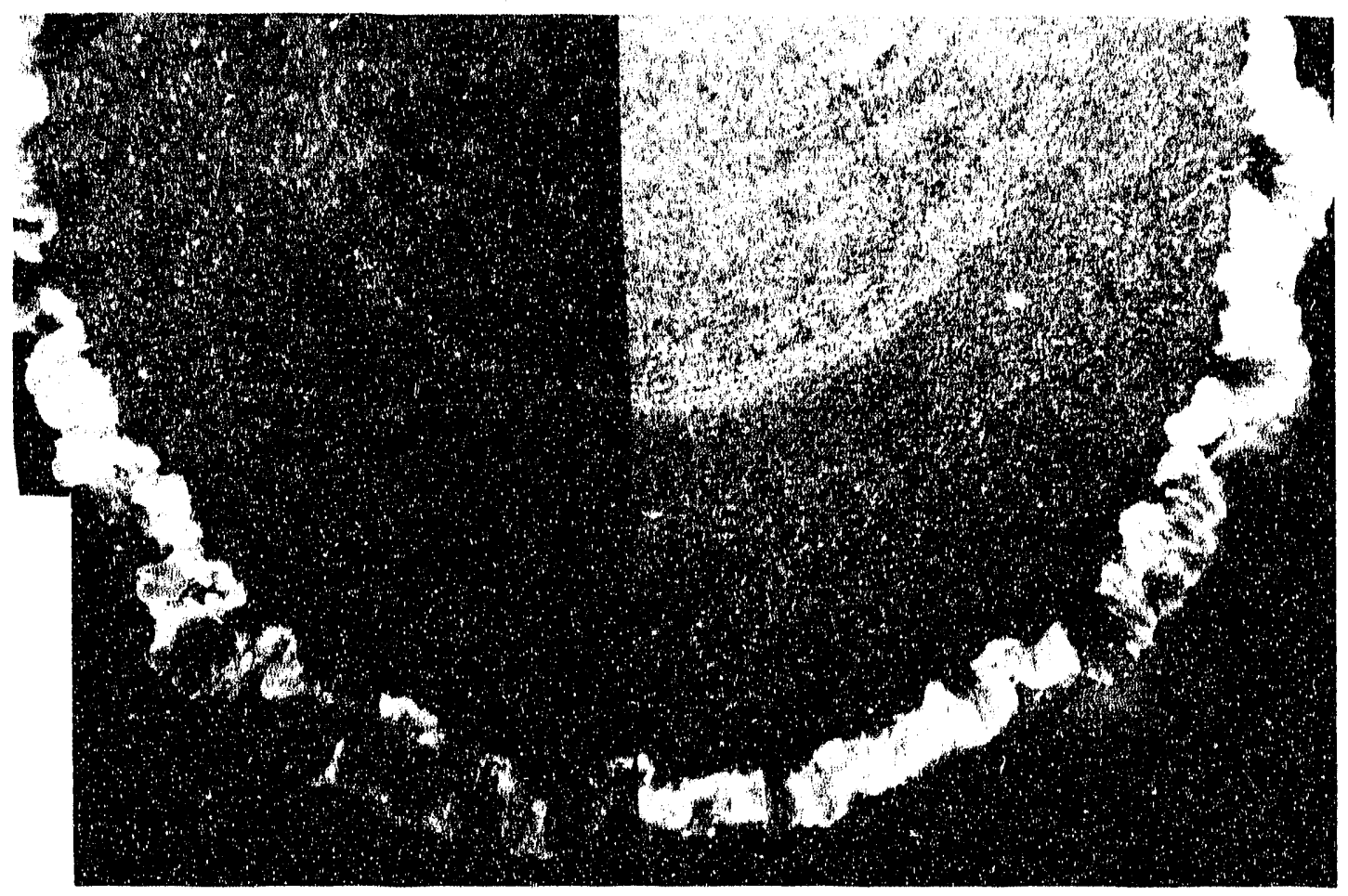

Figure 42. Anode from test $13614-35,1.3 \mathrm{~A} / \mathrm{cm}^{2}, \mathrm{BR}=1.5$ (8X). 


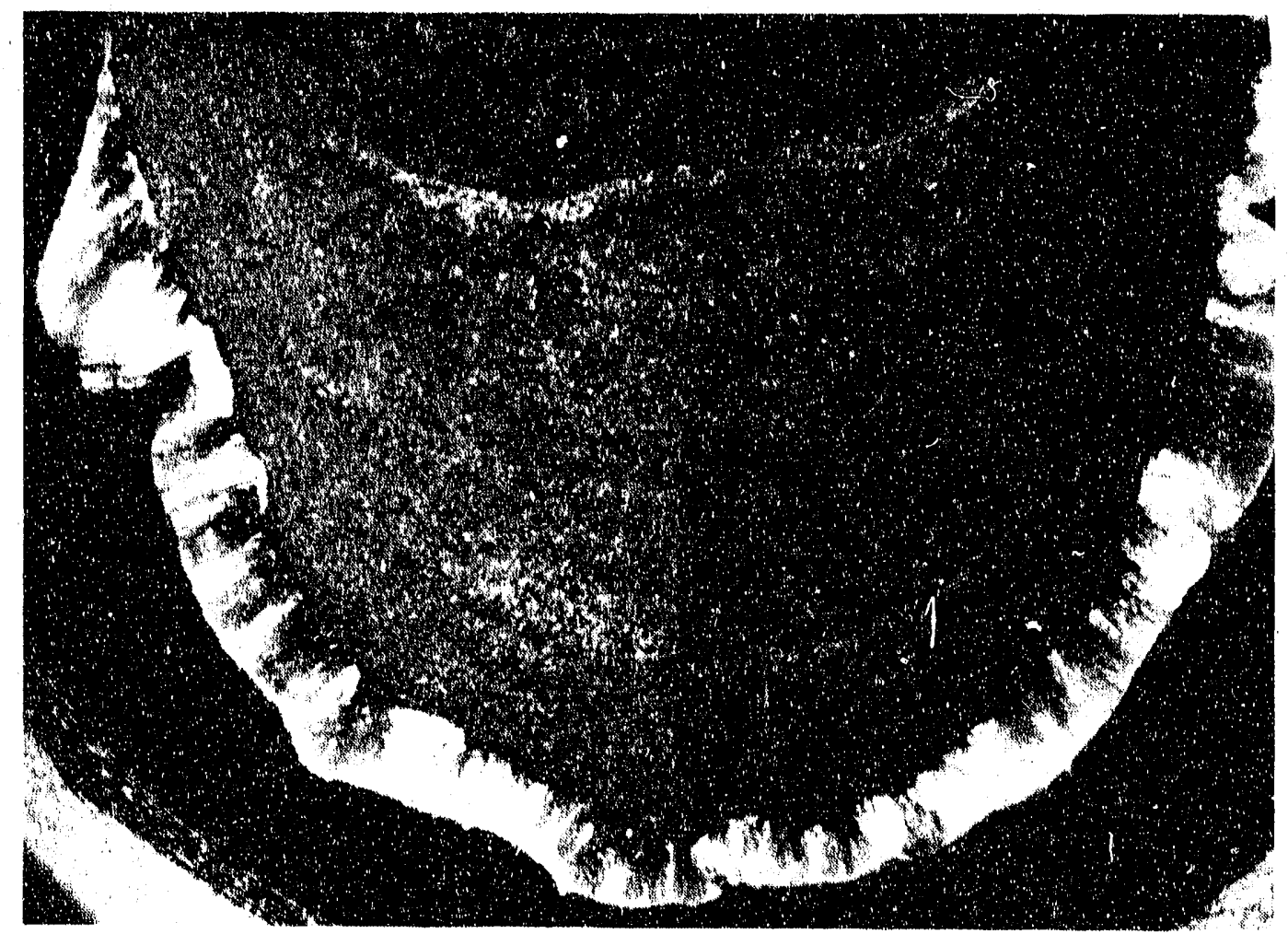

Figure 43. Arode from test $13614-21,1.3 \mathrm{~A} / \mathrm{cm}^{2}, \mathrm{BR}=1.6$ (8X).

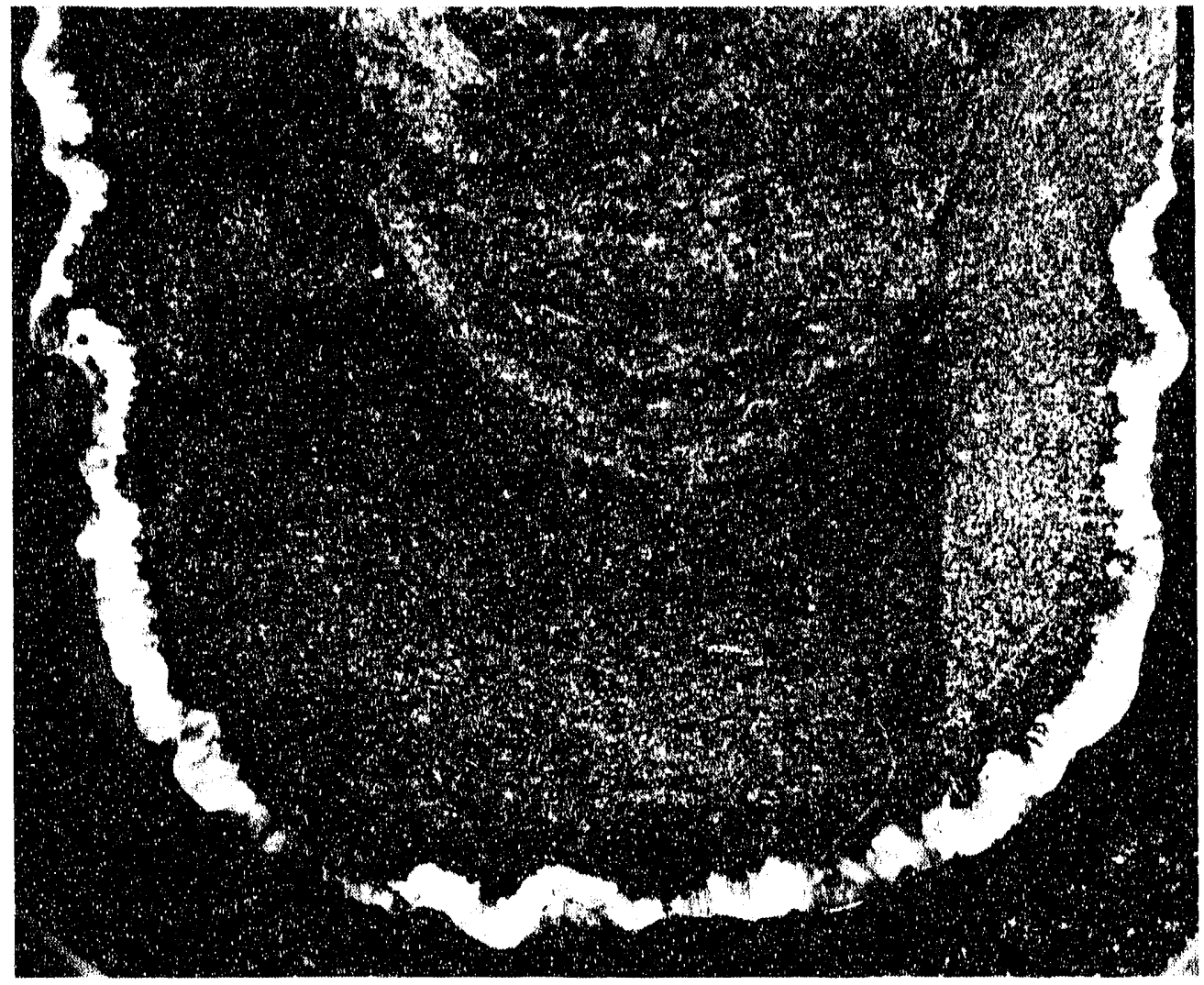

Eigure 44. Anode from test $13614-31,1.3 \mathrm{~A} / \mathrm{cm}^{2}, \mathrm{BR}=1.7$ (8X). 


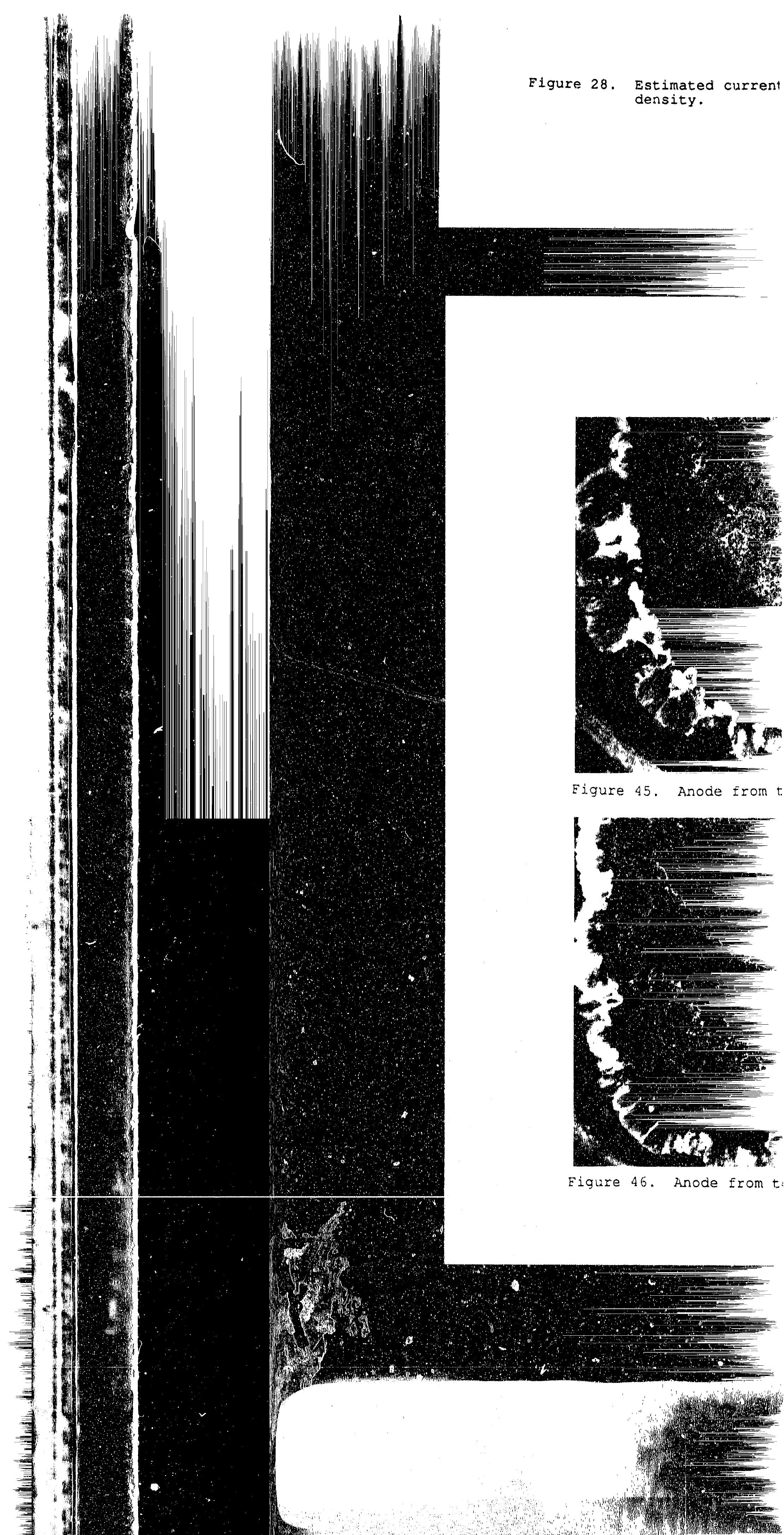




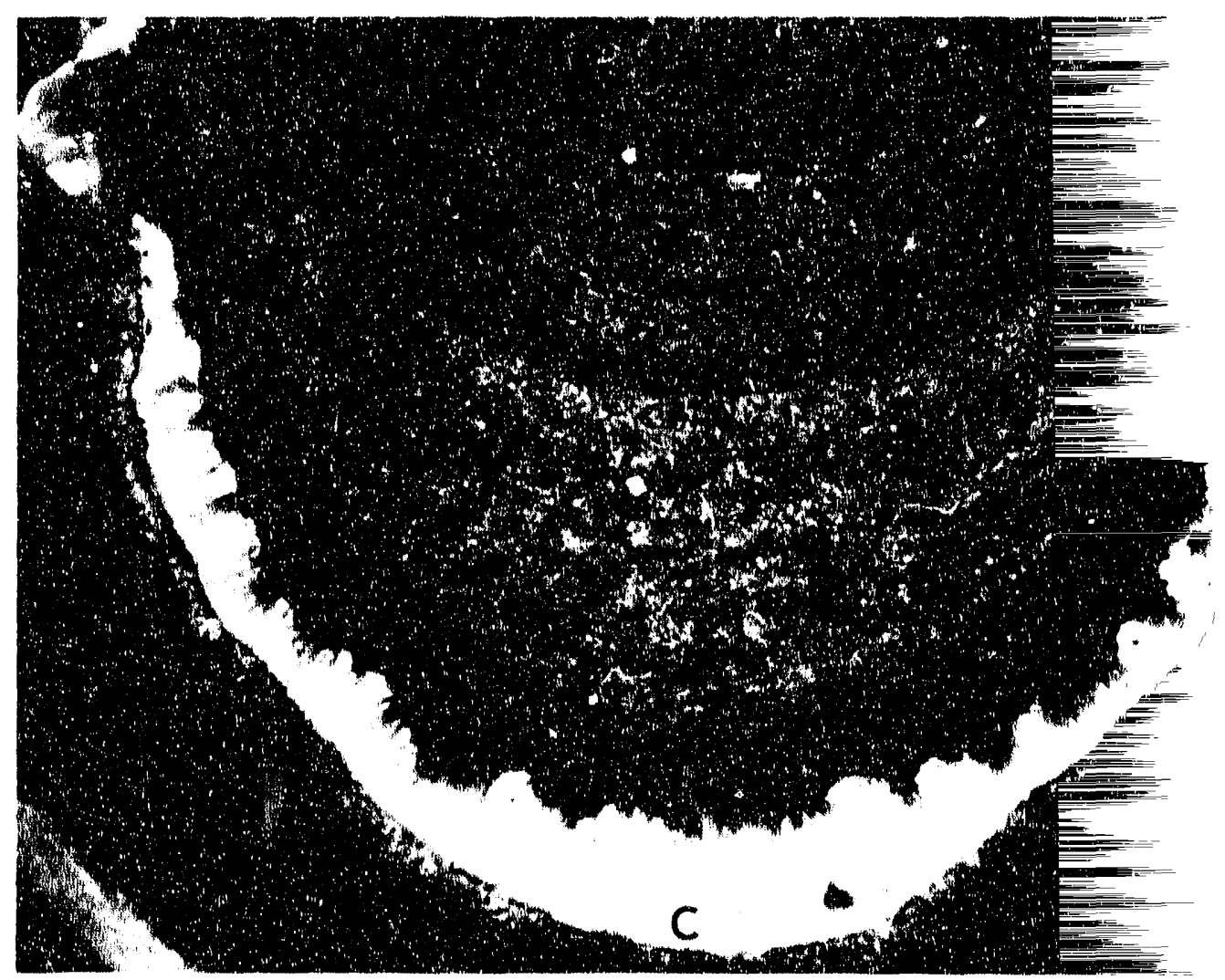

Eigure 47. Anode from test $13614-39,1.6 \mathrm{~A} / \mathrm{cm}^{2}, B R=1$ Some cryolite (C) adhered to the tip of upon removal from the melt.

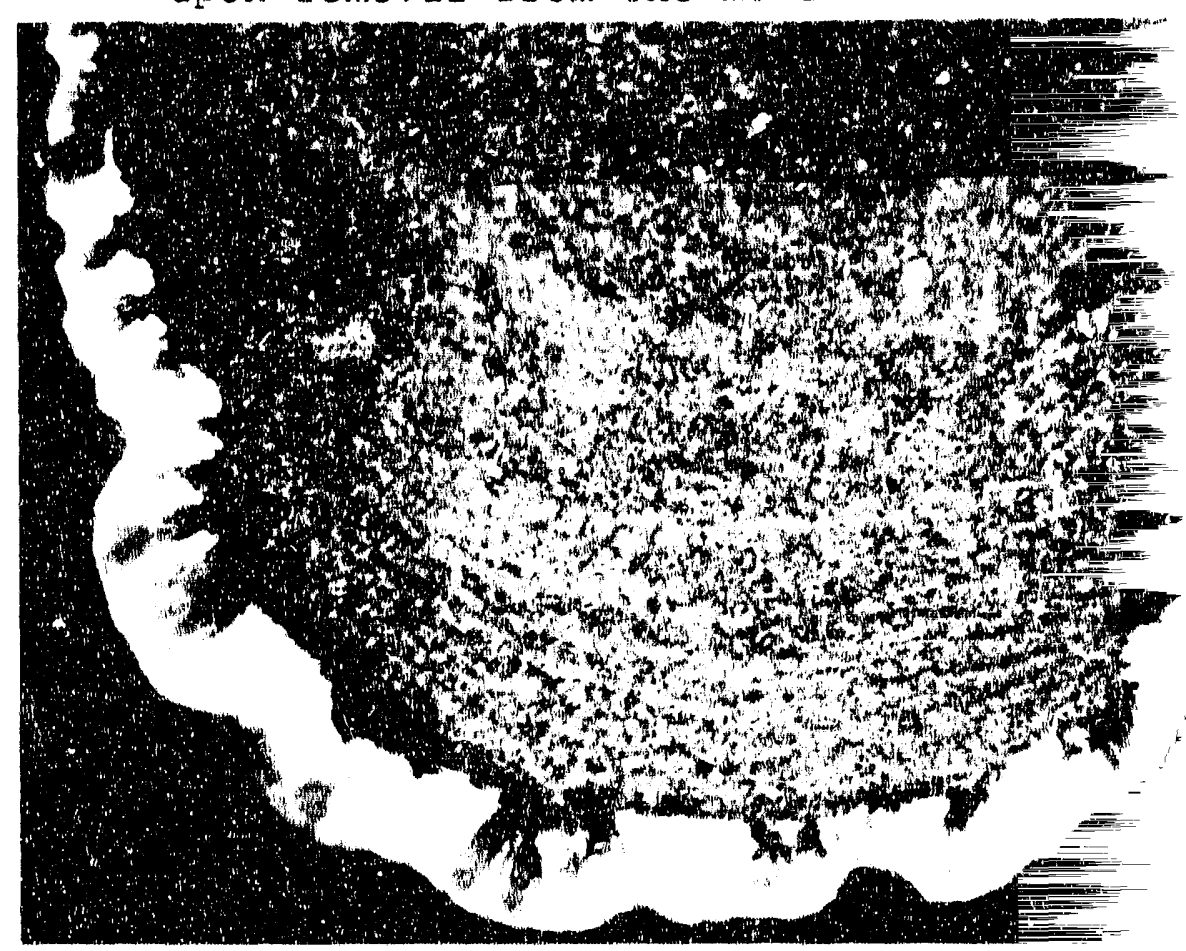

Eigure 48. Anode from test $13614-37,1.6 \mathrm{~A} / \mathrm{cm}^{2}$, 


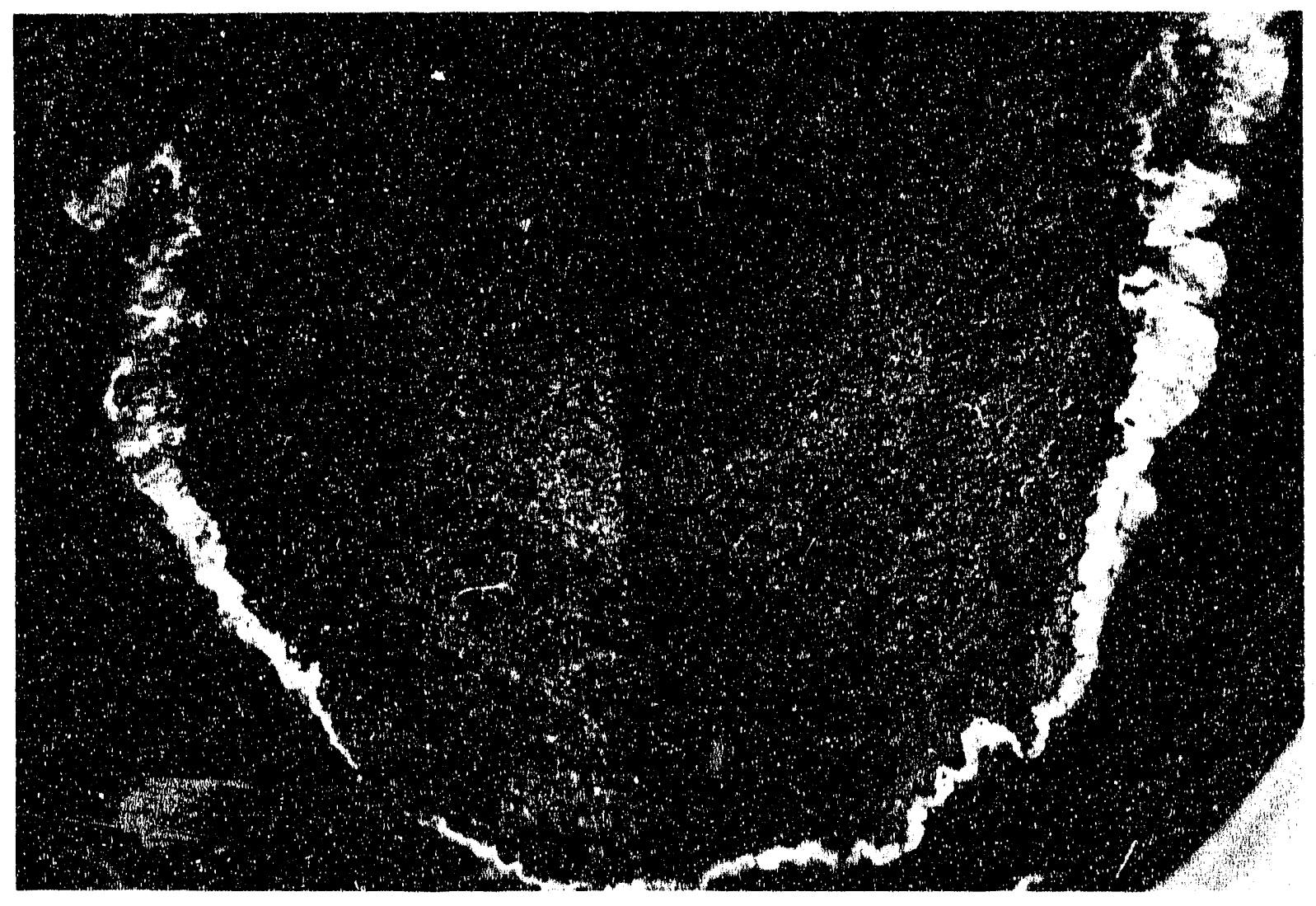

Eigure 49. Anode from test $13614-27,1.6 \mathrm{~A} / \mathrm{cm}^{2}, B R=1.7$ ( $\left.8 X\right)$. 


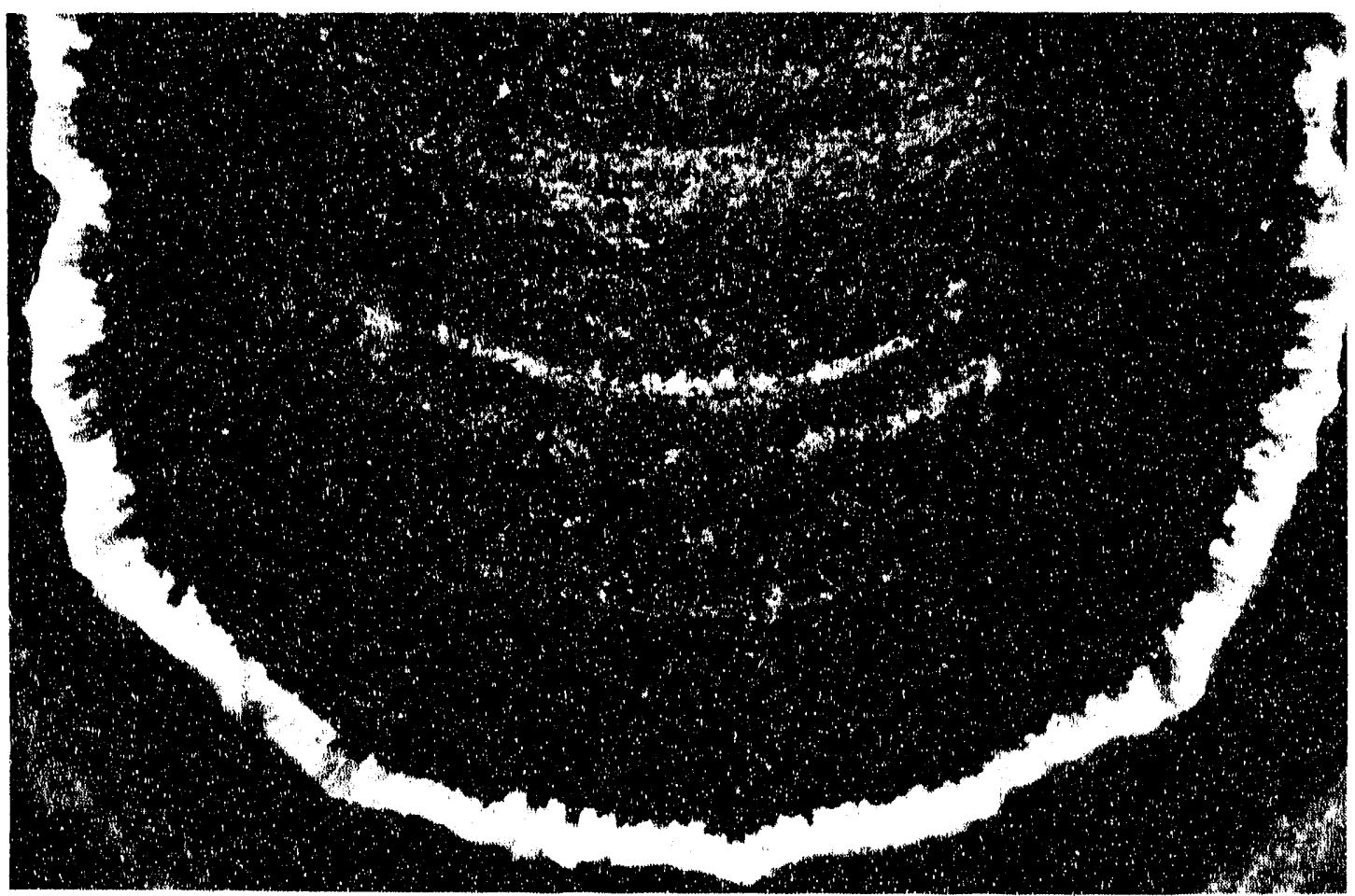

Eigure 50. Anode from test $13614-41,1.9 \mathrm{~A} / \mathrm{cm}^{2}, \mathrm{BR}=1.4$ (8X).

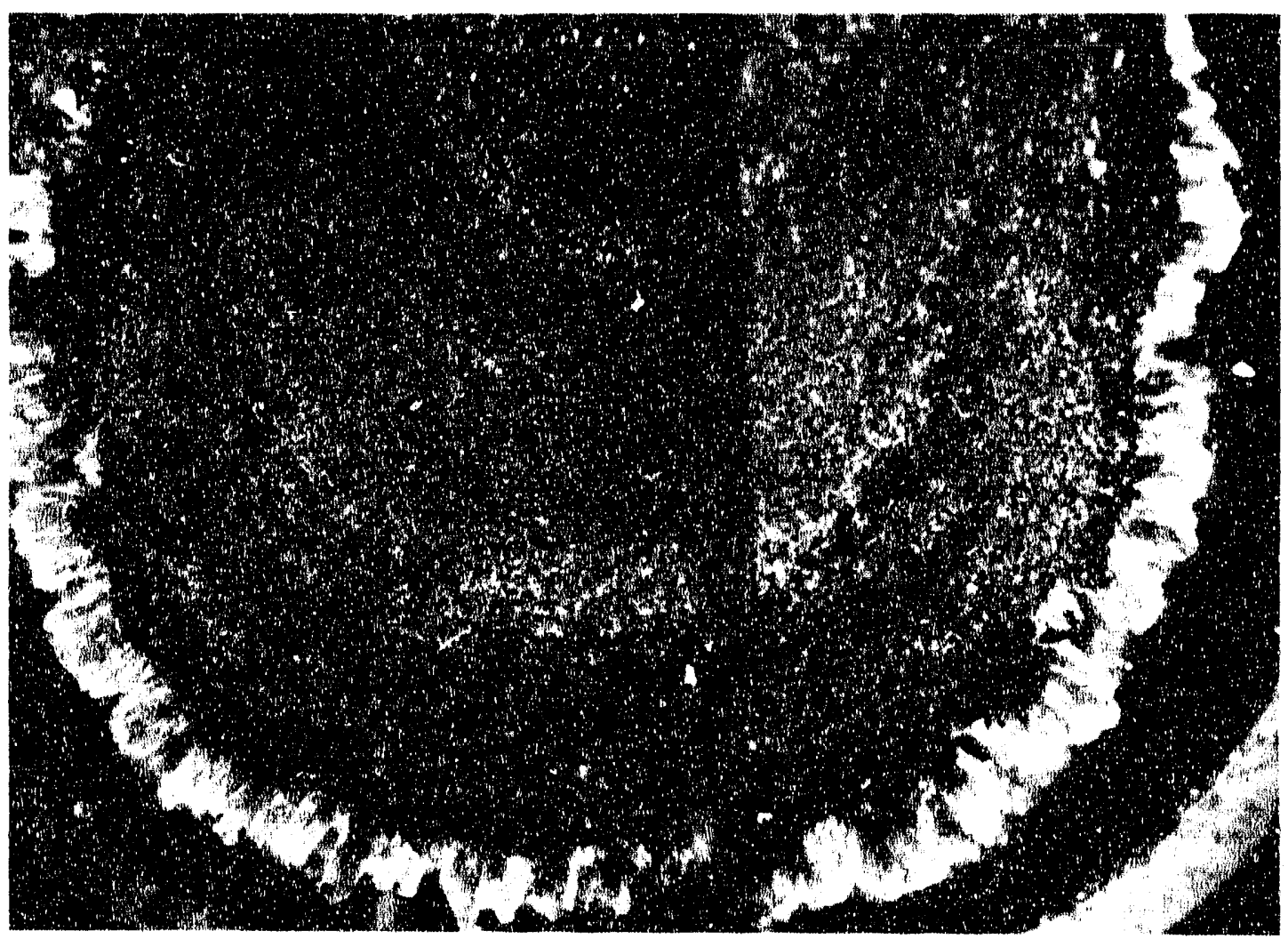

Eigure 51. Anode from test $13614-15,1.9 \mathrm{~A} / \mathrm{cm}^{2}{ }_{p} \mathrm{BR}=1.6$ (8X). 


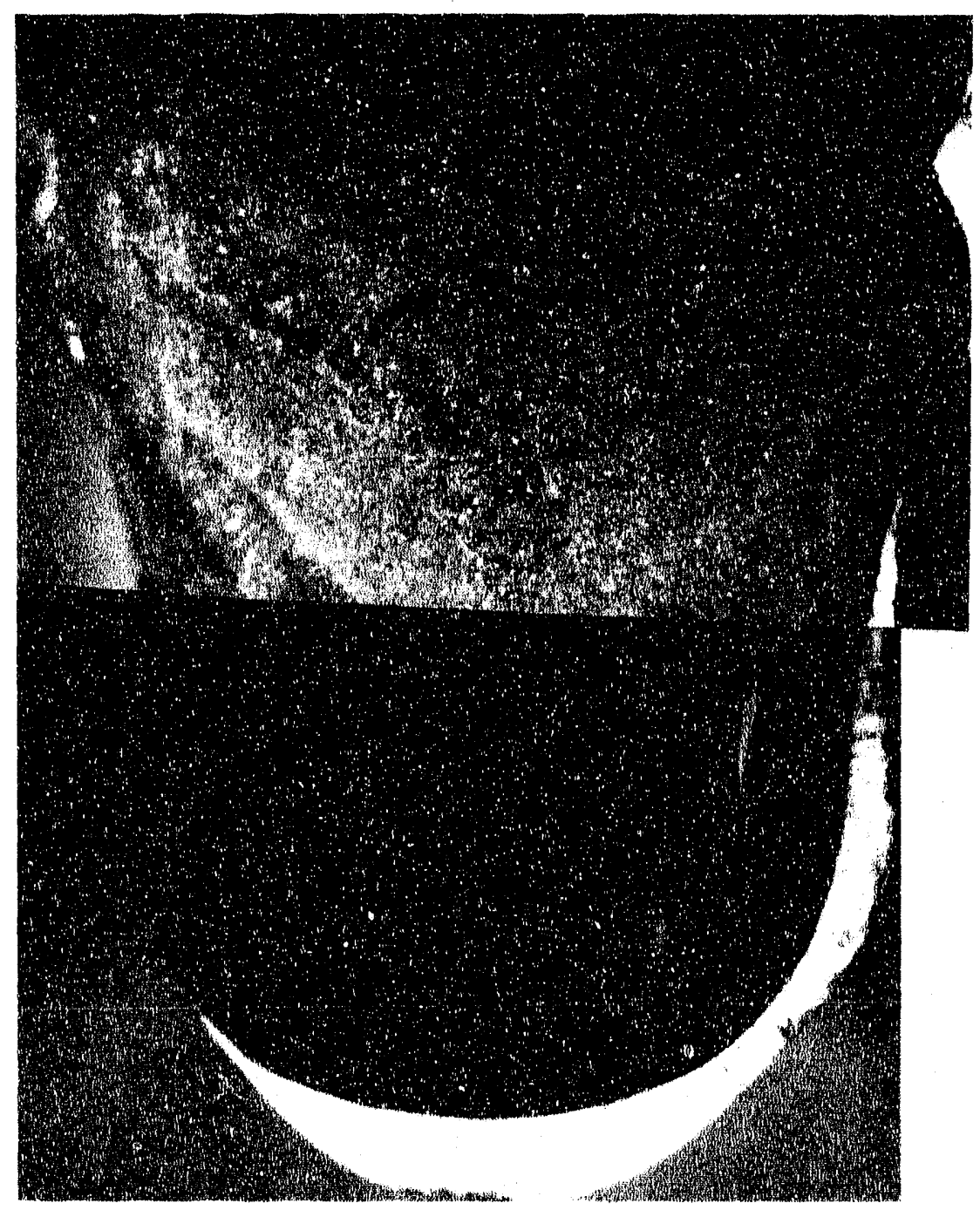

Figure 52. Anode from test $13614-45,1.3 \mathrm{~A} / \mathrm{cm}^{2}, \mathrm{BR}=1.6$ (8X). This anode was operated without $\mathrm{Ce}$ in the bath. 

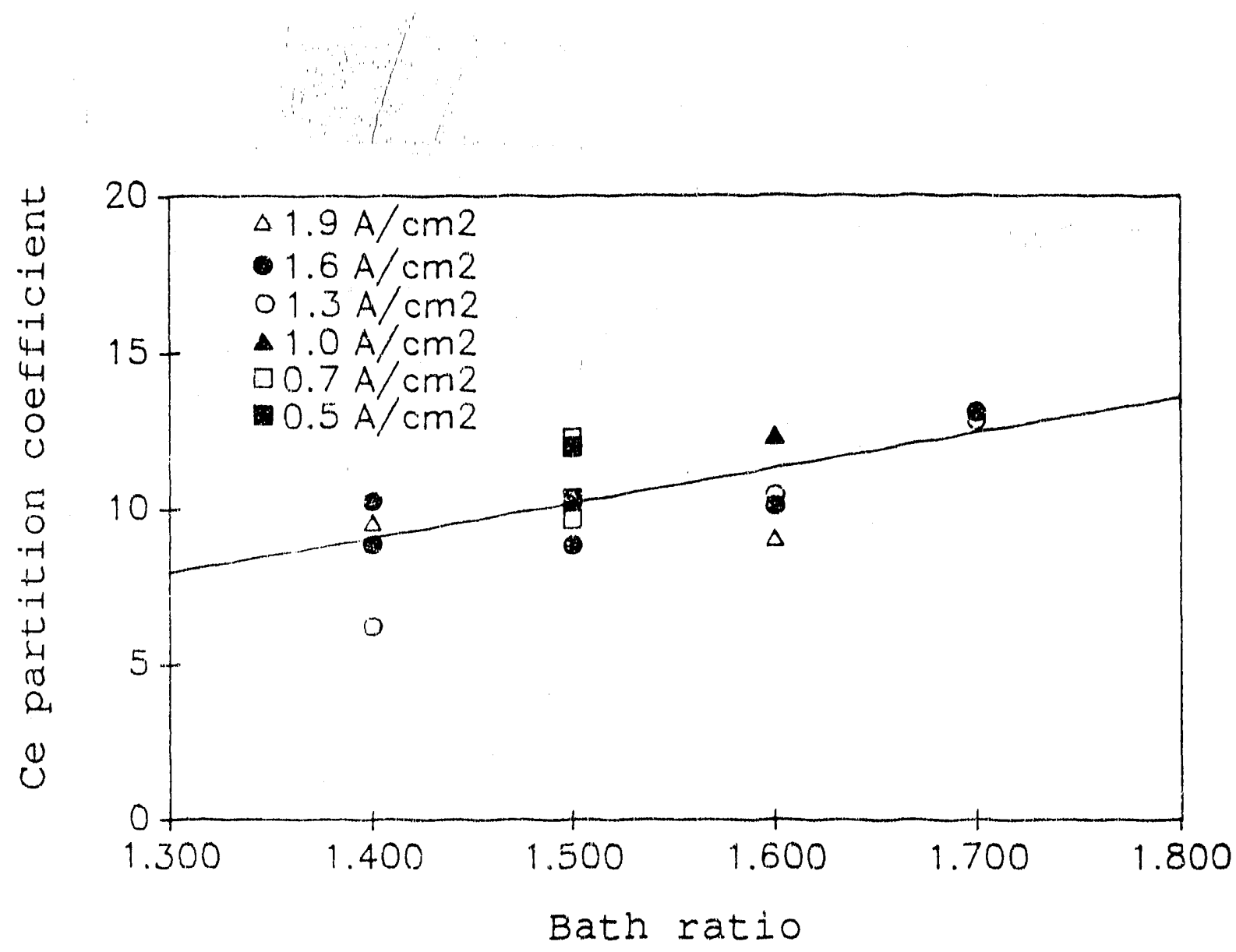

Figure 53. Cerium partition coefficient as a function of BR. 


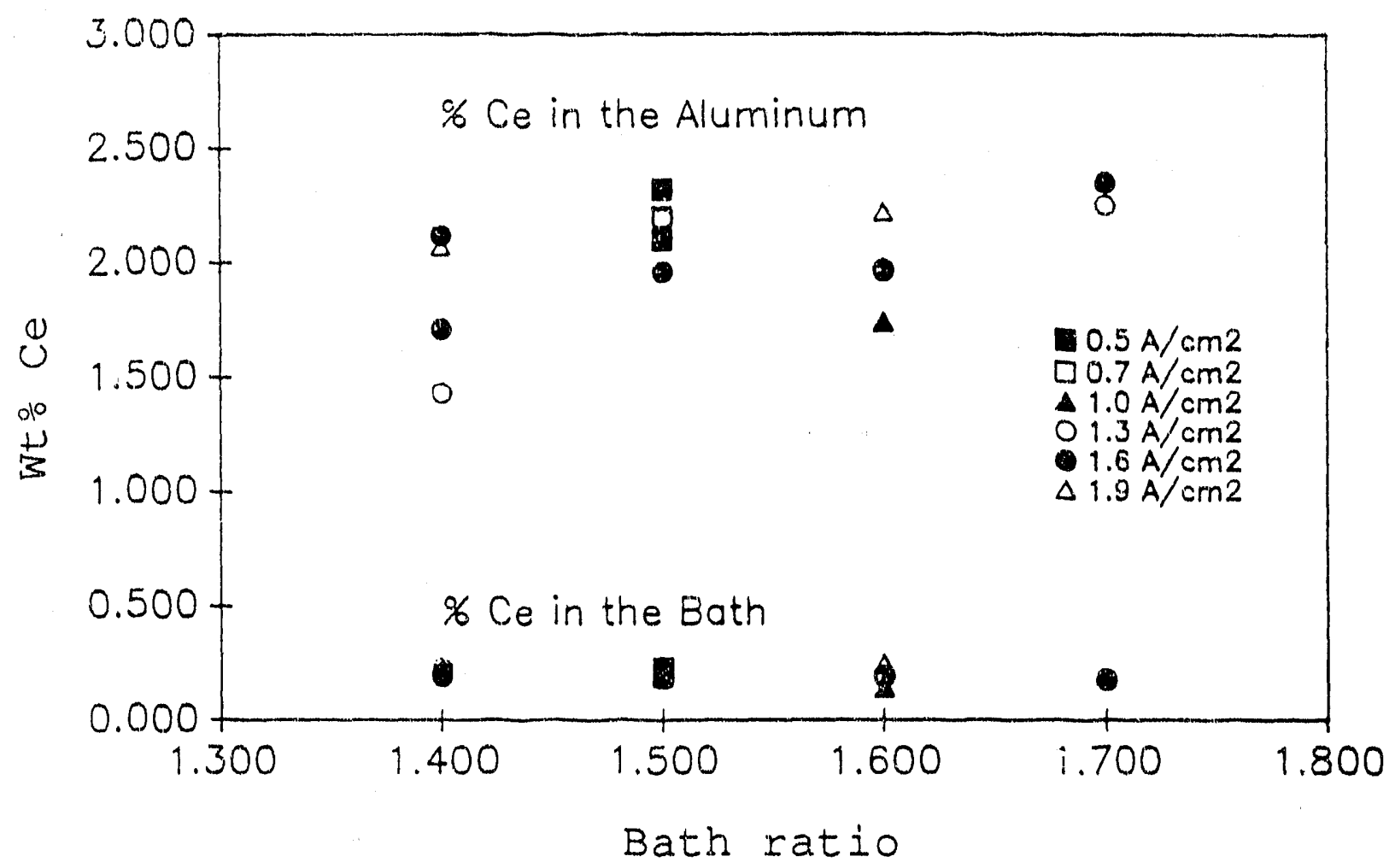

Figure 54. Weight percent $C e$ in the Al and bath as a function of $B R$.

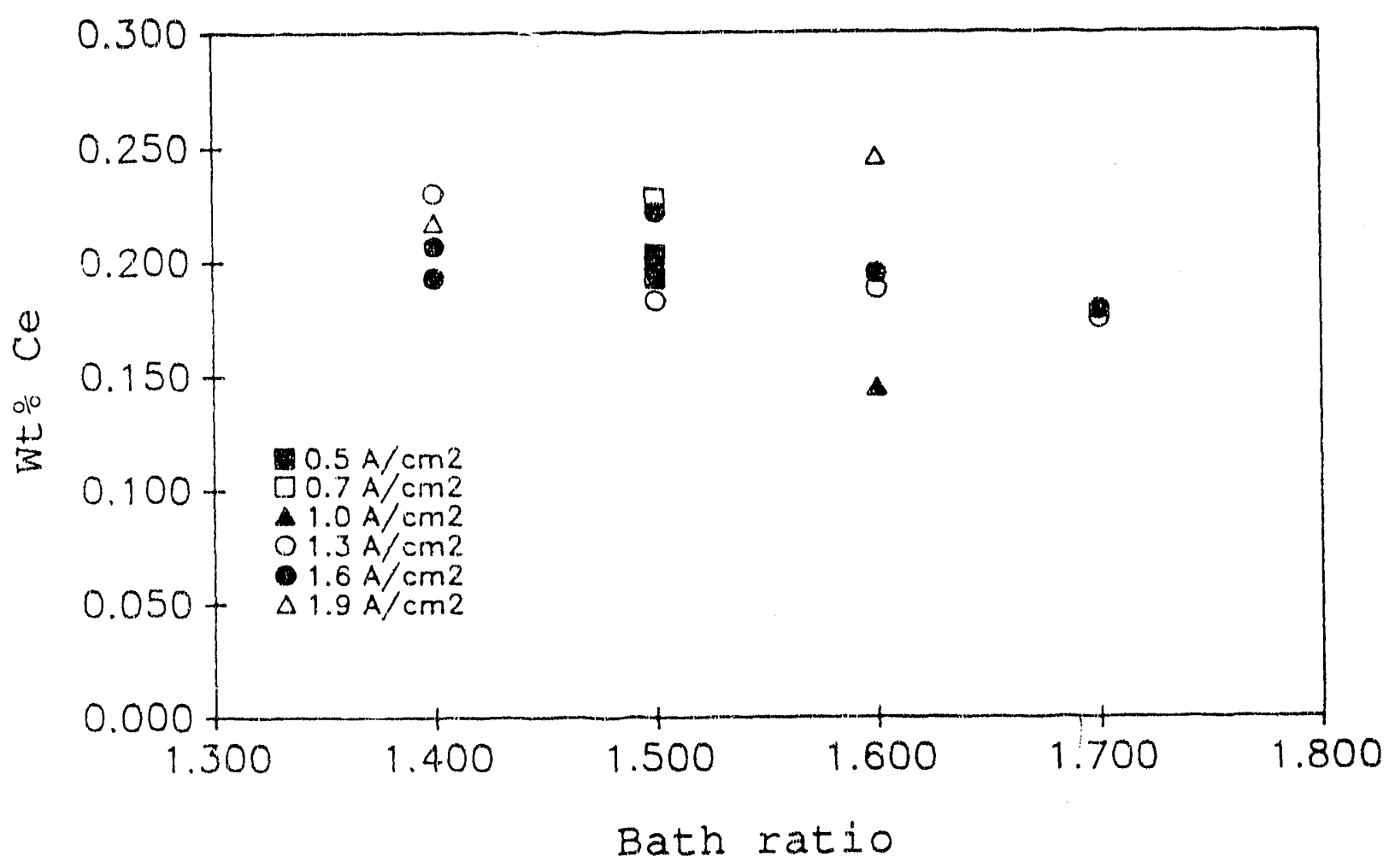

Eigure 55. Weight percent ce in the bath as a function of BR. 
In addition

$2 \mathrm{CeF}_{3}+4 / 3 \mathrm{Al}_{2} \mathrm{O}_{3}=2 \mathrm{CeO}_{2}+2 \mathrm{AlF}_{3}+2 / 3 \mathrm{Al}$

predicts that as the $\mathrm{BR}$ increases and $\mathrm{AlF}_{3}$ decreases, more $\mathrm{CeO}_{2}$ should form. Thus, a high $B R$ should increase the amount of CEROX coating being formed. Both reactions predict that the amount of $\mathrm{Ce}$ in the bath should be lowest at a high BR, as Ce is preferentially found in the coating $\left(\mathrm{CeO}_{2}\right)$ and $\mathrm{Al}$ metal (Ce).10

\section{6 SEM/EDX Analysis}

The anodes from the five lowest corrosion tests were crosssectioned and examined by optical microscopy and SEM/EDX analysis. The anodes, in order of increasing total corrosion, were from tests $13614-53$ (BR 1.5, CD 0.5), 13614-49 (BR 1.5, CD 0.7), 13614-21. ( $B R$ 1.6, $C D$ 1.3), 13614-35 (BR 1.5, $C D$ 1.3), and 13614-41 (BR 1.4, CD 1.9).

The CEROX lating quality varies considerably between the five anodes. Si: j.crographs of the CEROX on each is shown in Figures 56 through 65 . (n the anode from test 13614-53, the CEROX coating is 0.7 to $1 \mathrm{~mm}$ thick. It is fairly dense with some elongated pores. The exterior surface of the coating is irregular. The interface with the substrate is also irregular.

The coating the anode from test $13614-49$ is very thin and appears discontinuous on the bottom of the anode. On the sides of the anode, the coating becomes more continuous and is up to $1 . \mathrm{mm}$ thick. The interface with the substrate is irregular and a porous zone $\sim 50$ microns thick is present in the substrate next to the CEROX coating. The CEROX coating consists of rounded grains on the substrate surface.

The CEROX coating ( 1 mm thick) on the anode from test 13614-21 is the densest and most continuous coating seen on any anode. The coating surfice is smooth and very few pores are present in the coating; those that are appear to be closed pores, not extending from the substrate to the bath. The interface between the CEROX and substrate is smoother than in other samples but still has some irregularities.

On the anode from test 13614-35, it is evident that the CEROX coating provides protection where it is present (Figure 62) and regrows in areas that have been corroded. The interface with the substrate is very irregular, but some CEROX coating appears to cover most of the substrate surface. The thickness of the coating greatly varies, from $1.1 \mathrm{~mm}$ in thick areas to $0.1 \mathrm{~mm}$ in thin areas.

In the anode from test 13614-41, the CEROX coating appears less continuous and consists of elongated radiating grains with cryolite penetrating to the substrate between the CEROX grains. The coating 


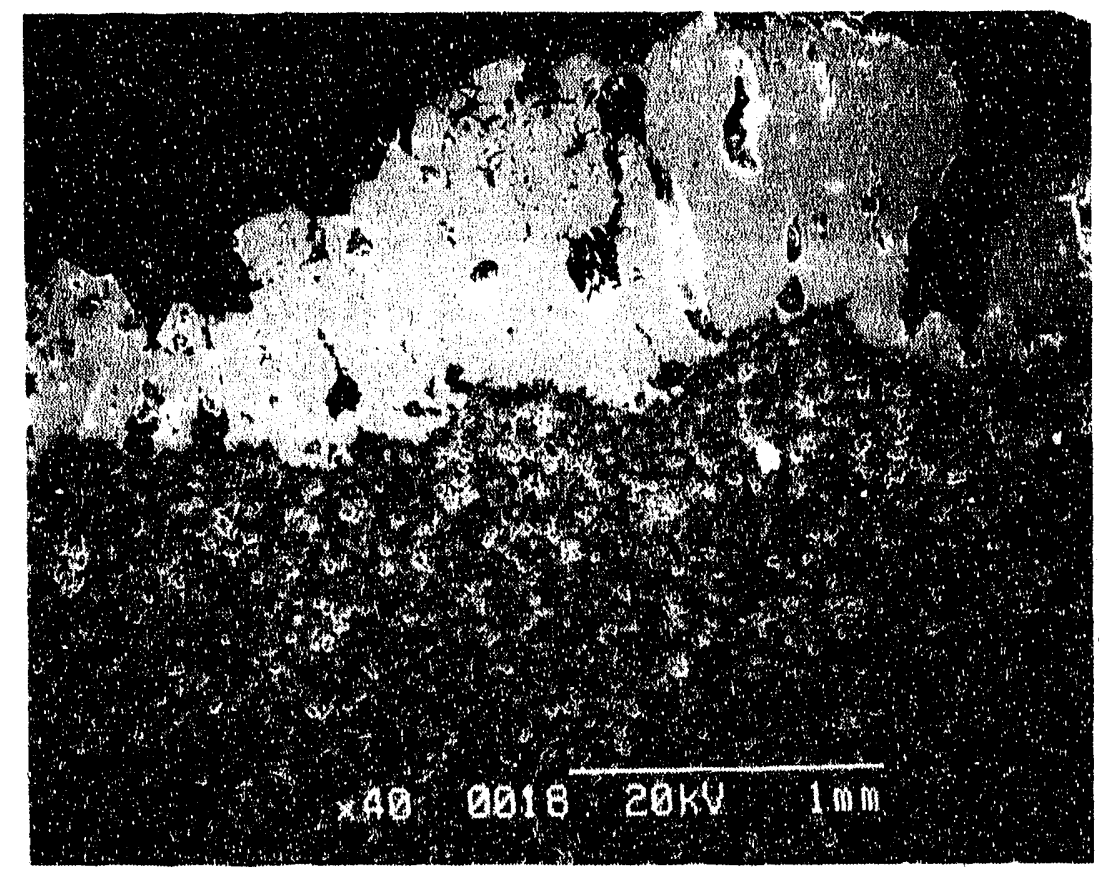

Figure 56. CEROX on the anode from test 13614-53 (40X).

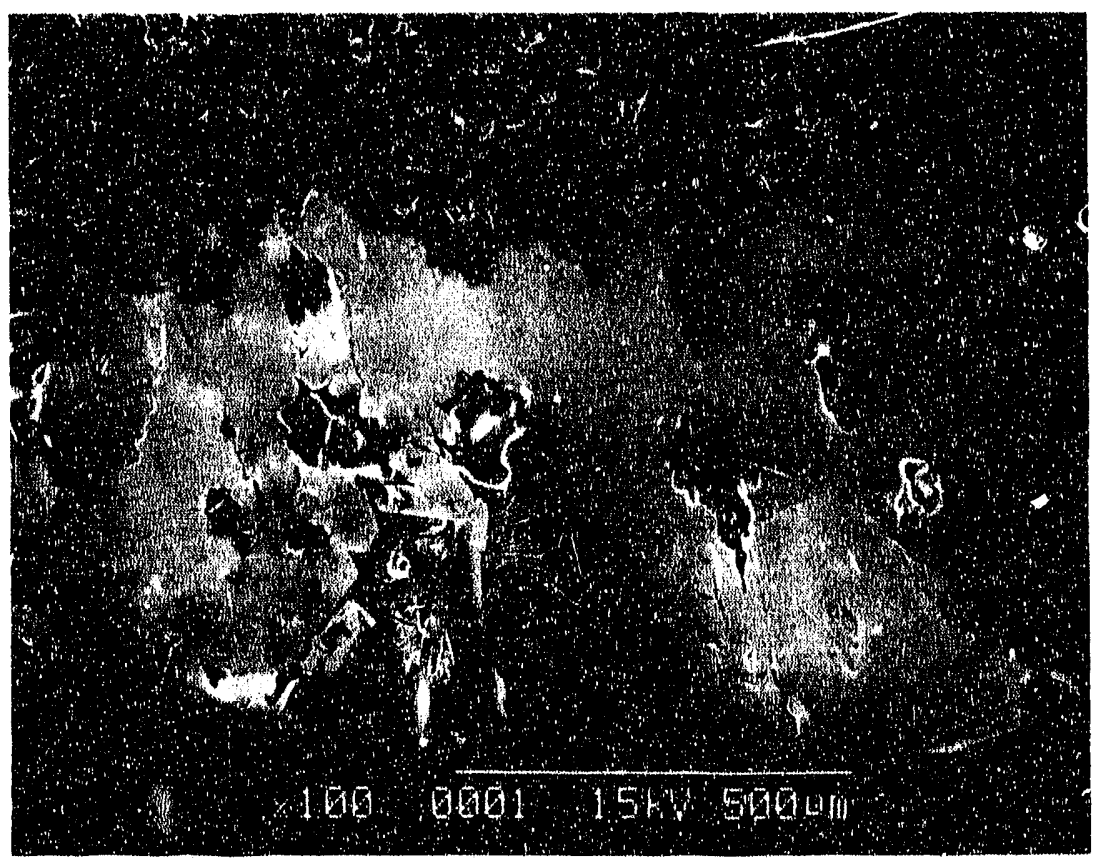

Figure 57. Hiaher magnification of the CEROX coating on the anode from test $13614-53$ (100X). 


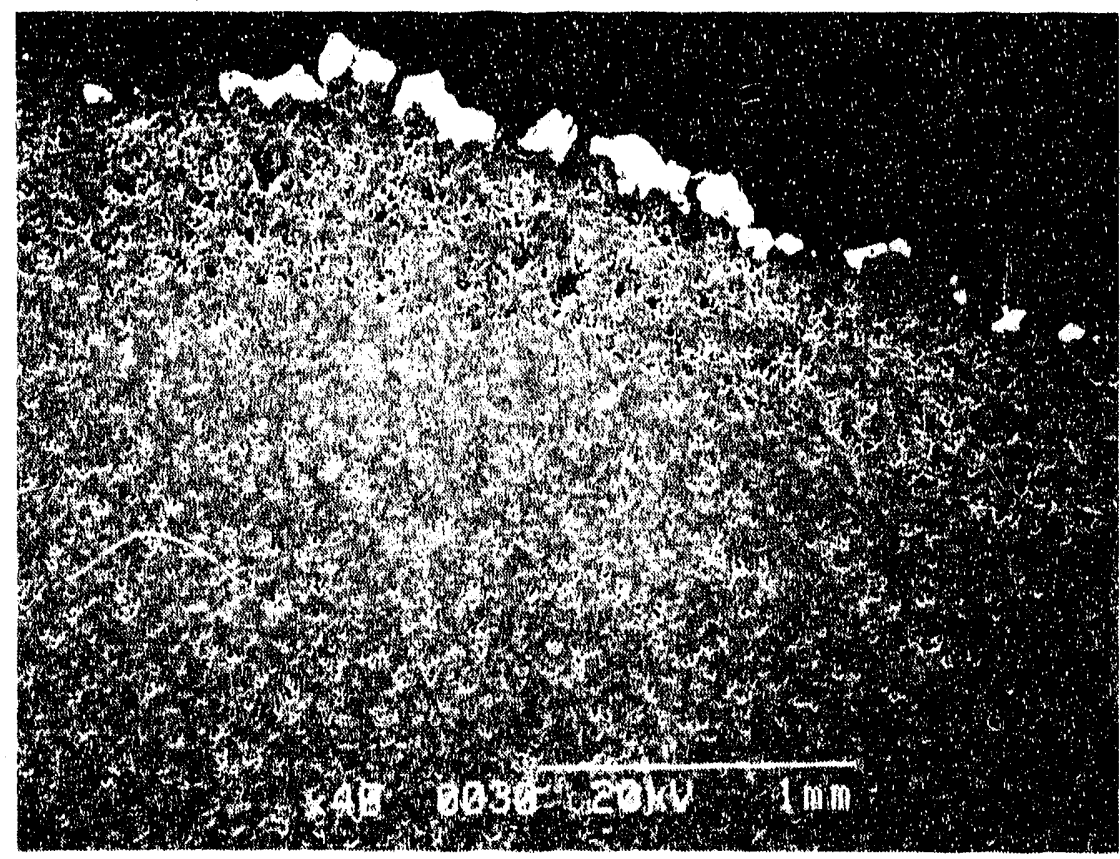

Figure 58. CEROX on the anode from test 13614-49 (40X).

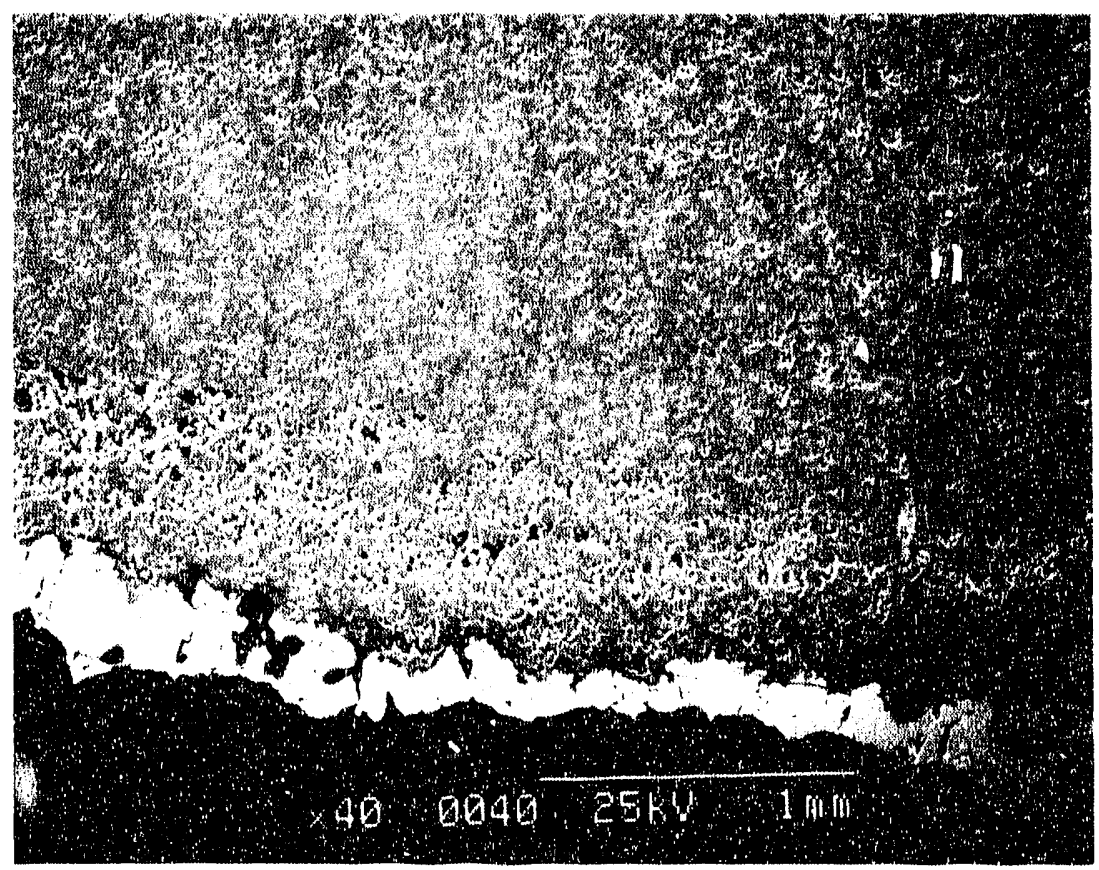

Eigure 59. Higher magnification of the CEROX coating on the anode from test 13614-49 (100X). 


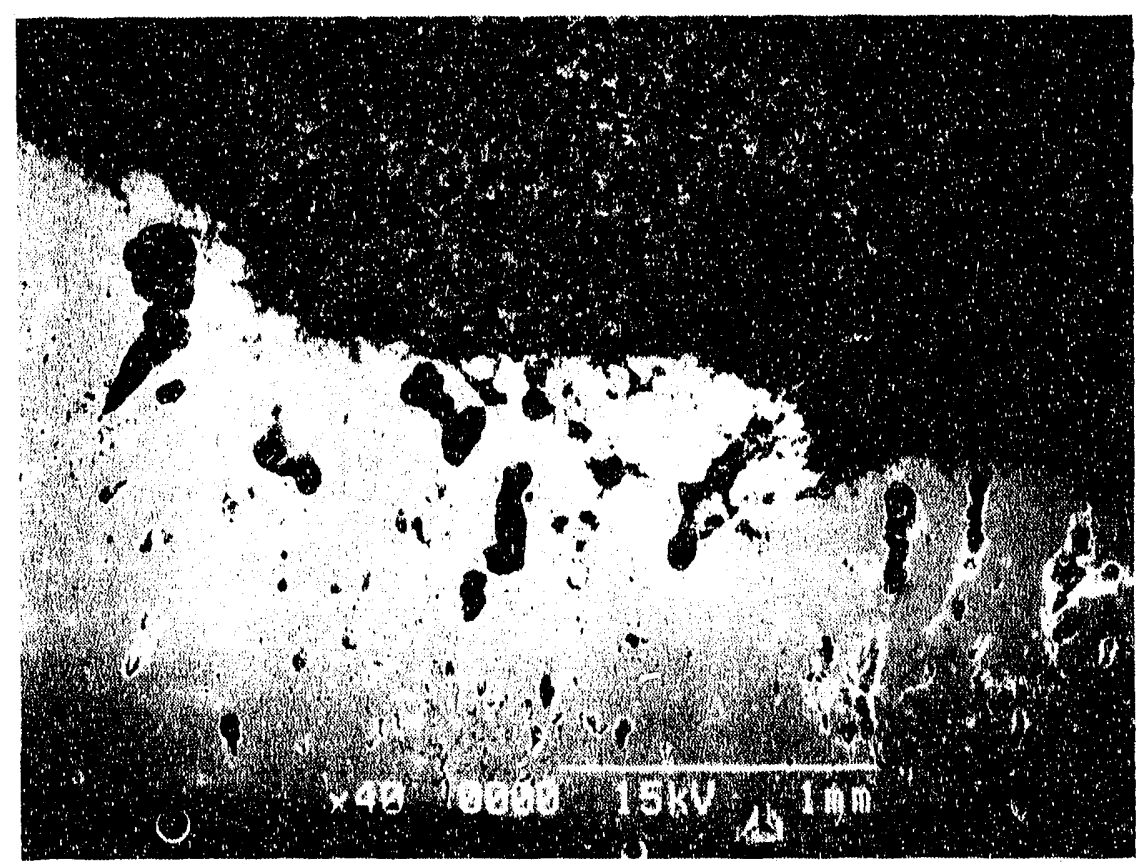

Eigure 60. CEROX on the anode from test 13614-21 (40X).

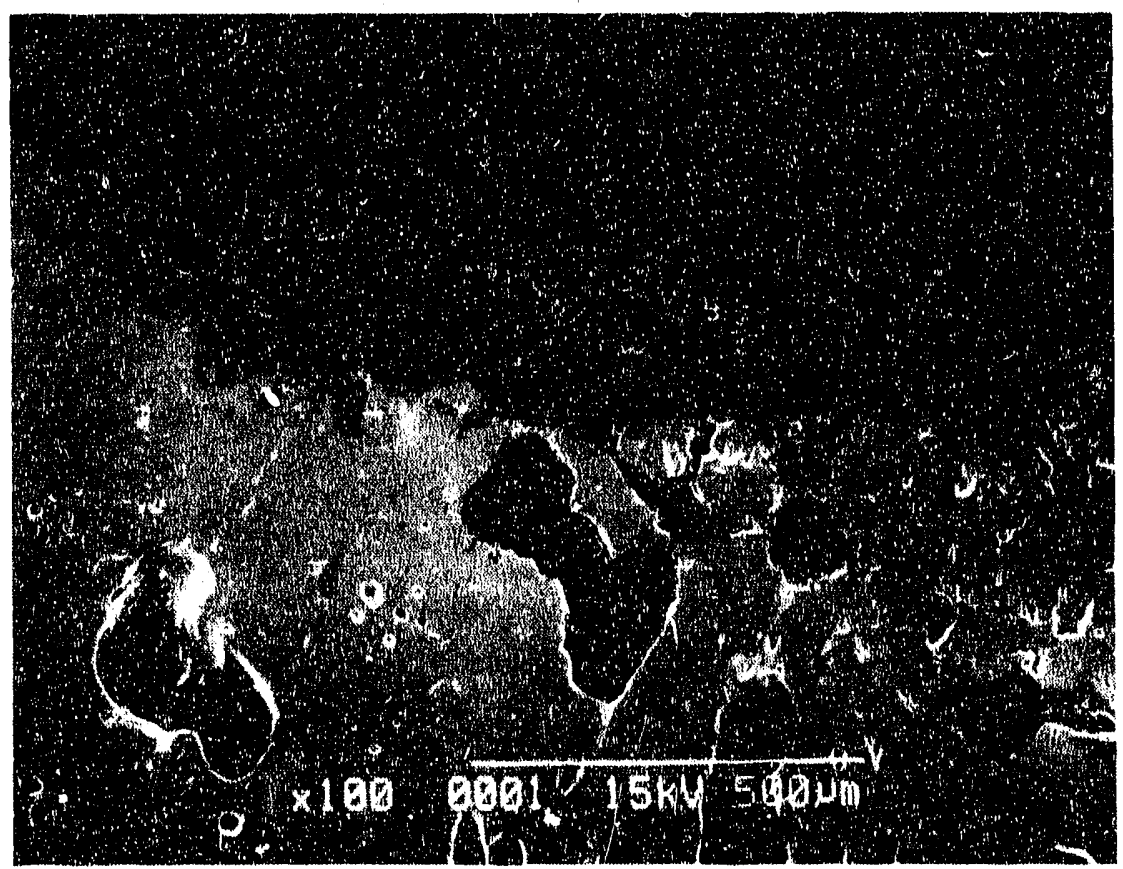

rigure 61. Higher magnification of the CEROX coating on the anode. from test 13614-21 (100X). 


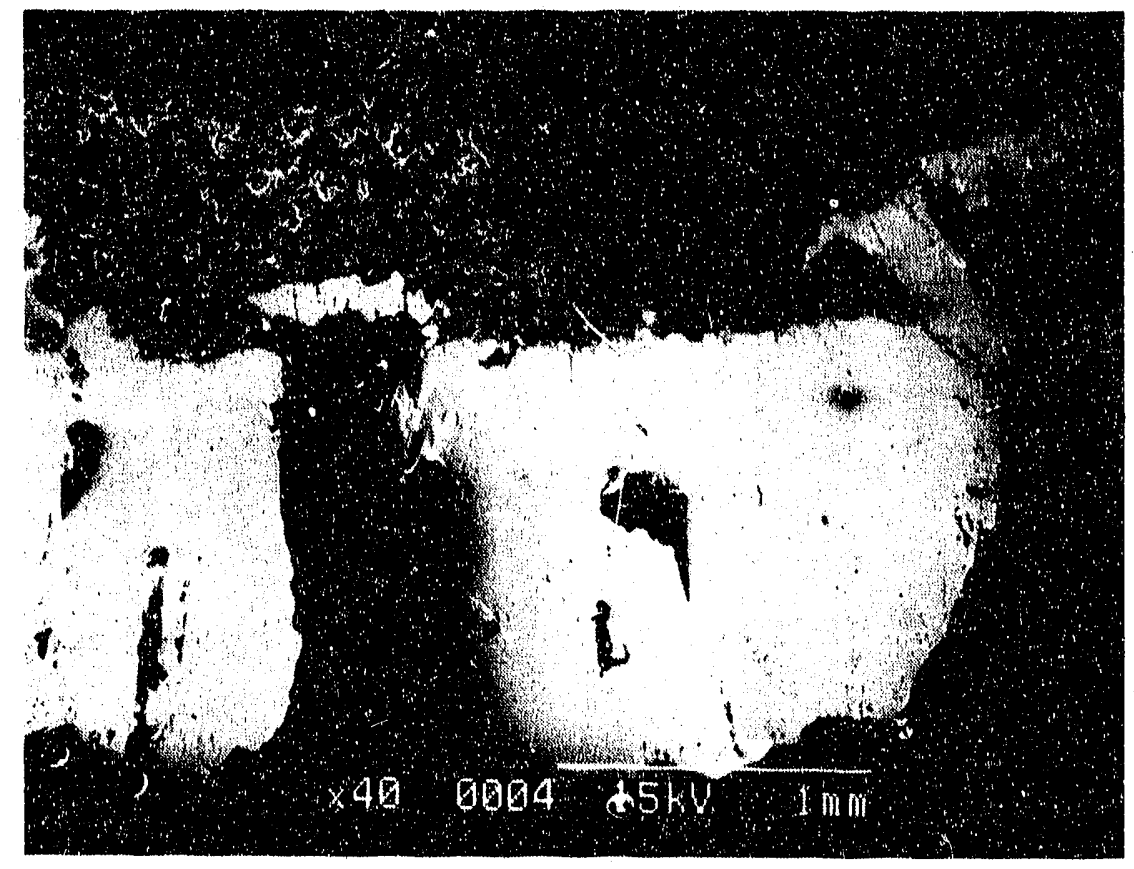

Figure 62. CEROX on the anode from test 13614-35 (40X).

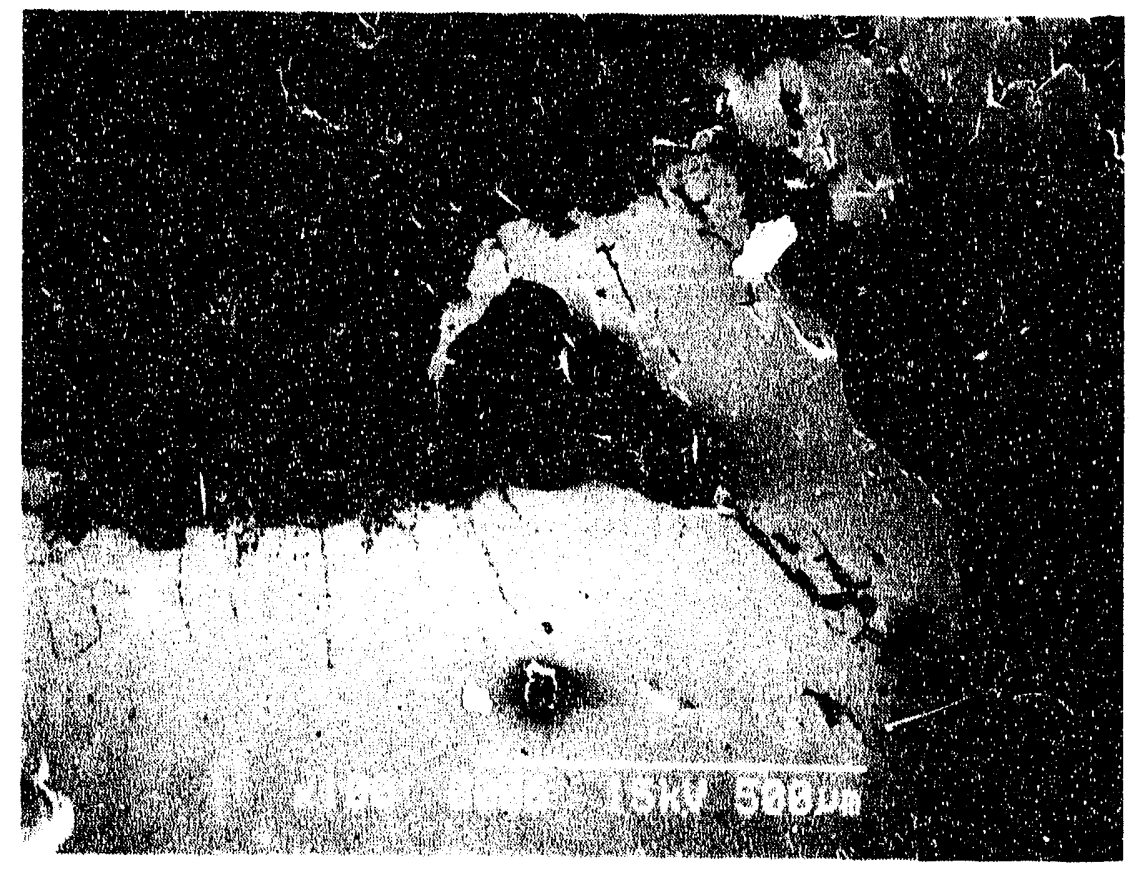

Eigure 63. Higher magnification of the CEROX coating on the anode from test 13614-35 (100X). 


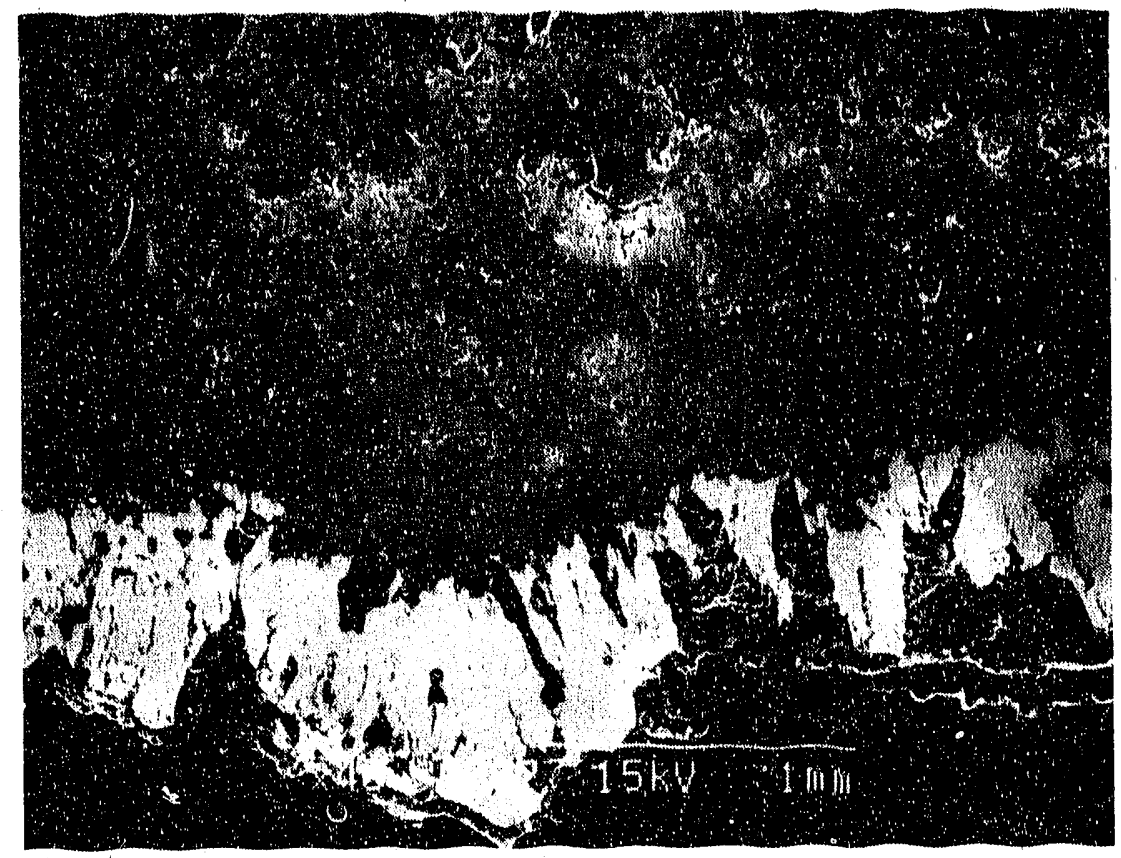

Eigure 64. CEROX on the anode from test $13614-41$ (40X).

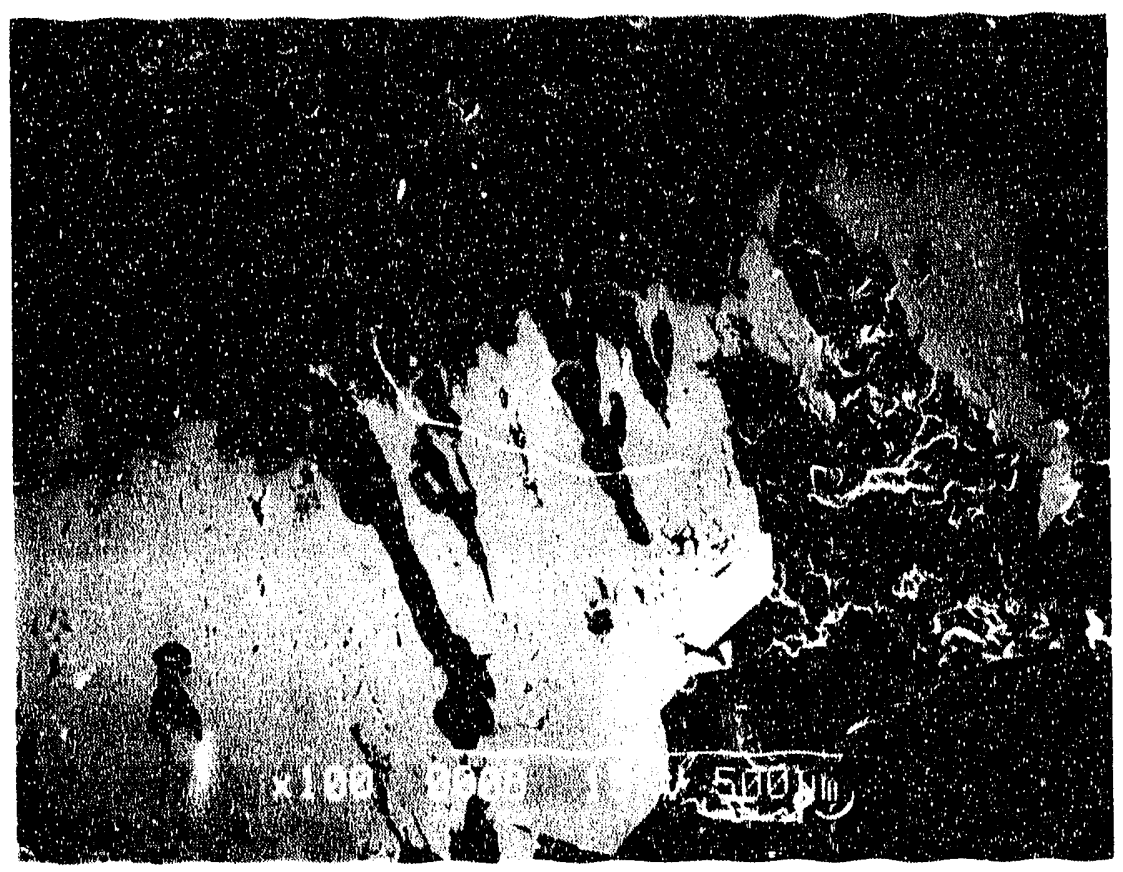

Figure 65. Higher magnification of the CEROX coating on the anode from test $13614-41$ (100X). 
is from 0.6 to $0.9 \mathrm{~mm}$ thick. The substrate interface is irregular.

The anode substrates all contajn similar features, but in varying degrees. Adjacent to the CEROX coating there is sometimes a discontinuous Cu-oxide phase (probably CuO) and a thin Ni-Al-Ee oxide phase that is $<20 \mu \mathrm{m}$ in thickness. Next, there is an outer region of the substrate that contains $\mathrm{NiO}$ and $\mathrm{NiFe}_{2} \mathrm{O}_{4}$, but little or no Cu-containing phase. Further into the substrate is another. layer, which contains $\mathrm{NiO}, \mathrm{NiFe}_{2} \mathrm{O}_{4}$, and a $\mathrm{Cu}$-oxide phase (possibly $\left.\mathrm{Cu}_{2} \mathrm{O}\right)$. Finally, in the center of the sample, cu metal is present with $\mathrm{NiO}$ and $\mathrm{NiFe}_{2} \mathrm{O}_{4}$. The average phase compositions in the oxidized region and the unoxidized region in the tested samples is shown in Table 7 .

Cryolite appears to be present in the pores throughout the oxidized region, and in some places, in pores in the cu metal-containing region of the anode. The oxidized layer has an increase in porosity over that in the untested anode, and porosity also seems increased in the central $\mathrm{Cu}$ metal region, as compared to the untested anode. Table 8 summarizes the thicknesses of the $\mathrm{Cu}$ depleted layer and the oxidation thickness in the five anodes examined by SEM. In the samples with little oxidation (test numbers 53 and 49), the shape and size of the $\mathrm{NiO}$ and $\mathrm{NiFe}_{2} \mathrm{O}_{4}$ in the $\mathrm{Cu}$ depleted and $\mathrm{Cu}$ oxidized region appears to be similar to that in the untested samples. However, in the samples with more extensive oxidation (test numbers 21, 35, and 41), great changes in the distribution of the phases is obvious. Alternating layers rich in $\mathrm{NiO}$ and $\mathrm{NiFe}_{2} \mathrm{O}_{4}$ occur. These features will be described in detail below in the description of the anodes from the five tests.

$13614-53$

Figure 66 shows a unique feature of this anode. On the side of the sample only, there is a $\mathrm{CeF}_{3}+\mathrm{Cu}$-oxide layer (A) between the CEROX layer (C) and the substrate (B). On the bottom of the anode, the $\mathrm{CeF}_{3}$ layer is not present (Figure 67). At this point, there is a thin $\mathrm{Cu}$ oxide phase (C) with $\mathrm{NiFe}_{2} \mathrm{O}_{4}$ (D) next to the CEROX (B). A small grain of $C u$ oxide (A) is also found within the CEROX.

The $\mathrm{Cu}$ depleted region is shown in figure 68 (layer $\mathrm{B}$ ). This layer consists of $\mathrm{NiO}$ and $\mathrm{NiFe}_{2} \mathrm{O}_{4}$ (Eigure 69) with a trace of $\mathrm{CeF}_{3}$ (bright white phase). In layer A (Figure 70), the $\mathrm{NiO}$ (B) and $\mathrm{NiFe}_{2} \mathrm{O}_{4}$ (A.) occur with $\mathrm{Cu}$ oxide (C), $\mathrm{CeF}_{3}$ (D), and cryolite (E). The Cu-oxide is prevalent along the grain boundaries of the $\mathrm{NiO}$ and $\mathrm{NiF}_{2} \mathrm{O}_{4}$. These phases are shown at higher magnification in E: gure 71 .

In the unoxidized region (Figure 72), the $\mathrm{Cu}$ metal (N) coexists with the $\mathrm{NiO}(\mathrm{O})$ and $\mathrm{NiFe}_{2} \mathrm{O}_{4}$. The material is more porous than before testing [Eigure $17(b)]$ and some cryolite may be present in the pores. The $\mathrm{NiFe}_{2} \mathrm{O}_{4}$ appears similar to that in untested material but the Nio may be more rounded and the percentage appears to be reduced. 
Table 7. Average phase composition in tested anodes.

\begin{tabular}{|c|c|c|c|}
\hline \multirow[b]{2}{*}{ Area } & \multicolumn{3}{|c|}{ Prase composition (wt:) } \\
\hline & $\mathrm{CuO}$ & $\mathrm{NiO}$ & $\mathrm{NiFe}_{2} \mathrm{O}_{4}$ \\
\hline \multirow[t]{2}{*}{$\begin{array}{l}\text { Oxidized } \\
\text { area }\end{array}$} & $\begin{array}{r}95.6 \text { CuO } \\
2.8 \mathrm{FeO} \\
1.6 \mathrm{NiO}\end{array}$ & $\begin{array}{r}87.3 \mathrm{NiO} \\
9.6 \mathrm{FeO} \\
3.1 \mathrm{CuO}\end{array}$ & $\begin{array}{rl}67.4 \mathrm{Fe}_{2} \mathrm{O}_{3} \\
31.6 \mathrm{NiO} \\
1.0 & \mathrm{CuO}\end{array}$ \\
\hline & $\mathrm{Cu}$ & NiO & NiEe, $\underline{Q}_{4}$ \\
\hline $\begin{array}{l}\text { Center area } \\
\text { with metallic } \\
\text { cu }\end{array}$ & $\begin{array}{r}94.0 \mathrm{Cu} \\
3.0 \mathrm{Fe} \\
3.0 \mathrm{Ni}\end{array}$ & $\begin{array}{r}90.8 \mathrm{NiO} \\
7.9 \mathrm{FeO} \\
1.3 \mathrm{CuO}\end{array}$ & $\begin{array}{l}70.0 \mathrm{Ee}_{2} \mathrm{O}_{3} \\
29.0 \mathrm{NiO} \\
1.0 \mathrm{CuO}\end{array}$ \\
\hline
\end{tabular}


Table 8. Cu oxidation and Cu depletion thickness.

\begin{tabular}{lcc}
\hline Experiment & $\begin{array}{c}\text { Cu Depletion } \\
(\mu \mathrm{m})\end{array}$ & $\frac{\begin{array}{c}\text { Oxidation } \\
(\mathrm{mm})\end{array}}{13614-53}$ \\
to 600 & 1.3 \\
$13614-49$ & 400 to 500 & 0.5 \\
$13614-21$ & $\sim 200$ & 9.0 \\
$13614-35$ & $\sim 1100$ & 12.0 \\
$13614-41$ & $\sim 500$ & 23.5 \\
\hline
\end{tabular}




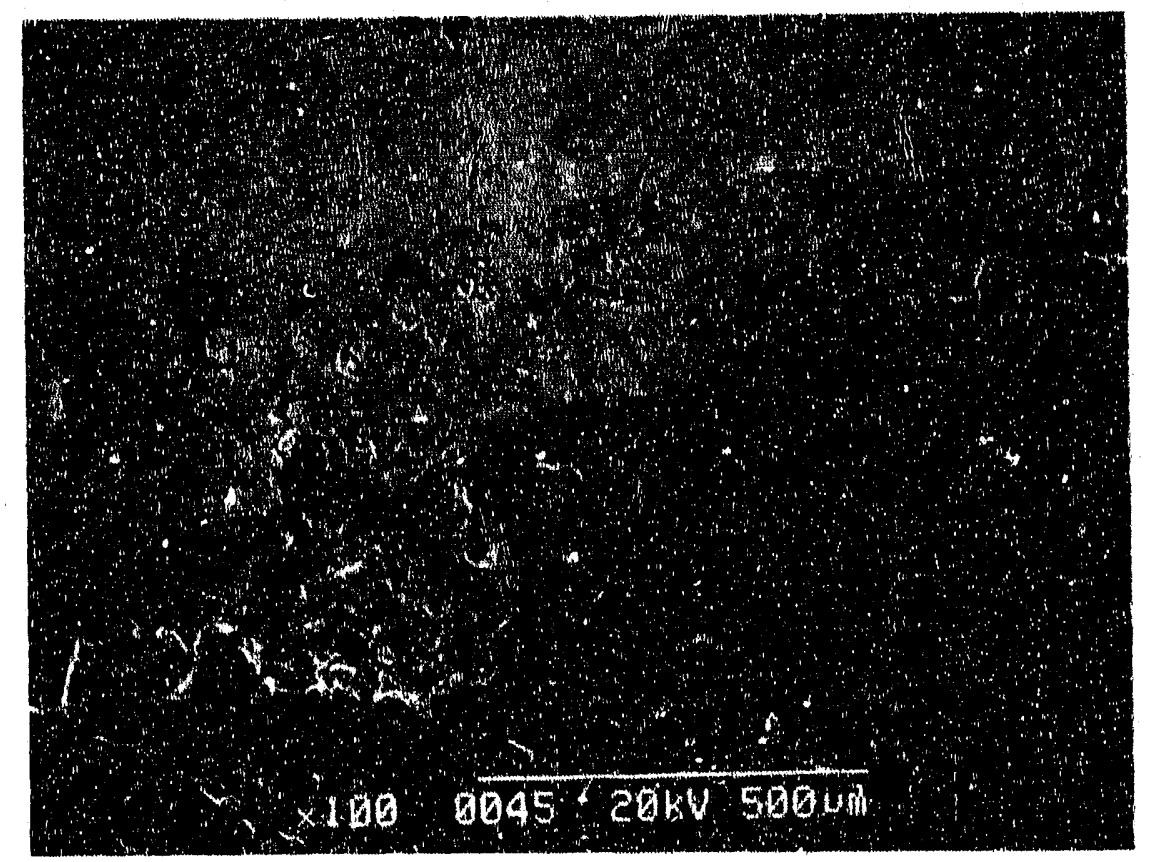

Eigure 66. $\mathrm{CeF}_{3}$ and $\mathrm{Cu}$ oxide layer (A) between the substrate (B) and the CEROX coating (C) (Anode 13614-53, 100X).

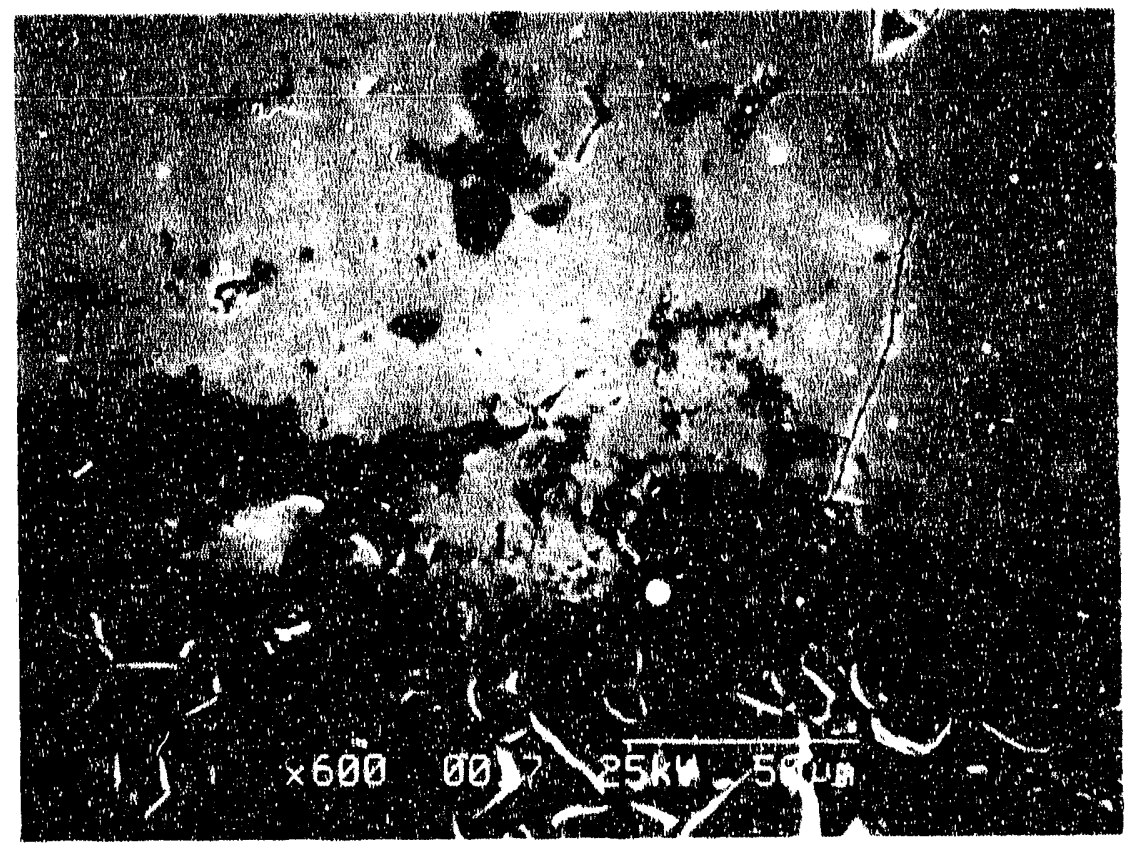

Eigure 67. Interface bet'seen the substrate and the CEROX coating (Anode 13614-53, 600X). $A=C u O$ in CEROX, $B=C E R O X$, $\mathrm{C}=(\mathrm{Cu}, \mathrm{Ni})$ oxide, $\mathrm{D}=\mathrm{NiFe}_{2} \mathrm{O}_{4}$ 


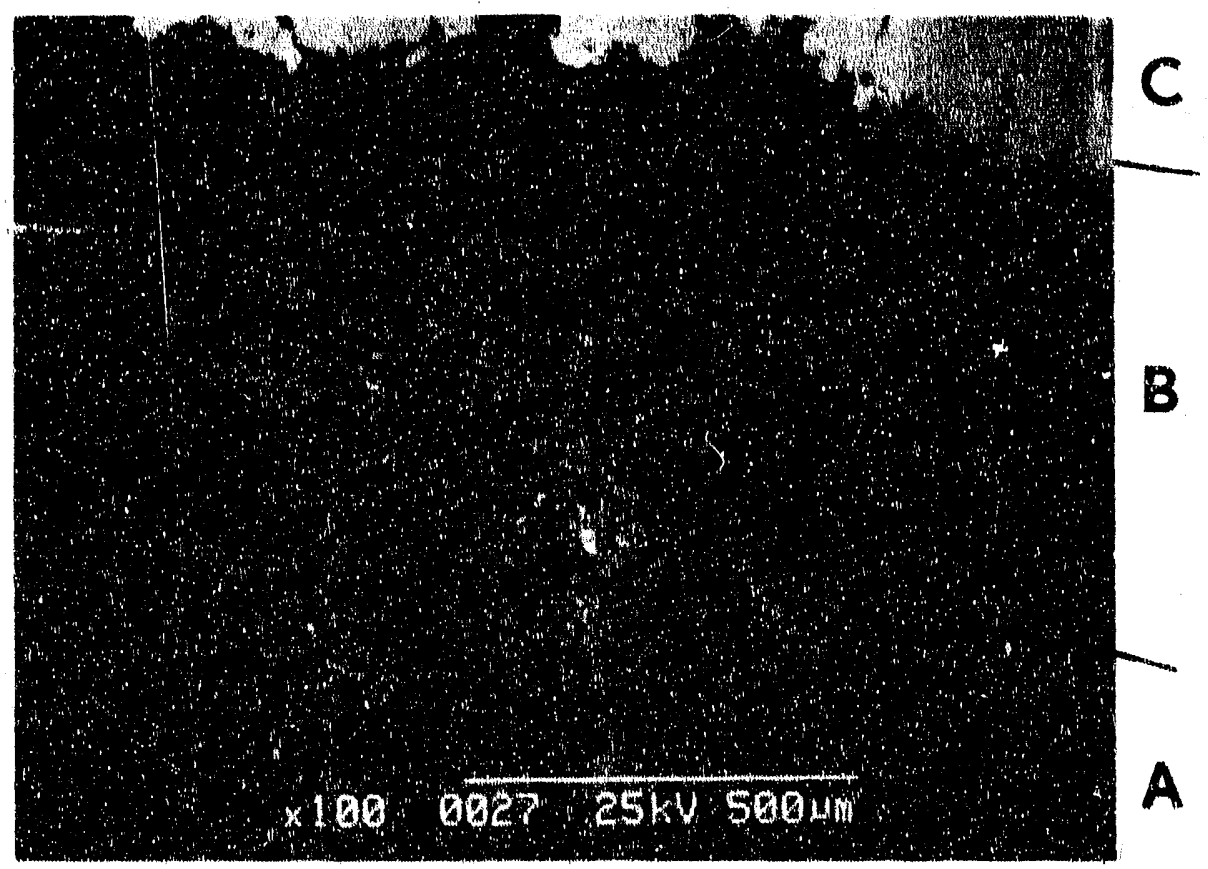

Figure 68. Cu depleted layer next to the CEROX coating (Anode 13614-53, 100X). $C=C E R O X, B=C u$ depleted zone, $A=C u$ oxide region

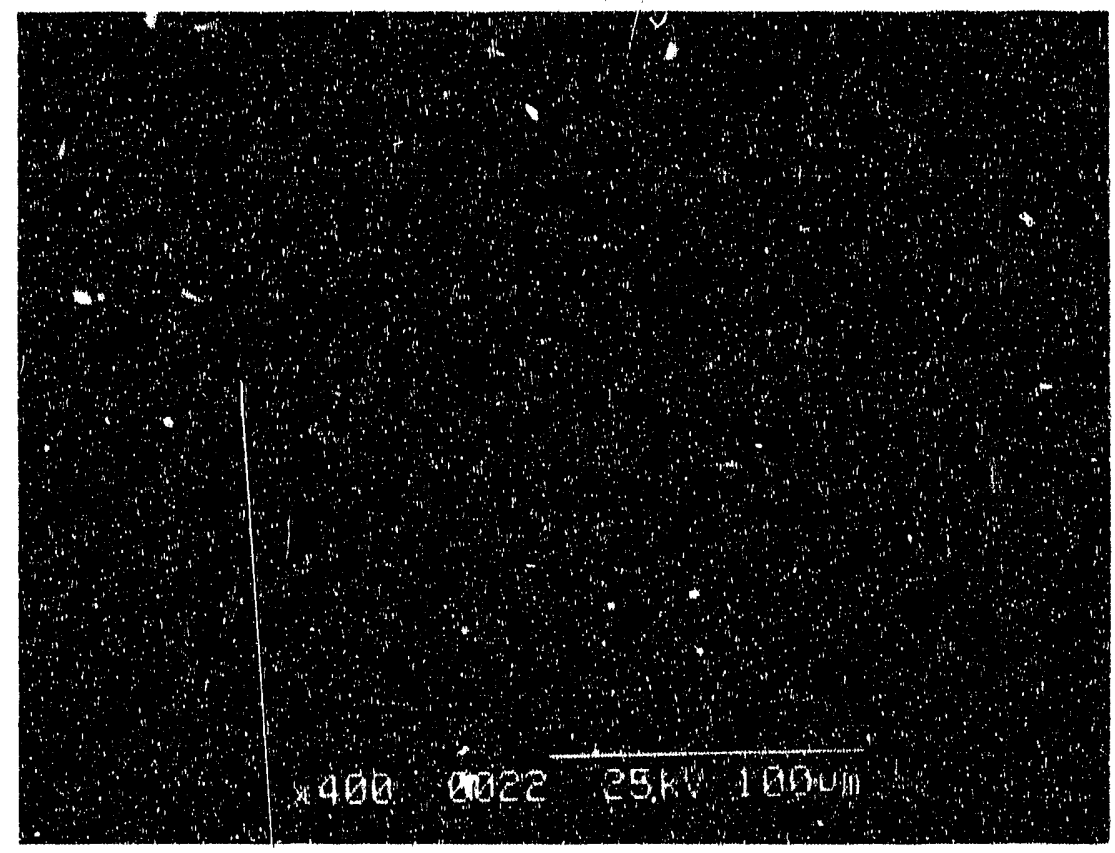

Figure 69. High magnification of the $\mathrm{Cu}$ depleted zone in Figure 53 (Anode 1.3614-53,400X). $\mathrm{E}=\mathrm{NiFe} \mathrm{O}_{4}, \mathrm{~F}=\mathrm{NiO}$, the bright white phases are $\mathrm{CeF}_{3}$. 


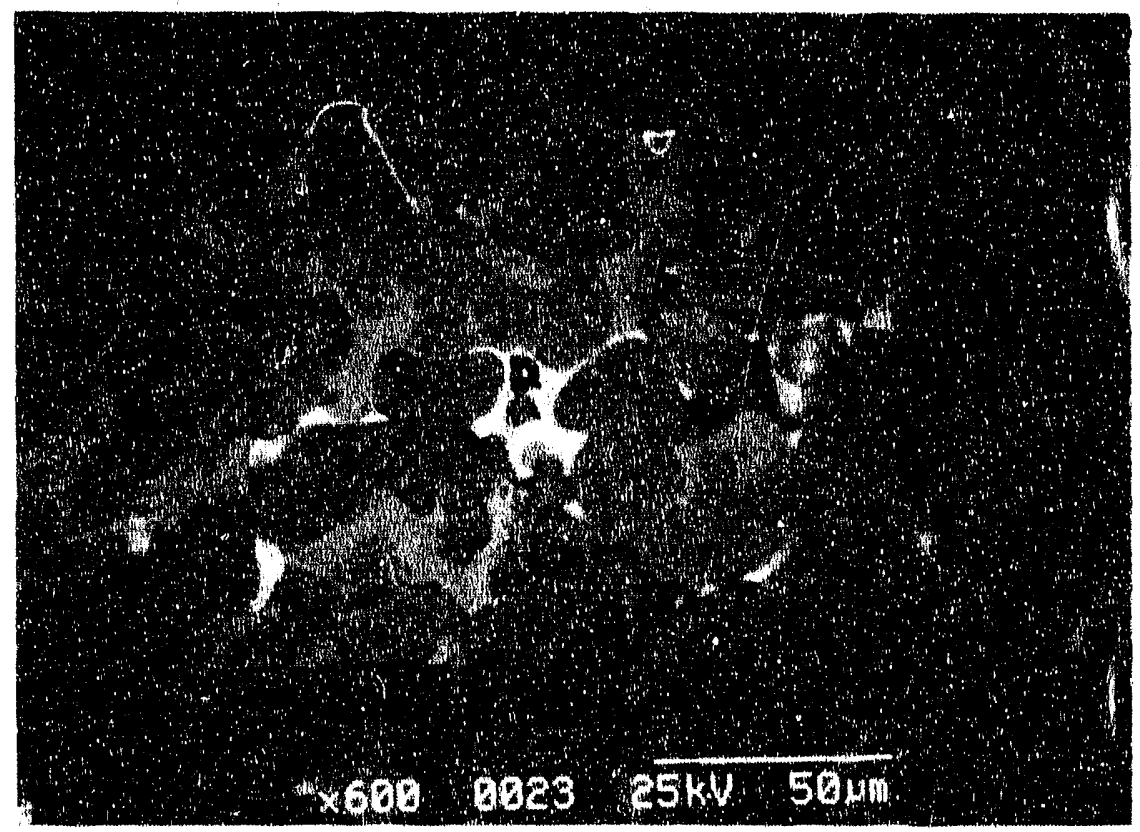

Eigure 70. The $C u$ oxide region in anode $13614-53$ (600X). $A=N i E e_{2} O_{4}, B=N i O, C=C u$ oxide, $D=C e E_{3}, E=c r y o l i t e$

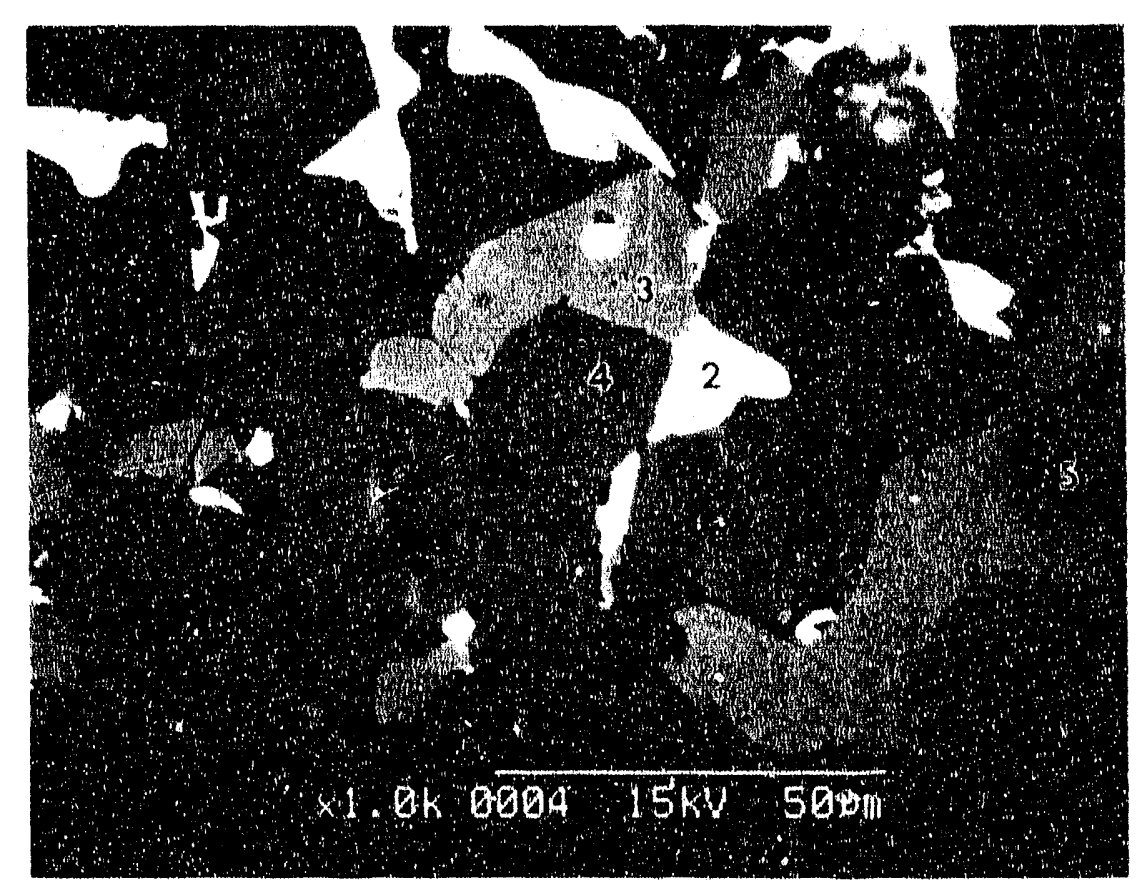

Eigure 71. Near the edge of the Cu oxide region (Anode 13614-53, 1000X). $\quad 2=\mathrm{Cu}$ oxide, $3=\mathrm{NiO}, 4=\mathrm{NiFe}_{2} \mathrm{O}_{4}, \quad 5=$ cryolite 


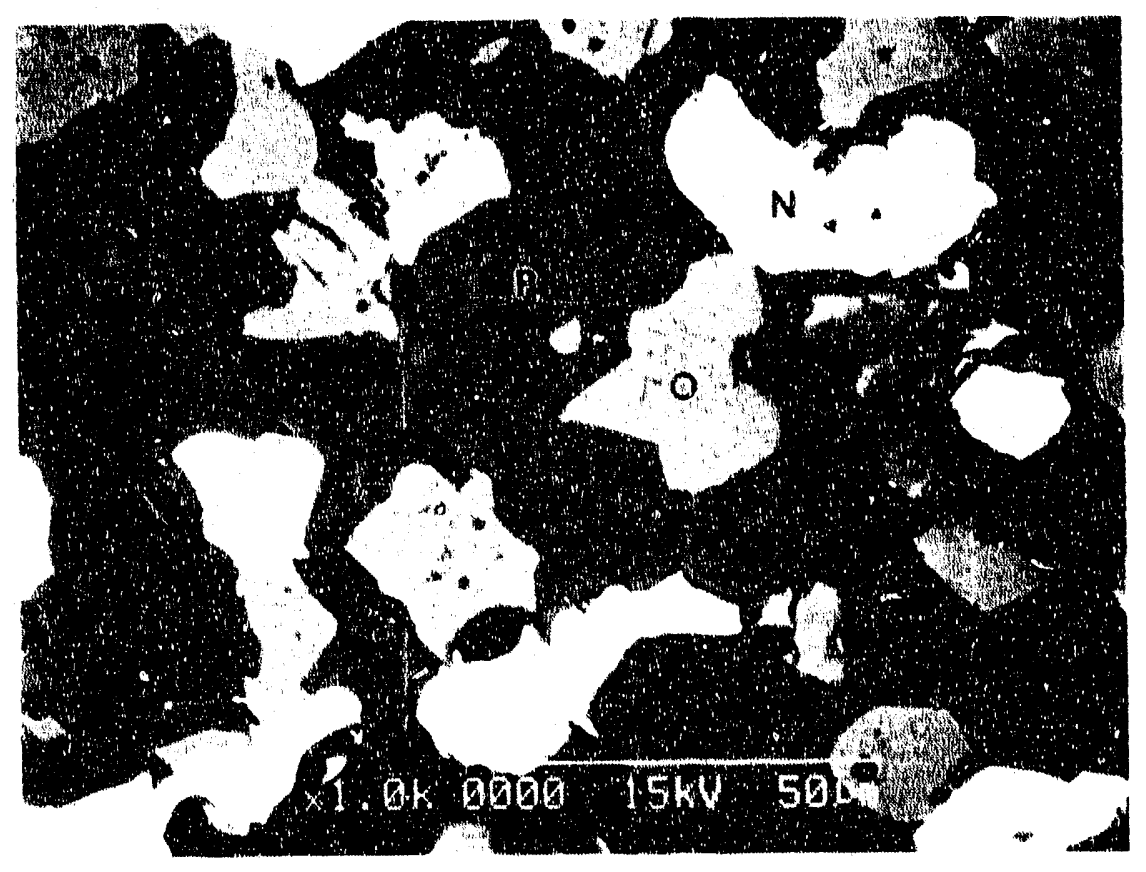

Eigure 72. In the center of the unoxidized area of anode
$13614-53(1000 \mathrm{x})$. $\mathrm{N}=\mathrm{Cu}, \mathrm{O}=\mathrm{NiO}, \mathrm{P}=\mathrm{NiEe} \mathrm{O}_{4}$, within some
of the black pores are cryolite. 


\section{$13614-49$}

The Cu depletion layer (B) in this sample j.s shown in Figure 73. It is of a similar thickness as in 13614-53. In this sample, oxidation is very minimal and layer $A$ is the layer that contains $C u$ metal, $\mathrm{NiO}$, and $\mathrm{NiFe}_{2} \mathrm{O}_{4}$. There is not a well developed Cu-oxide layer in this sample, but some grains of $\mathrm{Cu}$ oxide can be found at the interface of layers $A$ and $B$. As shown in Figure 74, the $C u$ depleted region is more porous than the region still containing $C u$ metal.

\section{$13614-21$}

Anode 13614-21 was much more extensively oxidized than anodes 49 or 53. This resulted in much greater change in the interior microstructure than in those anodes in which the $\mathrm{NiO}$ and $\mathrm{NiFe}_{2} \mathrm{O}_{4}$ basically appeared unchanged in shape and distribution. In Figure 75, the interface between the CEROX (C) and substrate is shown. At the interface, some light tan grains of Cu oxide can be seen along with the $\mathrm{Ni}-\mathrm{Al}-\mathrm{Cu}-\mathrm{Fe}$ oxide (the dark band at the interface).

As in the other samples, this sample contains a Cu-free layer (B) and Cu-oxide containing layer $(A)$, as shown in Figure 76 . Within the Cu-oxide layer there is some evidence of alignment of the Nio (medium gray phase) in layers. Eurther into the oxidized region, there are alternating porous and denser bands (Eigure 77). A closer look at these bands (Figure 78) shows that there are NiO rich layers ( $\left.L_{1}\right)$ with CuO (the white phase), then, layers of primarily $\mathrm{NiFe}_{2} \mathrm{O}_{4}$ and CuO with some $\mathrm{NiO}(\mathrm{K})$, while the porous zones (J) are $\mathrm{NiO}$ and $\mathrm{NiEe}_{2} \mathrm{O}_{4}$ without any $\mathrm{Cu}$ oxide phase. Micrographs at: $40 u x$ of the cumoxide region and the porous region are shown in Eigures 79 and 80 .

The boundary between the oxidized and unoxidized regions, shown in Figure 81, is typical of most of the samples. The cu region (Eigure 82) consists of $\mathrm{Cu}$ metai, $\mathrm{NiO}$, and $\mathrm{NiFe} \mathrm{O}_{1}$ as in the untested materials but has increased porosity over the untested samples.

\section{$13614-35$}

Anode 35 is also extensively oxidized and has a thick $C_{\text {L }}$ depleted region next to the CEROX (Layer $R$ in Figure 83). Within this region there is some evidence of Nio-rich layers. Within the cuoxide layer, microstructure is typical of the other samples (Figure 84) containing $\mathrm{NiO}, \mathrm{NiFe}_{2} \mathrm{O}_{4}$, and $\mathrm{Cu}$ oxide along grain boundaries. 


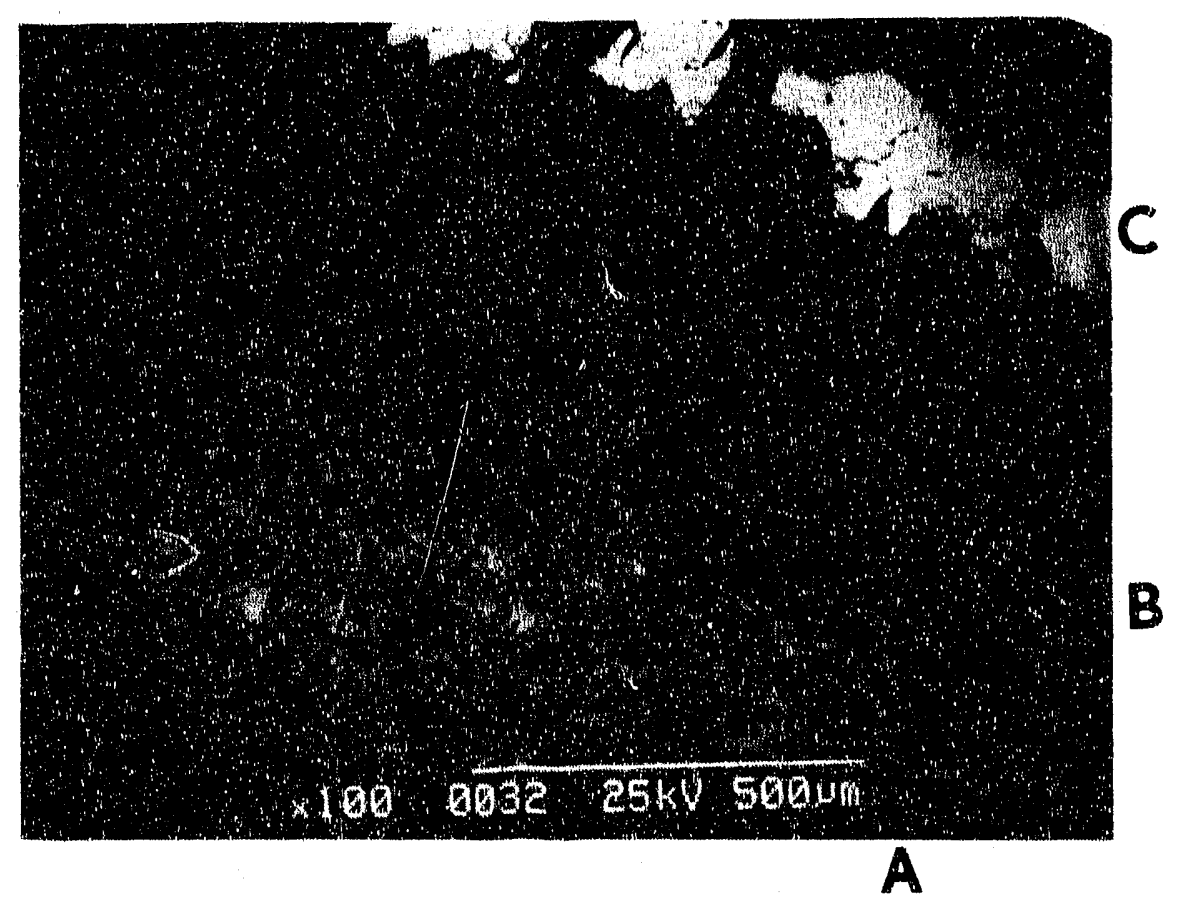

Eigure 73. At the edge of anode 13614-49 there is the CEROX coating (C), the $C u$ depleted layer (B) and then the interior Cu metal region (A) (100X).

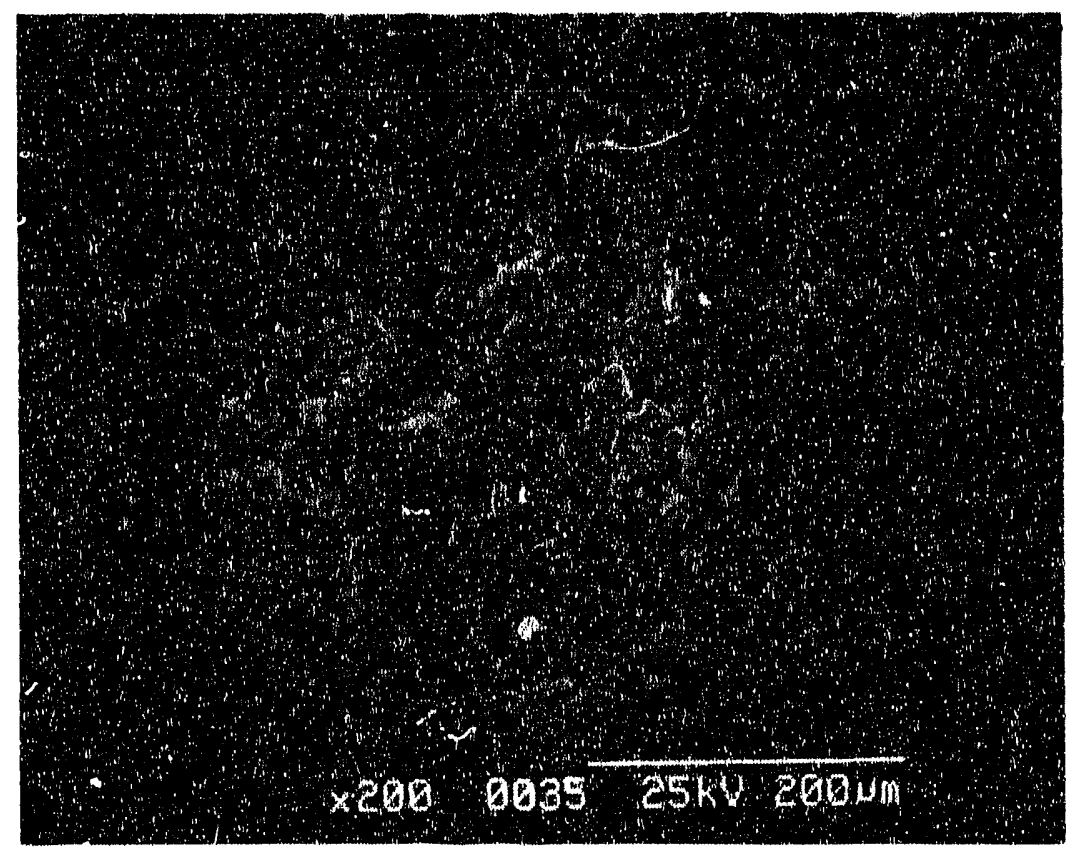

Figure 74. The boundary between the porous $\mathrm{Cu}$ depleted layer (top) and the denser center containing $\mathrm{Cu}$ metal (bottom) $(100 x)$. 


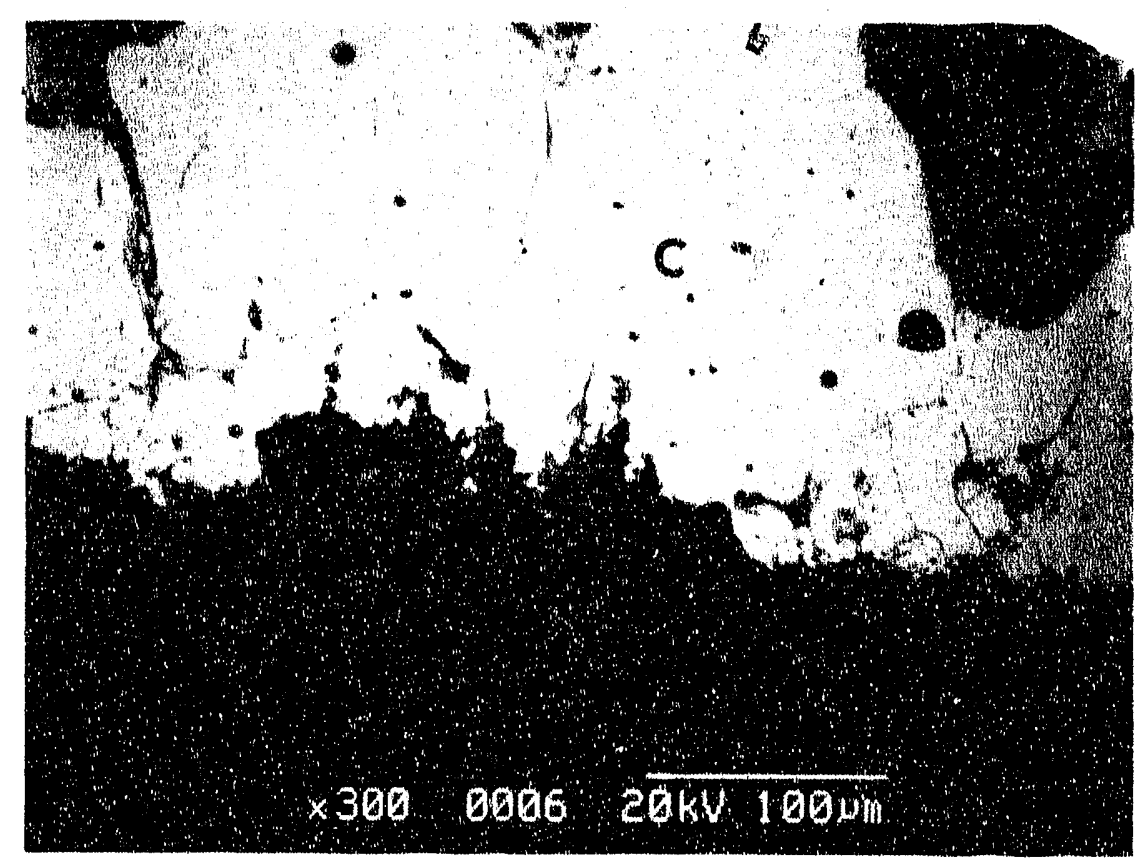

Figure 75. The interface between the CEROX coating (C) and the substrate (Ancde 13614-21, 300X).

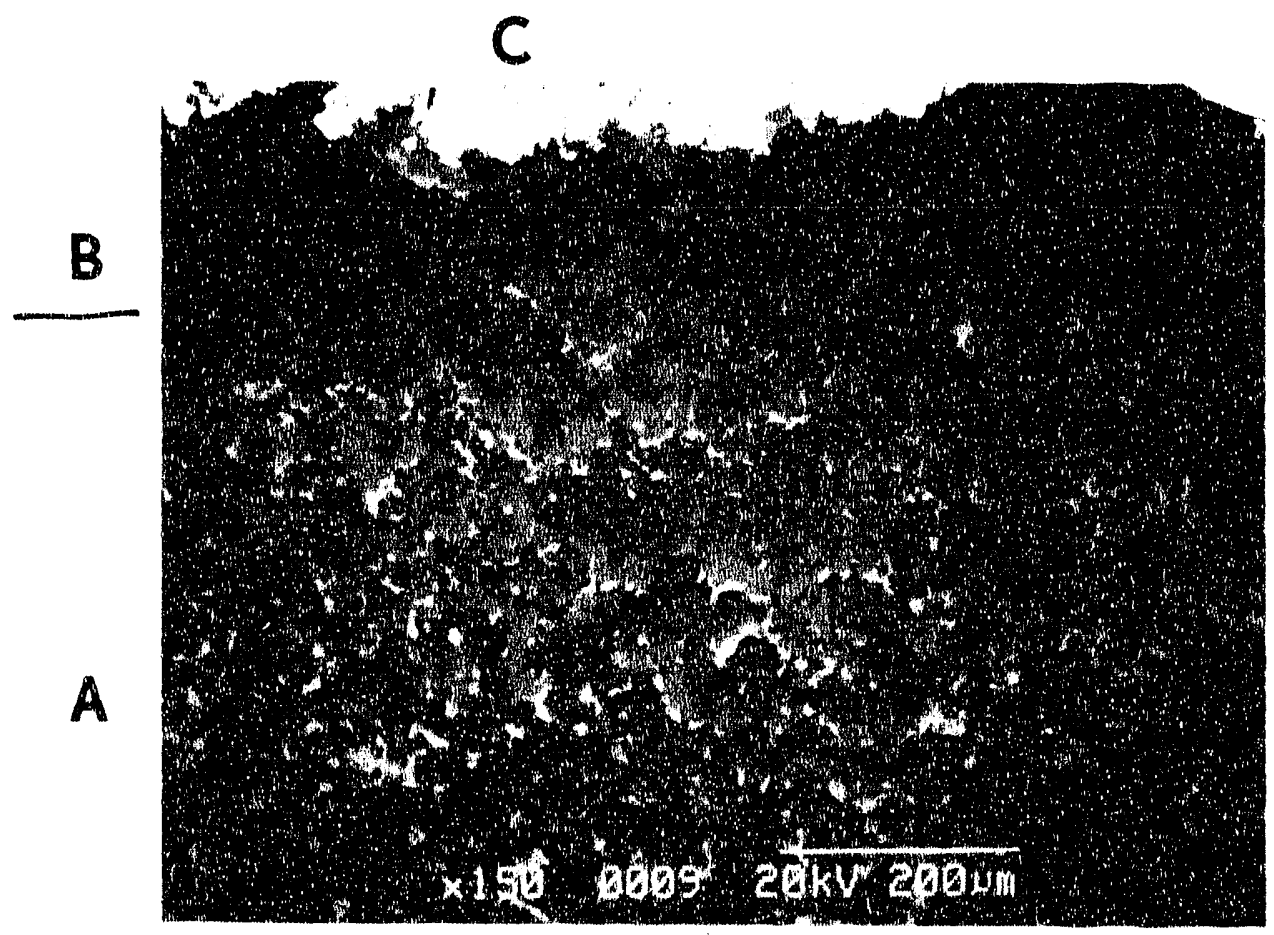

Eigure 76. The CEROX coating (C), Cu depleted zone oxide region (A) in anode 13614-21 (150X).

(B) and $\mathrm{Cu}$ 


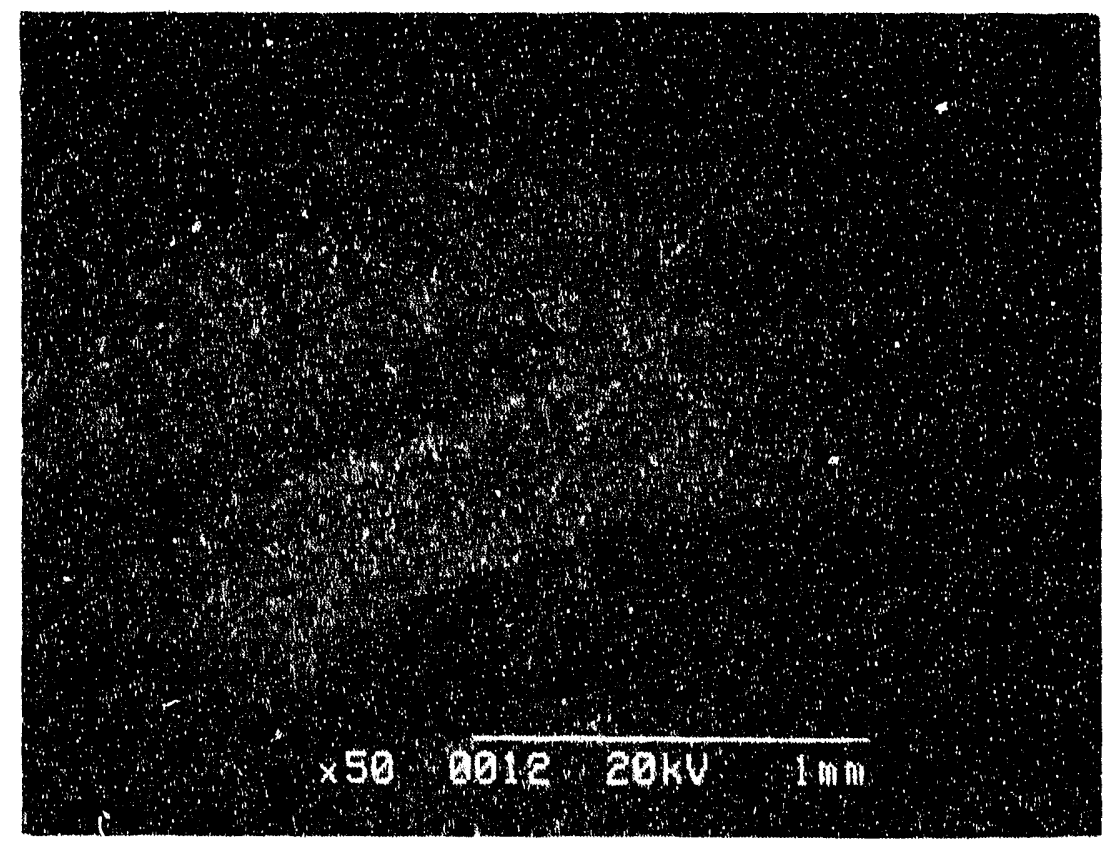

Figure 77. Porous and dense bands alternate within the oxidized region (Anode 13614-21, 50x).

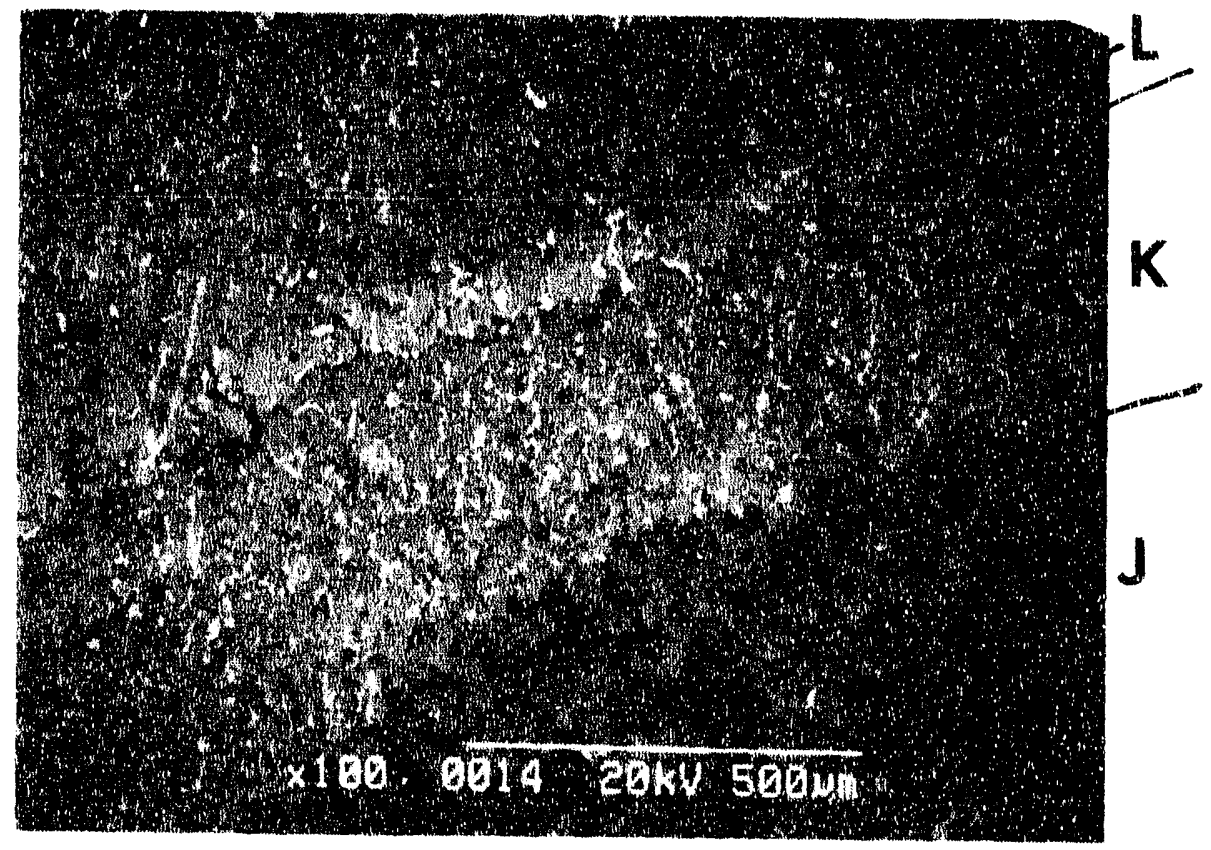

Eigure 78. Higher magnification of Figure 77, showing the porous zone (J), Cu oxide zone (Anode 13614-21, 100X).

(K), and Nio rich band (L) 


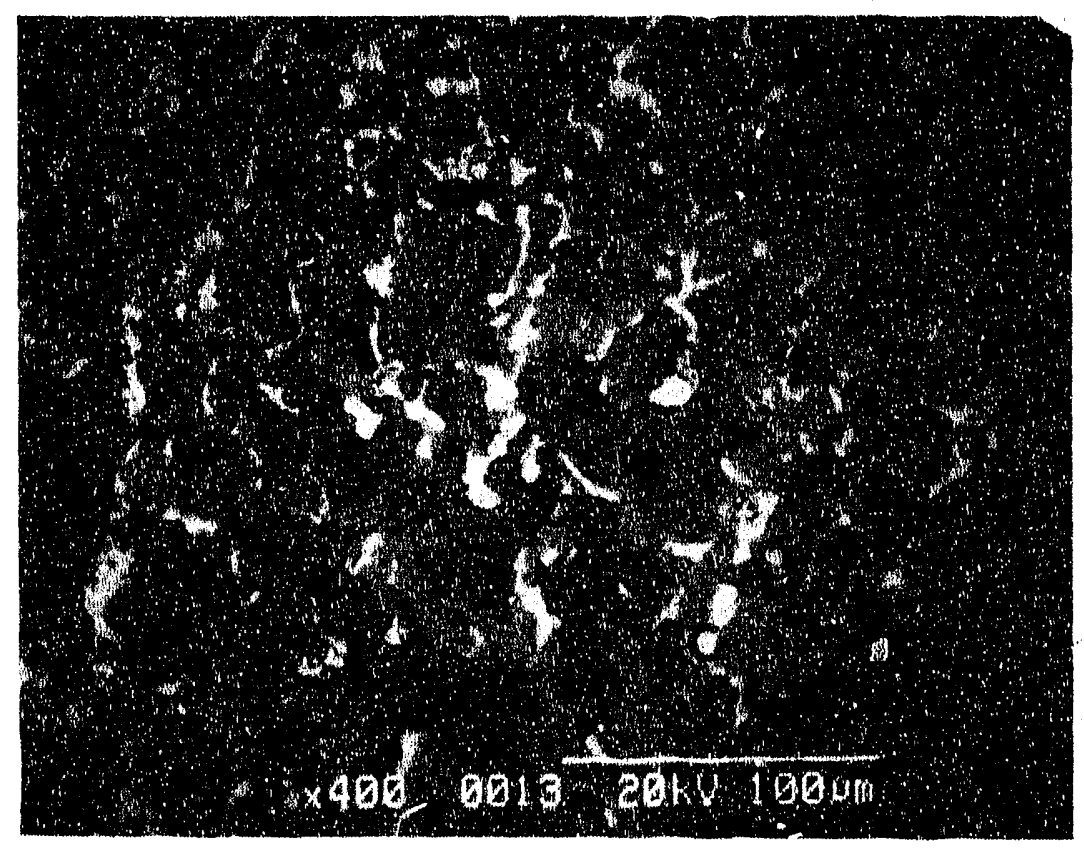

Eigure 79. The $\mathrm{Cu}$ oxide (C) rich zone from Eigure 78 also contains $\mathrm{NiO}$ (B) and $\mathrm{NiEe}_{2} \mathrm{O}_{4}$ (A) (Anode 13614-21, 400X).

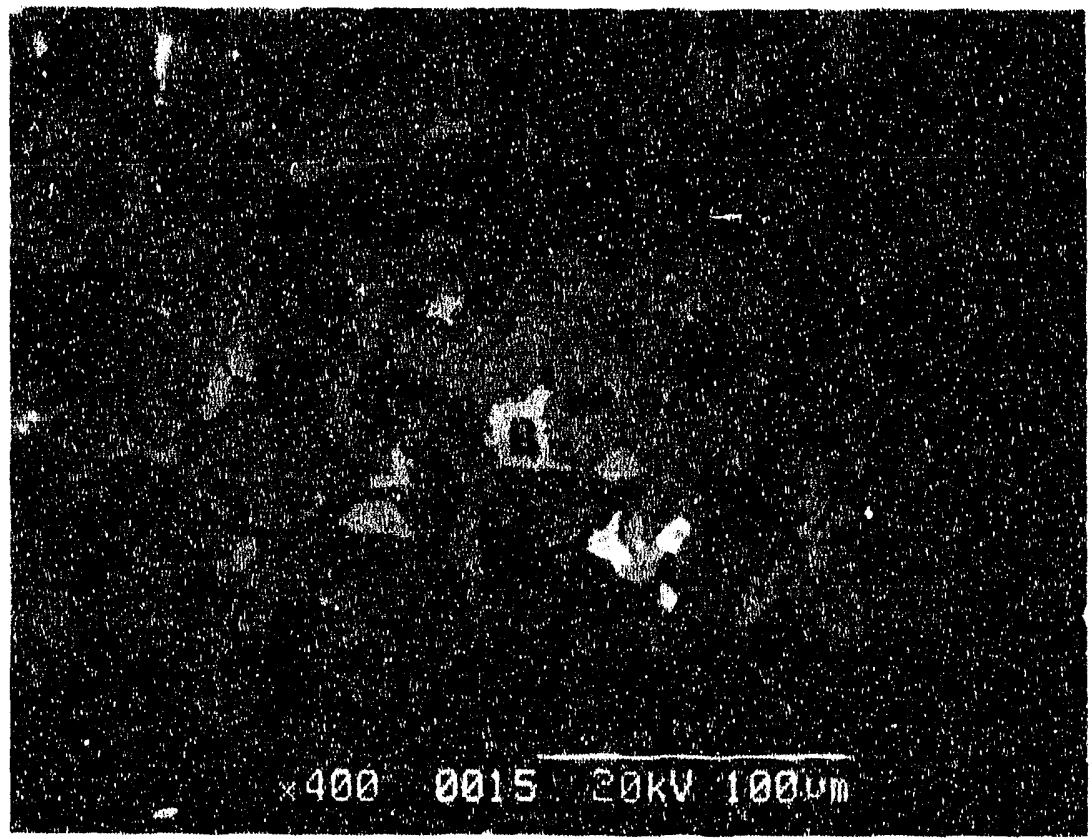

Figure 80 . The porous zone from Figure 78 contains primarily $\mathrm{NiO}$ (B) and $\mathrm{NiFe}_{2} \mathrm{O}_{4}$ (A) (Anode 13614-21, 400X). 


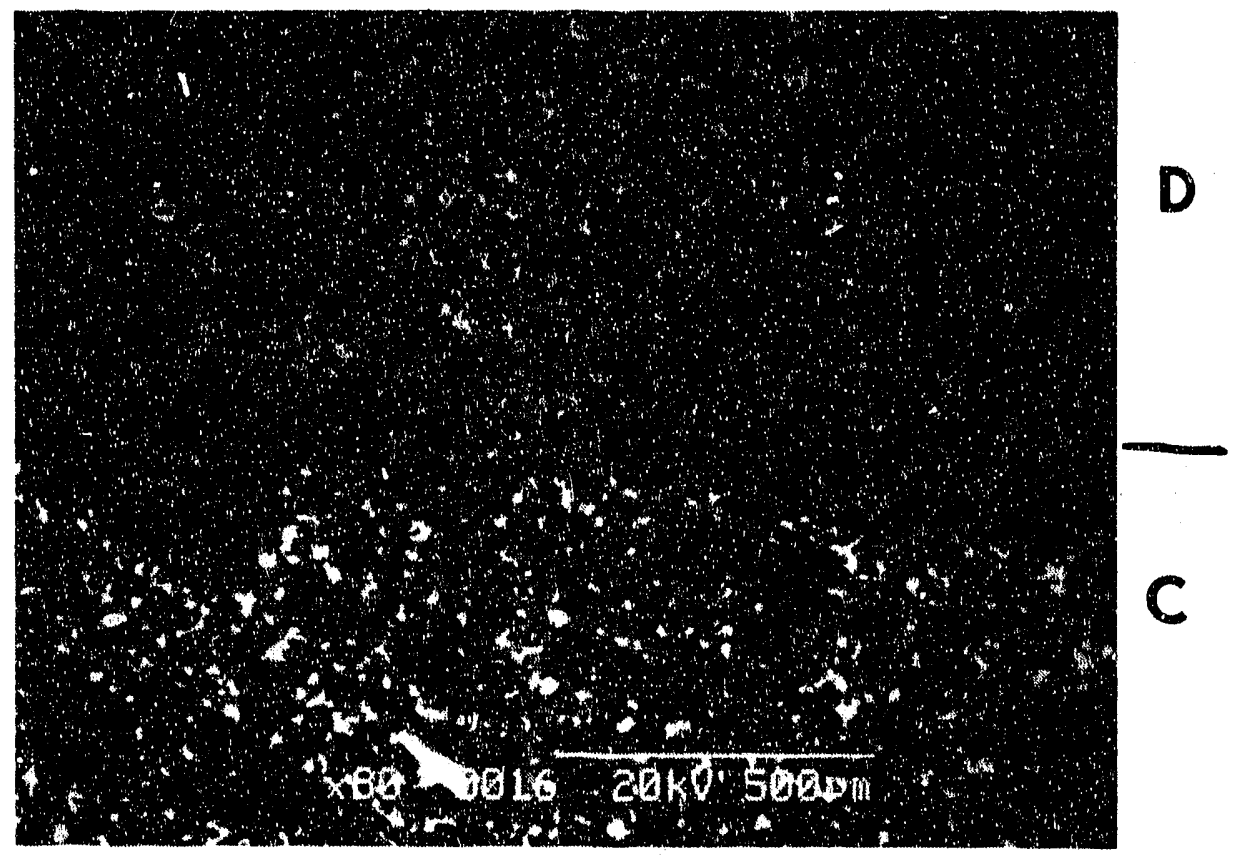

Figure 81. The boundary between the Cu oxide region (D) and the Cu metal zegion (C) (Anode 13614-21, 80X).

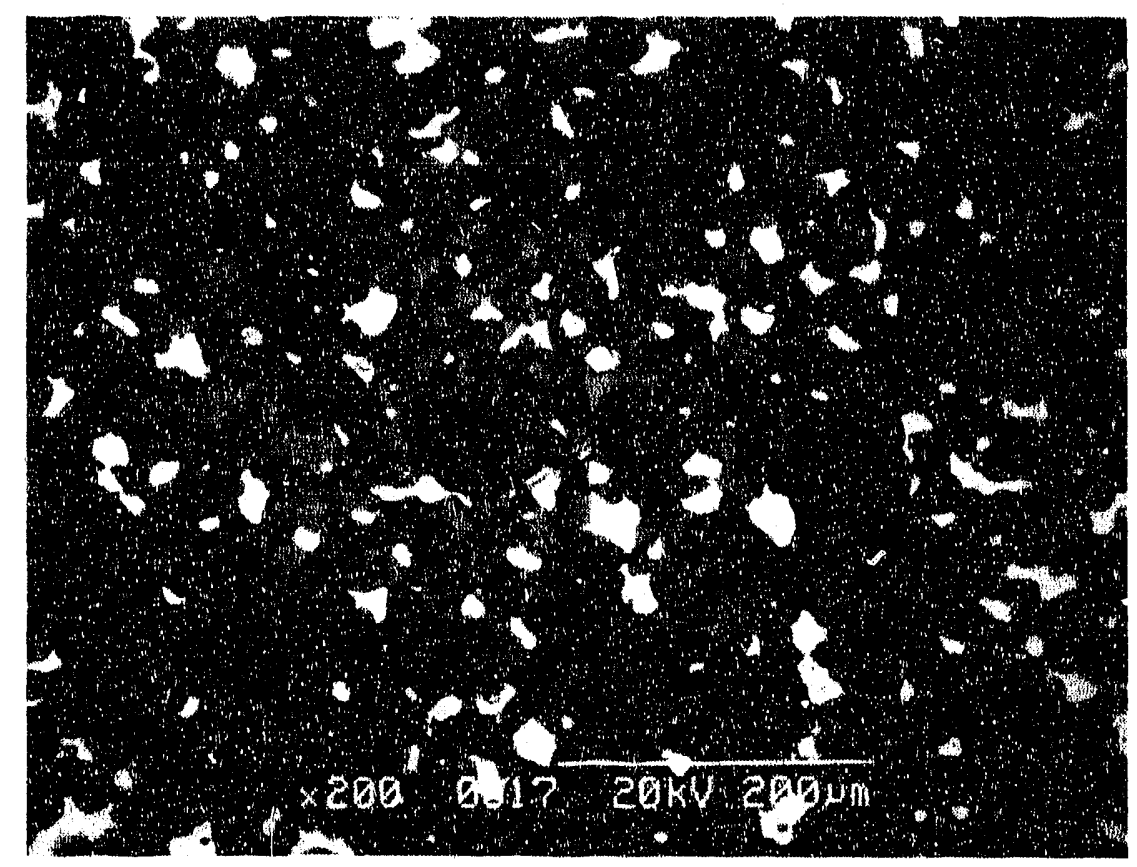

Figure 82. Cu metal region in the center of anode 13614-21 contains $\mathrm{Cu}$ metal (white), $\mathrm{NiO}$, and $\mathrm{NiFe}_{2} \mathrm{O}_{4}$. 


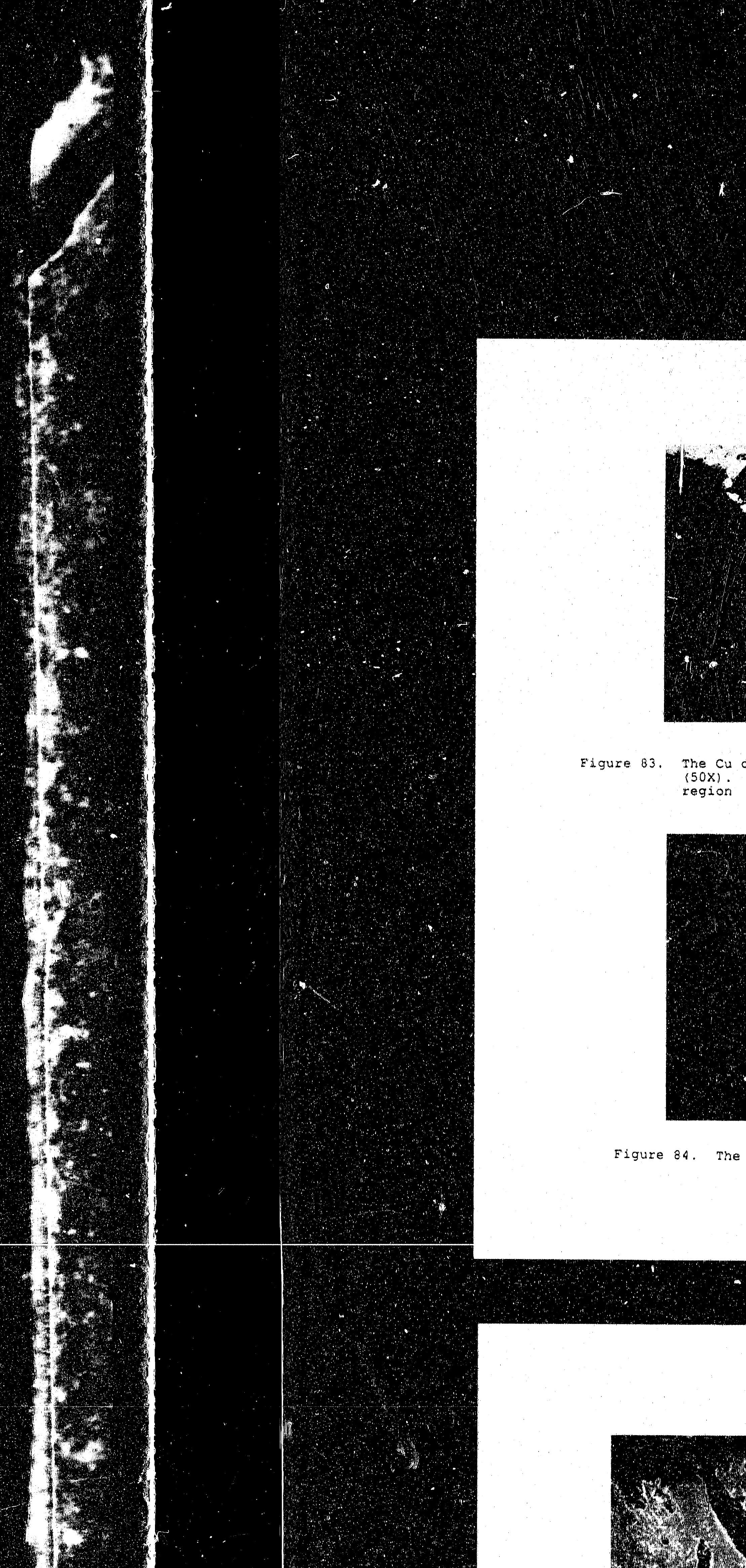




\section{$13614-41$}

Anode 41 has the most extensive oxidation thickness of the five anodes examined $(23.5 \mathrm{~mm}$ thick). Within this oxidized zone, there is extensive redistribution of the phases. The region next to the CEROX coating is shown in Figure 85 . In the outer Cu-free region, a layer of $\mathrm{NiO}$ (B) was found within the $\mathrm{NiFe}_{2} \mathrm{O}_{4}$ (A). However, the Nio in this layer had a different composition compared to that given in Table 6 and found in the bulk of the sample. In this Nio, the solid solution contained $\sim 66.5 \% \mathrm{NiO}, 25.1 \% \mathrm{CuO}$, and $8.38 \%$ FeO; in other words, it is a much more Cu-rich NiO than the NiO in the untested anodes and the NiO in the tested oxidized regions.

Layer $S$ in Figure 85 is found to consist of a NiO (C in Figure 86) of the Ni-rich composition, $92.68 \mathrm{NiO}, 0.7 \%$ CuO, and $6.7 \%$ FeO. The Cu-oxidized region is seen in Layer $T$ (Figure 85) and at the bottom of Figure 86. The $C u$ oxide phase (E) is along grain L sundaries of Nio. A trace of unoxidized $C_{h}$ is also seen in Figure 86 (F). These rare $\mathrm{Cu}$ metal grains in the oxidized regions are most often found near porous layers.

The anode from test 13614-41 also has developed layered structures within the oxidized region. As shown in Eigure $87, \mathrm{NiFe}_{2} \mathrm{O}_{4}$ forms layexs cunsisting of grains with sharp edges next to porous layers. These grains appear recrystallized compared to the more rounded grain boundaries of the $\mathrm{NiEe}_{2} \mathrm{O}_{4}$ in the untested samples.

\subsection{Discussion and Conclusions on Saturated Testing}

The $100 \mathrm{~h}$ saturated test program was altered during the testing so that lower $C D$ conditions were examined. This was a result of the large oxidation thicknesses that were observed in the tested anodes at $h_{i}$ igh $C D$ and the increases in the cell. voltage during testirig. The lower current density tests were found to have more limited oxidation, less microstructural changes, and lower corrosion.

The saturated tests defined the minimum corrosion of the CEROXcoated Cu cermet to occur at a BR of 1.5 to 1.6 and lower $C D(0.5$ to $\left.1.3 \mathrm{~A} / \mathrm{cm}^{2}\right)$. The long term test cell design somewhat hindered the evaluation at low $C D$ because of low $C E$ and the crusting of alumina on the anodes. The CEROX was found to reduce corrosion of the uricoated cermet by a factor of 7 at a BR of 1.6 and CD of 1.3 $\mathrm{A} / \mathrm{cm}^{2}$.

The stability of the $c u$ cermet substrate was found to be a problem. In the anodes tested at low $\mathrm{CD}$, the microstructural changes within the substrate were limited to some loss of Cu in the extericr

$\sim 500 \mu \mathrm{m}$ of the substrate, and some oxidation of the cu and increased porosity further into the sample. However, at higher $C D$, as the extent of oxidation became greater, porous and dense 


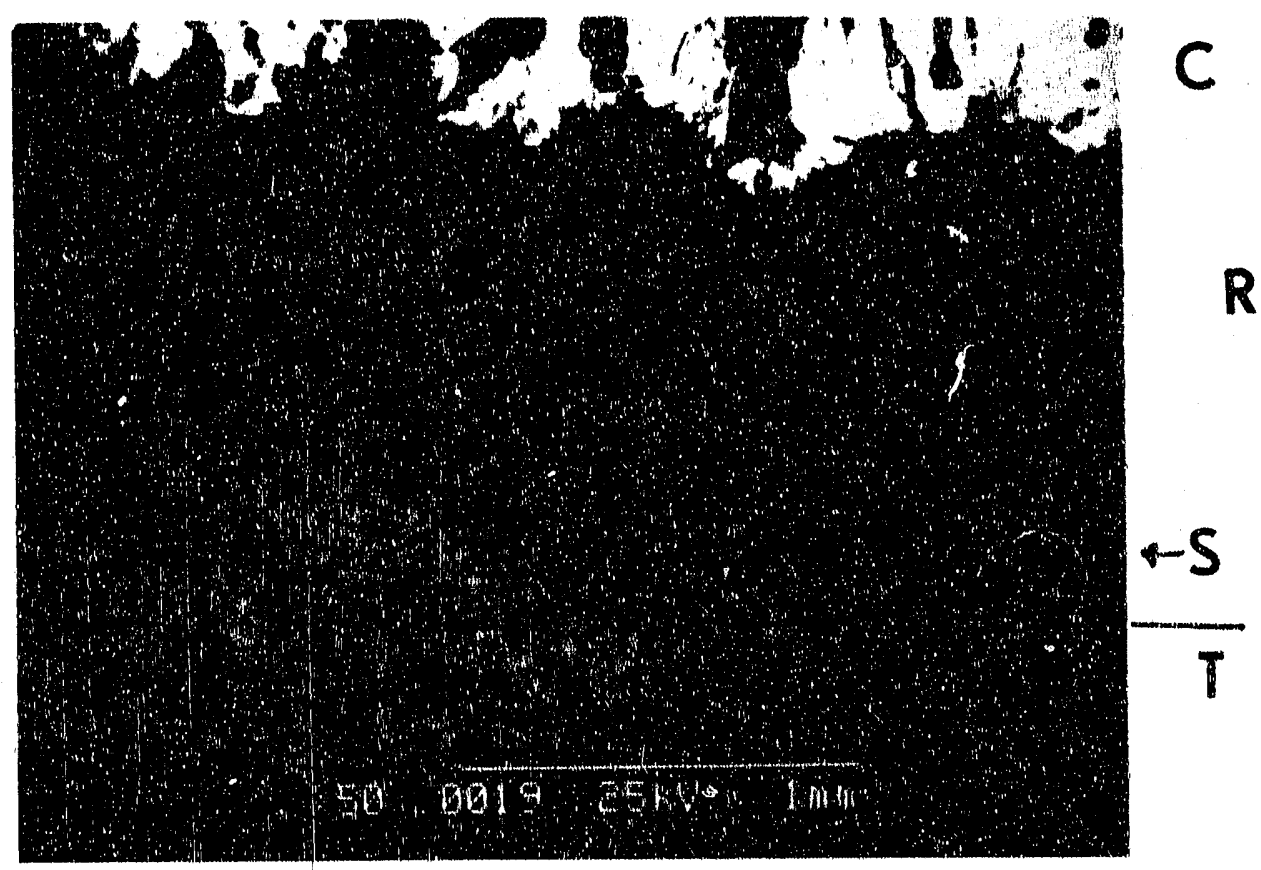

Figure 85. The edge of anode $13614-41$ consisted of the CEROX coatiing (C), the Cu depleted region (R), a NiO layer (S), and an oxidized zone (I') $(50 X) . \quad A=N i F e_{2} O_{4}, B=N i O$

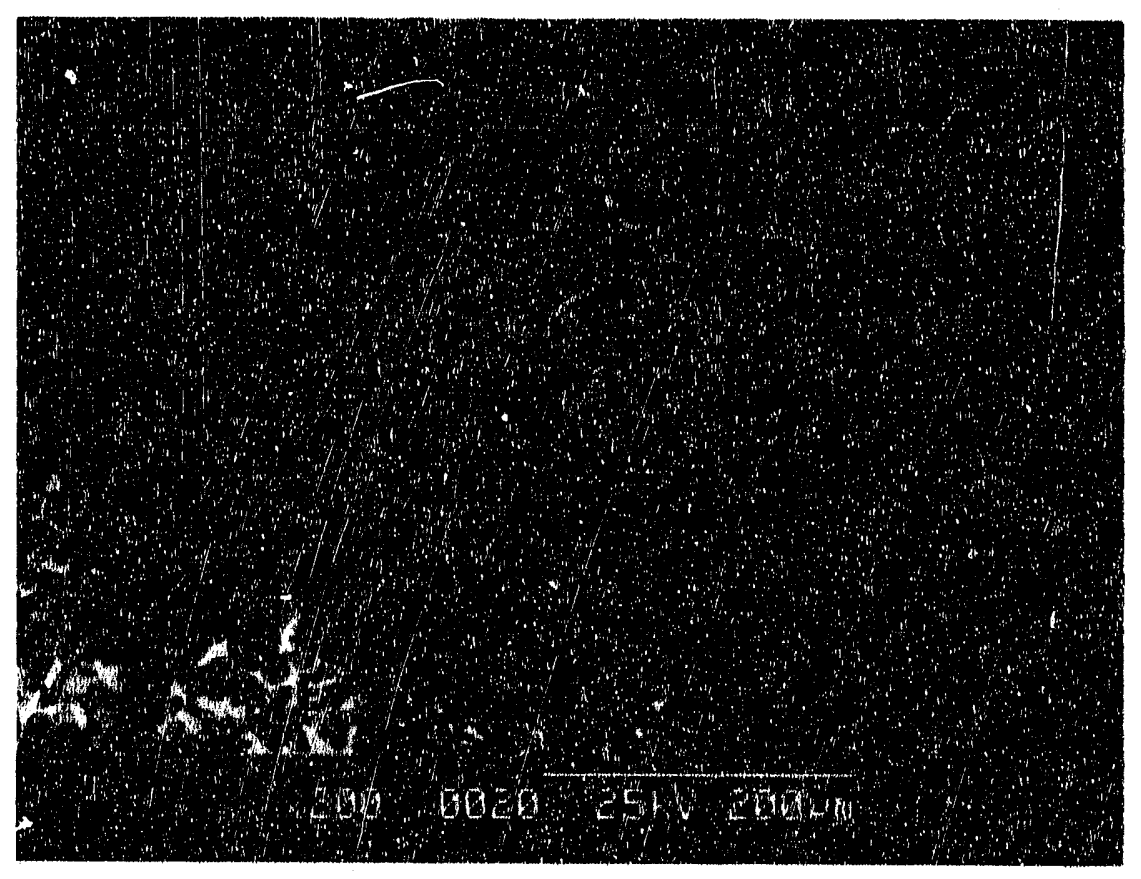

Eigure 86. Higher magnification of layer $S$ trom Eigure 85 (Anode $13614-41,200 X$ ). $C=N i O, D=N i E_{2} O_{4}, E=C u$ oxide, $\mathrm{E}=\mathrm{Cu}$ inetal. 


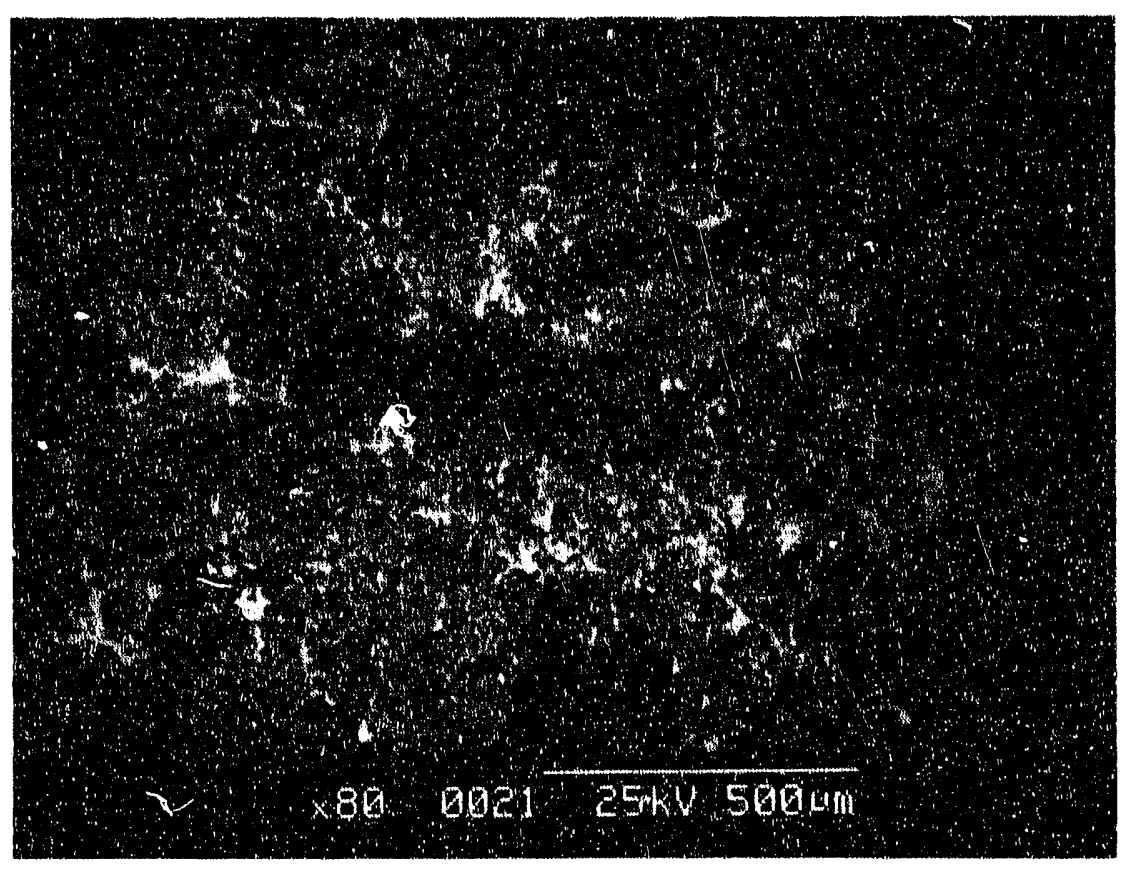

Gigure 87. Layered structure in the oxidized region of anode $13614-41$, layers of angular $\mathrm{NiFe}_{2} \mathrm{O}_{4}$ are evident $(80 \mathrm{X})$. 
alternating layers developed. Layers were found to be Nio-rich or $\mathrm{NiFe}_{2} \mathrm{O}_{4}-\mathrm{rich}$. Cu oxide typically was along grain boundaries of the other phases, but was absent from porous areas. Evidence of cryolite was found in the pores throughout the oxidized areas and even cucasional' $y$ in the $C u$ metal regions. The cryolite in the porous regions probably helped to form the layering in the sample by preferentially dissolving phases in one area and reprecipitating grains in another. However, in the low current density anodes, with limited oxidation, these features are not apparent. 


\section{NONSATURATED ALUMINA TESTS $(100 \mathrm{~h})$}

In industrial electrolysis cells, alumina concentration is generally maintained at 3 to $4 \frac{0}{8}$ in the bath; saturation can be up to 8 to 10\%, depending on bath composition. Achieving higher alumina concentrations in an industrial cell is difficult because of sludging in the bath. Yet, most laboratory testing of inert anodes has been at saturated bath conditions, not industrial conditions, because most laboratory test cells are constructed of alumina. Because oxide materials have been shown to have increased solubility at low alumina concentrations, ${ }^{6}$ there is much interest in laboratory testing to determine the corrosion at industrial conditions.

Attempts have been made in the past to operate CEROX-coated anodes under unsaturated alumina conditions in laboratory test cells.10,11 However, these tests have not been successful because of rapia discolution of the alumina liner (causing saturated conditions), dissolution of aluminum nitride potential liner material, and reaction of boron nitride liner material with ce in the bath. As part of this project, a novel cell was designed for testing at unsaturated conditions (see subsection 4.5).

\subsection{Experimental Design}

Five $100 \mathrm{~h}$ experiments were performed (Table 9). The best BR and $C D$ conditions from the saturated testing were chosen for the nonsaturated experiments. Tests were operated at BR of 1.5 and 1.6 and $C D$ of 0.5 and $0.7 \mathrm{~A} / \mathrm{cm}^{2}$ to reduce corrosion and minimize oxidation of the substrate. Alumina concentrations of 4 , 6 , and $7.2 \%$ were examined, corresponding to $50 \%$, 75\%, and $90 \%$ of saturation $\left(\sim 8 \frac{9}{5}\right) .35$

\subsection{Test cell operation}

A new test cell was designed as part of this project (Subsection 4.5). The test cell performed quite well in operating tests at nonsaturated alumina conditions. The crucible maintained integrity throughout the test as long as argon flowed around the exterior and interior. Less than saturated alumina bath conditions were maintained without difficulty. The cathode remained electricaliy isolated from the crucible at all times during testing. A thin region of slushy cryolite between the liquid bath and solid cryolite bottom did occur but the bottom remained frozen.

The BR fluctuations with time are shown in Figures 88 through 92. The lines are best linear fits provided to help compare the individual experiments. Most measured values are within \pm 0.1 units of the average value, which is always lower than the targeted value. The experiments targeted for $B R=1.5$ actually had average $B R$ values between 1.45 and 1.5 and extremes of 1.35 and 1.6 . The experiment targeted for $\mathrm{BR}=1.6 \mathrm{had}$ an average $\mathrm{BR}=1.51$ and 
Table 9. Nonsaturated alumina test conditions.

\begin{tabular}{|c|c|c|c|}
\hline EXPERIMENT & ALUMINA (wt\%) & BR & CD (A/ $\left.\mathrm{cm}^{2}\right)$ \\
\hline HS-2 & 6 & 1.5 & 0.5 \\
\hline HS-3 & 6 & 1.5 & 0.7 \\
\hline HS-4 & 6 & 1.6 & 0.7 \\
\hline HS-5 & 4 & 1.5 & 0.5 \\
\hline HS-6 & 7.2 & 1.5 & 0.5 \\
\hline
\end{tabular}




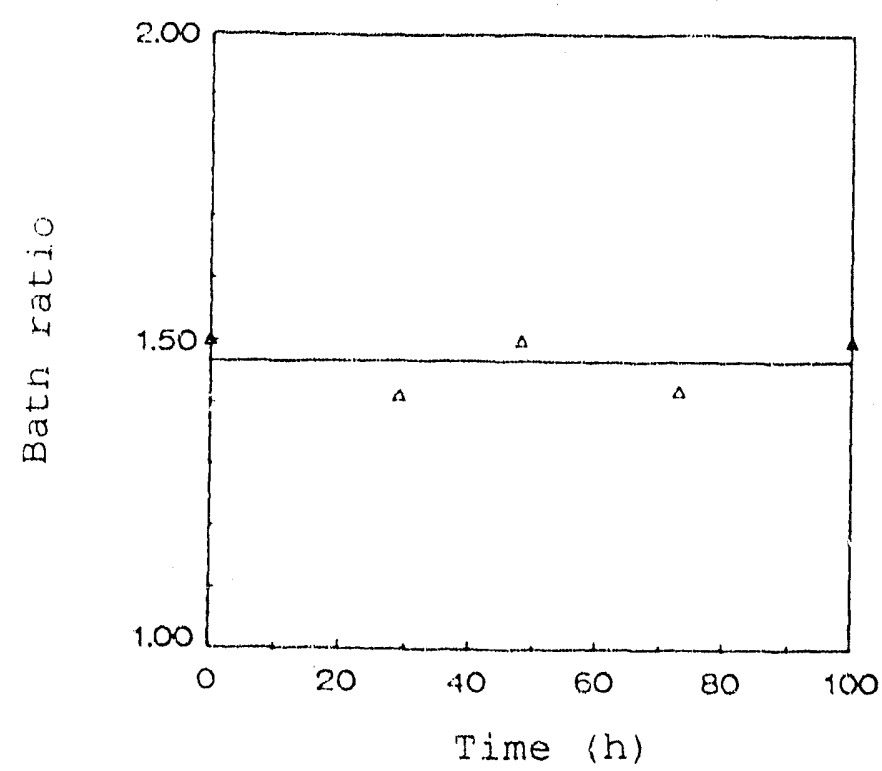

Eigure 88 . Bath ratio fluctuations during experiment 13608-20-HS-2. Target conditions: bath ratio $=1.5$ current density $=0.5 \mathrm{~A} / \mathrm{cm}^{2}$, alumina concentration $=6$ wt\%.

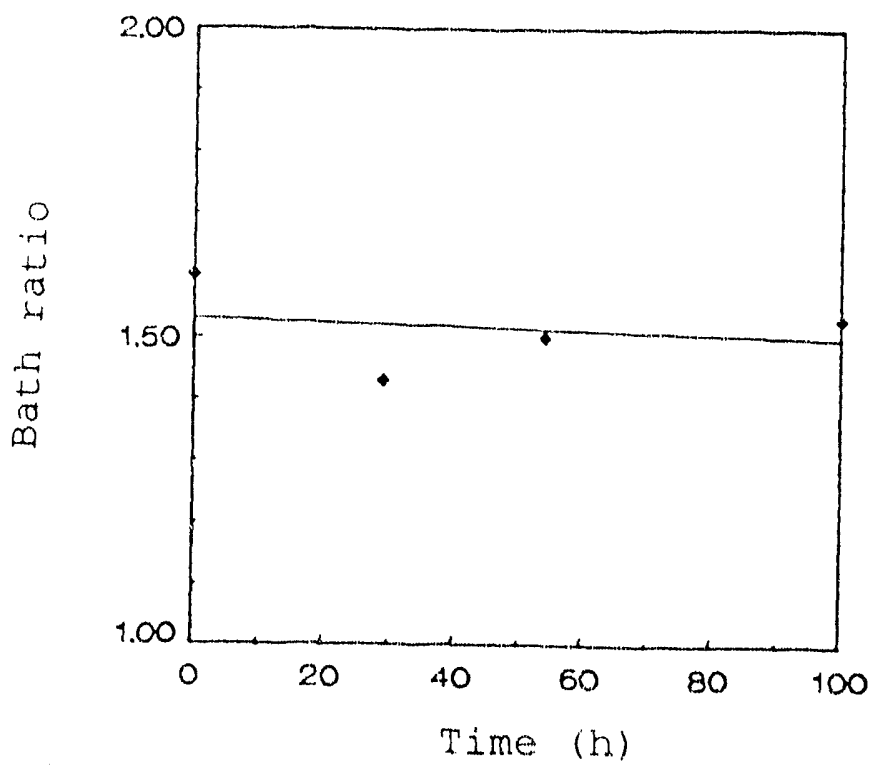

Eigure 90. Rath ratio fluctuations during experiment 13608-24. HS -4. Target conditions: bath ratio $=1.6$, curxent density $=0.7 \mathrm{~A} / \mathrm{cm}^{2}$, alumina concentration $=6$ н $7 \%$.

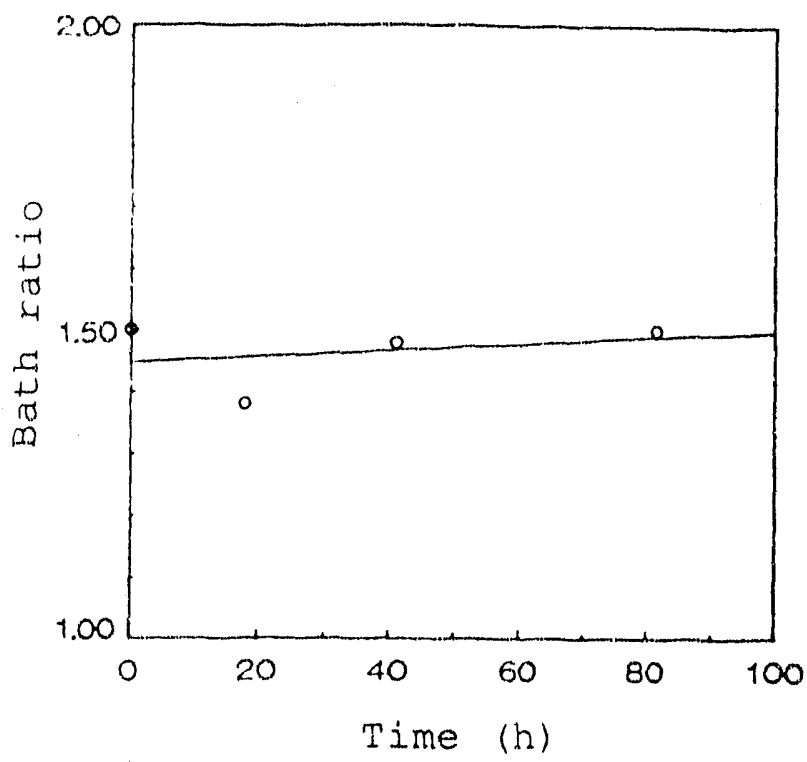

Eigure 89 . Bath ratio fluctuations during experiment 13608-22-HS-3. Target conditions: bath ratio $=1.5$, current density $=0.7 \mathrm{~A} / \mathrm{cm}^{2}$, alumina concentration $=6 \mathrm{w} / \mathrm{\%}$.

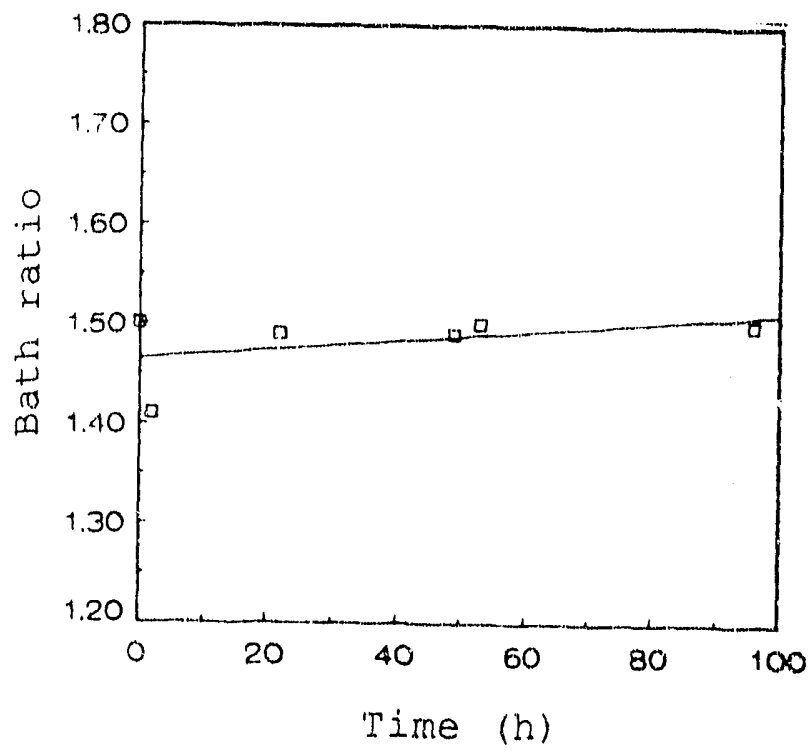

Fi.gure 91 . Bath ratio huctuations during experiment 13608-26-HS-5. Target conditions: bath ratio $=1.5$. current density $=0.5 \mathrm{~A} / \mathrm{cm}^{2}$, alumina concentration $=4 \mathrm{wt} \%$. 


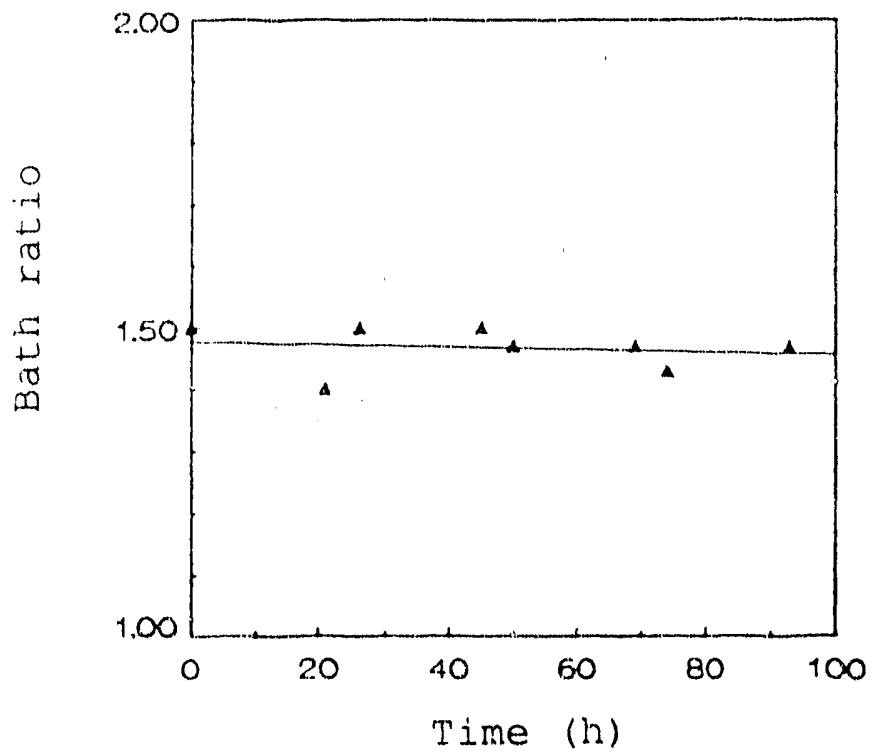

Figure 92 . Bath ratio fluctuations during experiment 13608-28-HS-6. Target conditions: bath ratio $=1.5$, current density $=0.5 \mathrm{~A} / \mathrm{cm}^{2}$, alumina concentration $=7.2 \mathrm{wt} \%$. 
extremes of 1.4 and 1.6 . This lowering of the BR from the initial targeted values is thought to be caused by intercalation of $\mathrm{Na}$ into the carbon of the exposed crucible.

The alumina concentration in the bath also changed with time (Figures 93 through 97). Experiments with alumina concentrations targeted for $6 \%$ had average values between 5.5 to $6 \%$ and, for the most part, varied by $\pm 1 \%$. The experiments targeted at $4 \%$ and $7.2 \%$ averaged at $4.6 \%$ and $6.5 \%$, respectively. The former generally stayed around 48 while the 7.28 alumina experiment was erratic with respect to alumina concentration, falling below 4 \% and ending as high as 11.5\%. Although there was some lack of control in the alumina concentration during theses tests, it is expected that the concentrations can be held to $\pm 0.5 \%$ in future tests by more frequent sampling and analysis.

In addition to fluctuations in BR and alumina concentration, the CD varied somewhat with time because the anodes do not have a controlled area exposed to the bath. Changes in anode immersion depth produces changes in the exposed surface area, which in turn changes the CD. Variation could be as much as $\pm 25 \%$ of the desired value.

The CE were calculated by recovering the All metal, weighing it, and comparing that amount to the theoretical amount expected. The results are shown in Eigure 98. The experiments at the higher CD $\left(0.7 \mathrm{~A} / \mathrm{cm}^{2}\right)$ had $\mathrm{CE}$ of 40 and $60 \%$. Those at the lower CD

$\left(0.5 \mathrm{~A} / \mathrm{cm}^{2}\right)$ have current efficiencies of $\sim 20$ to $37 \%$. These CE at the low $C D$ are better than those in the saturated $100 \mathrm{~h}$ test cell. This may be because of the reduction in electrolyzed carbon in the half-saturated test cell design.

\subsection{Microscopy Results}

The CEROX coatings deposited in all tests were similar to those seen in saturated testing (Eigures 99 through 103). The coatings varied in thickness across the surface of the anodes; the thickest sections were $5 \mathrm{~mm}$, and the average thickness was 2 to $3 \mathrm{~mm}$. All coatings were fairly dense near the substrate and iess dense in the outer 1 to $2 \mathrm{~mm}$. The coatings are thicker than in saturated testing because of the greater amount of $\mathrm{CeF}_{3}$ that was added to the cell to compensate for some melting of the frozen bottom. Apparentiy, the $\mathrm{CeF}_{3}$ levels in the melt were still higher than in the saturated testing, causing thicker CEROX coatings. Figure 104 shows the levels of $\mathrm{Ce}$ in the bath and metal at the end of the tests and Figure 105 shows the calculated ce distribution coefficient. In the saturated tests, Ce in the metal averaged $22 \%$ (Figure 54) while it averaged $\sim 2.9$ s in the nonsaturated tests. The Ce concentration in the bath averaged $\sim 0.2 \%$ in the saturated tests and $0.35 \%$ in the nonsaturated baths. The ce partition coefficient averages $\sim 10$, which is similar to that in the saturated alumina tests. 


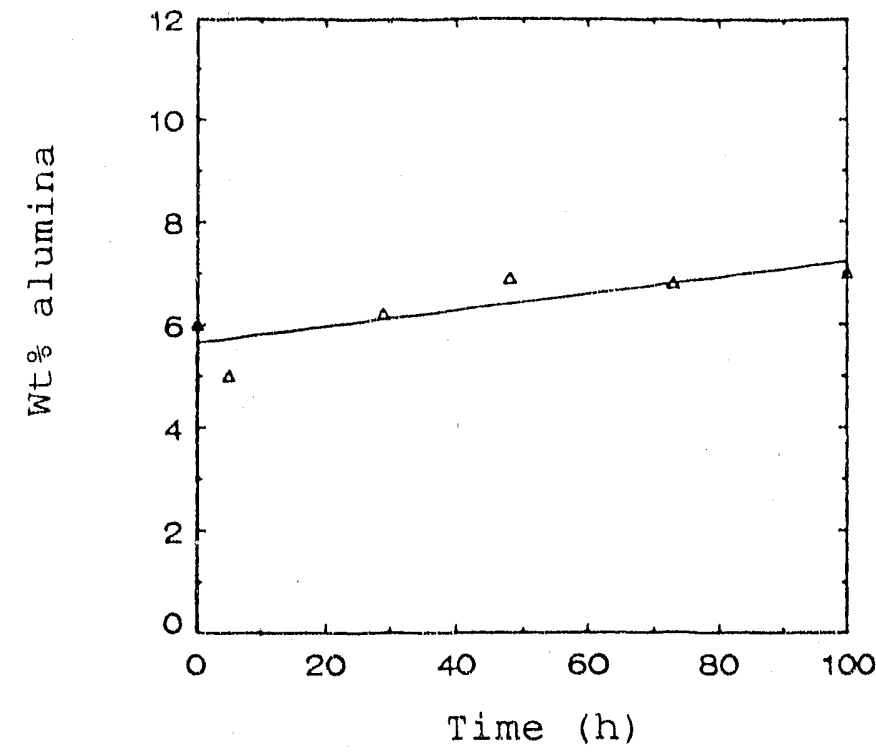

Eigure 93. Alumina concentration fluctuations during experiment 13608-20-HS-2. Target conditions: bath ratio $=1.5$, current density $=0.5 \mathrm{~A} / \mathrm{cm}^{2}$, alumina concentration $=6 \mathrm{wt} \%$.

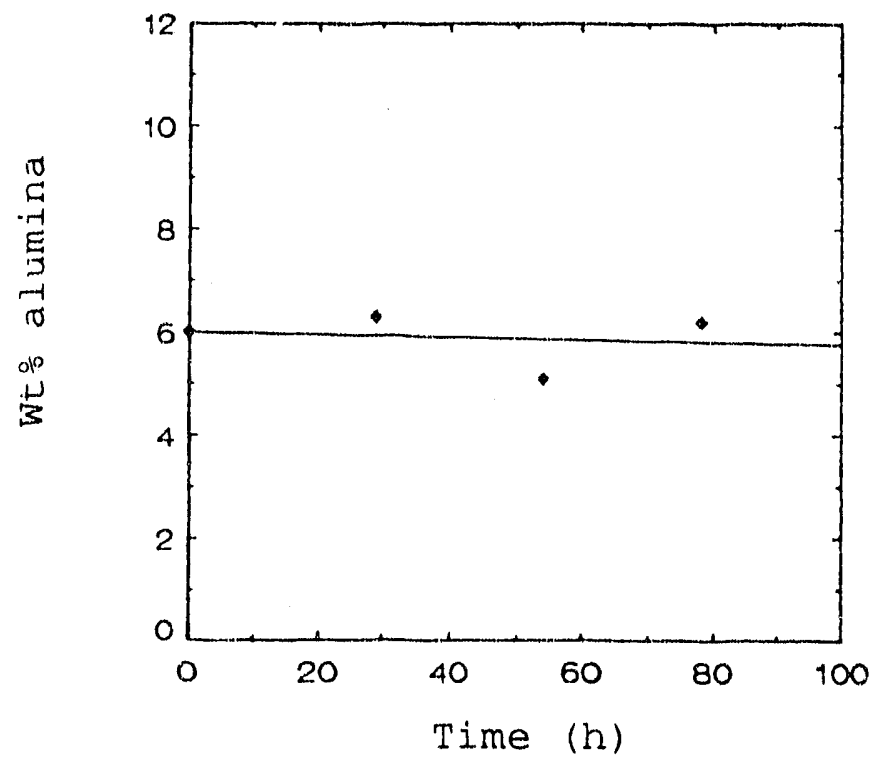

Eigure 95. Alumina concentration fluctuations during experiment 13608-24-HS-4. Target conditions: bath ratio $=1.6$, current density $=0.7$ $\mathrm{A} / \mathrm{cm}^{2}$, alumina concentration $=6 \mathrm{wt} \%$.

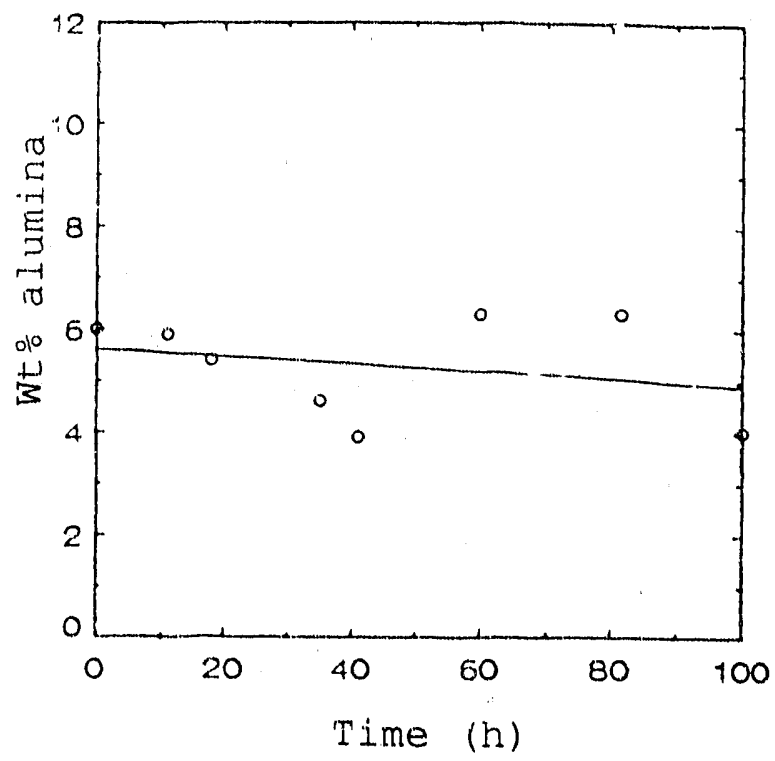

Figure 94 . Alumina concentration fluctuations during experiment 13608-22-HS-3. Target conditions: bath ratio $=1.5$, current density $=0.7 \mathrm{~A} / \mathrm{cm}^{2}$, alumina concentration $=6 \mathrm{wt} \%$

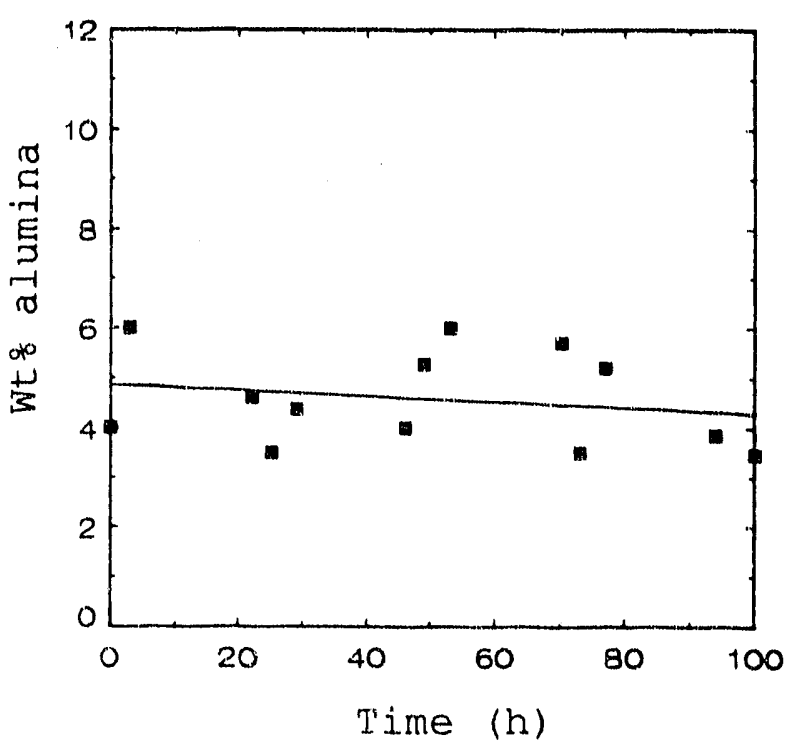

Eigure 96 . Alumina concentration fluctuations during experiment 13608-26-HS-5. Target conditions: bath ratio $=1.5$, current density $=0.5$ $\mathrm{A} / \mathrm{cm}^{2}$, alumina concentration $=4 \mathrm{w} \%$. 


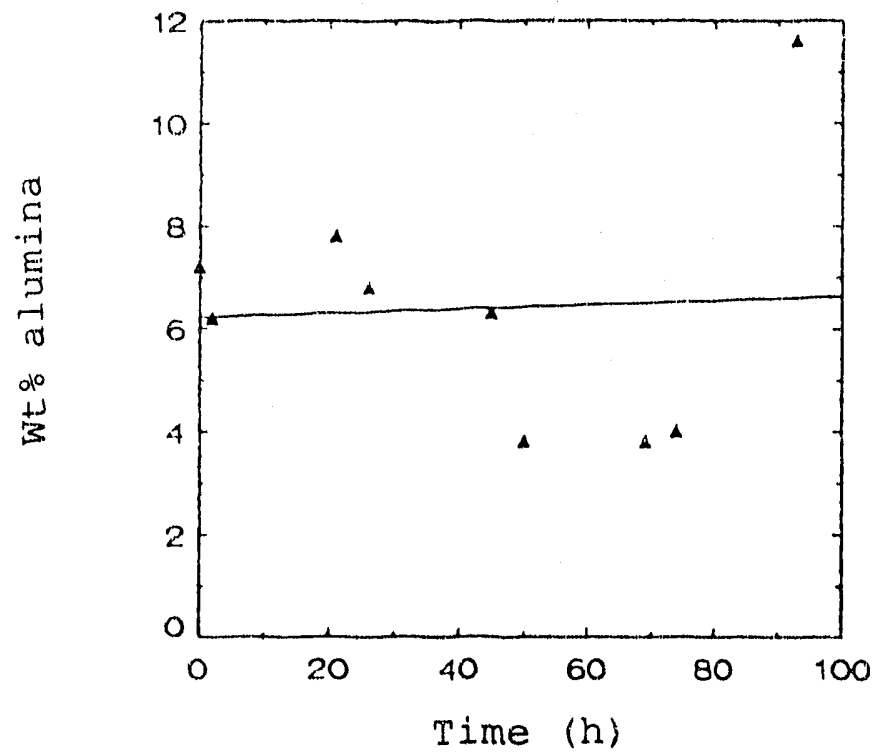

Eigure 97 . Alumina concentration fluctuations during experiment 13608-28-HS-6. Target conditions: bath ratio $=1.5$, current density $=0.5$ $\mathrm{A} / \mathrm{cm}^{2}$, alumina concentration $=7.2 \mathrm{w} \%$. 


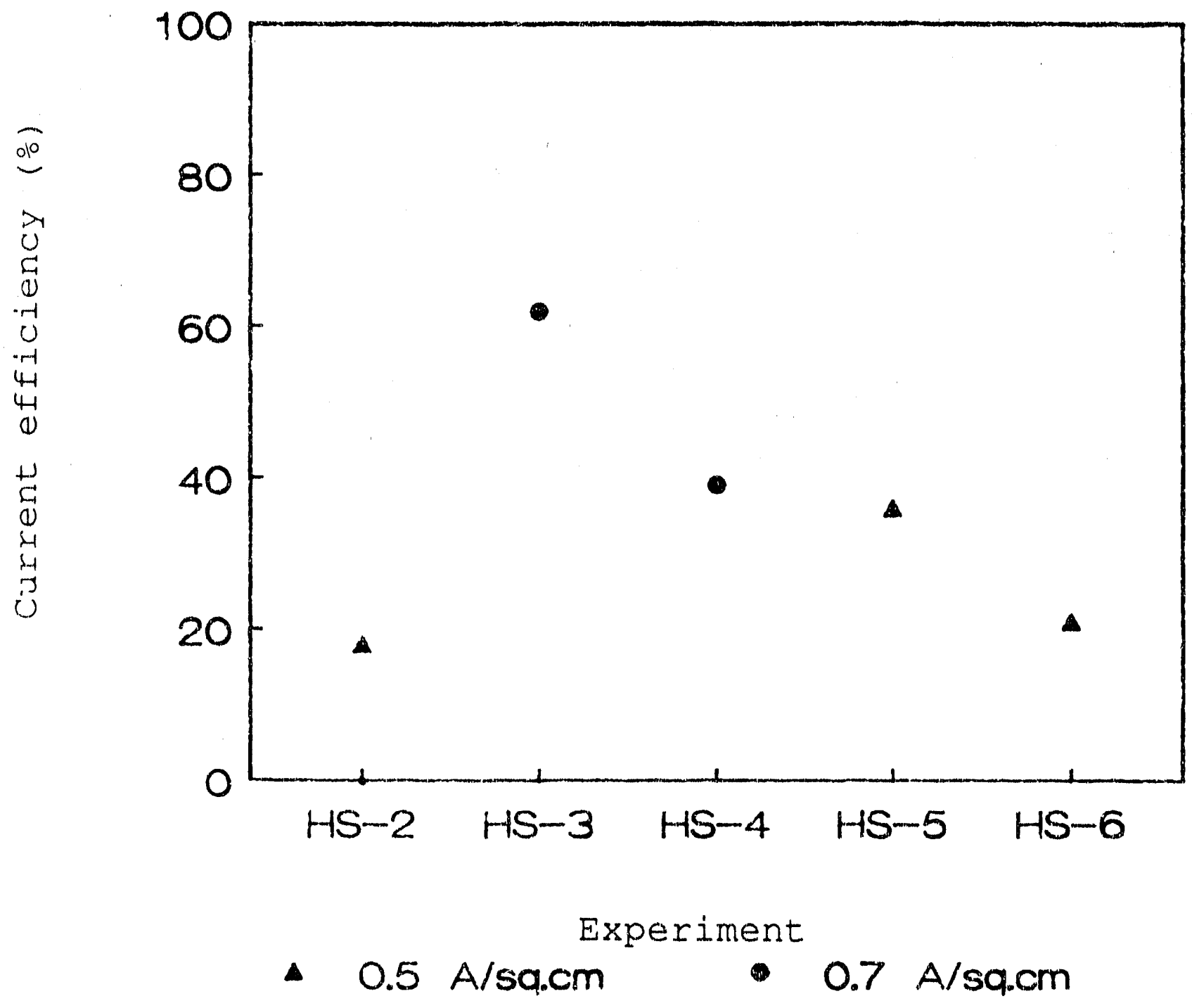

Eigure 98. Current efficiencies of the nonsaturated tests. 


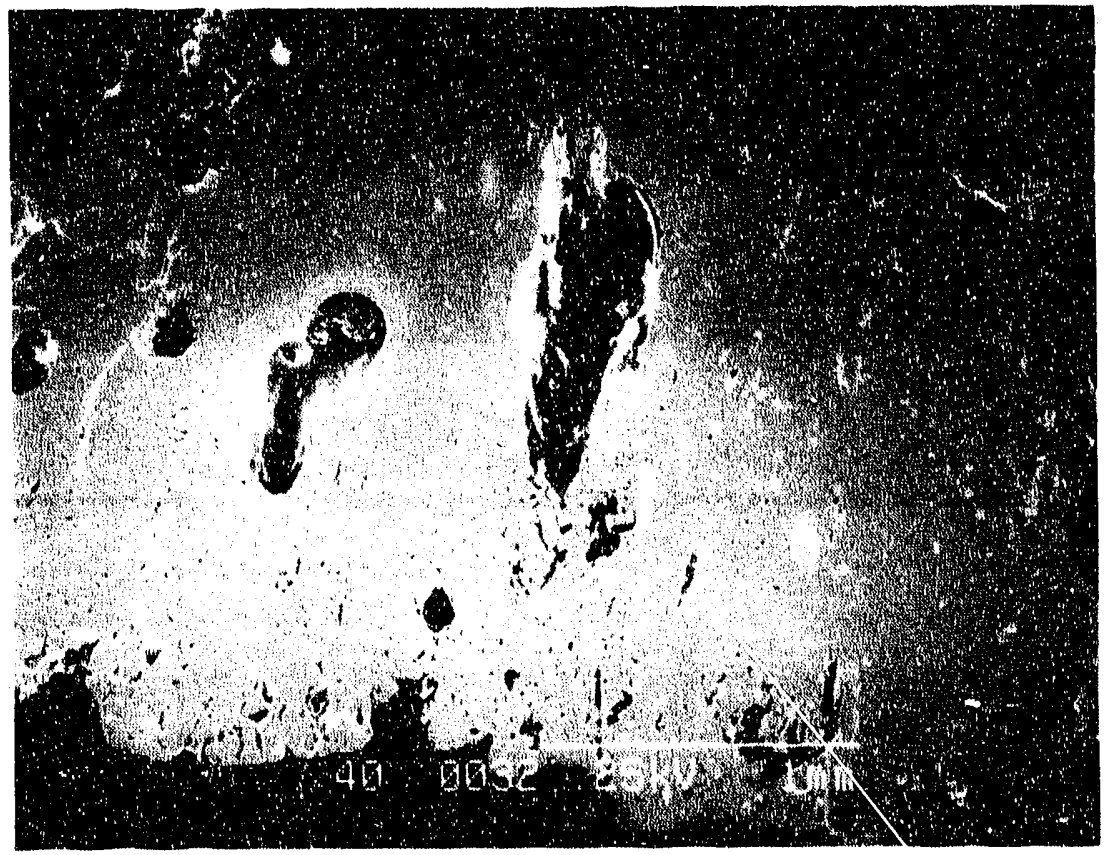

Figure 99. The CEROX coating on anode HS-2 (40X). 


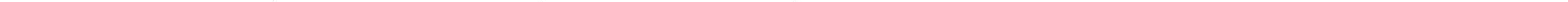




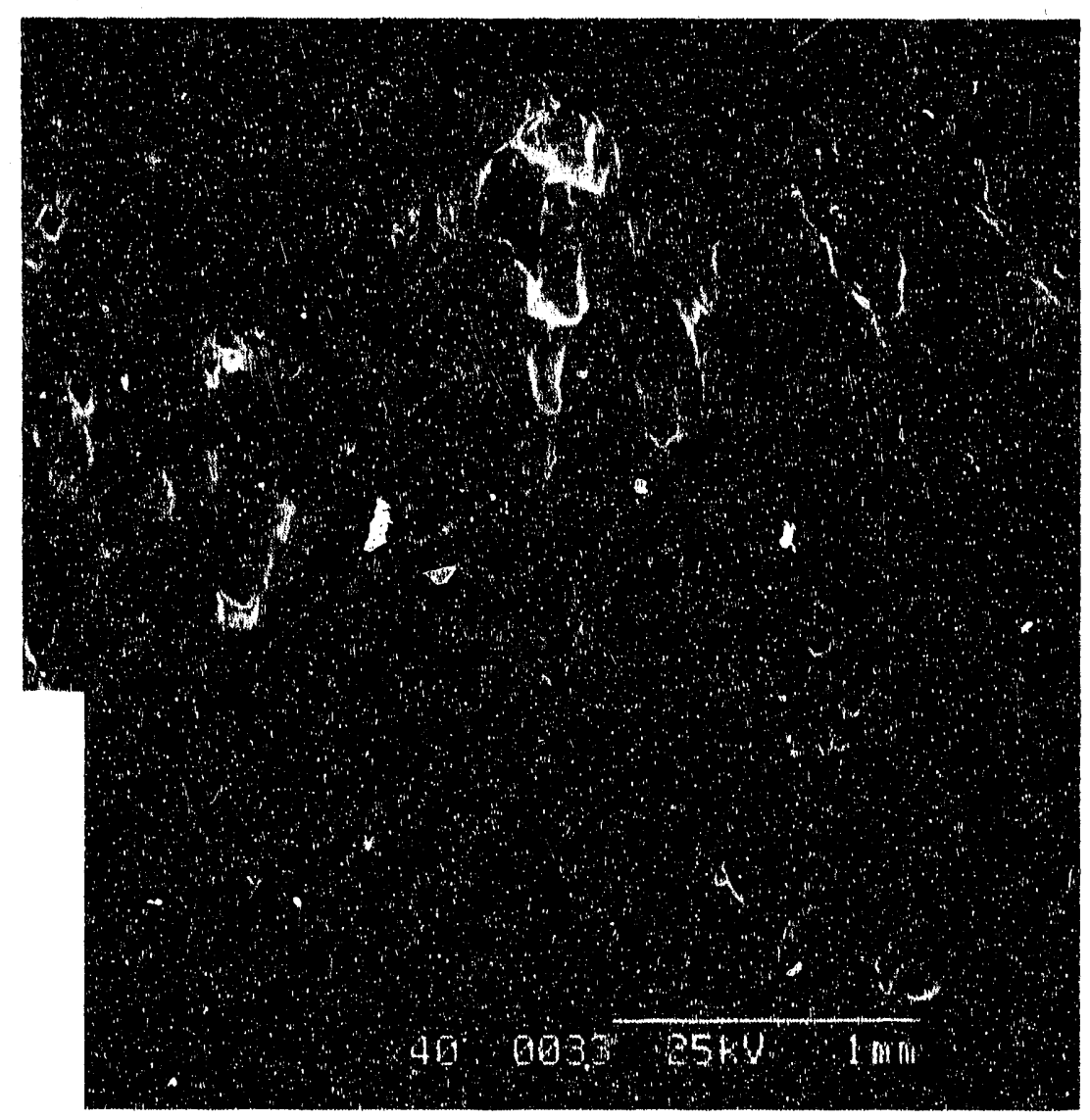

Eigure 101. The CEROX coating on anode HS-4 (40X). 


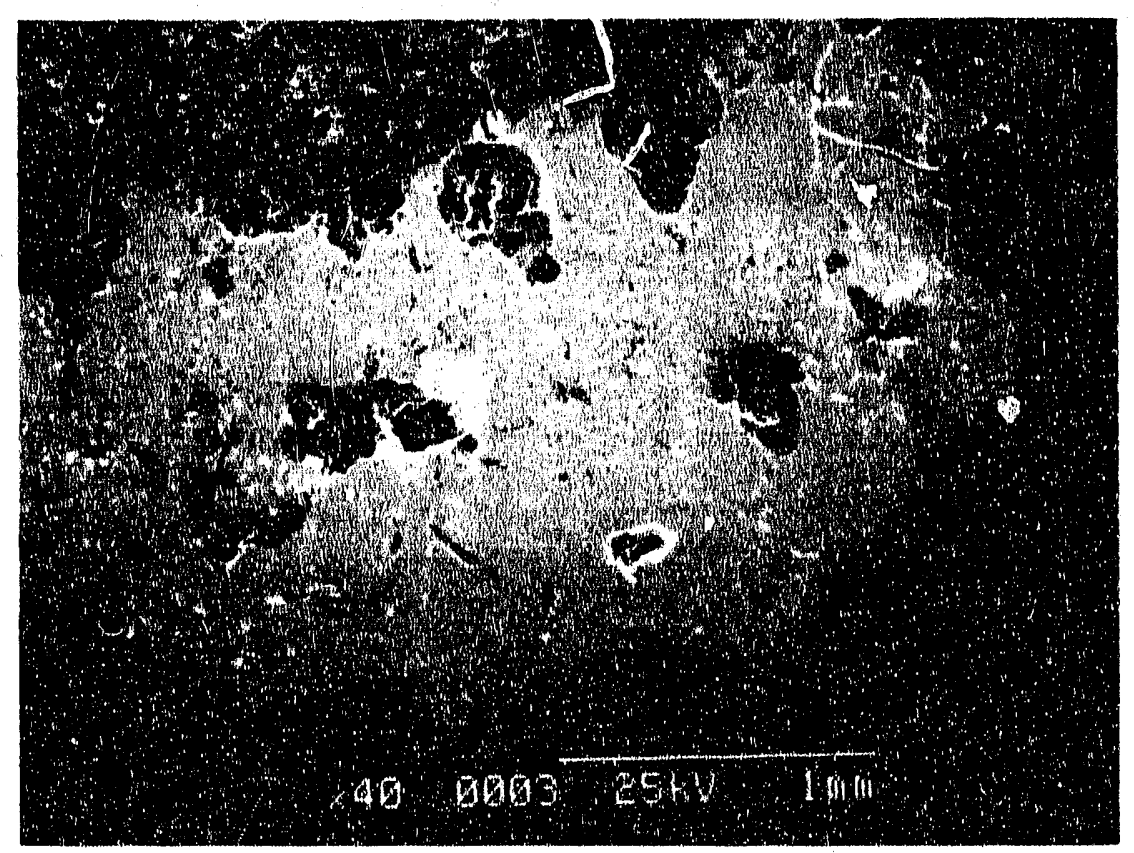

Eigure 102. The CEROX coating on anode HS-5 (4OX). 


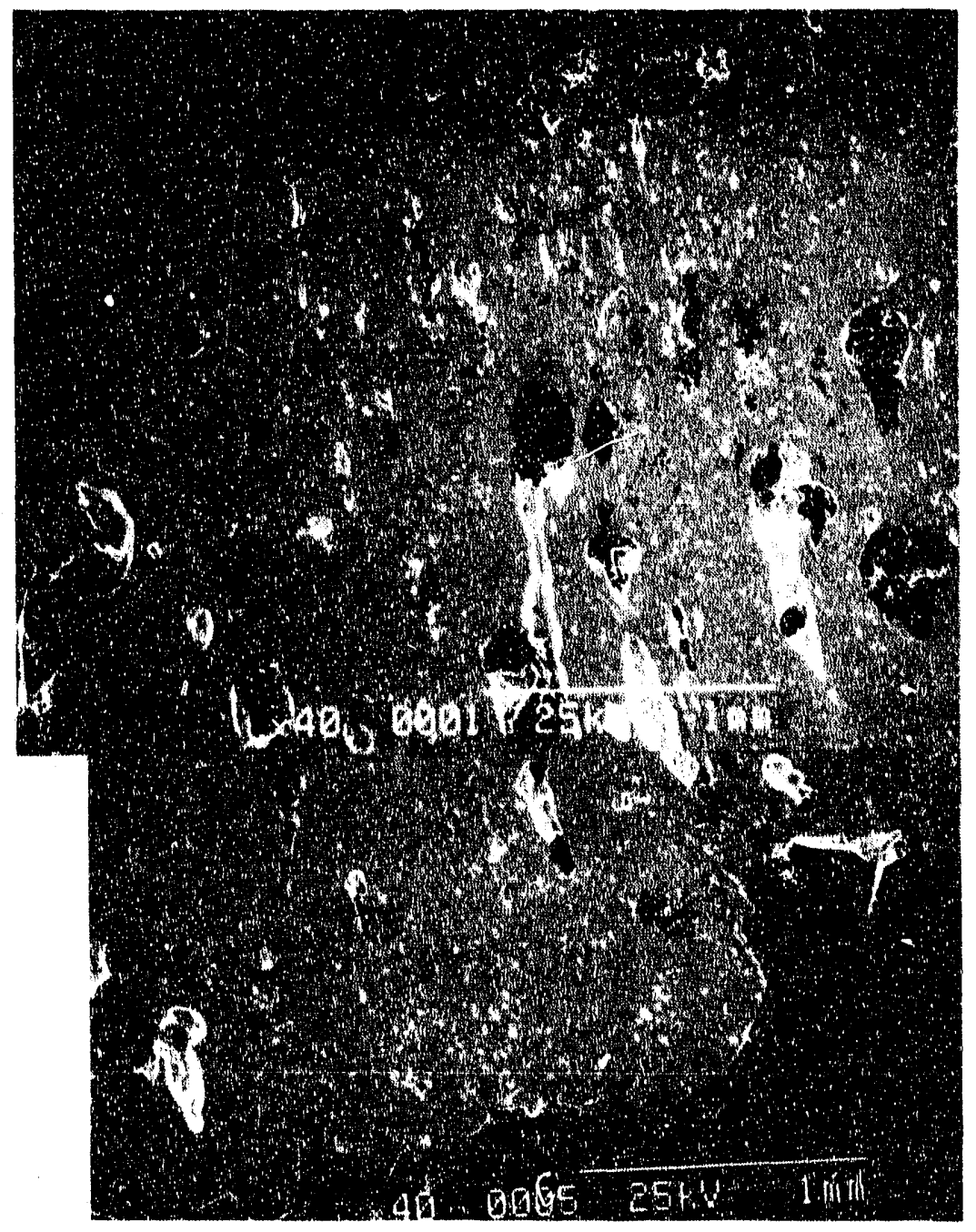

Eigure 103. The CEROX coating on anode HS-6 (40X). 


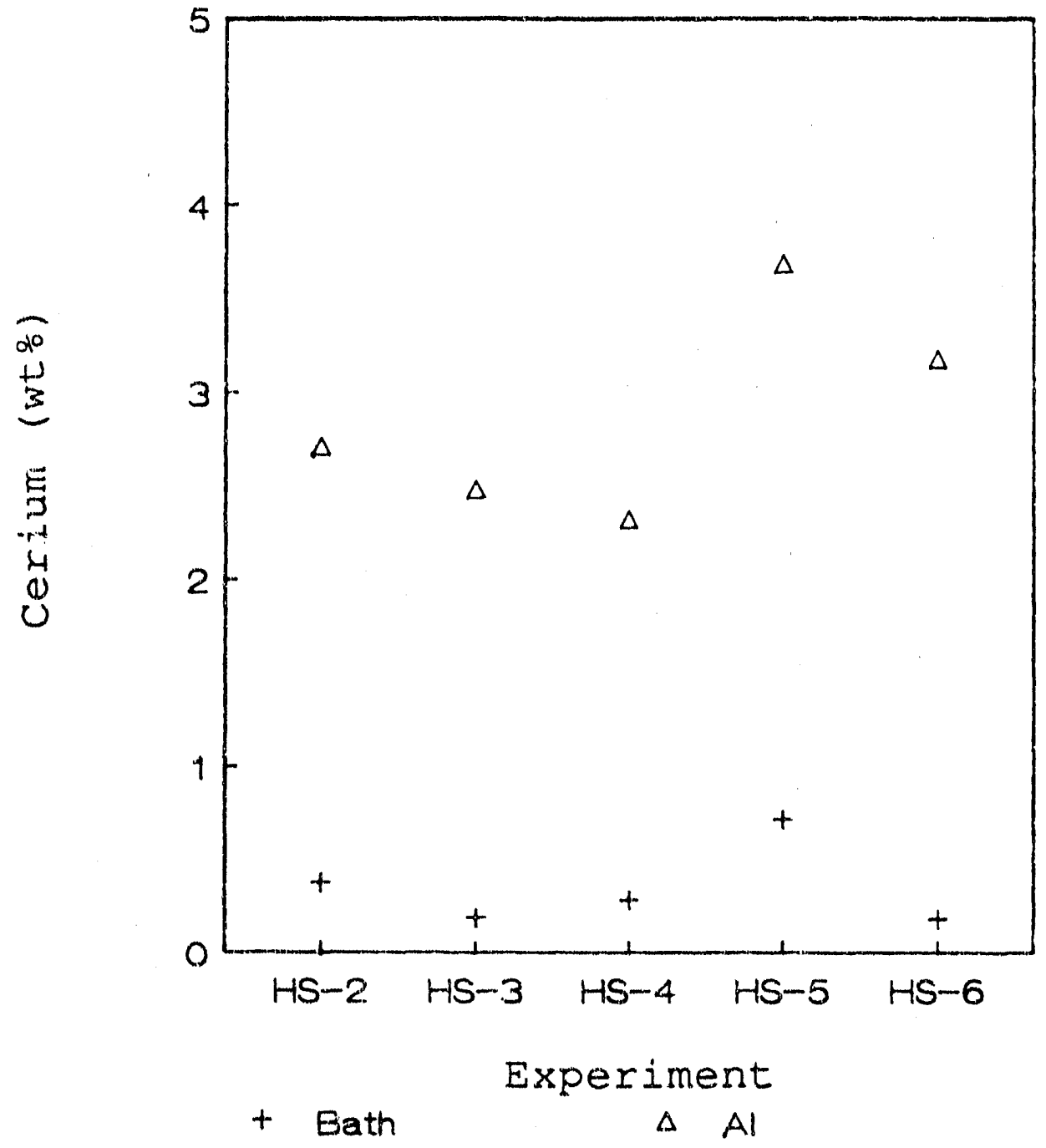

Eigure 104. The wto $\mathrm{Ce}$ in bath and metal for the nonsaturated alumina tests. 


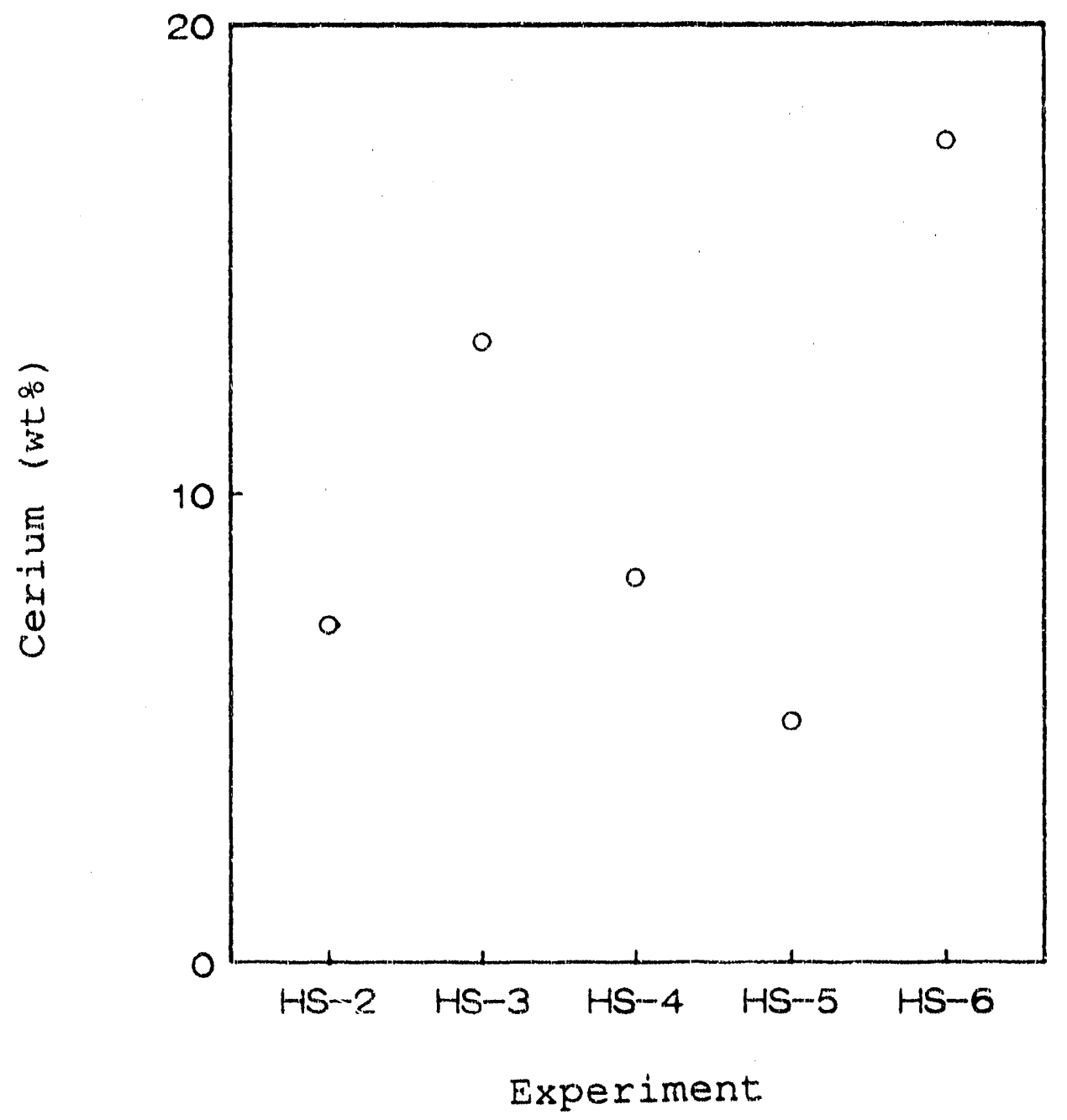

Eigure 105. Ce partition coefficient in the nonsaturated alumina tests. 
Oxidation layers were $\sim 1.25 \mathrm{~mm}$ thick in the experiments at $0.5 \mathrm{~A} / \mathrm{cm}^{2}$ and 3 to $6 \mathrm{~mm}$ thick in the experiments at $0.7 \mathrm{~A} / \mathrm{cm}^{2}$. The difference in oxidation layer thickness with $C D$ is also seen in saturated experiments. SEM micrographs of each sample (Eigure 106 through 116) show that the microstructure of the oxidized region is similar to that in the saturated tests ( $\mathrm{f}=\mathrm{NiFe}_{2} \mathrm{O}_{4}, \mathrm{n}=\mathrm{NiO}, \mathrm{C}=\mathrm{Cu}$ oxide in the $1000 x$ photos). The $100 x$ photos show that the cu depleted regions in the anodes are also similar to those found in saturated alumina tests.

\subsection{Corrosion Results}

Corrosion resilts for the less than saturated tests are shown in Table 10. Corrosion as a function of alumina concentration is shown in Eigure 116 for tests at $a$ BR of 1.5 and $C D$ of $0.5 \mathrm{~A} / \mathrm{cm}^{2}$ (HS-2, HS-5, HS-6). The values at 1008 alumina saturation are averages of the two tests operated at those conditions in the saturated test cell design. The corrosion appears to follow almost a linear trend of increasing corrosion with decreasing alumina. As in most of the saturated testing, the $\mathrm{Ni}$ corrosion is lowest. However, in these tests, Fe corrosion is somewhat higher than $\mathrm{Cu}$ corrosion. The test with the highest total corrosion (HS-5, 4.89\% total corrosion), is still lower than the corrosion in the ce-free saturatod test $(5.11 \%)$.

Figure 117 shows the effect of $B R$ on the metal impurities at $6 \%$ alumina and $a \mathrm{CD}$ of $0.7 \mathrm{~A} / \mathrm{cm}^{2}$ (HS-3 and $\mathrm{HS}-4$ ). The corrosion is about the same for both tests. The effect of $C D$ on metal impurities is shown in Eigure 118 (HS-2 and HS-3) at 6\% alumina and a BR of 1.5. Again, little effect is seen.

\subsection{Discussion and Conclusions on Nonsaturated Testing}

The novel laboratory cell design for unsaturated alumina operation (which utilizes tempexature gradients to maintain frozen salt as part of the electrolyte containment) has been demonstrated to successfully operate with unsaturated alumina conditions in tests up to $100 \mathrm{~h}$ long. This design allows for testing a variety of anode materials in the alumina saturation conditions expected in industrial cells. With more sampling and analysis, it should be possible to maintain $B R$ and alumina concentration within a narrower range.

The tests on CEROX-coated anodes in these tests revealed that CEROX coatings can be deposited in unsaturated conditions. The ce concentration was slightly higher than in saturated tests but the rROX coatings, other than being thicker than in saturated tests, appeared similar to coatings deposited in saturated tests. The cu cermet also appeared similar to substrates tested in saturated tests, with some oxidation in the outer 1 to $6 \mathrm{~mm}$. 


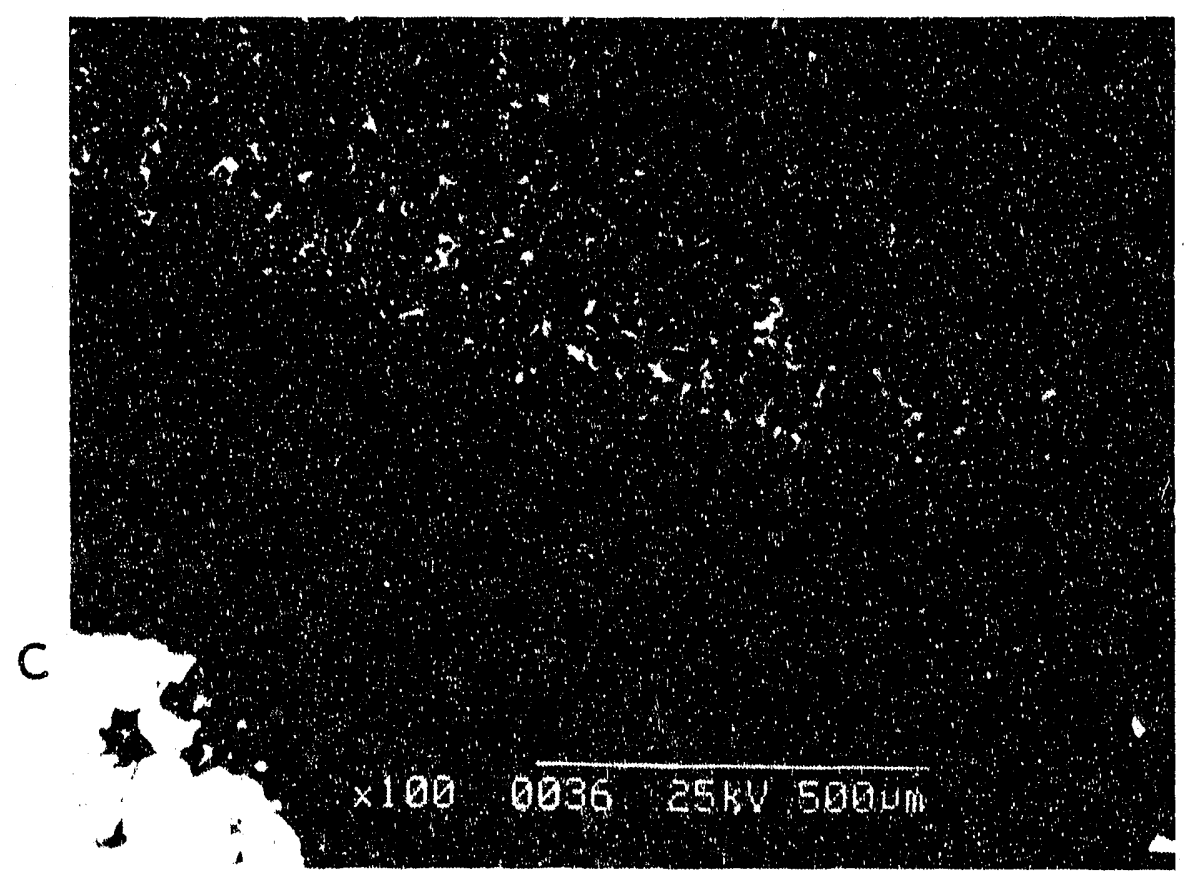

Eigure 106. Edge of HS-2 next to the CEROX coating (C) shows a $\mathrm{Cu}$ depleted region and then an oxidized $\mathrm{Cu}$ region $(100 x)$.

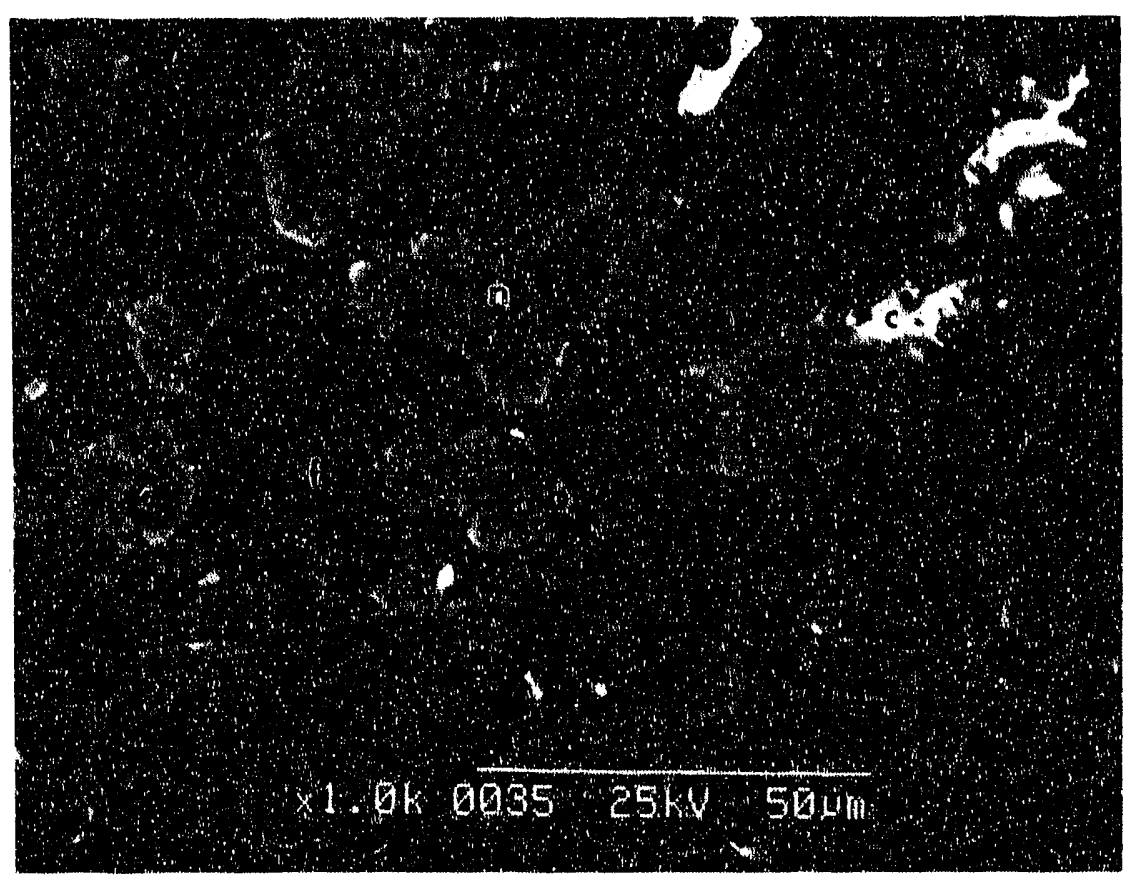

Eigure 107. The oxidized region in $\mathrm{HS}-2(1000 \mathrm{X}) . \mathrm{n}=\mathrm{NiO}, \mathrm{C}=\mathrm{Cu}$ oxide, $\quad \mathrm{I}=\mathrm{NiFe}_{2} \mathrm{O}_{4}$ 


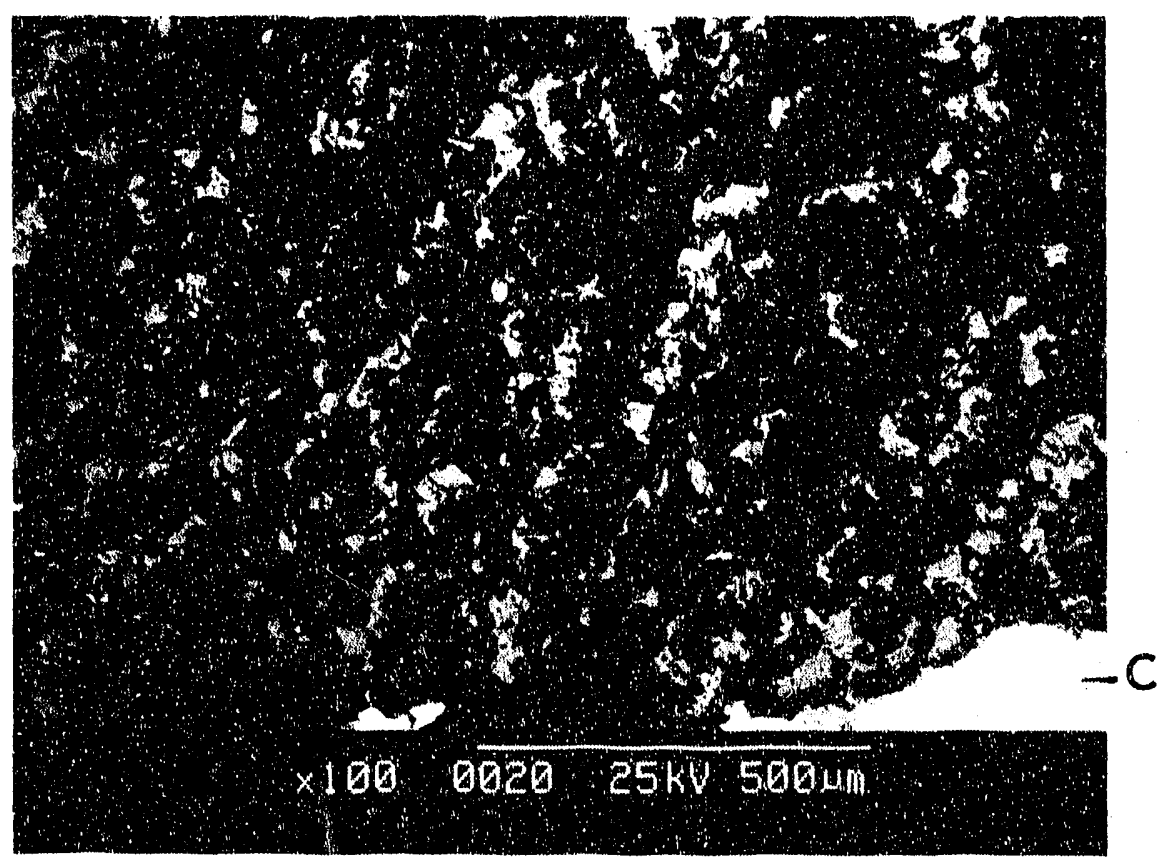

Eigure 108. Edge of HS-3 next to the CEROX (C) coating (100X).

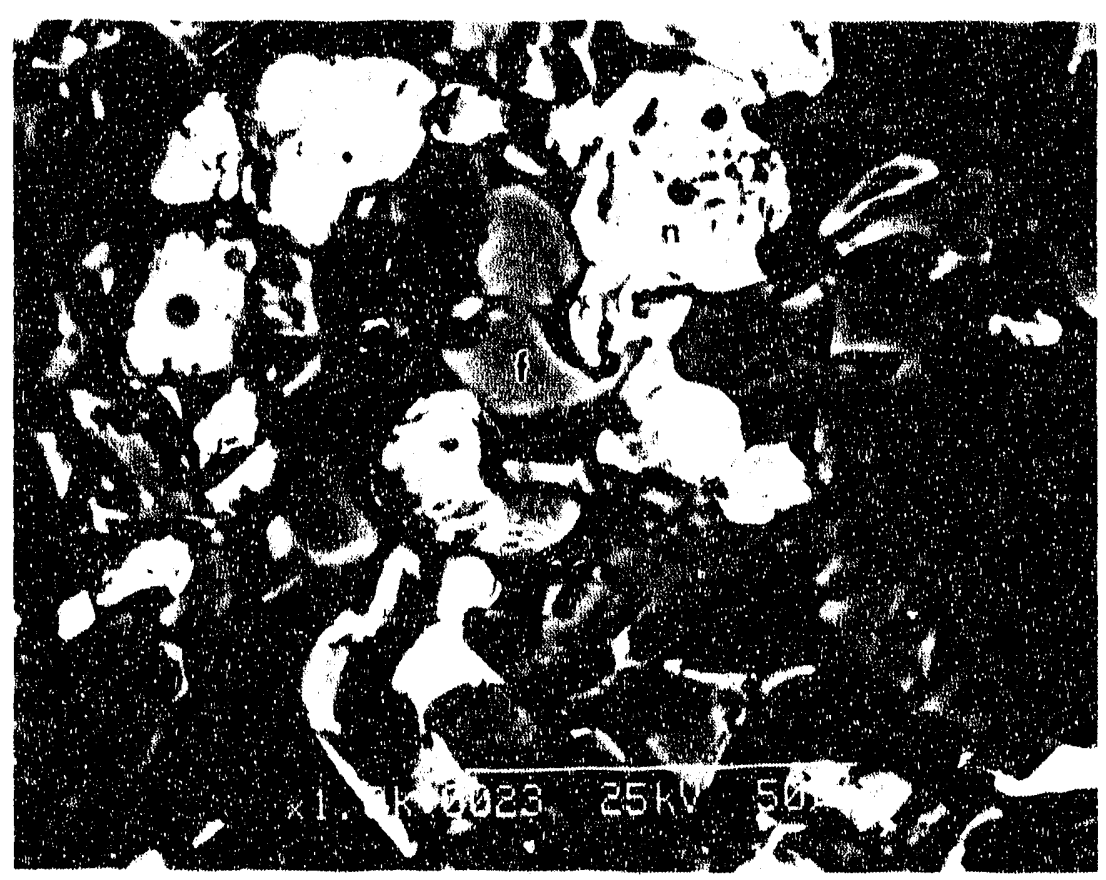

Figure 109. Oxidized region of $\mathrm{HS}-3$ (1000X). $n=\mathrm{NiO}, \quad \mathrm{f}=\mathrm{NiFe}_{2} \mathrm{O}_{4}$ 


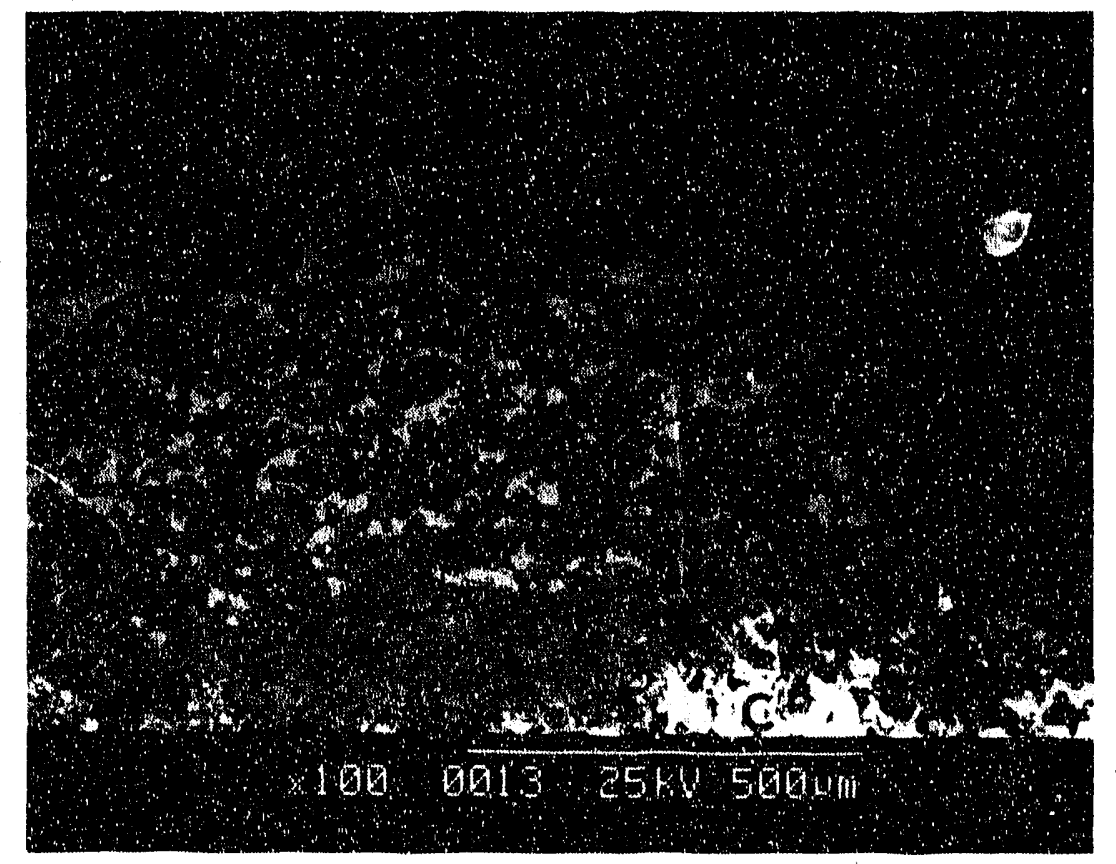

Figure 110. Edge of HS-4 next to the CEROX (C) coating (100X).

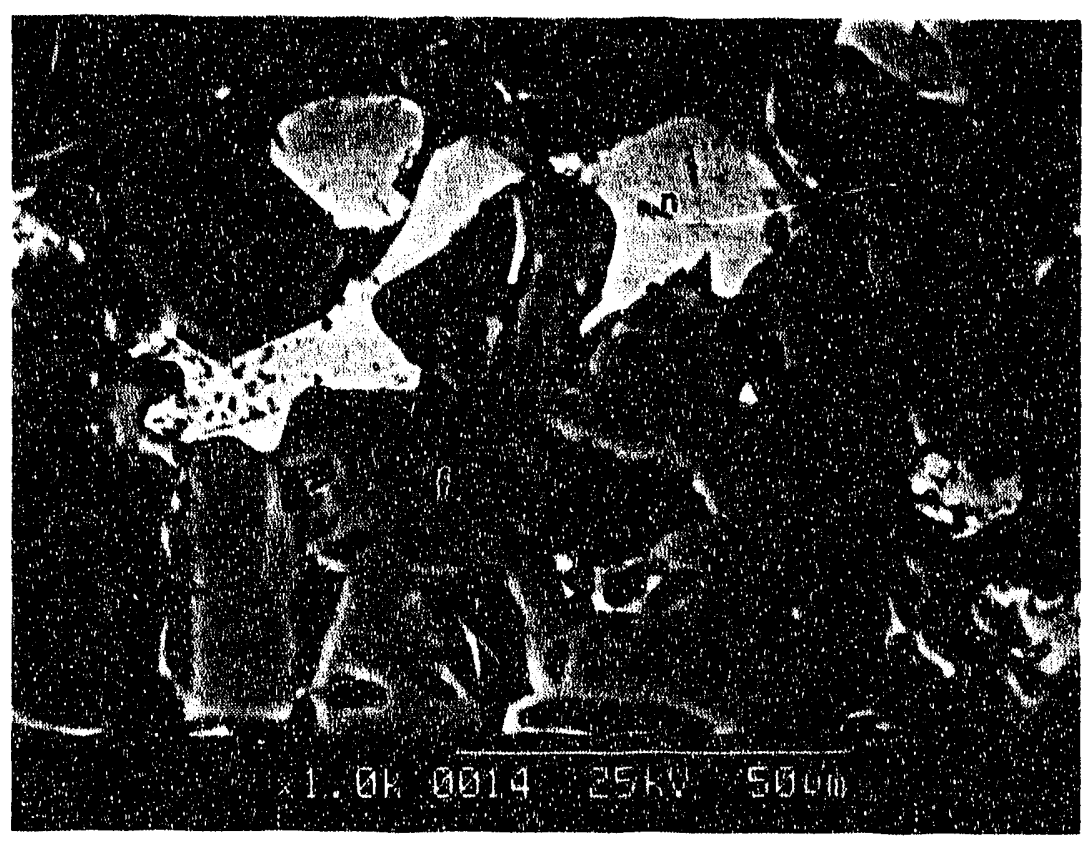

Fiqure 111. The oxidized region in $\mathrm{HS}-4(1000 \mathrm{X}) . \mathrm{n}=\mathrm{NiO}, \mathrm{f}=\mathrm{NiFe}_{2} \mathrm{O}_{4}$ 


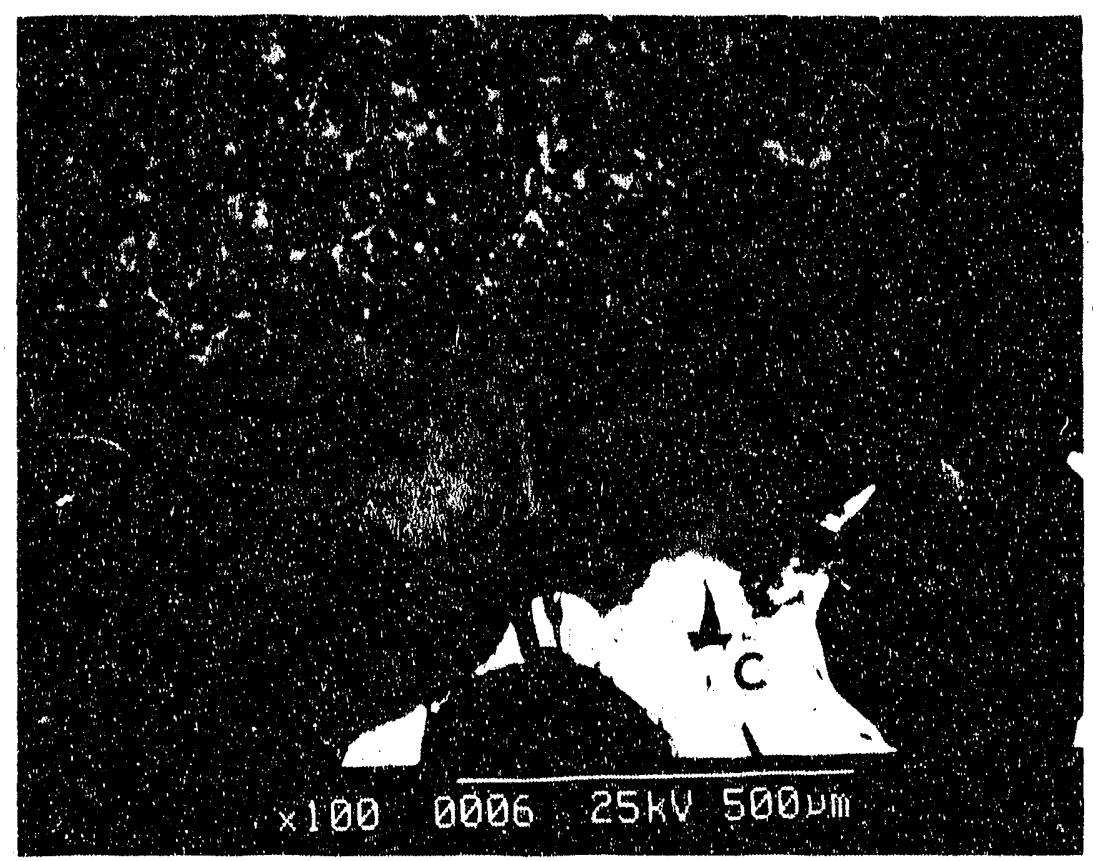

Eigure 112. Edge of HS-5 next to the CEROX (C) coating (100X).

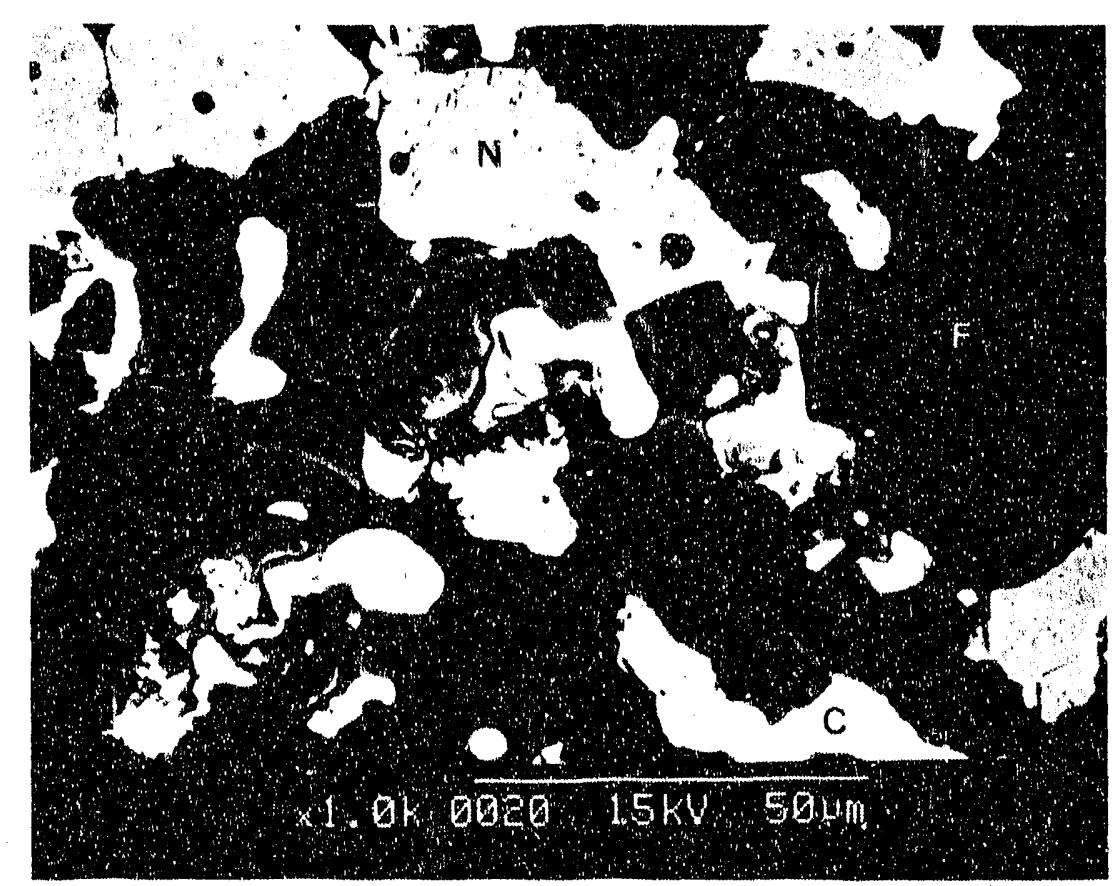

Eigure 113. The oxidized region in $\mathrm{HS}-5(1000 \mathrm{X}) . \mathrm{n}=\mathrm{NiO}, \mathrm{f}=\mathrm{NiFe}_{2} \mathrm{O}_{4}$, $\mathrm{c}=\mathrm{Cu}$ oxide 


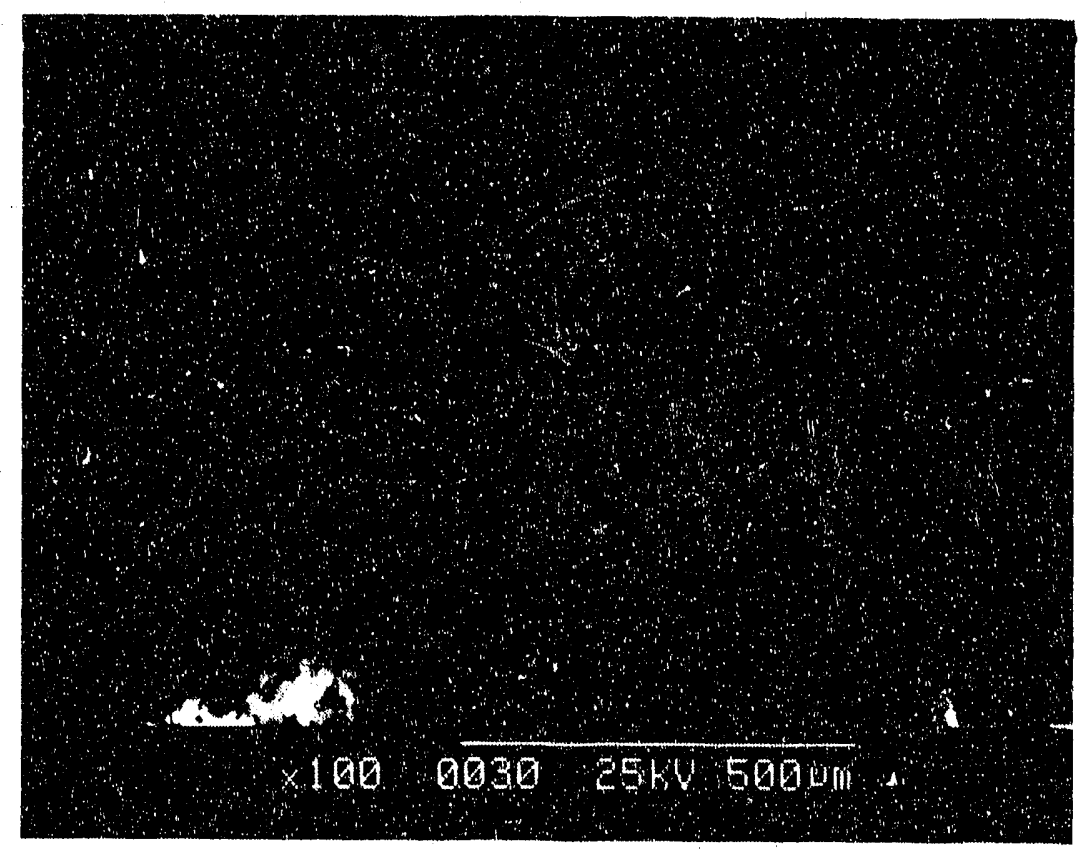

Eigure 114. Edge of HS-6 next to the CEROX (C) coating (100X).

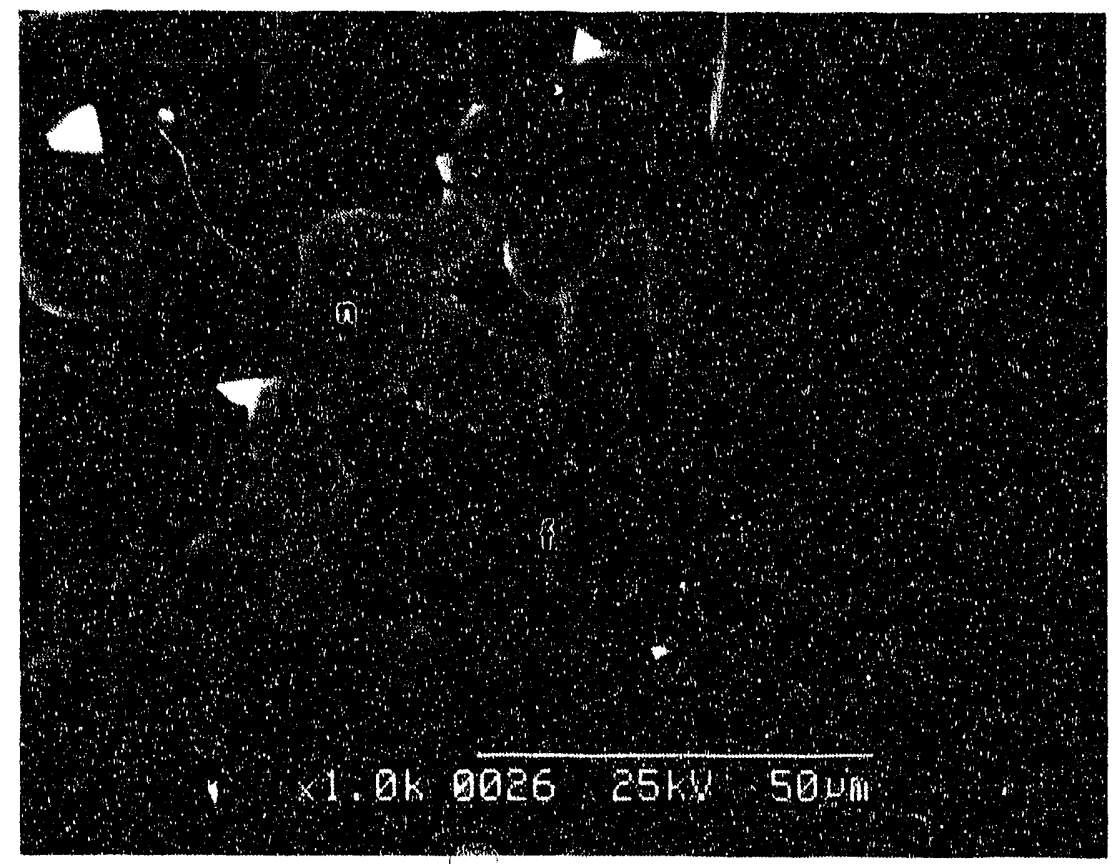

Eigure 115. The oxidized region in $\mathrm{HS}-6(1000 \mathrm{X}) . \mathrm{n}=\mathrm{NiO}, \mathrm{f}=\mathrm{NiFe} \mathrm{O}_{1}$ 


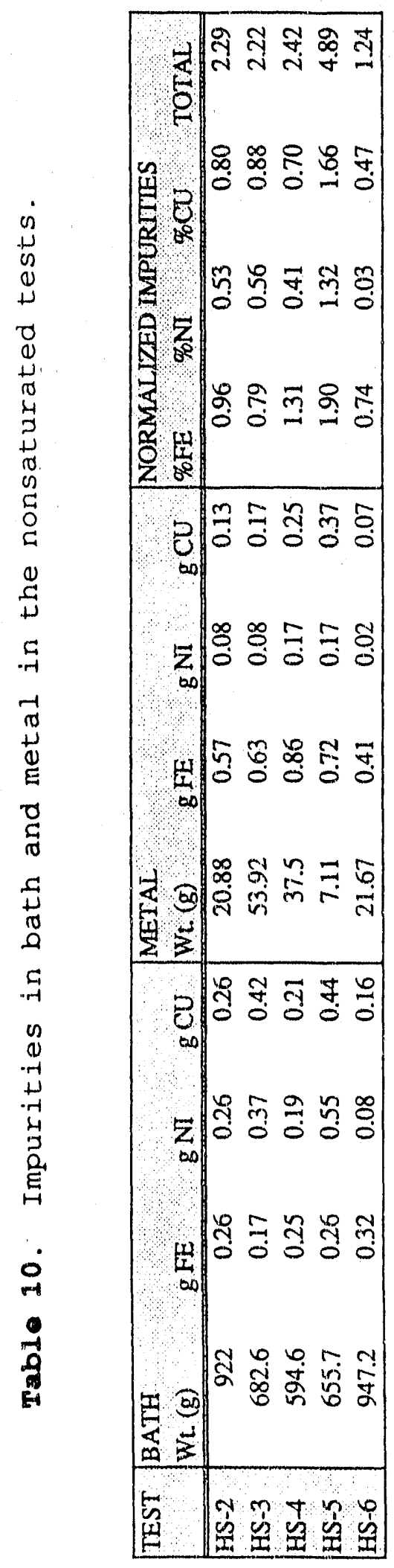


EFFECT OF [ALUMINA]

$B R=1.5, C D=0.5 \quad A / C M^{2}$

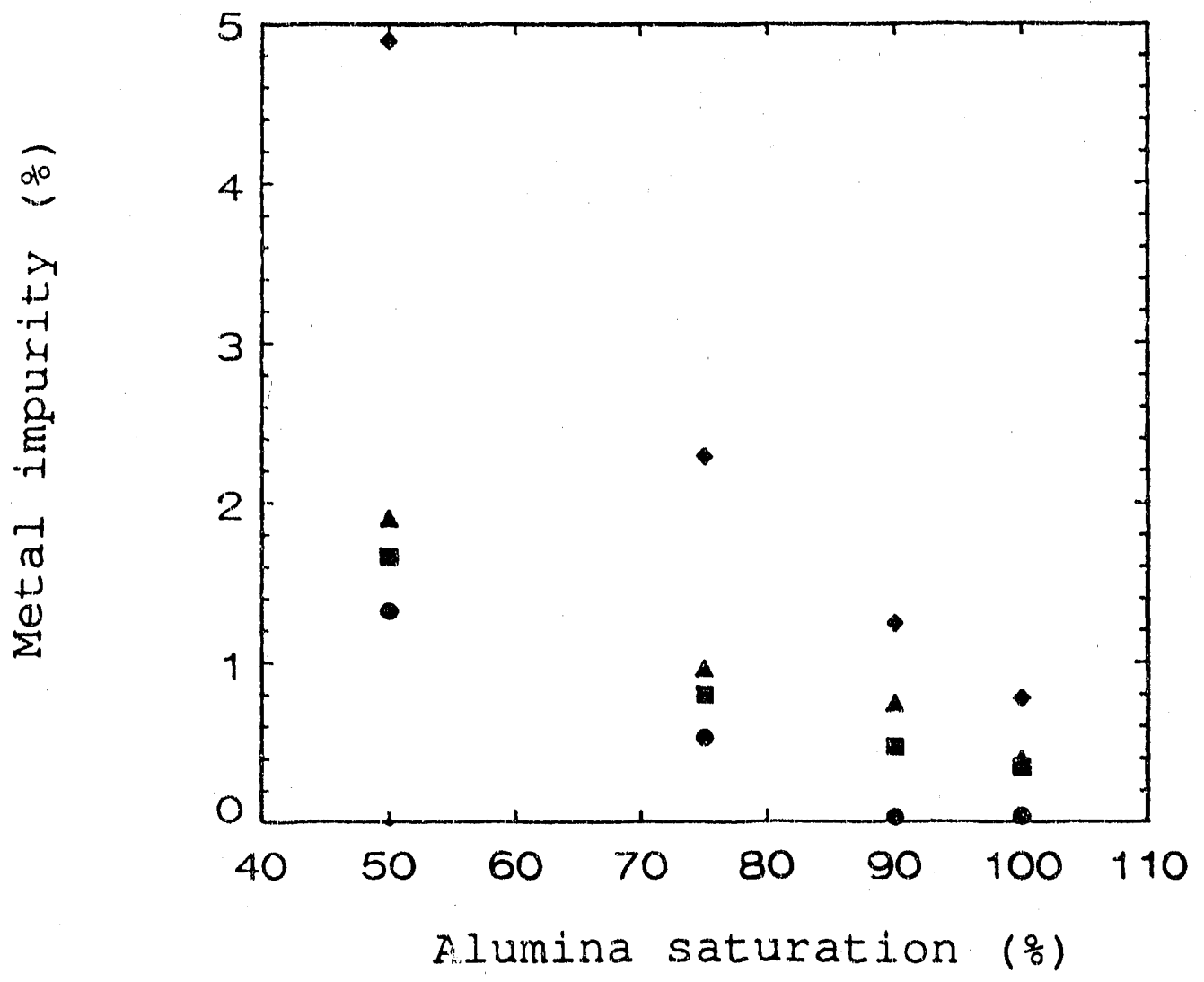

$\triangle F E$ NI $*$ TOT

Figure 116. Normalized corrosion versus alumina concentration for the nonsaturated alumina tests. 


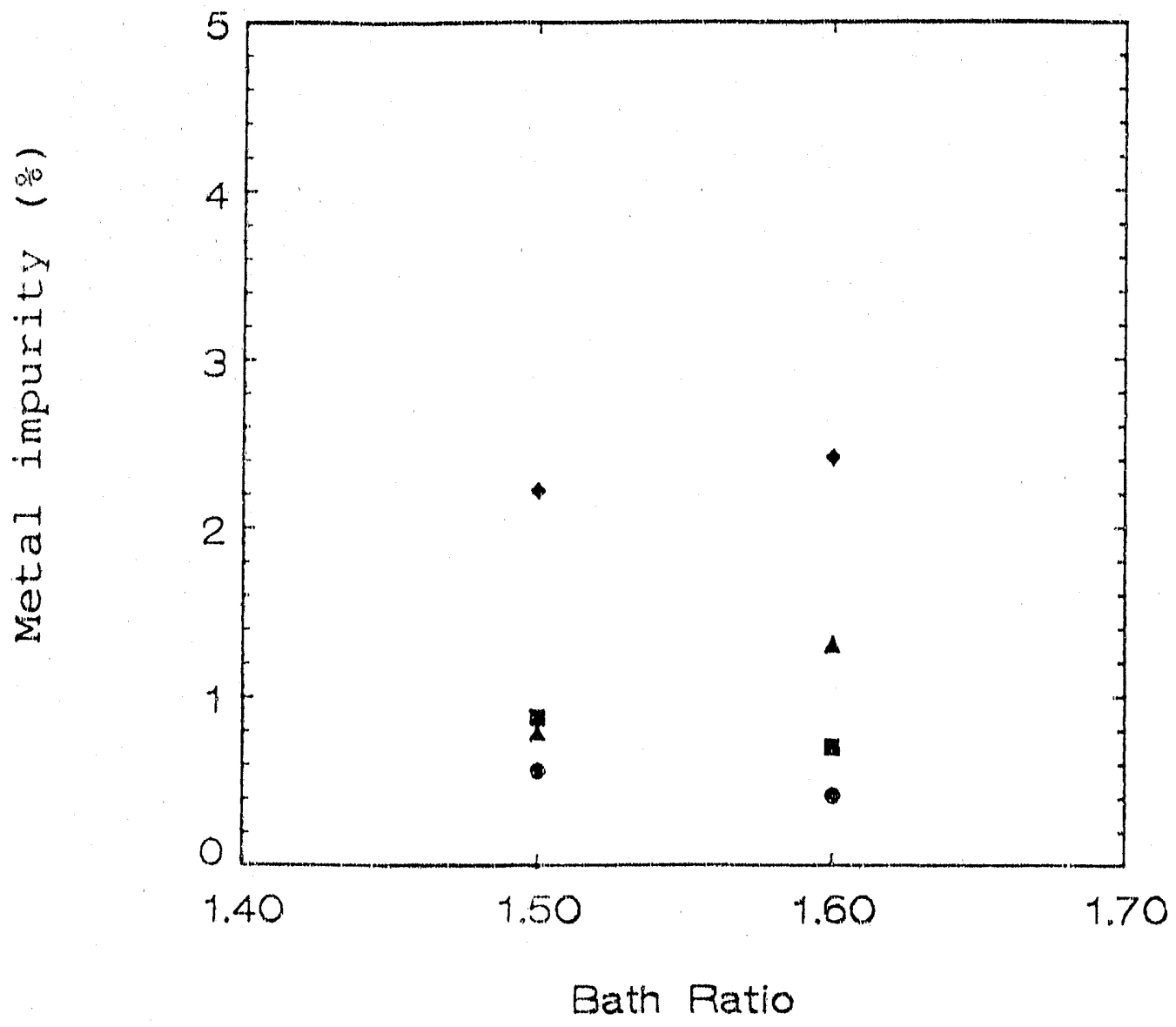

Eigure 117. Arode corrosion versus BR.

Target conditions: $C D=0.7 \mathrm{~A} / \mathrm{cm}^{2}$, alumina $=6$ wto $\diamond=$ Total, $\quad=\mathrm{Cu}, \bullet=\mathrm{Ni}, \Delta=\mathrm{Fe}$. 


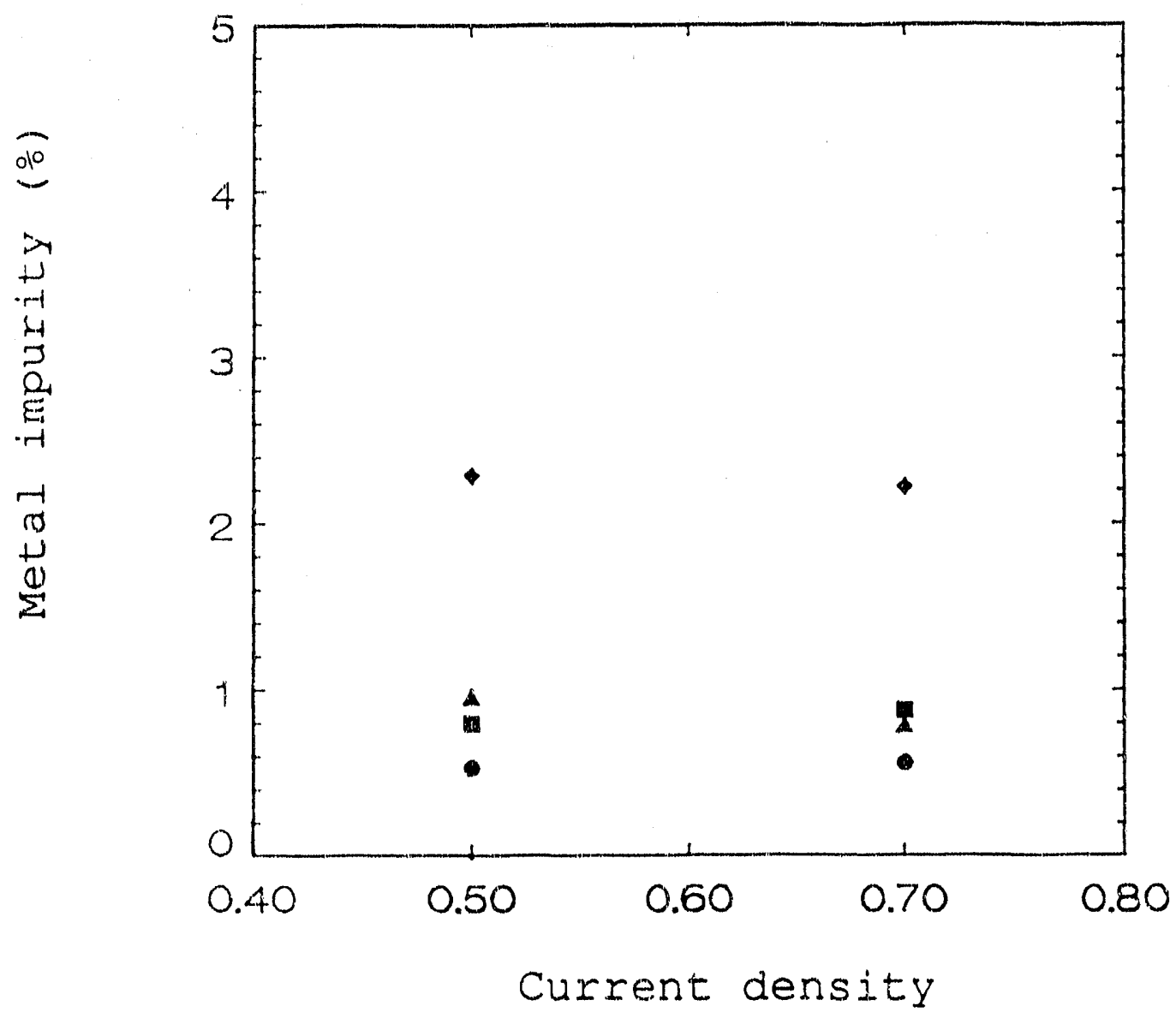

Eigure 118. Anode corrosion versus $C D$.

Target conditions: $B R=1.5$, alumina $=6$ wto $\mathrm{m}=\mathrm{Cu}, \quad=\mathrm{Ni}, \Delta=\mathrm{Fe}, \downarrow=$ Total. 
Because of the problems with controlling cell conditions and the resulting overlap of $B R$ and $C D$ in tests, it is not surprising that it is not possible to detect the effect (if any) of these parameters on corrosion in unsaturated alumina baths. However, there does appear to be an approximate linear increase in corrosion with decreasing alumina concentration. In saturated baths, total corrosion at $0.5 \mathrm{~A} / \mathrm{cm}^{2}$ and $a$ BR of 1.5 averaged 0.655 \% . In unsaturated baths at the same conditions, total corrosion increased to $1.24 \%$ at $\sim 90 \%$ of saturation, $2.29 \%$ at $-75 \%$ of saturation, and $4.89 \%$ at $\sim 50 \%$ of alumina saturation. This is $\sim 7.5$ times increase in corrosion at $50 \%$ of saturation. Future tests should be under more controlled test conditions to verify this increase in corrosion. In addition, a saturated test should be performed in the unsaturated test cell design for a direct comparison. 


\section{CEROX RESISTANCE MEASUREMENTS}

Walker ${ }^{10}$ made rough measurements of the resistance of the CEROX coating in the Phase I project. In Phase III, more accurate measurements to quantify the resistance were made in order to determine the voltage penalty and resulting economic penalty imposed by operating with a CEROX coating.

\subsection{Modelling}

The systern is composed of a cermet anode, an anode-coating interface, a CEROX coating, a coating-electrolyte interface, and an electrolyte (Eigure 119). If the system is assumed to behave linearly, a network of resistors and capacitors can be used as a model. Account should be taken of the resistances associated with the electrolyte $\left(R_{e}\right)$, coating $\left(R_{c}\right)$, and the two interfaces $\left(R_{1}\right.$ : anode-coating interface, $R_{c t}$ : coating-electrolyte interface). Possible capacitances of the coating $\left(C_{c}\right)$ and the two interfaces $\left(C_{1}\right.$ : anode-coating interface, $C_{d_{1}}$ : coating-electrolyte interface) should also be considered. The cermet is assumed to have negligible resistance. An impedance has also been added to account for mass transfer effects $\left(w_{m t}\right)$. The response of the resulting circuit (Figure 120) to a perturbation can be compared to data from the system to determine the value of the resistance associated with the coating.

$R_{c t}$ and $W_{m t}$ are the charge transfer resistance and the mass transfer impedance of the reaction occurring at the coating surface. At. high temperatures, $R_{c t}$ is often reduced because kinetics are generally fast. $W_{m t}$ is also less jmportant at high temperatures because the diffusion coefficient of the reactants increases with temperature. If $R_{c t}$ and $W_{m t}$ are negligjble at the high temperature of this system, the modelling circuit reduces to that shown in Figure 120 (b). The electrolyte resistance, $R_{n}$ is determined from the electrolyte conductivity, which can be measured. The remaining resistances are due only to the coating.

\subsection{Experimental Procedure}

Four experiments were performed in baths saturated with alumina at a $\mathrm{BR}$ of 1.5. $\mathrm{CeF}_{3}$ concentrations of 0 to $4.5 \%$ were added to the cell before testing to generate a range of CEROX coating thicknesses. The four experiments had target cERox thicknesses of $0.0,0.5,1.0$, and $1.5 \mathrm{~mm}$ (corresponding to $0,1.8,3.1$, and $4.5 \%$ $\mathrm{CeF}_{3}$ in the bath, respectively).

The anodes were operated for $5 \mathrm{~h}$ at $240 \mathrm{~mA} / \mathrm{cm}^{2}$ with a potentiostat. After the coating period, the current was set to zero and the system equilibrated for 10 to $15 \mathrm{~min}$. A series of current pulses generated by an EG\&G Princeton Applied Research Model 175 function generator coupled to a stonehart. Associates BC 1200 potentiostat was then applied to the system. The pulses were $0.1 \mathrm{~ms}$ in duration 
COATING-ELECTROLYTE INTERFACE

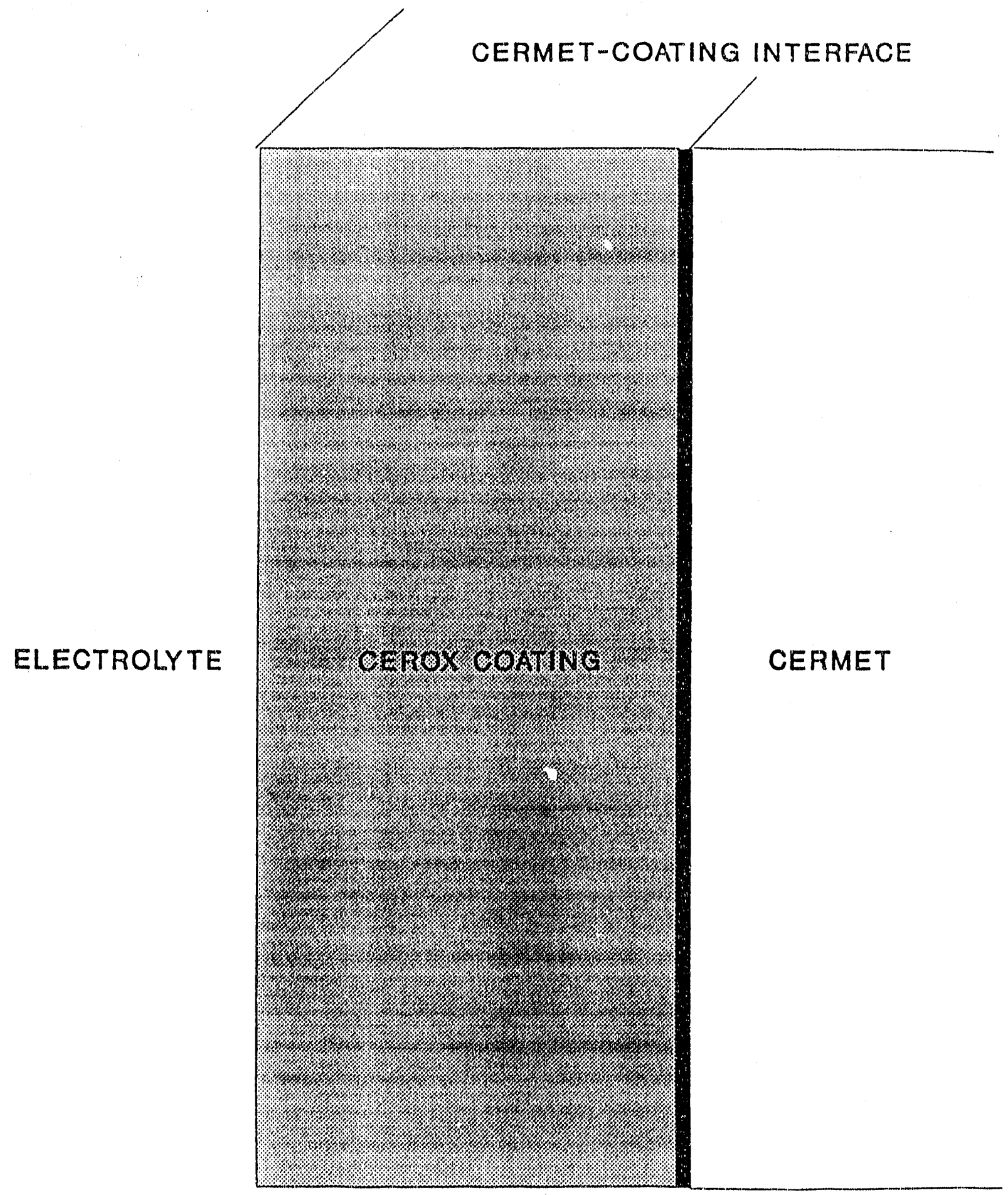

Figure 119. Physical schematic of the system. 
Figure 120.

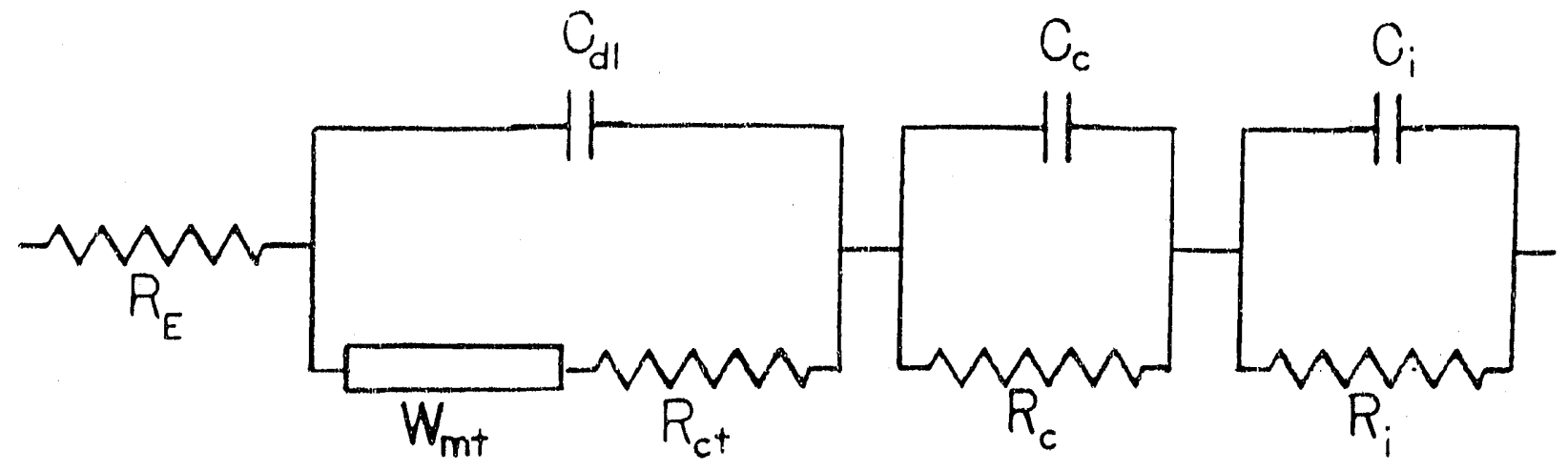

(a) Electronic circuit model of the system.

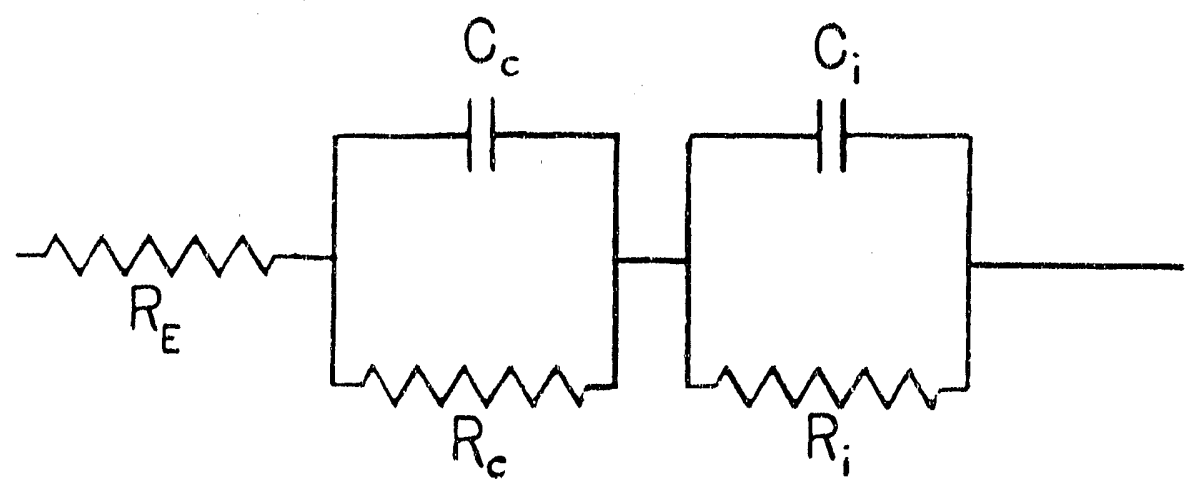

(b) Simplified model. 
and performed at 5 different amplitudes $(30,90,150,210$, and 240 $\mathrm{mA} / \mathrm{cm}^{2}$. Each of the 5 pulses was performed at 5 rotation rates 10 , $500,1000,1500$, and $2000 \mathrm{rpm})$ for a total of 25 pulses/anode. The current pulse and the voltage response were recorded with a Nicolet Instrument corporation 310 osililoscope. The measurements were taken from the anode to cathode and also from the anode to a molybdenum-hook reference electrode. ${ }^{36}$ No difference was found in resistances calculated from measurements taken with or without the reference.

\subsection{Microscopy Results}

Anodes were cross-sectioned and examined by optical microscopy and SEM [Figure 121 (a) through (c)]. Actual coating thicknesses were measured to be $0,0.7,1.34$, and $2.00 \mathrm{~mm}$. All coatings were similar in nature with substantial porosity. Oxidation of $\mathrm{Cu}$ in these samples was usually limited to $100 \mu \mathrm{m}$ on the exterior of the anodes. Any loss of conductivity in the cermets caused by the oxidations is considered to be equal for each experiment because they all experienced the sarne electrolysis conditions.

\subsection{Resistance Results and Discussion}

Resistance versus $C D$ is shown for the four anodes in Figures 122 through 125. There may be a slight increase in resistance with $C D$, but this effect is only seen in the experiments with 1.34 and $2.0 \mathrm{~mm}$ coatings. Even in those two experiments the change was so small it is considered negligible, and the system was considered to behave linearly.

The data from the experiments with no coating and a $0.7 \mathrm{~mm}$ coating showed some change in resistance with rotation rate. The trend was not clear, however, and the high resistances were the first measured. For these reasons the change in resistance is believed to be caused by taking measurements before the system was at equilibrium. In both of these experiments, the measurements taken at the last three rotation rates $(1000,1500$, and 1000 for no coating, and 500, 1500, and 2000 for the $0.7 \mathrm{~mm}$ coating) showed no change in resistance.

The experiments with $1.34 \mathrm{~mm}$ and $2.0 \mathrm{~mm}$ coatings also show a change in the resistance with rotation rate. Here again a trend was not established, but instead the data showed a step increase in resistance at the highest rotation rates. More scatter is also observed in the measurements taken at high rotation. These observations indicate a noisy carbon contact on the rotator, which increases the contact resistance with rotation rate. The measurements taken at low rotation rates are consistent and considered reliable.

If the data taken before the system reached equilibrium are ignored, and effects caused by electrical contacts are removed, 
(a) $\mathrm{RC}-3$,

$0.7 \mathrm{~mm}$ thick CEROX
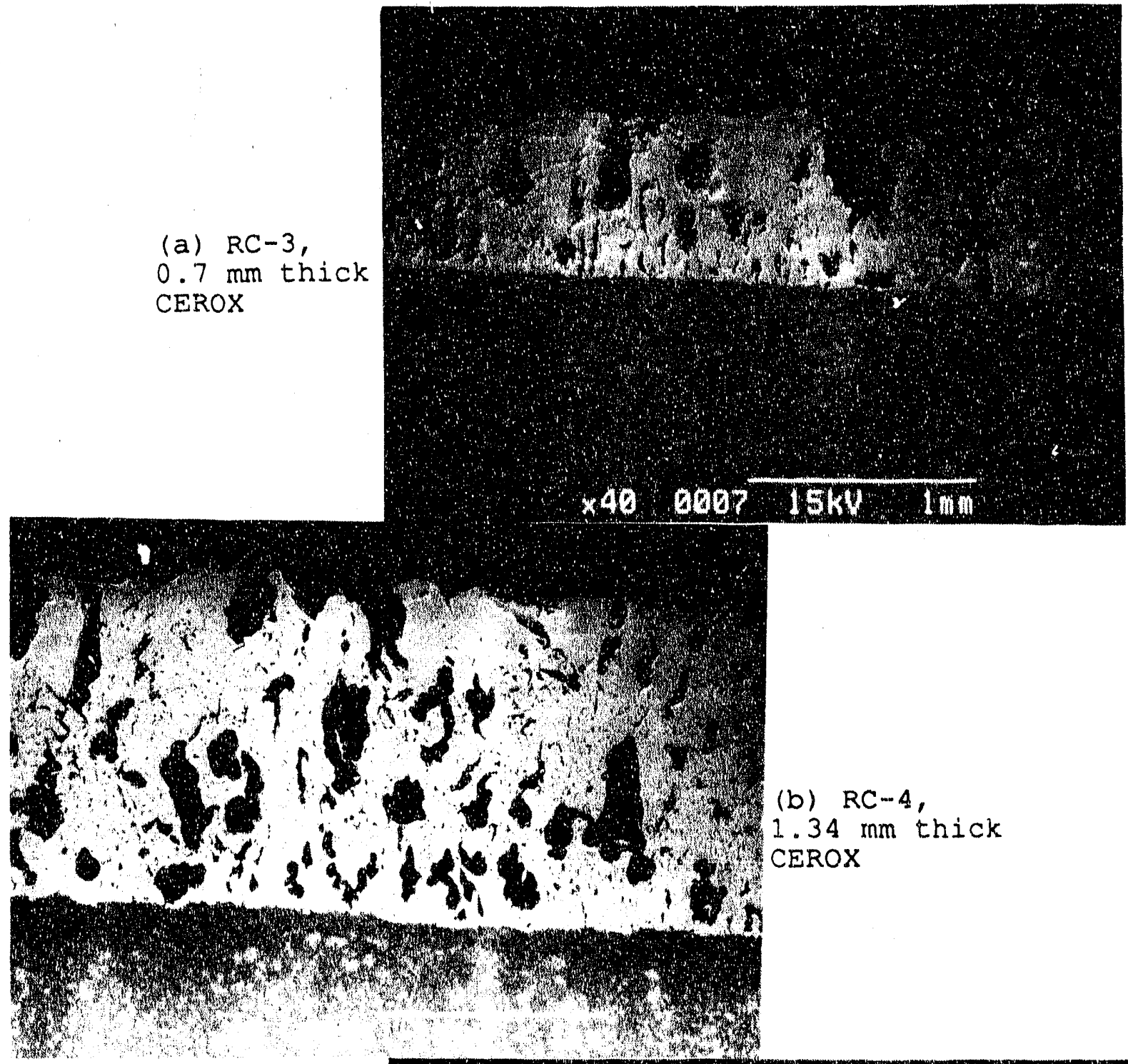

(c) R.C-5

$2.0 \mathrm{~mm}$ thick CEROX

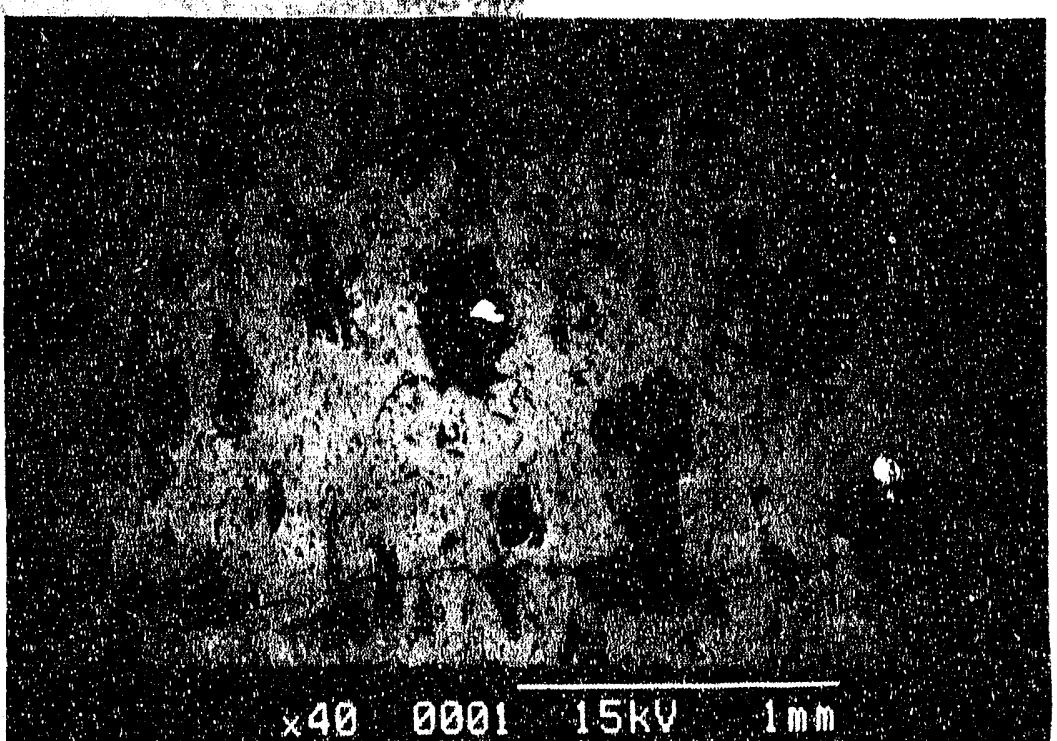

Figure 121. CEROX coatings on anodes from resistance tests (40X). 


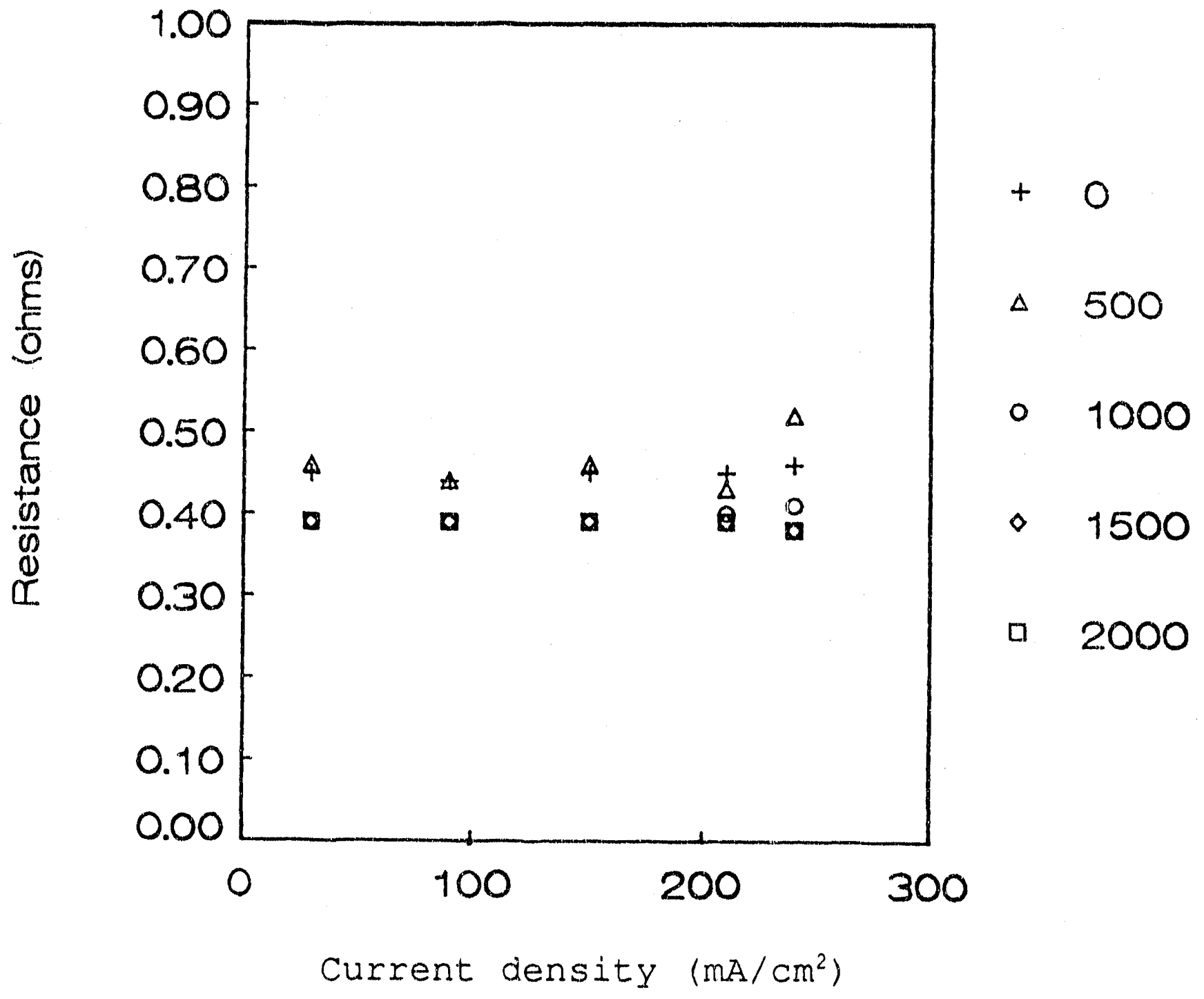

Eigure 122. Resistance as a function of $C D$ and rotation rate, no CEROX coating. 


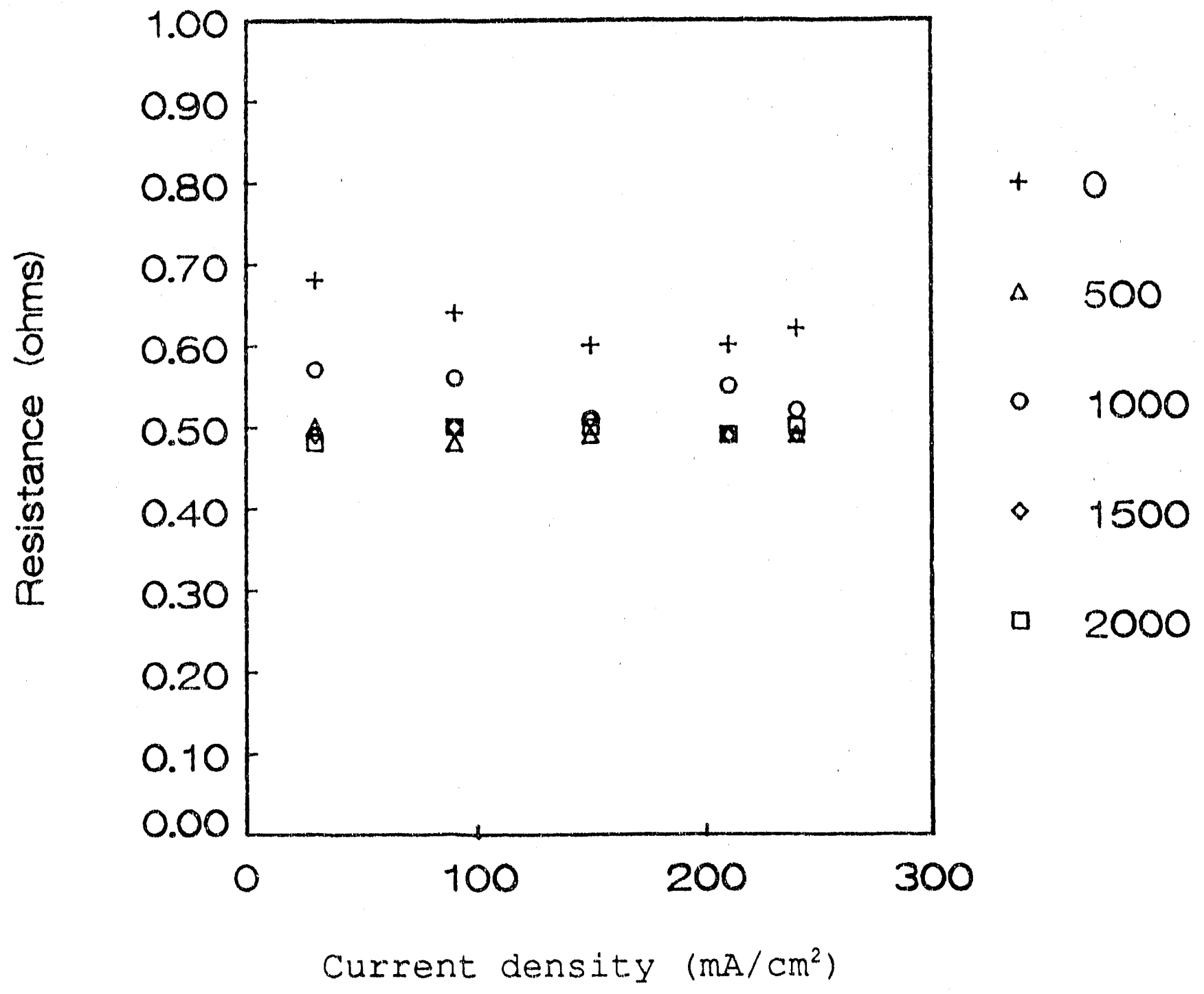

Figure 123. Resistance as a function of $C D$ and rotation rate, coating thickness $=0.7 \mathrm{~mm}$. 


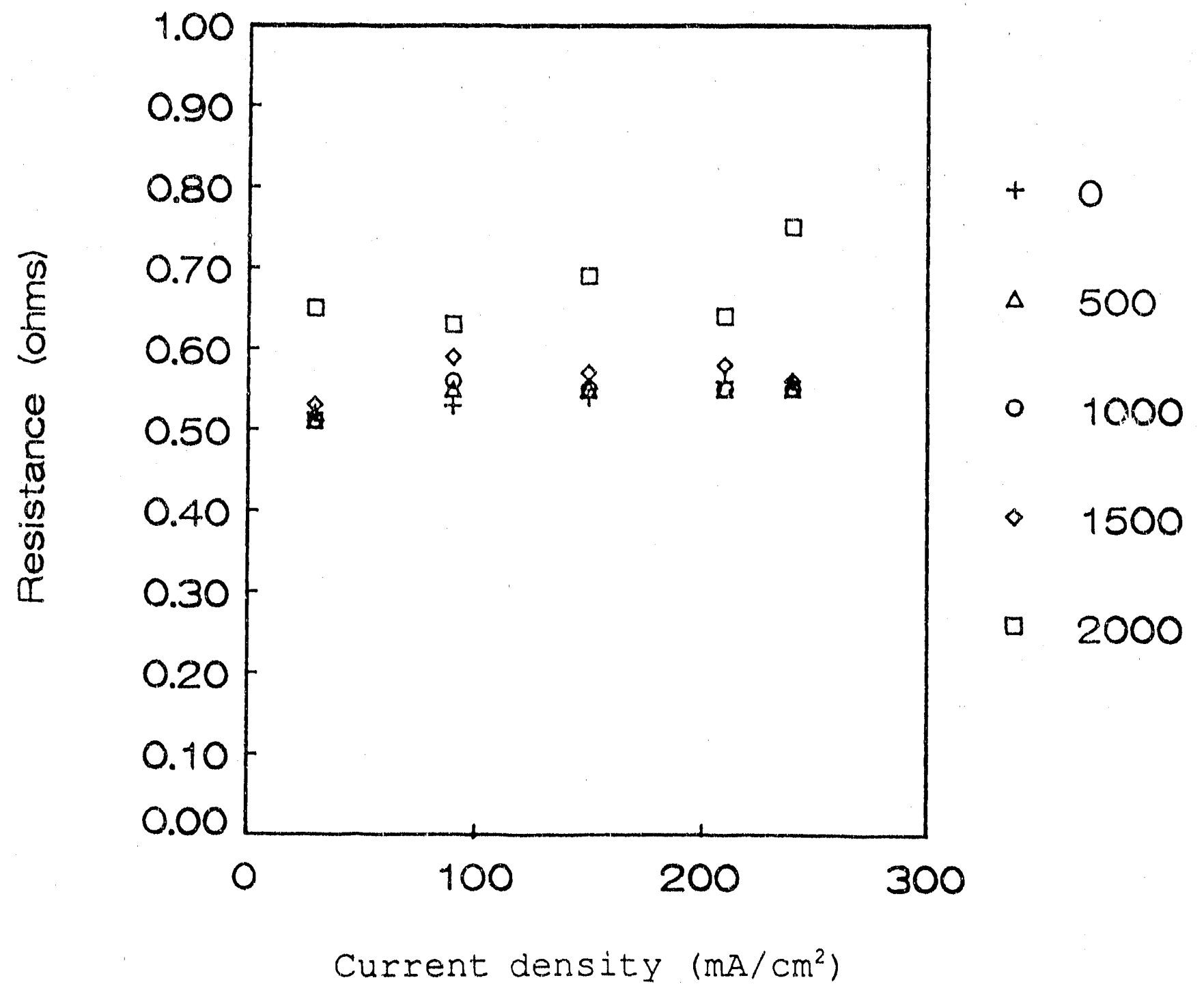

Eigure 124. Resistance as a function of $C D$ and rotation rate, coating thickness $=1.34 \mathrm{~mm}$. 


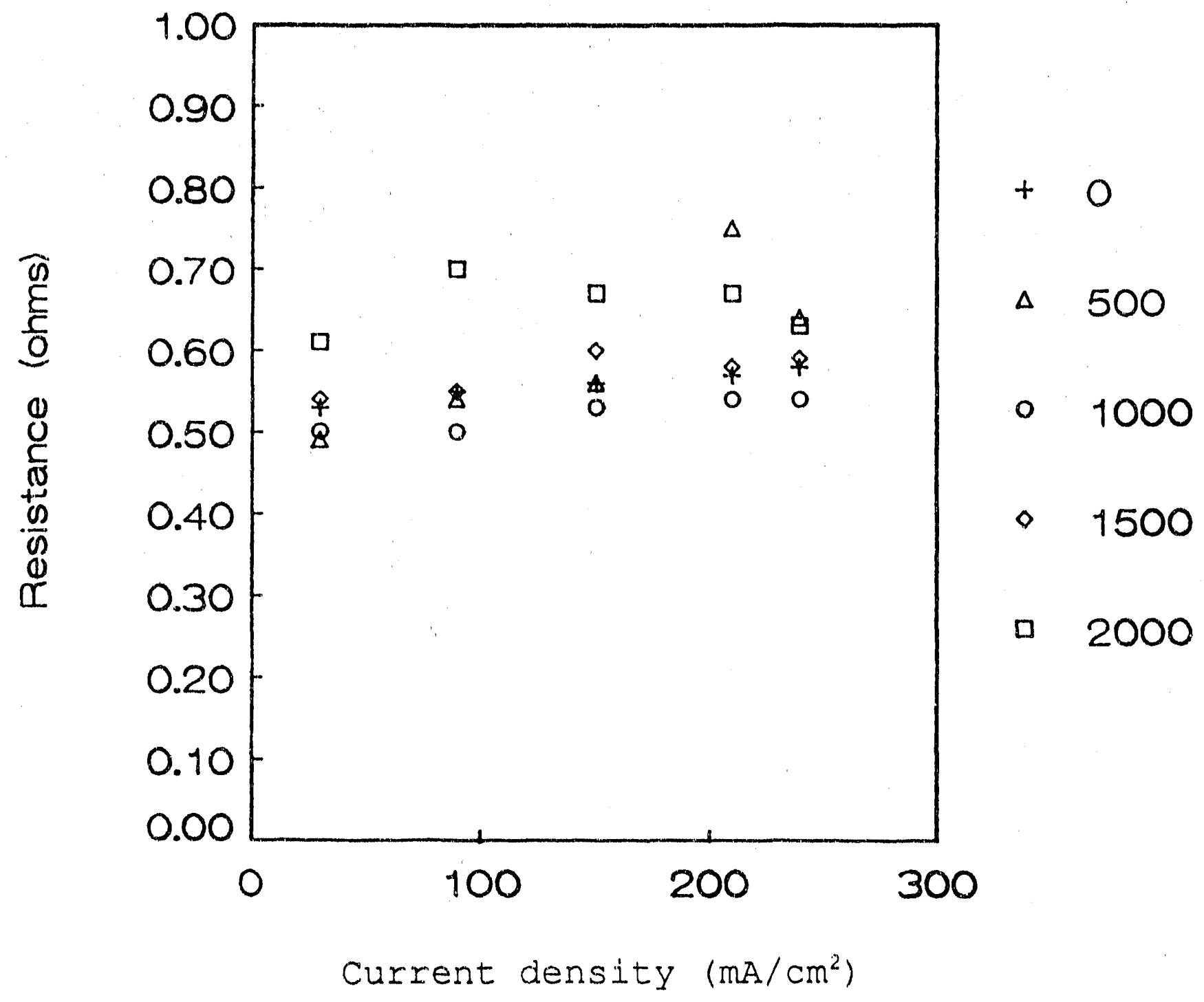

Figure 125. Resistance as a function of CD and rotation rate, coating thickness $=2.0 \mathrm{~mm}$. 
changes in the hydrodynamics of the system (i.e., changes in rotation rate of the anode) show no effect on the resistance measured. Stated another way, mass transfer resistance (or $W_{m t}$ ) is negligible in these measurements.

No charging was seen in the voltage responses to the current pulses, indicating that either $R_{c t}$ or $C_{d l}$ is very small. In either case, the parallel combination of these components in the model is negligible. Because $W_{m t}$ is also small, the circuit shown in

Figure 120 (b) is applicable to this system and only the electrolyte resistance needs to be removed from the measurements in order to determine the coating resistance.

For a cylindrical system, the conductivity is related to the resistance by

$$
x=\ln \frac{\frac{r_{0}}{r_{1}}}{2 \pi H R}
$$
where $\boldsymbol{K}$ is conductivity, $R$ is resistance, and $H$ is the height of the electrodes. ${ }^{37}$ The outer radius and the inner radius are $r_{0}$ and $r_{1}$, respectively (Figure 126). Eor determining the electrolyte resistance, $r_{0}$ is the ID of the graphite liner and $r_{1}$ is the radius of the uncoated anode. The conductivity was calculated to be $0.5 \Omega^{-1} \mathrm{~cm}^{-1}$. This value is $\sim 1 / 4$ of the values reported in the literature for industrial baths, ${ }^{1}$ but those baths often contain more additives to increase conductivity. In this study, the $0.5 \Omega^{-1} \mathrm{~cm}^{-1}$ also includes all the resistance voltage drops in the experimental apparatus. These drops would raise the calculated resistance above that for the electrolyte alone. The system resistance drops were the same for all the experiments so they are easily subtracted from the coating resistance.

Because the conductivity of the solution was known, the resistance caused by the coating could be determined. The conductivity of the CEROX was calculated using Equation (19), where $r_{0}$ is the radius to the outer edge of the coating and $r_{1}$ is the radius of the bare cermet. The conductivities calculated for the three cocted anodes are shown in Figure 127. The error bars are present to show ranges of uncertainty in the original resistance measurement from the oscilloscope. Fairly good agreement is seen between the three experiments with the conductivity equal to $\sim 0.20 \pm 0.05 \Omega^{-1} \mathrm{~cm}^{-1}$. This value is in fair agreement with 0.24 to $0.27 \Omega^{-1} \mathrm{~cm}^{-1}$ reported by Walker.10

\subsection{Conclusions on Resistance Testing}

Current pulses were applied to a rotating cylindrical electrode system to determine the conductivity of the protective coating 


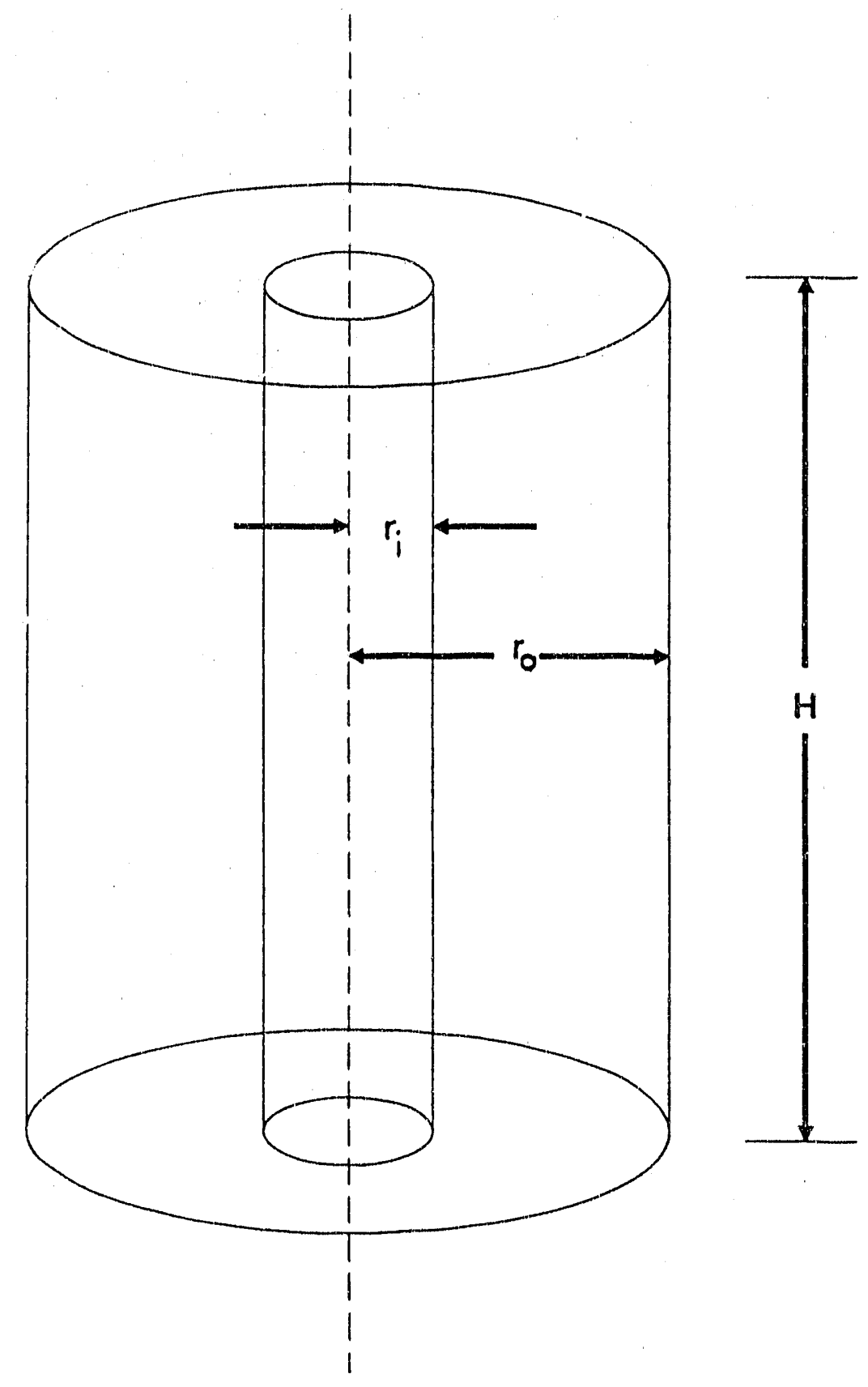

Figure 126. Cylindrical system. 


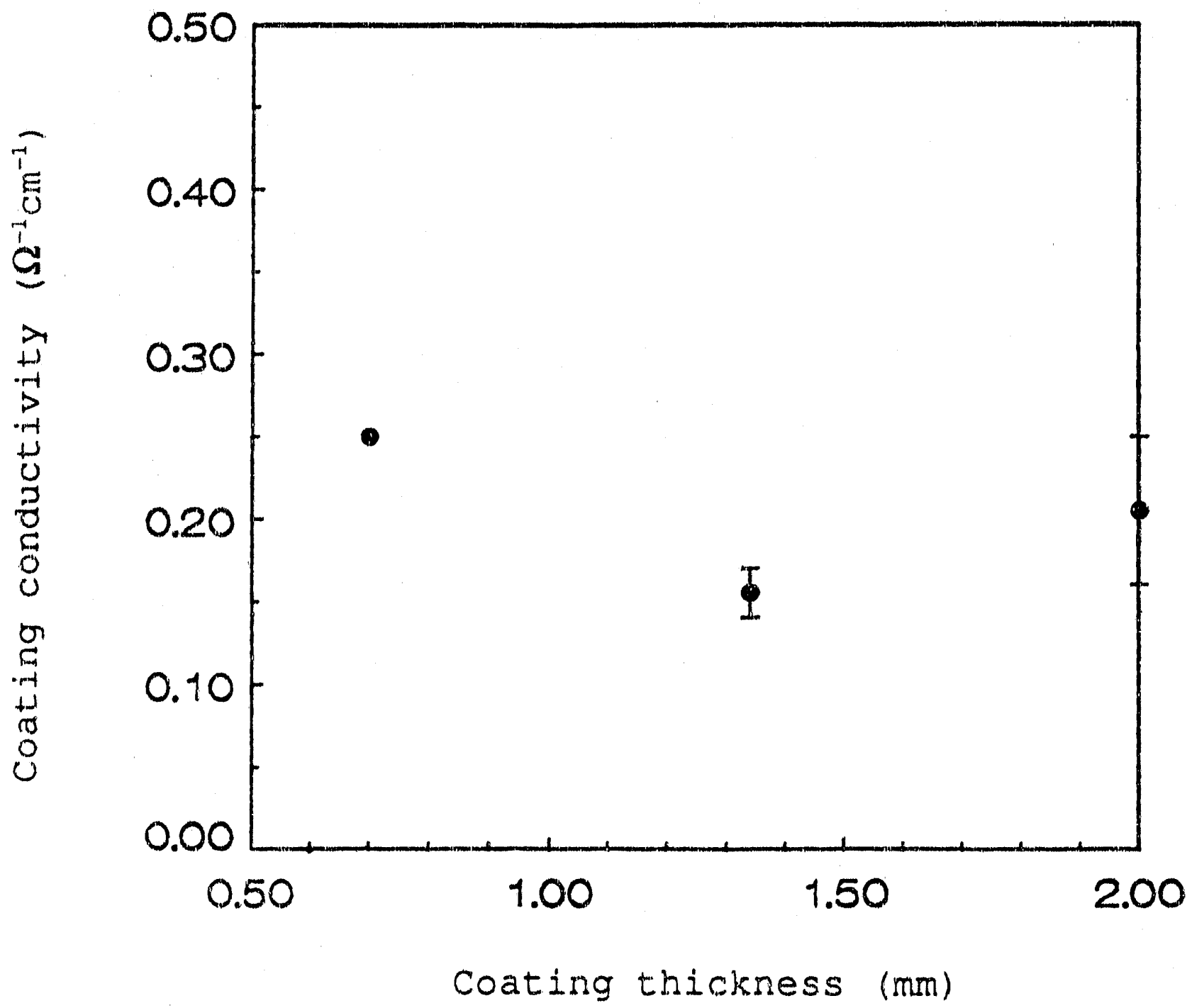

Figure 127. Conductivities calculated from the experimental data. 
(CEROX) used on inert anodes in aluminum electrowinning applications. The data were compared to a model, and component values were determined. The coating conductivity was $0.2 \Omega^{-1} \mathrm{~cm}^{-1}$, which is in good agreement with other reported values.

The added energy cost associated with the coating resistance was calculated. If the anodes are operated at $0.7 \mathrm{~A} / \mathrm{cm}^{2}$, and the process has a CE of $90 \%$, a $1 \mathrm{~mm}$ thick coating having a conductivity of $0.2 \Omega^{-1} \mathrm{~cm}^{-1}$, would add $\$ 26.21$ to the cost of producing 1 ton of Al. This calculation assumes an energy cost of 2.5 cents/kw.h. 


\section{CONCLUSIONS ON PHASE III TESTING}

The Phase III project was successful in defining the optimum conditions for CEROX coatings and protection on the cu cermet substrate, for demonstrating the increase in corrosion in baths unsaturated with alumina, and for accurately defining the electrical conductivity of the CEROX coating. The main conclusions are

- The CEROX coating is densest and most continuous when formed at a BR of 1.5 to 1.6 .

- With a CEROX coating on a $\mathrm{Ni}$ ferrite/Cu cermet substrate, the minimum corrosion was at a BR of 1.5 to 1.6. Corrosion appeared to be increased at both higher and lower BR.

- There appears to be a slight decrease in corrosion of the cu cermet substrates with decreasing $C D$.

- At a $C D$ of $1.3 \mathrm{~A} / \mathrm{cm}^{2}$ and a $\mathrm{BR}$ of 1.6 , the CEROX coating decreased corrosion compared to an uncoated Cu cermet by a factor of 7 .

- The most protective CEROX coatings are formed at a BR of 1.5 to 1.6 , but this is higher than currently employed in the aluminum industry. Operation at this bath composition may lead to lower $C E$ and higher operating temperatures.

- In baths unsaturated with alumina, thick and dense CEROX coatings could be deposited with higher levels of $\mathrm{CeF}_{3}$ in the bath.

- An increase in corrosion was found in baths unsaturated with alumina.

- The Cu cermet substrate contained a region of varying thickness that was devoid in $\mathrm{Cu}$ next to the CEROX coating.

- Oxidation of the cu metal in the substrate was present to varying depths. In the oxidized zone, there were changes in the $\mathrm{NiO}$ and $\mathrm{NiFe}_{2} \mathrm{O}_{4}$ distribution, as well as increased porosity. Greater oxidation occurred in the anodes tested at higher current densities. In the most oxidized anodes a cell voltage increase was noted during the $100 \mathrm{~h}$ of testing, probably as a result of the loss or oxidation of the cu metal.

- The present cu cermet undergoes too extensive corrosion and oxidation for use as a long term inert anode. 
- The conductivity of the CEROX coating is $\sim 0.2 \Omega^{-1} \mathrm{~cm}^{-1}$. This translates to an increased energy cost of $\sim \$ 25 /$ ton of aluminum based on a price of 2.5 cents/kW.h, $90 \% \mathrm{CE}$, and operation with a $1 \mathrm{~mm}$ thick coating at $0.7 \mathrm{~A} / \mathrm{cm}^{2}$. 


\section{RECOMMENDATIONS}

When Alcoa discontinued their cermet work in 1985, they had developed a $\mathrm{Ni}$ ferrite/NiO/Cu cermet that achieved a targeted aluminum purity of $99.5 \%$ in a test of $264 \mathrm{~h}$. A.lcoa felt that the $\mathrm{Cu}$ cormet material had potential as an anode but purity of the aluminum needed to be further increased.

ELTECH undertook the Phase I. II, and III DOE Projects to demonstrate the viability of the CEROX coating as a method to reduce corrosion of the $\mathrm{Cu}$ cermet to an acceptable level. The tests were also directed toward defining the operation conditions at which the CEROX coating was most protective. These goals have been achieved. Tests have also shown that under identical test conditions, the CEROX-coated $\mathrm{Cu}$ cermet had 1/7 the corrosion of the uncoated $\mathrm{Cu}$ cermet.

However, there are differences between the results of these tests and those of Alcoa. First, the best corrosion achieved in Phase III testing was $0.471 \%$ total corrosion. This corrosion is not $1 / 7$ of the lowest corrosion $(0.5 \%)$ reported by Alcoa. Second, the oxidation of the $\mathrm{Cu}$ in the cermets was extensive in the ELTECH substrates, while Alcoa reported that oxidation of their substrates was limited and did not increase in thickness with time.

Some of the difference in the amount and distribution of the corrosion components may be a result of differences in cell design and operation between ELTECH and Alcoa. It is sometimes difficult to correlate corrosion from one laboratory cell to another or from a laboratory cell to an industrial cell.

Another possible explanation for the difference in corrosion and oxidation between the Alcoa and the ELTECH tests may be a result of differences in the $\mathrm{Cu}$ cermet substrate. Alcoa prepared their own substrate from stackpole $\mathrm{Ni}$ ferrite/NiO oxide powder. In the ELTECH Phase II project, somewhat porous ( 948 TD) substrates were prepared in house from non-spray dried ferrite powder. Improved dense ( 99\% TD) cerwets were prepared by ELTECH from Ceramic Magnetics spray dried ferrite powder for Phase III testing. Both substrates of ELTECH were subjected to extensive oxidation of the $\mathrm{Cu}$ and increased porosity, particularly at higher CD. Neither of the ELTECH Cu cermet substrates behaved similarly to the Alcoa reported behavior.

Based on these conclusions, the following research is recommended for continued work on inert anodes for aluminum electrowinning.

1. Because the present ELTECH-prepared substrate has too much corrosion and oxidation, investigations of other substrates should be undertaken. These investigations should include examination and testing of Alcoa Cu cermet material (to deter- 
mine if the oxidation behavior is different/better), as well as investigations of other potential cermet substrates for CEROX. Tests should be short-term screening tests with and without CEROX. The best candidate materials should be tested in longer term tests.

When an acceptable substrate is found, laboratory experiments to extend the useful range of the CFROX coating can continue. The CEROX coating has been found to protect the cu cermet substrate best: at conditions that are not typjcal of industrial conditions: specifically, higher (BR 1.5 to 1.6) than industrial. (BR 1.15) bath ratios and higher (saturated) than industrial alumina concentrations ( $50 \%$ of saturation). Tests with the improved substrates should be directed towards determining if an adequate CEROX coating can be achieved under conditions closer to industrial conditions.

2. Perform additional laboratory tests at industrial alumina concentrations. Tests could study the influence of the $\frac{8}{\partial} \mathrm{CeF}_{3}$ and $C D$ on the corrosion at various $\mathrm{Al}_{2} \mathrm{O}_{3}$.

3. Study the CEROX coating at industrial BR. Because the higher $B R$ (1.5) requires a slightly higher operating temperature and $\mathrm{CE}$ is reportedly reduced, there is a driving force to reduce $B R$ to an industrial level. Experiments could include adding LiF at a BR of 1.5 to decrease the melting point or operating tests at lower $B R$ and varying the ce concentration to determine if corrosion can be reduced to an acceptable level.

After laboratory testing has shown that a suitable substrate is available and the CEROX coating affords good protection at acceptable operating conditions, tests directed toward commercialization of the technology can proceed.

4. Perfom laboratory tests to prove the ability to remove ce from Al metal and achieve acceptable Al purity.

When tests prove that Ce can be removed from Al metal, pilot-scale testing can proceed.

5. Pilot-scale testing (with and without a CEROX coating) should be performed to prove the protection offered by the CEROX coating and to determine the commercially obtainable Al metal purity. Tests should be operated at the preferred conditions for CEROX operation. 


\section{REEERENCES}

1. Grjotheim, K; Krohn, C.; Malinovsky, M.; Matiasovsky, K. and Thonstad, J; Aluminum Electrolysis Fundamentals of the HallHeroult Process, 2nd Edition, Aluminum-Verlag, Dusseldorf, 1982 .

2. Billehaug, $K$. and Oye, H.A.; "Inert Anodes for Aluminum Electrolysis in Hall-Heroult Cells," Aluminum 57 (2), 1980, pp. 146-150.

3. Billehaug, $K$. and Oye, H.A.; "Inert Anodes for Aluminum Electrolysis in Hall-Heroult Cells," Aluminum 57 (3), 1980, pp. 228-231.

4. A Survey of Potential processes for the Manufacture of Aluminum, Arthur D. Little, Inc. ANL-OEPM-79-4.

5. Horinouchi, K; Tachikawa, N. and Yamada, K., "DSA in Aluminum Reduction Cells," Proceedings of the First International Symposium on Molten Salt Chemistry and Technology, Kyoto, Japar (April 22-23, 1983).

6. Weyand, J.D.; Ray, S.P.; Eaker, E.W.; DeYoung, D.H., and Tarcy, G.P.; "Inert Anodes for Aluminum Smelting," Final Report February 1986; DOE/CS/40158-20.

7. Baker, F.W. and Rolf, R.L., "Hall Cell operation with Inert Anodes" in Light Metals 1986, R. E. Miller (ed), The Metallurgical Society, Warrendale, PA, 1986.

8. McLeod, A.D., Lihrmann, J.M., Haggerty, J.S., and Sadoway, D. R., "Selection and Testing of Inert anode Materials for Hal] Cells" in Light Metals 1987, R. E. Miller (ed), The Metallurgicai society, Warrendale, PA, 1987.

9. Duruz, J.J. and DeNora, V.; "The Dynamic Equilibrium of SelfE'orming Anode," Presented at the Meeting of the Electrochemical society.

10. Walker, J.K., Cerium Oxide Coated Anodes Eor Aluminum Electrowinning, Final Report, June 1987; DE/ID/12655-1.

1.1. King, H.L., Long-Term Testing of In-Situ Cerium Oxide-Coated Anodes Eor Aluminum Electrowinning, Final Report, October 1989; DE/ID/12655-2.

12. Belyaev, A.I. and Studentsov, Y.E., Legkie Metally 5 (3), 15, 1936 .

13. Belyaev, A.I. and Studentsov, Y.E., Legkie Metally 6 (3), 17 1937. 
14. Kronenberg, M.L.; "Gas Depolarized Graphite Anodes for Aluminum Electrowinning,"J. Electrochem Soc. 116, 1969, pp. 1160-1164.

15. Gadeau, R.; Bull. Soc. Fr. Electrician 7, 1974, p. 540.

16. Stender, V.V. and Trofimenko, V.V.; Khim. Tekhnol 12, 1969, p. 42 .

17. Belyaev, A.I., Legkie Metally 7 (1), 7, 1938.

18. Alder, H.P., US Patent 4,057,480, November 8, 1977.

19. Thonstad, $\mathrm{J}$.; "The solubility of Aluminum in $\mathrm{NaE}-\mathrm{AlF}_{3} \cdots \mathrm{Al}_{2} \mathrm{O}_{3}$ Melts," Can. J. Chem. 43, 1965, pp. 3429-3432.

20. Yoshida, K. and Dewing, E.W.; "Activities in NaE-AlF $\mathrm{F}_{3}$ Melts Saturated with $\mathrm{Al}_{2} \mathrm{O}_{3}$," Met. Trans. 3, 1972, pp. 683-686.

21. Alder, H.P., US Patent 3,960,678, June 1, 1976.

22. Alder, H.P., US Patent 3,974,046, August 10, 1976.

23. Ray, S.P., US Patent 4,374,050, February 15, 1983.

24. Tarcy, G.P., "Corrosion and Passivation of Cermet Anodes in Cryolite-Type Electrolytes" in Light Metals 1986, R. E. Milier (ed.) The Metallurgical Soc., Warrendale, PA, 1986.

25. Ray, S.P., US Patent 4,374,761, February 22, 1983.

26. Ray, S.P., "Inert Anodes for Hall Cells" in Light Metals 1986 , R. E. Miller (ed.), The Metallurgical Soc., Warrendale, PA 1986.

27. Strachan, D.M.; Koski, O.H.; Morgan, L.G.; Westerman, R.E.; Peterson, R.D.; Richards, N.E.; and Tabereaux, A.T., "Results From a 100-Hour Electrolysis Test of a Cermet Anode: Materials Aspects" in Light Metals 1990, pp. 395-401, C. M. Bickert (ed.), The Minerals, Metals \& Materials Society 1990 .

28. Peterson, R.D.; Richards, N.E.; Tabereaux, A.T.; Koski, O.H.; Morgan, I.G.; and Strachan, D.M., "Results of 100 Hour Electrolysis Test of A Cermet Anode: Operational Results and Industry Perspective," in Iight Metals 1990, pp. 385-393, C. M. Bickert (ed.), The Minerals, Metals \& Materials society 1990.

29. Duruz, J.J. and Derivaz, J.P., US Patent 4,397,729, Aug. 9, 1983. 
30. DeNora, V., spaziante, P.M., and Nidola, A., US Patent 4,098,669, Jul. 4, 1978 .

31. Duruz, J.J., Derivaz, J.P., Debely, P., and Adorian, J., European Patent EP-A-0114085, November 25, 1987.

32. Windisch, C.E. Ir. and Strachan, D.M. Inert Electrodes Program Eiscal Year 1990 Annual Report, Pacific Northwest Laboratories, PNL-7777, UC-313.

33. Hart, P.E.; Brenden, B.B.; Davis, N.C.; Koski, O.H.; Marschman, S.C.; Pool, K.H.; Schilling, C.H.; Windisch, C.F.; and Wrona, B.J. Inert Anode/Cathode Program Fiscal Year 1986 Annual Report, Pacific Northwest Laboratories, PNI-6247, UC$95 \mathrm{f}$.

34. Grjotheim, K. and Welch, B.J., Aluminum Smelter Technology, Aluminum-Verlag, Dusseldorf, 1980.

35. Skybakmoen, E.; Solheim, A., and Sterten, A., "Phase Diagram Data in the system $\mathrm{Na}_{3} \mathrm{AlF}_{6}-\mathrm{Li}_{3} \mathrm{AlF}_{6}-\mathrm{AlF}_{3}-\mathrm{Al}_{2} \mathrm{O}_{3}$ Part IJ. Alumina Solubility," Light Metals 1990, C. M. Bickert (ed.), The Minerals, Metals, \& Materials Society, Warrendale, PA, 1990.

36. Burgman, J.W.; Leistra, J.A.; and Sides, P.J. "Aluminum/Cryolite Reference Electrodes for Use in CryoliteBased Melts," J. Electrochem. Soc., 133 (3), 1986, pp. 496500 .

37. Newman, J.S., Electrochemical Systems, New Jersey: PrenticeHall Inc., 1973. 
Appendix A

Normalization Example 
As described in subsection 4.8.4, corrosion values of $\mathrm{Fe}$, $\mathrm{Ni}$, and $\mathrm{Cu}$ in the cryolite bath and $\mathrm{Al}$ metal were normalized to project the industrial metal purity that would result from use of these anodes. The normalization procedure was described, step by step, in Subsection 4.8.4. Appendix A contains an example of the calculations for this procedure based on corrosion data obtained from a Phase II experiment at a BR of $1.35, C D$ of $1 \mathrm{~A} / \mathrm{cm}^{2}$ and without $\mathrm{CeF}_{3}$ in the bath.

Ce-free anode operated at $1 \mathrm{~A} / \mathrm{cm}^{2}, \mathrm{BR}$ of 1.35 .

Amount of $A$ l recovered from test $=50.9 \mathrm{~g}$.

Amount of cryolite recovered from test $=551.0 \mathrm{~g}$.

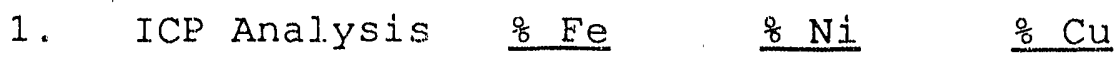

$\begin{array}{llll}\text { Metal } & 0.53 & 0.23 & 0.16 \\ \text { Bath } & 0.94 & 0.11 & 0.085\end{array}$

Calculate $\mathrm{g}$ of $\mathrm{Fe}, \mathrm{Ni}$ or $\mathrm{Cu}$.

$g$ in $\mathrm{Al}$ metal $=g$ of $\mathrm{Al}$ metal $\times \frac{\mathrm{Ee}, \mathrm{Ni}, \text { or } \mathrm{Cu}}{100}$

$g$ in cryolite $=g$ of cryolite $x \frac{\circ \mathrm{Fe}, \mathrm{Ni}, \text { or } \mathrm{Cu}}{100}$

$50.9 \mathrm{~g}$ of Al $\times \frac{0.538 \mathrm{Fe}}{100}=0.27 \mathrm{~g} \mathrm{Fe}$ in $\mathrm{Al}$

551. $\mathrm{g}$ of bath $\times \frac{0.94 \% \mathrm{Fe}}{100}=5.18 \mathrm{~g} \mathrm{Fe}$ in bath

$50.9 \mathrm{~g}$ of Al $\times \frac{0.23 \% \mathrm{Ni}}{100}=0.12 \mathrm{~g}$ of $\mathrm{Ni}$ in al

$551 \mathrm{~g}$ of bath $\times \frac{0.11 \frac{\mathrm{O}}{\mathrm{N} i}}{100}=0.61 \mathrm{~g}$ of $\mathrm{Ni}$ in bath

$50.9 \mathrm{~g}$ of $\mathrm{Al} \times \underline{0.168 \mathrm{O}} \mathrm{Cu}=0.08 \mathrm{~g}$ of $\mathrm{Cu}$ in $\mathrm{Al}$ 100

$551 \mathrm{~g}$ of bath $\times \frac{0.085 \frac{\mathrm{Cu}}{\mathrm{Cu}}}{100}=0.47 \mathrm{~g}$ of $\mathrm{Cu}$ in bath 
2. Add the contamination of bath and metal to determine total contamination in grams.

$\begin{array}{lrrr} & \text { g Fe } & \text { g Ni } & \text { q Cu } \\ \text { Metal } & 0.27 & 0.12 & 0.08 \\ \text { Bath } & \frac{+5.18}{5.45} & \frac{+0.61}{0.73} & \frac{+0.47}{0.55} \\ \text { Total } & & \end{array}$

$\begin{array}{llll}\text { 3. } & \begin{array}{l}\text { Subtract } \\ \text { Background } \\ \text { Corrosion }(g)\end{array} \quad \underline{-0.05} & -0.08 & =0.004 \\ & 5.40 & 0.65 & 0.54\end{array}$

4. Normalize for industrial Al production. Calculate the theoretical amount of al produced at $1 \mathrm{~A} / \mathrm{cm}^{2}(2.7 \mathrm{~A})$ for 100 hours assuming $95 \%$ current efficiency.

Theoretical $g$ of $A I=\frac{2.7 A \times 605 \times 60 \mathrm{~min} \times 100 \mathrm{~h} \times 27 \mathrm{~g} / \mathrm{mol} \mathrm{A.} \times 0.95}{3 \text { electrons } \times 96,500}$

Theoretical Al at $1 \mathrm{~A} / \mathrm{cm}^{2}, 100$ hours $=86.12 \mathrm{~g}$

Theoretical Al at $0.6 \mathrm{~A} / \mathrm{cm}^{2}, 100$ hours $=51.67 \mathrm{~g}$

Theoretical Al at $1.4 \mathrm{~A} / \mathrm{cm}^{2}, 100$ hours $=120.56 \mathrm{~g}$

$$
\begin{aligned}
& \frac{5.4 \mathrm{gFe}}{86.12 \mathrm{gAl}} \times 100=6.27 \% \mathrm{Fe} \\
& \frac{0.65 \mathrm{gNi}}{86.12 \mathrm{gAI}} \times 100=0.75 \% \mathrm{Ni} \\
& \frac{0.54 \mathrm{gCu}}{86.12 \mathrm{gAI}} \times 100=0.63 \% \mathrm{Cu}
\end{aligned}
$$



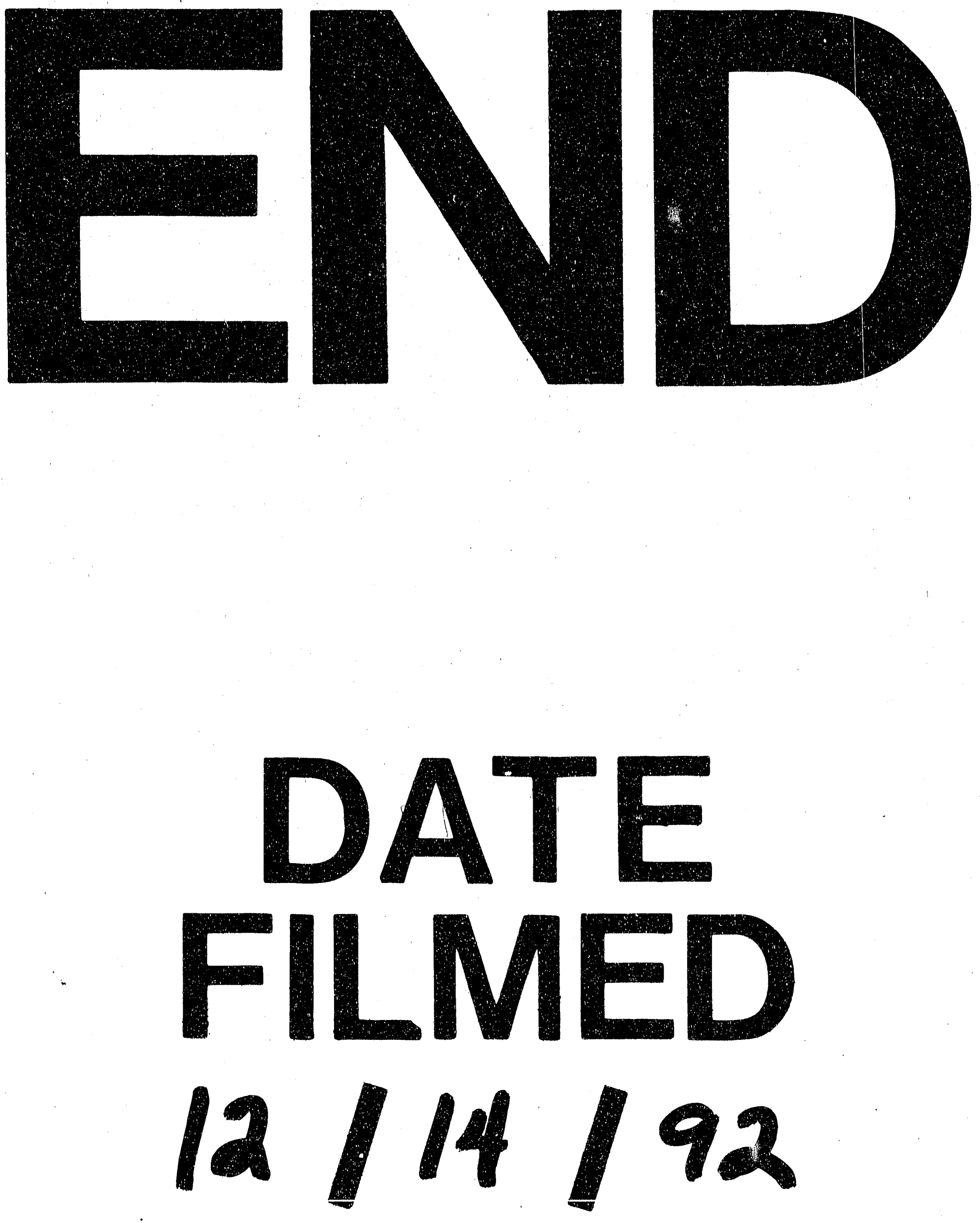
